\title{
Status of Chronic Oxidation Studies of Graphite
}

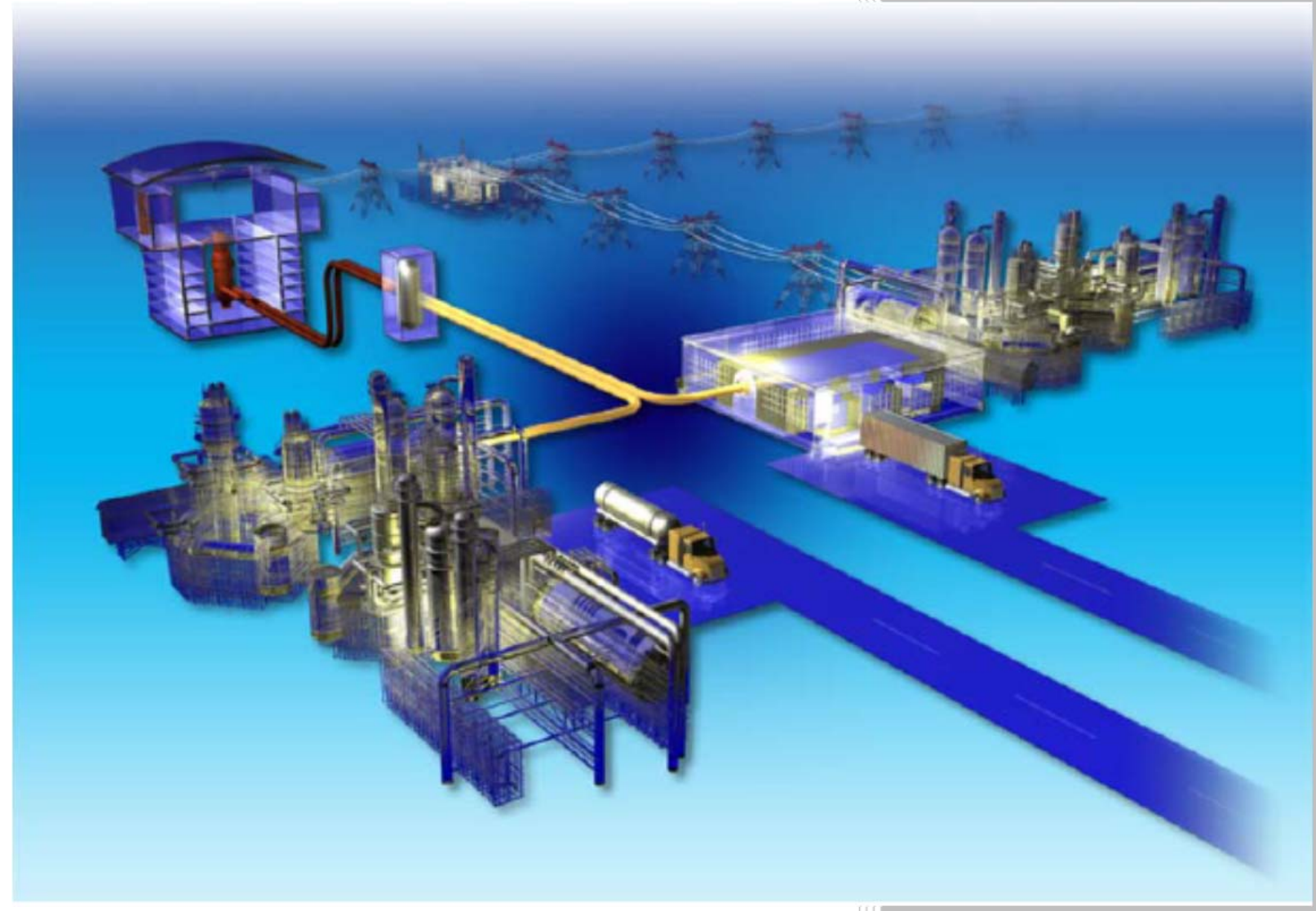

Approved for public release.

Distribution is unlimited.

Cristian I Contescu

Robert W Mee

May 2016 


\section{DOCUMENT AVAILABILITY}

Reports produced after January 1, 1996, are generally available free via US Department of Energy (DOE) SciTech Connect.

Website http://www.osti.gov/scitech/

Reports produced before January 1, 1996, may be purchased by members of the public from the following source:

National Technical Information Service

5285 Port Royal Road

Springfield, VA 22161

Telephone 703-605-6000 (1-800-553-6847)

TDD 703-487-4639

Fax 703-605-6900

E-mail info@ntis.gov

Website http://www.ntis.gov/help/ordermethods.aspx

Reports are available to DOE employees, DOE contractors, Energy Technology Data Exchange representatives, and International Nuclear Information System representatives from the following source:

Office of Scientific and Technical Information

PO Box 62

Oak Ridge, TN 37831

Telephone 865-576-8401

Fax 865-576-5728

E-mail reports@osti.gov

Website http://www.osti.gov/contact.html

This report was prepared as an account of work sponsored by an agency of the United States Government. Neither the United States Government nor any agency thereof, nor any of their employees, makes any warranty, express or implied, or assumes any legal liability or responsibility for the accuracy, completeness, or usefulness of any information, apparatus, product, or process disclosed, or represents that its use would not infringe privately owned rights. Reference herein to any specific commercial product, process, or service by trade name, trademark, manufacturer, or otherwise, does not necessarily constitute or imply its endorsement, recommendation, or favoring by the United States Government or any agency thereof. The views and opinions of authors expressed herein do not necessarily state or reflect those of the United States Government or any agency thereof. 


\title{
STATUS OF CHRONIC OXIDATION STUDIES OF GRAPHITE
}

\author{
Cristian I Contescu ${ }^{1}$ and Robert W Mee ${ }^{2}$ \\ ${ }^{1}$ Oak Ridge National Laboratory \\ ${ }^{2}$ University of Tennessee at Knoxville
}

May 2016

Prepared by

OAK RIDGE NATIONAL LABORATORY

Oak Ridge, Tennessee 37831-6283

managed by

UT-BATTELLE, LLC

for the

US DEPARTMENT OF ENERGY

under contract DE-AC05-00OR22725 
This page was intentionally left blank 


\section{CONTENTS}

Page

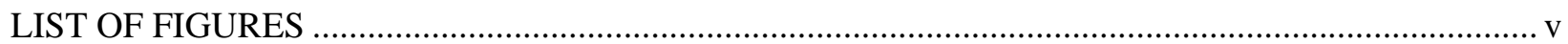

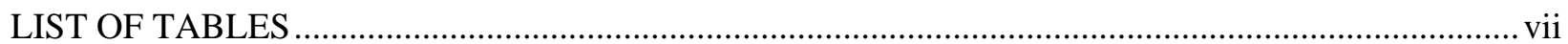

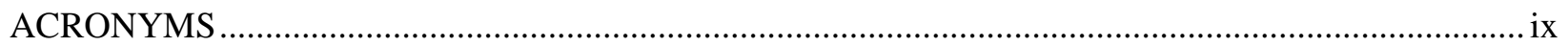

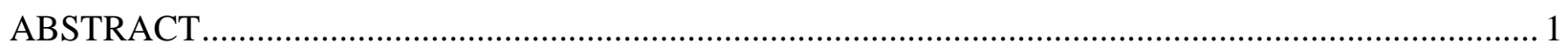

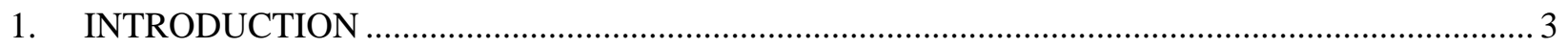

2. GENERAL INFORMATION AND UPDATE ON EXPERIMENTAL RESUTLS.................5

2.1. GRAPHITE GRADES AND MEASUREMENTS PERFORMED …................................. 5

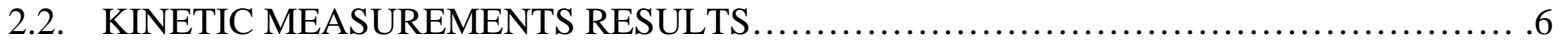

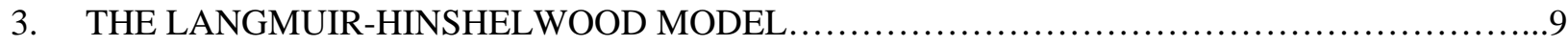

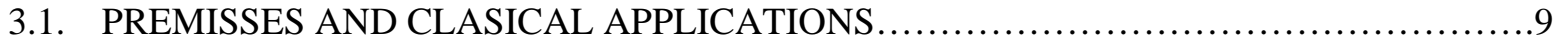

3.2. LIMITATIONS OF THE LANGMUIR-HINSHELWOOD MODEL $\ldots \ldots \ldots \ldots \ldots \ldots \ldots \ldots \ldots$

3.3. STOCHASTIC MODEL - AN ALTERNATIVE TO DETERMINISTIC LH MODEL........12

4. NEW KINETIC MODEL FOR GRAPHITE OXIDATION BY MOISTURE.....................15

4.1. WATER SURFACE COMPLEXES AND REACTION ROUTES ........................15

4.2. COOPERATIVE BEHAVIOR IN REACTION KINETICS ...........................17

4.3. ENHANCED KINETIC MODEL FOR GRAPHITE OXIDATION .......................19

4.3.1. Site Cooperativity and Apparent Reaction Order...............................19

4.3.2. Enhanced LH Model with Boltzmann Activation of Surface Sites....................21

4.3.3. Testing the Boltzmann-enhanced LH Model ............................................................ 22

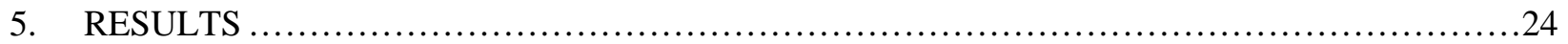

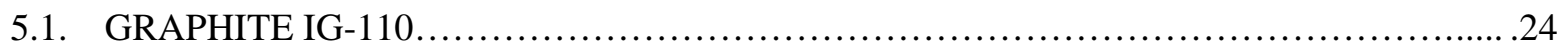

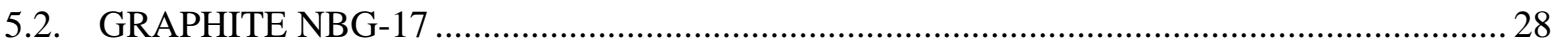

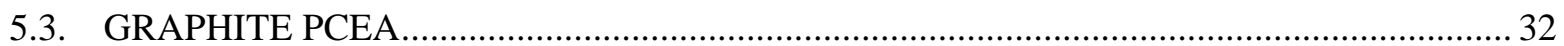

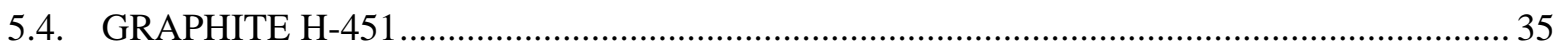

5.5 COMPARISON OF THE TWO MODELS .............................................

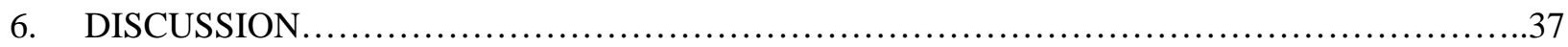

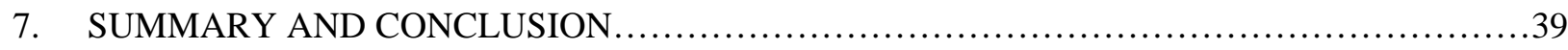

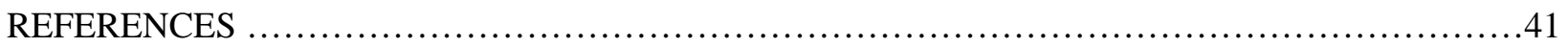

ANNEXES: PHYSICAL MEASUREMENTS AND TEST CONDITIONS............................44

ANNEX 1 - Physical measurements on graphite IG-110 specimens before and after tests.............45

ANNEX 2 - Log of experimental results - graphite IG-110................................47

ANNEX 3 - Physical measurements on graphite NBG-17 specimens before and after tests .........53

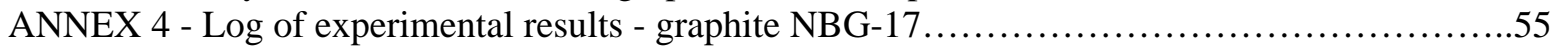

ANNEX 5 - Physical measurements on graphite PCEA specimens before and after tests...............63

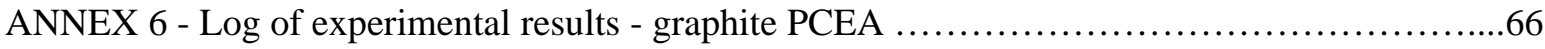


This page was intentionally left blank 


\section{LIST OF FIGURES}

\section{Figure}

1 Comparison of oxidation by moisture rate data for graphite grades PCEA, NBG-17 and IG-110 characterized at ORNL (2012-2016) and for historic grade H-451.

2 Behavior of the global oxidation rate predicted for solids with a Gauss distribution of surface sites' desorption energies....................................................................... 13

3 Energy diagram steps of dissociative chemisorption of $\mathrm{H}_{2} \mathrm{O}$ on a vacancy site on graphite basal plane.

4 Schematic diagram of surface complexes formed by chemisorption of water at exposed zig-zag and armchair sites on graphene, and of their subsequent transformations during graphite gasification....16

5 Schematic diagram of surface complexes formed by adsorption of water on hydrogen saturated and oxygen-containing zig-zag sites on graphene edges, and of their subsequent transformations during graphite gasification

6 Left: Comparison between hyperbolic and sigmoidal dependence of reaction rate versus ligand concentration indicating, respectively, lack of cooperativity (blue hyperbola line) and positive cooperativity (red sigmoid curve). Right: By varying the Hill parameter sigmoid curves are able to describe a multitude of positive cooperative phenomena.

7 Temperature dependence of apparent reaction order calculated directly from experimental data compared with model predictions based on best fit LH parameters.

8 Experimental evidence of site cooperativity effects: Oxidation rates measured according to Method 1 (random $P_{\mathrm{H} 2 \mathrm{O}}$ variation from multiple specimens) follow an increasing trend with $P_{\mathrm{H} 2 \mathrm{O} \text {, albeit }}$ scattered, while rates measured according to Method 2 (continuous $P_{H 2 O}$ decrease on the same specimen) are higher and show a trend reversed to that expected....

9 Oxidation rates measured for graphite IG-110 and the trends predicted by LH model with 6 parameters.

10 Comparison between rates measured for oxidation of IG-110 graphite and rates predicted by the LH model.

11 Oxidation rates measured for graphite IG-110 and the trends predicted by the Boltzmann-enhanced LH model (10 parameters).

12 Comparison between rates measured for oxidation of IG-110 graphite and the rates predicted by the Boltzmann-enhanced LH model.....................................................28

13 Fit of LH model to oxidation data for graphite NBG-17 at $P_{H 2}=0$ and $P_{H 2}=26 \mathrm{~Pa}$.

14 Fit of Boltzmann-enhanced LH model to oxidation data collected for graphite NBG-17 at $P_{H 2}=0$ and $P_{\mathrm{H} 2}=26 \mathrm{~Pa}$ 
15 Goodness of fit comparison between the LH model and the Boltzmann-enhanced LH model applied

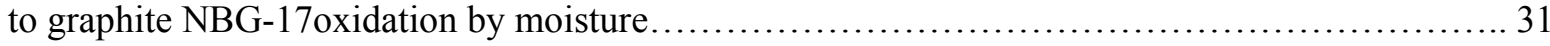

16 Fit of PCEA oxidation data using the LH model (top panel) and the Boltzmann-enhanced LH model

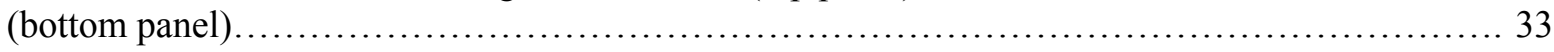

17 Goodness of fit comparison between LH model and Boltzmann-enhanced LH model applied to graphite PCEA oxidation by moisture.................................................. 34

18 Goodness of fit comparison between LH and Boltzmann-enhanced LH models applied to graphite

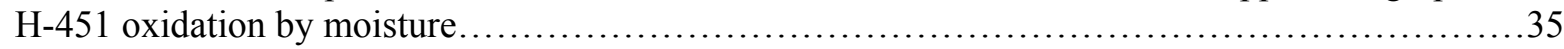

19 Visualization of electronic states localized at edge carbon atoms of graphene with different number

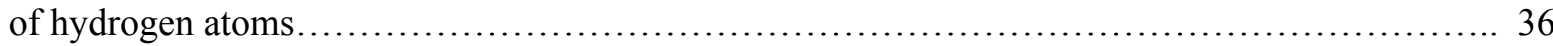




\section{LIST OF TABLES}

Table

Page

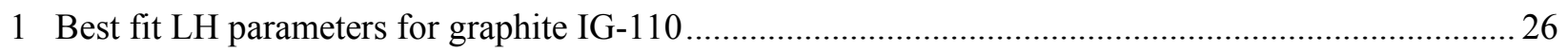

2 Best fit parameters for graphite IG-110 using the Boltzmann-enhanced LH model ......................... 27

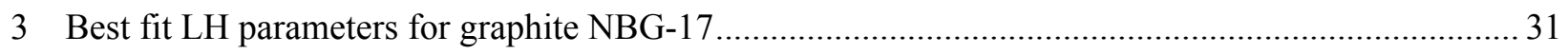

4 Best fit parameters for graphite IG-110 using the Boltzmann-enhanced LH model .......................... 31

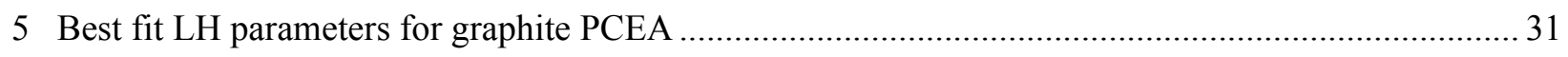

6 Best fit parameters for graphite PCEA using the Boltzmann-enhanced LH model ............................ 31

7 Best fit LH parameters for graphite H-451 (“low water” variant) …................................................ 36

8 Best fit parameters for graphite H-451 using the Boltzmann-enhanced LH model............................ 36

9 Comparison of scattered regression plots between observed and model-predicted rates ...................... 36 
This page was intentionally left blank 


\section{ACRONYMS}

$\begin{array}{ll}\text { ASTM } & \text { American Society for Testing and Materials } \\ \text { BLH } & \text { Boltzmann-Langmuir-Hinshelwood (kinetic model) } \\ \text { DFT } & \text { density functional theory (method) } \\ \text { GA } & \text { General Atomics (company) } \\ \text { HTGR } & \text { High Temperature Gas-cooled Reactor } \\ \text { LH } & \text { Langmuir-Hinshelwood (kinetic model) } \\ \text { MLE } & \text { maximum likelihood estimation (method) } \\ \text { MS } & \text { mass spectrometer / mass spectrometry } \\ \text { ORNL } & \text { Oak Ridge National Laboratory } \\ \text { TPD } & \text { temperature-programmed desorption } \\ \text { TPO } & \text { temperature-programmed oxidation } \\ \text { STM } & \text { scanning tunneling microscopy }\end{array}$


This page was intentionally left blank 
ORNL/TM-2016/195

\begin{abstract}
Graphite will undergo extremely slow, but continuous, oxidation by traces of moisture that will be present, albeit at very low levels, in the helium coolant of an HTGR. This chronic oxidation may cause degradation of mechanical strength and of other properties of graphite components if a porous oxidation layer penetrates deep enough in the bulk of graphite components during the lifetime of the reactor. The current research on graphite chronic oxidation is motivated by the acute need to understand the behavior of each graphite grade during prolonged exposure to chemical attack by moisture at high temperature. The goal is to provide the elements needed to develop predictive models for long-time oxidation behavior of graphite components in the cooling helium of HTGR. The tasks derived from this goal are: (1) Oxidation rate measurements in order to determine and validate a comprehensive kinetic model suitable for prediction of intrinsic oxidation rates as a function of temperature and oxidant gas composition; (2) Characterization of effective diffusivity of water vapor in the graphite pore system in order to account for the in-pore transport of moisture; and (3) Development and validation of a predictive model for the penetration depth of the oxidized layer, in order to assess the risk of oxidation-caused damage of particular graphite grades after prolonged exposure to the environment of helium coolant in an HTGR.

The most important - and most time consuming - of these tasks is the measurement of oxidation rates in accelerated oxidation tests (but still under kinetic control) and the development of a reliable kinetic model. This report summarizes the status of chronic oxidation studies on graphite, and then focuses on model development activities, progress of kinetic measurements, validation of results, and improvement of the kinetic models. Analysis of current and past results obtained with three nuclear graphite grades showed that the classical Langmuir-Hinshelwood model cannot reproduce all data collected so far.

Starting from here we propose a modification of the $\mathrm{LH}$ model to include temperature activation of the graphite surface, modeled as a Boltzmann activation function. The Boltzmann-enhanced LangmuirHinshelwood model (BLH) was tested successfully on three grades of graphite. The model is a robust, comprehensive mathematical function that allows better fitting of experimental results spanning a wide range of temperatures and partial pressures of water vapor and hydrogen. However, the model did not improve much the fitting of old data on graphite $\mathrm{H}-451$ oxidation by water.
\end{abstract}


This page was intentionally left blank 
ORNL/TM-2016/195

\section{INTRODUCTION}

High purity isotropic graphite is used as a neutron moderator and structural element in High Temperature Gas-Cooled Reactors (HTGRs). Although stable at the operating temperatures of HTGRs (about $700-900{ }^{\circ} \mathrm{C}$ ) in a reducing environment, graphite is susceptible to oxidation by traces of oxygen, water, and carbon dioxide if these gases are present in the high temperature gas environment. Even though the chemical composition of the helium coolant is strictly controlled, water (moisture) is the most difficult gas species to remove. Depending on specific designs, the admissible water vapor partial pressure in HTGR varies between about 5 Pa (Fort St. Vrain, USA, 1976-1979) and 0.04 Pa (PBMR project, South Africa), with most practical values grouped around 1.1 - 1.4 Pa (Peach Bottom, USA, 1967-1974; HTR-10, China, 2003) at total helium pressures of 7 - 9 MPa [1,2,3,4,5,6]. Over the predicted lifetime of several decades, it is inevitable that extremely slow, but continuous (chronic) oxidation of graphite by traces of water will occur at these high temperatures. The reaction products are hydrogen and carbon dioxide:

$$
\mathrm{C}_{\text {graphite }}+\mathrm{H}_{2} \mathrm{O}_{\text {vapor }}=\mathrm{CO} \text { gas }+\mathrm{H}_{2} \text { gas }
$$

The main concern about oxidation by moisture is not about accumulation of $\mathrm{CO}$ (a toxic gas) and $\mathrm{H}_{2}$ (flammable and explosive in mixtures with air) in the reactor. The amounts will be small and the coolant gas composition is controlled. The real concern is that chronic oxidation of graphite may slowly but surely corrode the fuel elements and other structural components in the core, weakening their mechanical strength and jeopardizing the reactor integrity. Early analyses of the possible effect of chronic oxidation were carried out at General Atomics (GA) Company. In the 1970's they performed accelerated oxidation tests of graphite grade $\mathrm{H}-451$, which at the time was the U. S. graphite candidate for HTGRs. The report by Velasquez, Hightower and Burnette [7] contains carefully measured slow oxidation rates in presence of moisture and hydrogen. The results were analyzed according to the Langmuir-Hinshelwood (LH) model for graphite oxidation by moisture. The numerical values of all kinetic parameters obtained by fitting the LH model to the experimental observations were provided. Building on these results, Richards [8] performed a finite element analysis of moisture transport in porous graphite and consumption in the oxidation reaction. He concluded that chronic oxidation of graphite under normal operating conditions in HTGR will not affect safety operation. According to this analysis, oxidation by moisture will occur only in a thin layer (about 1-2 mm) at the surface of graphite components provided the steam concentration in helium at a total design pressure of $63 \mathrm{~atm}$ is kept below $0.1 \mathrm{ppm}$ (less than 6.4 Pa partial pressure).

The problem with this analysis is that the kinetic data used as input were those from the GA report on graphite H-451, while the measurements of oxidized layer thickness used for model validation were performed with graphite 2020. Later it became clear that the graphite microstructure is a very strong differentiator between grades of nuclear graphite; and that structural properties have a strong influence on oxidation behavior of various grades [9,10]. Moreover, graphite $\mathrm{H}-451$ is no longer available, and little is known about the oxidation by moisture of the newer grades regarded as possible candidates for HTGR in the United States.

The need to understand their behavior during operation of gas-cooled reactors motivated the initiation of a new research direction at Oak Ridge National Laboratory (ORNL) in 2012 - systematic investigation of chronic oxidation by moisture of new grades of graphite selected as HTGR candidates. This report summarizes the achievements and the current status of this multi-year research effort. It makes reference to already published studies $[11,12,13,14]$ and contains updates on the latest results. The main goal is to emphasize the experimental progress so far and the challenges encountered with data analysis. A second 
goal is to underscore, as often as possible, our current understanding of the relationship between graphite microstructure and oxidation behavior. Along these lines, this report will highlight current knowledge gaps and will point to those areas where better understanding is required to further the model development of graphite chronic oxidation. Based on information from quantum chemical calculations and stochastic models for graphite gasification kinetics, this report concludes that the classical LangmuirHinshelwood model has limited applicability over broad ranges of experimental conditions, and advances an enhanced kinetic model which better fits available kinetic results for several grades of nuclear graphite. 
ORNL/TM-2016/195

\section{GENERAL INFORMATION AND UPDATE ON EXPERIMENTAL RESULTS}

\subsection{GRAPHITE GRADES AND MEASUREMENTS PERFORMED}

Chronic oxidation by traces of moisture and hydrogen in helium was studied at ORNL for the following three graphite grades:

- PCEA - medium grain nuclear graphite obtained from petroleum needle coke by an extrusion process developed by GrafTech International, USA [15];

- NBG-17 - medium grain nuclear graphite developed by SGL Carbon (Germany / France) and obtained by vibrational molding from a coal-tar pitch coke [16];

- IG-110 - fine grain nuclear graphite manufactured by Toyo Tanso (Japan) from highly crystalline petroleum coke using isostatic pressing.

Three types of measurements were performed:

- Oxidation kinetics measurements in accelerated oxidation tests. The goal of this task is to determine the graphite-specific kinetic parameters in the oxidation rate equation over a broad range of temperature and gas composition conditions. The measurements were completed for graphite grades PCEA, NBG-17 and IG-110 [11,12,13]. A high sensitivity thermogravimetric system was employed for the experimental work. It allows control of temperature, flow rate, and composition of the oxidant gas. Typically, a series of weight loss rates were measured for each graphite grade in isothermal conditions with duration varying from 3 hours (more often) to 12 hours (in some instances). The specimens were machined as cylinders, $4 \mathrm{~mm}$ diameter and $20 \mathrm{~mm}$ long. The small diameter was selected in order to minimize as much as possible the diffusional limitations and to maximize the surface/volume ratio. Measurements were made at temperatures between 800 and $1100{ }^{\circ} \mathrm{C}$ and total pressure equal to the atmospheric pressure. All data were reduced at standard conditions, taking into account the actual pressure in the reaction tube. A $1.5 \mathrm{~L} / \mathrm{min}$ flow rate of ultrahigh purity helium was used which corresponds to $7.5 \mathrm{~cm} / \mathrm{s}$ linear velocity in the reaction tube. The gas composition was adjusted to contain partial pressures of water vapor between 3 and $1000 \mathrm{~Pa}$, occasionally with added partial pressures of hydrogen between 10 and $300 \mathrm{~Pa}$. The final weight loss of individual specimens was in general less than $0.5 \%$, and only occasionally reached $1.5 \%$ in the most aggressive oxidation conditions. At these low oxidation levels the correction for the "burn-off factor" that accounts for the variation of oxidation rates with the degree of oxidation was not necessary (assuming the microstructure did not change over this small range).

- Water vapor effective diffusivity in graphite. The goal of this task is to determine the effective diffusion coefficient for water, which is a property of the pore system in each graphite grade. The ratio $\beta=D_{\text {eff }} / D_{\text {gas }}$ between the effective diffusivity measured for the porous material $\left(\mathrm{D}_{\text {eff }}\right)$ and the bulk diffusivity in free gas $\left(\mathrm{D}_{\text {gas }}\right)$ defines the structural parameter $\beta$ characteristic to each graphite grade. This parameter accounts for the increased diffusional resistance to water vapor transport in the pore system, and depends on graphite microstructure, mainly on pore sizes, connectivity and tortuosity. These measurements were performed so far for grades PCEA and NBG-17 only [14] by an outside contractor (Porous Materials Inc., Ithaca, NY) according to procedure in ASTM F229 [17] adapted for graphite materials. Graphite samples were machined as thin $(3 \mathrm{~mm})$ rectangular slabs and placed between two parallel flows of helium gas. The humidity difference between the two flows was held constant and the total pressure difference was varied. The water diffusion rate at 
zero pressure difference and known water concentration gradient was calculated from mass balance calculations using four-point measurements of pressure, humidity, flow rate, and temperature at gas inlet and outlet on each side of the graphite specimen. The results show that water diffusivity is slower in graphite NBG-17 than in PCEA, in agreement with the structural differences [14].

- Density profile of the oxidized layer. Measurements for graphite PCEA are complete, and those for graphite NBG-17 are currently in progress. The goal is to correlate the density profile in the oxidized layer with information from oxidation kinetics and water diffusivity, and thus to demonstrate the validity of a predictive model for chronic oxidation [18]. The predictive model is based on the mass balance equation for combined transport and reaction in the pore system. The ultimate objective is to determine the effect of temperature and total pressure on the maximum depth of the oxidized layer that will develop on the surfaces of graphite components during lifetime exposure to humidity traces in normal operating conditions. Work is currently in progress for further validation of the model with at least one more graphite grade (NBG-17).

The remainder of this report will discuss in detail recent results on modeling and interpretation of oxidation rate measurements for several grades of nuclear graphite. Modeling oxidation kinetics is of prime importance in comparison with oxidation layer profile and diffusivity characterization. A robust, comprehensive kinetic model, able to describe experimental results on a broad range of conditions, should be the solid ground for further development of predictive models of chronic graphite oxidation. The starting point of this analysis is recent experimental results (2015-2016) on oxidation by moisture of graphite IG-110. These data were very difficult to model using the classical Langmuir-Hinshelwood (LH) kinetics. Looking back to results for other grades of graphite, it became obvious that the LH model cannot consistently reproduce all experimental data available for the grades investigated so far: not only for IG110, but also for PCEA (2013-2014) and NBG-17 (2014-2015). This finding made it necessary to critically review the applicability of the LH model for graphite oxidation kinetics. Based on this analysis, we propose an improved model that enhances the capabilities of the classical LH model. The enhanced model accounts for surface stoichiometry variations through a variable kinetic order coefficient, which is modeled by a Boltzmann distribution function and accounts for the temperature-dependent activation of surface sites on graphite. It will be shown in conclusion how this enhanced model is more successful in reproducing the experimental results obtained not only for graphite IG-110, but also for grades NBG-17 and PCEA, for which the respective experimental results were re-analyzed with the new model.

\subsection{KINETIC MEASUREMENTS RESULTS}

Figure 1 shows examples of kinetic measurement results for graphite grades PCEA, NBG-17, and IG110. The double logarithmic scale was used to represent large variations of oxidation rates over broad ranges of water vapor partial pressures. Symbols represent measured oxidation rates and continuous lines show predicted rates based on best non-linear fitting according to the classical LH model. Each color indicates oxidation rates observed and predicted at constant temperature. Only data measured in mixtures of $\mathrm{H}_{2} \mathrm{O} / \mathrm{He}$ are shown in these figures. Similar measurements were made in mixtures of $\left(\mathrm{H}_{2} \mathrm{O}+\mathrm{H}_{2}\right) / \mathrm{He}$ (not shown here). The graph for graphite $\mathrm{H}-451$ was built by digitizing the graphs of experimental oxidation rates reported in the 1978 report from General Atomics [7].

The four graphs of Fig. 1 show common trends and significant differences between the four graphite grades.

First, the oxidation rates increase with the partial pressure of water vapor, $P_{\mathrm{H} 2 \mathrm{O}}$, but the rate of increase depends on temperature and, at constant temperature, on the actual range of $P_{H 2 O}$. 

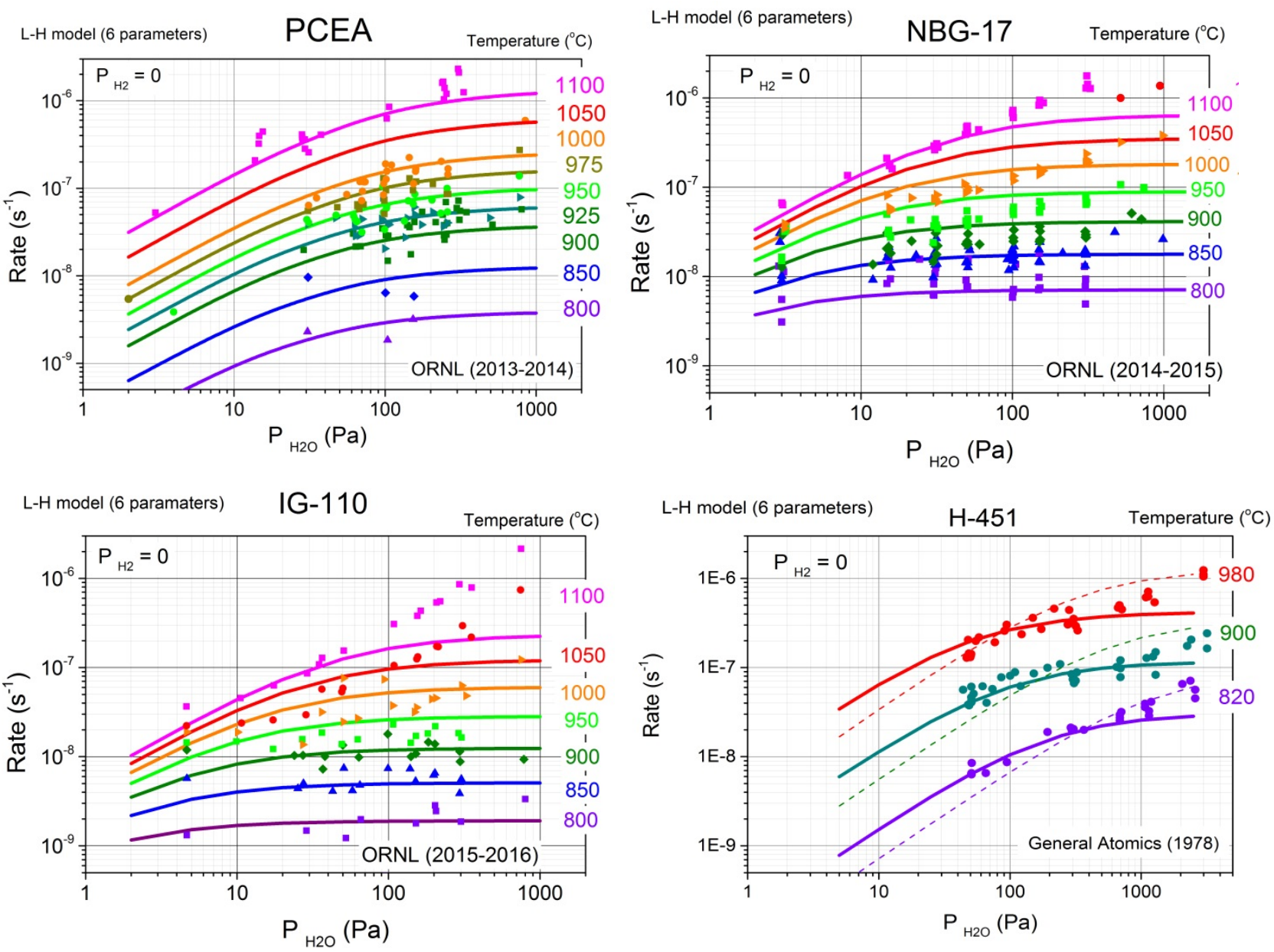

Figure 1: $\quad$ Comparison of oxidation by moisture rate data for graphite grades PCEA, NBG-17 and IG-110 characterized at ORNL (2012-2016) and for historic grade H-451. Data points for grade H-451 were obtained by digitizing the graphs in the GA report [7] and the models compared are "low water" for $P_{\mathrm{H} 2 \mathrm{O}}<300 \mathrm{~Pa}$ (solid lines) and "combined model" at $P_{\mathrm{H} 2 \mathrm{O}}<3000 \mathrm{~Pa}$ (dotted lines).

Second, all experimental values at constant temperature are more or less scattered, yet still show a trend which agrees in general with the isothermal trends predicted by models. Two sources of scattering were identified: material variability and experimental errors during measurements. The error caused by material variability was about twice as large as the measurement errors [11,12]. Data scattering was observed also in the classical report on graphite H-451 [7].

Third, each graphite grade exhibits different behavior in oxidation by moisture. When all data available for three graphites are compared on the same scale with the data reported for the historic grade H-451, as in Figure 1, differences are easily seen. It appears that the new grades of graphite show slower oxidation rates than grade $\mathrm{H}-451$ at the same temperature. It can also be observed that graphite IG-110 shows slower oxidation rates than graphite NBG-17 at low temperatures.

Fourth, predictions based on the best fit of kinetic parameters in the LH model deviate from experimental oxidation rates. These deviations are observed systematically at high temperatures (above about $950-1000{ }^{\circ} \mathrm{C}$ ) and high water vapor pressures (above about $100 \mathrm{~Pa}$ ). Deviations are larger for grades IG-110 and NBG-17 than for graphite PCEA. Deviations were also reported in the GA study on 
graphite H-451, and are clearly seen in the plots drawn with digitized data extracted from the GA report [7]. Faced with the dilemma that oxidation rate data of graphite $\mathrm{H}-451$ cannot be represented by a single set of kinetic parameters, the authors of the GA report proposed that two different sets of parameters should be used for the so-called "low water" range $\left(\mathrm{P}_{\mathrm{H} 2 \mathrm{O}}<300 \mathrm{~Pa}\right)$ and "high water" range $\left(300<\mathrm{P}_{\mathrm{H} 2 \mathrm{O}}<\right.$ $3000 \mathrm{~Pa}$ ). Realizing that splitting the $\mathrm{P}_{\mathrm{H} 2 \mathrm{O}}$ range is not practical, they designed an empirical set of parameters to be used in the "combined" range that covers all pressures investigated $\left(0<\mathrm{P}_{\mathrm{H} 2 \mathrm{O}}<3000 \mathrm{~Pa}\right)$. Figure 1 shows only the "low water" and the "combined" model for graphite H-451.

Figure 1 demonstrates that the LH model cannot consistently reproduce all oxidation rate data measured over broad ranges of temperature and water vapor pressure. It is to be observed, in all fairness, that not all previous studies on kinetics of graphite oxidation reported that the classical LH model may have limited applicability. The limitations may have not been observed in the early studies (1950's and 1960's) that have advanced the LH model because they contained only a limited number of experimental data points. Later, other reports identified some limitations and attributed them to particular properties of their graphite (or carbon materials in general). 


\section{THE LANGMUIR-HINSHELWOOD MODEL}

\subsection{PREMISES AND CLASSICAL APPLICATIONS}

In the literature on graphite oxidation it was long time assumed that oxidation by $\mathrm{H}_{2} \mathrm{O}$ (reaction $\mathrm{I}$ ) has similar kinetic behavior as oxidation by $\mathrm{CO}_{2}$ (reaction II):

$$
\mathrm{C}_{\text {graphite }}+\mathrm{CO}_{2 \text { gas }}=2 \mathrm{CO}_{\text {gas }}
$$

Both processes can be formally described by the same general rate equation, where indices ${ }_{\text {ox }}$ and ${ }_{\text {prod }}$ refer to the oxidant agent $\left(\mathrm{H}_{2} \mathrm{O}\right.$ or $\left.\mathrm{CO}_{2}\right)$ and oxidation products $\left(\mathrm{H}_{2}\right.$ or $\left.\mathrm{CO}\right)$ :

$$
\text { Rate }=\frac{k_{1}\left(P_{\text {ox }}\right)^{m}}{1+k_{2}\left(P_{\text {prod }}\right)^{n}+k_{3} P_{o x}}
$$

and the exponents $m$ and $n$ are the respective reaction orders for the oxidant and the oxidation product. This non-linear equation agrees with the observations that oxidation is accelerated by the increase of oxidant partial pressure, $P_{o x}$, and it is slowed down by an excess of the reaction product, $P_{\text {prod }}$. The temperature dependence is formally introduced by assuming that all rate constants $k_{i}(i=1,2,3)$ in Eq. (1) obey the classical Arrhenius relationship:

$$
k_{i}=A_{i} \exp \left(-\frac{E_{i}}{R T}\right)
$$

The particular form of Eq. (1) for oxidation by water vapor is given in Eq. (3). This form was used previously in numerous studies, including the above-referenced GA report [7]:

$$
\operatorname{Rate}\left(P_{H 2 O}, P_{H 2}, T\right)=\frac{k_{1} P_{H 2 O}}{1+k_{2}\left(P_{H 2}\right)^{n}+k_{3} P_{H 2 O}}
$$

At the microscopic level, graphite gasification is the result of a series of processes that include gas adsorption, surface diffusion, reactions at active surface sites, and desorption of oxidation products. For reactions occurring in the pore space, two additional steps include oxidant $\left(\mathrm{H}_{2} \mathrm{O}\right)$ diffusion from gas phase and diffusion of the oxidation products $\left(\mathrm{CO}\right.$ and $\left.\mathrm{H}_{2}\right)$ back to the gas phase. However, the exact sequence of elementary reaction steps that yield the overall kinetic equation (3) is not known. At least two different reaction schemes were proposed for graphite oxidation by water, which both lead to the rate equation (3). Gadsby et. al. [19] proposed that inhibition by hydrogen is caused by molecularly adsorbed $\mathrm{H}_{2}$ blocking surface sites according to the following chain of elementary reaction steps:

$$
\begin{aligned}
& \mathrm{C}_{\mathrm{f}}+\mathrm{H}_{2} \mathrm{O}(\mathrm{g}) \stackrel{j_{1}}{\stackrel{i_{1}}{\rightarrow}} \mathrm{C}\left(\mathrm{H}_{2} \mathrm{O}\right) \\
& \mathrm{C}\left(\mathrm{H}_{2} \mathrm{O}\right) \stackrel{j_{3}}{\rightarrow} \mathrm{CO}_{(\mathrm{g})}+\mathrm{H}_{2}(\mathrm{~g}) \\
& \mathrm{C}_{\mathrm{f}}+\mathrm{H}_{2}(\mathrm{~g}) \stackrel{i_{2}}{\stackrel{j_{2}}{\rightarrow}} \mathrm{C}\left(\mathrm{H}_{2}\right)
\end{aligned}
$$

Giberson and Walker [20] proposed a different mechanism, where surface blockage is caused by chemisorption of atomic hydrogen on reactive surface sites:

$$
\mathrm{C}_{\mathrm{f}}+\mathrm{H}_{2} \mathrm{O} \stackrel{i_{1}}{\rightarrow} \mathrm{C}(\mathrm{O})+\mathrm{H}_{2}
$$




$$
\begin{aligned}
& \mathrm{C}_{\mathrm{f}}+1 / 2 \mathrm{H}_{2} \underset{j_{2}}{\stackrel{i_{2}}{\rightarrow}} \mathrm{C}(\mathrm{H}) \\
& \mathrm{C}(\mathrm{O}) \stackrel{i_{3}}{\rightarrow} \mathrm{CO}+\mathrm{C}_{\mathrm{f}}
\end{aligned}
$$

In the above schemes, $\mathrm{C}_{\mathrm{f}}$ is a free carbon surface site and $\mathrm{C}\left(\mathrm{H}_{2} \mathrm{O}\right), \mathrm{C}\left(\mathrm{H}_{2}\right), \mathrm{C}(\mathrm{O})$ and $\mathrm{C}(\mathrm{H})$ are surface sites with adsorbed $\mathrm{H}_{2} \mathrm{O}, \mathrm{H}_{2}, \mathrm{O}$, and $\mathrm{H}$, respectively. Both reaction schemes correspond formally to the global rate equation (3), but the significance of rate constants is different. In the Gadsby mechanism, $k_{1}=\left(i_{1}\right.$ $\left.j_{3}\right) /\left(j_{1}+j_{3}\right) ; k_{2}=i_{2} / j_{2} ; k_{3}=i_{1} /\left(j_{1}+j_{3}\right)$ and $m=1$. In the Giberson and Walker mechanism, $k_{1}=i_{1} ; k_{2}=i_{2} / j_{2}$; $k_{3}=i_{1} / j_{3}$ and $m=0.5$. In these schemes, the arrows represent fast (irreversible) elementary steps $(\rightarrow)$ or equilibrium processes $(\longleftrightarrow \longrightarrow)$ and scripts $i$ and $j$ associated with the arrows are rate constants of forward and backward transformations.

A totally different mechanism was proposed by Long and Sykes [21] who assumed that $\mathrm{H}_{2} \mathrm{O}$ molecules dissociate on carbon surface into $\mathrm{H}^{*}$ and $\mathrm{OH}^{*}$ radicals that are adsorbed at adjacent carbon atoms. This step is followed by hydroxyl dissociation and desorption of molecular $\mathrm{H}_{2}$ :

$$
\begin{aligned}
& 2 \mathrm{C}_{\mathrm{f}}+\mathrm{H}_{2} \mathrm{O} \underset{j_{1}}{\stackrel{i_{1}}{\rightarrow}} \mathrm{C}(\mathrm{H})+\mathrm{C}(\mathrm{OH}) \\
& \mathrm{C}(\mathrm{H})+\mathrm{C}(\mathrm{OH}) \stackrel{i_{1}{ }^{*}}{\rightarrow} \mathrm{C}\left(\mathrm{H}_{2}\right)+\mathrm{C}(\mathrm{O}) \\
& \mathrm{C}\left(\mathrm{H}_{2}\right) \stackrel{i_{2}}{\stackrel{j_{2}}{\rightarrow}} \mathrm{C}_{\mathrm{f}}+\mathrm{H}_{2} \\
& \mathrm{C}(\mathrm{O}) \stackrel{i_{3}}{\longrightarrow} \mathrm{CO}
\end{aligned}
$$

In this mechanism the definition of rate constants $k_{i}$ in global Eq. (3) are even more complicated: $k_{1}=i_{1}$ $i_{1}{ }^{*} /\left(i_{1}{ }^{*}+j_{1}\right) ; k_{2}=i_{2} / j_{2} ; k_{3}=\left(i_{1} i_{1}{ }^{*}\right)\left(1 / i_{1}{ }^{*}+1 / j_{2}+1 / i_{3}\right) /\left(i_{1}{ }^{*}+j_{1}\right)$ and $n=1$. The experimental data used in support were collected at steam pressures between 1.3 and $100 \mathrm{kPa}$ and temperatures between 680 and $800{ }^{\circ} \mathrm{C}$.

These examples show that the rate constants $k_{\mathrm{i}}$ in Eq. (3) are in fact mechanism-dependent composite constants, i.e. they are mathematically defined by combinations of rate constants for several elementary reaction steps. The specific combinations depend on which elementary reaction scheme is accepted. This question does not have a clear answer. The rate constants of elementary steps are supposed to obey the Arrhenius temperature dependence

$$
i=a \exp \left(-\frac{\epsilon}{R T}\right)
$$

where the pre-exponent $a$ is a frequency factor related to the number of molecular events occurring per unit of time (e.g. successful collisions between reacting species leading to reactions). The exponential is derived from the Boltzmann distribution of molecules with the energy above a specific energy threshold, $\varepsilon$, which is required for successful completion of one molecular reaction. It is generally assumed that the energy barrier of elementary reaction steps is a positive number (positive activation energy).

These assumptions are not necessarily true for the composite constants $k_{\mathrm{i}}$ of the global reaction rate, Eq. (3). Not only that their significance is so much obscured by the existence of several possible reaction mechanisms, but their mathematical definition - the ratio of two exponentials (in the simplest case) allows for any sign, positive or negative, of the number under the exponential sign (depending on the difference of energy barriers between elementary steps). Because of that fact, the kinetic parameters $A_{i}$ and $E_{i}$ in the global rate equation (3) should be regarded as apparent constants (mechanism-dependent) that should not necessarily carry clear significations at the level of molecular processes. Although the majority of chemical reactions have positive activation energy, examples can be found in the graphite oxidation literature of negative apparent activation energies obtained from the best fit of the LH model, 
Eq. (3), to experimental data [22]. Other reports [23] chose not to explicitly mention the negative activation energy result, but that is obvious at a closer inspection of data. Examples of negative activation energies were encountered mostly in studies relying on a large enough number of experimental data points $[11,12,13]$.

The arguments provided above lead to the recognition that the LH model has limited applicability for graphite oxidation kinetics. We have previously reported that the best fit of the LH model to experimental data for oxidation by moisture of graphite PCEA and NBG-17 led to negative activation energies $[11,12,13]$. Even more difficult was to fit recently measured data on graphite IG-110. The best LH fit for all these graphites shows deviations at high temperatures and high $P_{H 2 O}$, where the measured rates are in general higher than what the LH fit would predict. These deviations were shown in Fig. 1.

\subsection{LIMITATIONS OF THE LANGMUIR-HINSHELWOOD MODEL}

The limitations of the LH model when used in the graphite oxidation context reside in its very basic assumptions. The underlying premise of all reactions schemes presented above (and of others $[24,25,26,27,28]$ that will not be discussed here) is that the solid graphite surface contains a finite number of non-interacting, equivalent reaction sites, which can be occupied with equal probability by any surface species (either oxidant or reaction product) such as $\mathrm{H}_{2} \mathrm{O}, \mathrm{H}_{2}, \mathrm{CO}, \mathrm{H}^{*}, \mathrm{OH}^{*}$ etc. In other words, the surface was assumed to be energetically and structurally homogeneous, elementary reaction steps were supposed to occur independently of each other, and the extent of reactive surface was supposed to be a small fraction of the total available surface (such that the lateral interactions could be neglected). These assumptions, even though necessary in the early stages of theory development, are no longer supported by the current understanding of nuclear graphite structure and properties.

Another criticism of the LH models (when applied to oxidation by water) follows from the character of oxidation rate dependence on water vapor pressure. The slope of $\ln ($ Rate $)$ versus $\ln \left(P_{\mathrm{H} 2 \mathrm{O}}\right)$ curves is the apparent reaction order for water, based on the empirical linear equation

$$
\text { Rate }=k P_{\mathrm{H} 2 \mathrm{O}}^{m} \quad \text { or } \quad \ln (\text { Rate })=\ln k+m \ln \left(P_{\mathrm{H} 2 \mathrm{O}}\right)
$$

According to the classical LH equation (3), an increase in $P_{H 2 O}$ will cause a proportional increase in rate as long as $1>>k_{3} P_{\mathrm{H} 2 \mathrm{O}}$ and the retardation effect of $\mathrm{H}_{2}$ can be neglected $\left(P_{\mathrm{H} 2} \approx 0\right)$. However, as $P_{\mathrm{H} 2 \mathrm{O}}$ continues to increase, the proportional effect of $P_{\mathrm{H} 2 \mathrm{O}}$ at the numerator gradually diminishes in comparison with the gradually increasing contribution of $k_{3} P_{\mathrm{H} 2 \mathrm{O}}$ term in the denominator. Consequently, the apparent reaction order in the LH model is expected to vary from near one at low $P_{H 2 O}$ to near zero at high $P_{H 2 O}$. Measurements made in a narrow range of $P_{\mathrm{H} 2 \mathrm{O}}$ did not conflict with this prediction but some reports of kinetic measurements over broader ranges of $P_{\mathrm{H} 2 \mathrm{O}}$ and temperature indicate a variation contrary to the $\mathrm{LH}$ prediction: the apparent kinetic order was close to zero at low temperatures, and increased towards unity at higher temperatures and high $P_{H 2 O}[26,31]$.

Other studies invalidated the LH assumption on the energetic equivalence and reaction independence of surface sites. Binford and Eyring [31] observed that the character of oxidation rate dependence on $P_{\text {H2O }}$, Eq. (4), changes with the temperature. They proposed that two oxidation processes occur simultaneously on graphite surface: one with zero order with respect to $P_{\mathrm{H} 2 \mathrm{O}}$ and one with first order. This implies that two types of active sites exist on "imperfect graphite lattice" and their relative number varies with the oxidation temperature [31]. Similar observations were made in carbon gasification by $\mathrm{CO}_{2}$ [32]. Magne et al. [33] found by thermodesorption and mass spectroscopy that water chemisorbed on carbon above $200{ }^{\circ} \mathrm{C}$ forms a surface complex that decomposes on increase of temperature in $\mathrm{CO}$ and $\mathrm{H}_{2}$ simultaneously. They hypothesized the presence of two types of surface sites: labile sites that react first and stable sites that participate in steady state oxidation reactions. Other authors suggested that the adsorption strength of carbon monoxide, water or hydrogen on carbon changes with temperature, and so it does the mechanism of surface site blocking by these species [34,35]. Olander et al. [36] studied the 
formation and evolution of the surface complex formed by adsorption of water on pure graphite. Their results show that $\mathrm{H}_{2} \mathrm{O}$ adsorb dissociatively into $\mathrm{H}^{*}$ and $\mathrm{HO}^{*}$ radicals bounded at neighboring carbon atoms. Then the surface complex undergoes rearrangements in an activated process $(170 \mathrm{~kJ} / \mathrm{mol})$ by which one $\mathrm{H}$ atom migrates from $\mathrm{C}-\mathrm{OH}$ to $\mathrm{C}-\mathrm{H}$ to form a pair of $>\mathrm{C}=\mathrm{O}$ and $>\mathrm{CH}_{2}$. This is followed by desorption of $\mathrm{H}_{2}$ and $\mathrm{CO}$. Moreover, Binford and Eyring [31] found that graphite specimens that had reacted for a while at high temperature $\left(1300{ }^{\circ} \mathrm{C}\right)$ showed abnormally high oxidation rates after lowering the temperature $\left(900^{\circ} \mathrm{C}\right)$. This apparent lack of reversibility shows that some complex interactions occur between surface species, in disagreement with the basic hypothesis of the LH model.

The role of the graphite microstructure was later added to the discussion. Miura and Morimoto [37] found that water chemisorption on natural graphite starts from $25{ }^{\circ} \mathrm{C}$. Chemisorption occurs differently at crystal edge carbon atoms with zig-zag and armchair configuration. Lusier et al. [36] suggested that surface sites active in carbon gasification by steam may have a continuous distribution of properties: (a) zig-zag sites that adsorb $\mathrm{H}$ strongly and irreversibly; (2) armchair sites that preferentially adsorb $\mathrm{H}$ and participate in oxygen-exchange reactions; (3) stable sites that form strong $>\mathrm{C}=\mathrm{O}$ groups; (4) unstable sites (most reactive) where weakly bound oxide forms and desorbs as $\mathrm{CO}$, while $\mathrm{H}$ adsorbs in limited amounts, if at all.

Obviously the LH model premises about the equivalence and independence of reactive surface sites do not hold for graphite materials. The microstructure is an important factor for surface reactivity, which is not accounted for in the LH model.

\subsection{STOCHASTIC MODELS - AN ALTERNATIVE TO DETERMINISTIC LH MODEL}

Based on what is known today about the microstructure of graphite materials, it should be easy to argue that mechanistic oxidation models like those presented in schemes (III) - (V) above are inadequate to fully describe the complexity of gasification reactions. The rate equation (3) of the LH model was derived by combining the Langmuirean assumptions enumerated above with the steady-state approximation. The latter is an approximation commonly used in descriptive chemical kinetics according to which the forward and backward reactions have equal rate at steady state conditions. Although formally correct, many of previous models were statistically deficient. As Fig. 1 shows, LH model predictions using a single set of "best fit" parameters fail to correctly reproduce a large number of experimental data points over a broad range of conditions. We have the choice to either restrict the range of variables (water pressure, temperature) for which one can define a statistically significant set of LH model parameters, or to accept that several sets of parameters are valid over various ranges of experimental conditions.

A third option is finding a proper mathematical form of the kinetic equation, such that it is able to reproduce correctly the temperature dependence (apparent activation energies) and concentration dependence (apparent reaction order) for steady state oxidation by moisture of particular grades of graphite, over a broad range of conditions. The measurements should be conducted in kinetic regime and be free of transport limitations (as much as possible), and therefore the result should represent intrinsic properties of graphite grades of interest.

It goes without questioning that the carbon (or graphite) surface is covered by a copious number of surface complexes formed after exposure to oxygen, carbon dioxide, water, etc. The issues that still do not have an answer are the same, irrespective whether oxidation is caused by air (oxygen), water (moisture) or carbon dioxide:

- Which (and when) surface complexes are active in gasification reactions?

- What factors determine whether active surface complexes act as just spectators or even as inhibitors of gasification?

- How many surface sites (carbon atoms) are affected by the gasification reaction induced by one single $\mathrm{H}_{2} \mathrm{O}$ molecules? 
The fact remains that surface complexes formed under common circumstances (temperature, gas exposure, etc) have a wide range of structures and reactivity. If this fact is neglected, then all attempts to formulate rational chemical kinetics mechanisms using deterministic premises are empirical and have limited capacity to capture the global process. It was argued in the recent literature [39] that a stochastic (probabilistic) description of surface reactions may be more successful. A series of recent papers by Haynes $[40,41,42]$ and Hurt $[43,44]$ investigate the possibility that carbon gasification reactivity in air (oxygen) reflects the nanoscale diversity of local surface topography, atomic configurations, and bonding energies of surface complexes. As argued by Hurt and Haynes [44] heterogeneity may be intrinsic, related to local structures, or may be induced, a reflection of chemical changes occurring between neighboring surface sites. The result of surface heterogeneity is that the desorption energy of surface complexes is better described by a distribution function, $f\left(E_{d e s}\right)$ than by a unique value. The focus on the desorption energy is significant because gasification (oxidation) occurs through desorption of surface complexes. Then, the total rate of global gasification reaction can be written as

$$
R_{\text {total }}=\int f\left(E_{\text {des }}\right) R\left(E_{\text {des }}\right) \mathrm{d} E_{\text {des }}
$$

where $R\left(E_{\text {des }}\right)$ is the local gasification rate, which can be approximated by the LH model. The distribution function $f\left(E_{d e s}\right)$ can conveniently by modeled by a Gauss distribution characterized by its center $E_{d e s}{ }^{\circ}$ and standard deviation $\sigma_{\mathrm{E}-\mathrm{des}}$. El-Genk et al. [45] used Gaussian-like distributions of adsorption and desorption energies of oxygen complexes to model the kinetics of oxidation by air of several graphite grades. Hurt and Hayes [44] demonstrate that, with these assumptions, the pressure dependence of the reaction rate depends on the breadth of the Gauss distribution. This is shown in Figure 2, reproduced from their work. The case with $\sigma_{\mathrm{E}-\mathrm{des}}=0$ corresponds to a homogeneous surface (energetically and structurally), as in the basic LH model. In this case the plot of $\ln ($ Rate $)$ vs. $\ln \left(P_{o x}\right)$, Eq. (4), starts with high slope at low pressure and bends to zero slope at high pressure. This is the typical LH behavior, where the apparent reaction order $m$ is close to unity at low pressure (adsorption control) and trends towards zero at high pressure (saturation of surface sites, desorption control). However, if surface nonuniformity is introduced in the model $\left(\sigma_{\mathrm{E}-\mathrm{des}} \neq 0\right)$, the $\ln ($ Rate $)$ vs. $\ln \left(P_{o x}\right)$ plots bend less, as shown by simulations by the same authors [44] reproduced in Fig. 2. The larger the breath $\sigma_{\mathrm{E}-\mathrm{des}}$ of the Gauss distribution (or the more heterogeneous the distribution of surface complexes is) the less bending is observed and the higher remains the apparent reaction order. Recall, the latter was introduced by Eq. (4) above as the slope of the log-log variation of oxidation rate versus oxidant pressure:

$$
m=\frac{d \ln (\text { Rate })}{d \ln \left(P_{o x}\right)}=\frac{1}{1+\frac{k_{a d s} P_{o x}}{k_{d e s}}}
$$

The right term in Eq, (6) is valid for the most general and simplest form of the LH kinetic model, in absence of hydrogen retardation $\left(P_{H 2}=0\right)$. The two kinetic constants $k_{a d s}$ and $k_{d e s}$ correspond to the rate of oxidant adsorption and gasification product desorption.

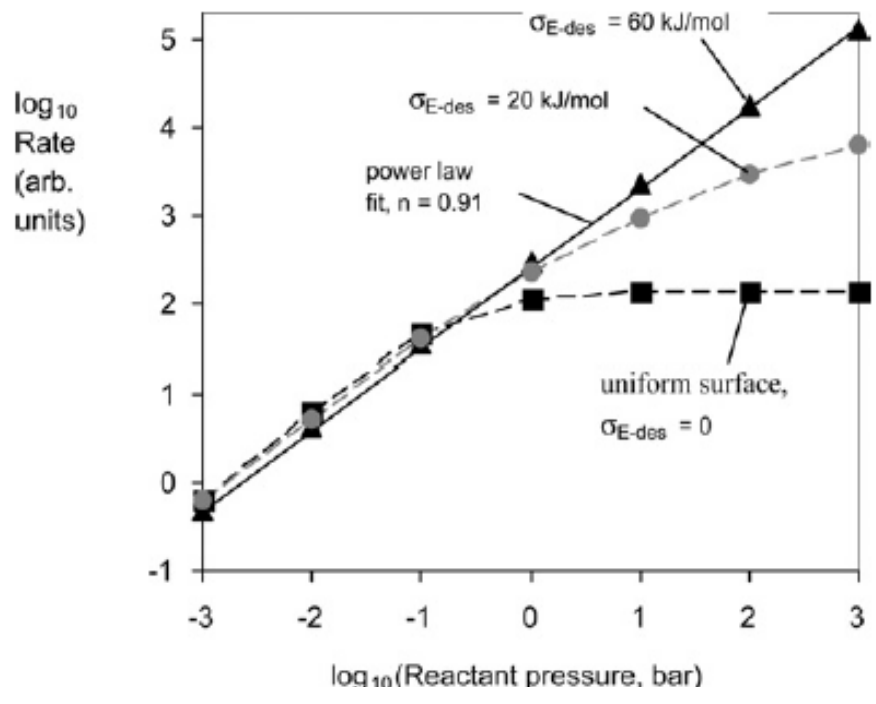

Figure 2: Behavior of the global oxidation rate predicted for solids with a Gauss distribution of surface sites' desorption energies (from ref. [44]). 
As Fig. 2 shows, the "persistent power law" identified by Hurt and Haynes [44] for carbon gasification in air can be explained by the energetic and structural heterogeneity of real surfaces. Application of this model required prior knowledge of desorption energy distribution function for surface complexes for the graphite grade of interest. The $f\left(E_{\text {des }}\right)$ function can be determined experimentally using the method of temperature-programmed desorption (TPD) of surface species on each graphite grade $[46,47,48,49]$.

The equipment available at ORNL is suitable for such measurements, because the thermogravimetric balance (TAG) is connected to a mass spectrometer (MS). In the future it is worth pursuing this route, but for the moment we do not have experimental information on desorption energy distribution of surface complexes formed by exposure to moisture. Therefore, a different route for development of a global model for graphite oxidation by moisture was chosen.

We need first to look at the structure, energetics and reactivity on surface complexes formed by interaction of water with graphite surfaces. Recent literature information obtained by computational chemistry methods shall be used. 


\section{NEW KINETIC MODEL FOR GRAPHITE OXIDATION BY MOISTURE}

\subsection{WATER SURFACE COMPLEXES AND REACTION ROUTES}

The structure, energetics and reactivity of surface complexes formed by interaction of water with graphite surfaces can be modeled by using powerful molecular simulation methods based on quantum density functional theory (DFT). In essence, DFT calculations confirm that dissociative chemisorption is the first step of graphite gasification by water, as proposed by Long and Sykes [21] from experimental observations. Perfect graphite is essentially hydrophobic, and water experiences very weak, delocalized physisorption. However, if atomic vacancies are present on the flat basal plane, physisorption interactions are stronger [50] and as a result a carbon atom is slightly pulled out towards the $\mathrm{H}$ atom of an water molecule [51]. From this strong physisorption state $(18 \mathrm{~kJ} / \mathrm{mol})$ dissociative chemisorption of water occurs after overcoming a barrier of $72-84 \mathrm{~kJ} / \mathrm{mol}$. A second path of lesser energy barrier $(45 \mathrm{~kJ} / \mathrm{mol})$ is available for gas-phase molecules that avoid the physisorption state and go directly to the dissociative chemisorption state. After one more intermediate state the chemisorbed $-\mathrm{OH}$ breaks into $\mathrm{O}$ and $\mathrm{H}$ atoms bonded to separate $\mathrm{C}$ atoms. The total exothermicity of the final state is $306 \mathrm{~kJ} / \mathrm{mol}$. The energy diagram in Fig. 3 shows the molecular transformations and the structures of intermediate states [51]. The second dissociation path (not shown in the diagram) is more probable at high temperatures. Note that a direct transition from gas phase to the completely dissociated and separated state has negative activation energy.
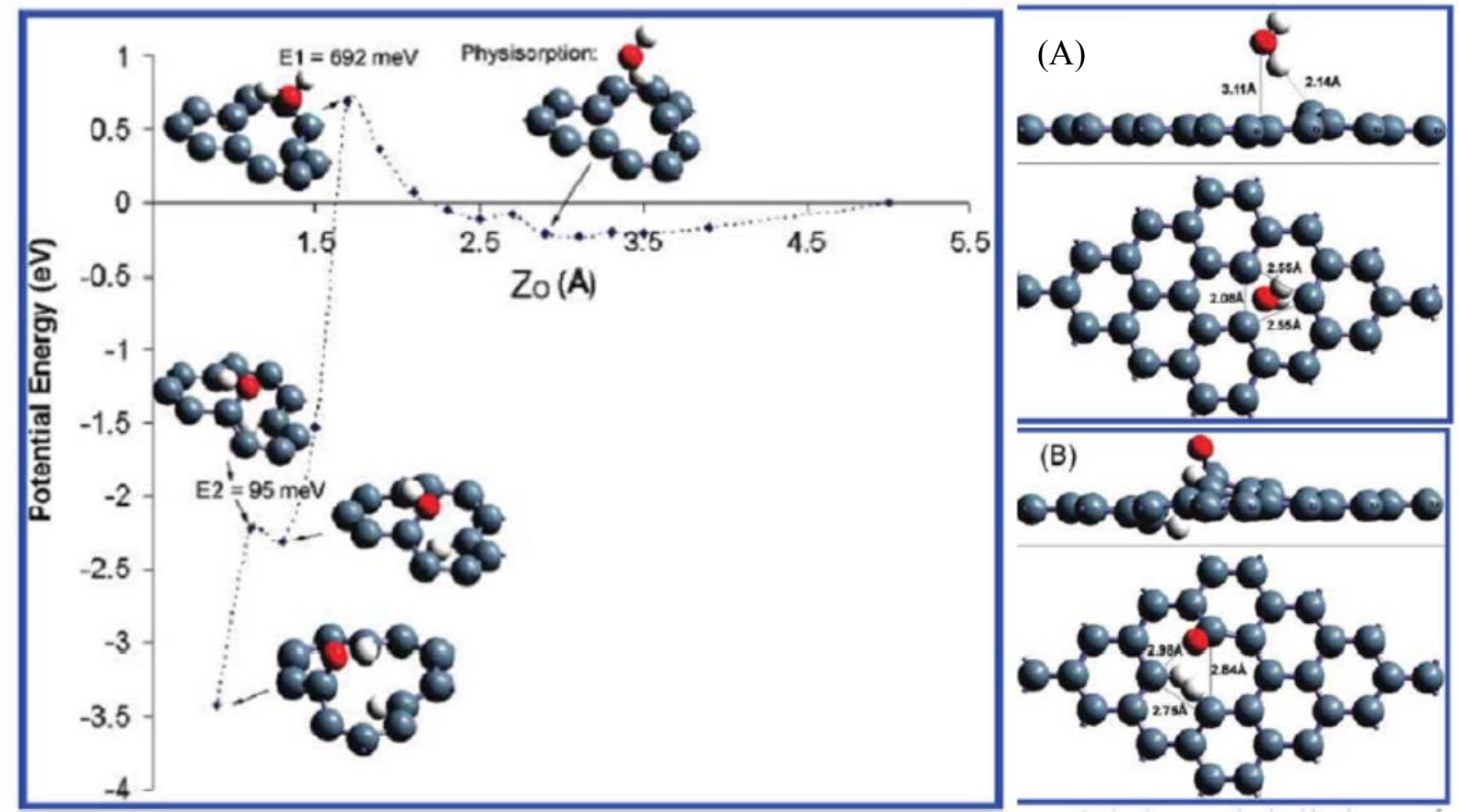

Figure 3: $\quad$ Energy diagram steps of dissociative chemisorption of $\mathrm{H}_{2} \mathrm{O}$ on a vacancy site of graphite basal plane. The structures in the right panels represent strong physisorbed state (A) and the chemisorbed state (B) with totally dissociated $\mathrm{H}_{2} \mathrm{O}$ molecule $(\mathrm{O}$ - red; $\mathrm{C}$ - navy blue; $\mathrm{H}$ - grey). Adapted from [51].

More significant, and much more complex, are the processes occurring at graphite edges. In essence dissociative chemisorption of water remains the first step. Espinal et al. [52] used DFT calculations to 
investigate the water reactions with clean, oxidized and hydrogenated carbon surfaces. They confirmed that $\mathrm{H}_{2} \mathrm{O}$ chemisorption on clean zig-zag and armchair sites is highly exothermic and forms stable surface intermediate complexes containing oxygen bonded in hydroxyls, semiquinones, and cyclic ethers groups. The zig-zag configuration is energetically more reactive than the armchair configuration. Figure 4 shows the transformations chain of most probable surface complexes formed at zig-zag and armchair sites on graphene sheets. The vertical position of structural formula reflects the stability of various complexes with respect to the initial state, but the drawing is not at scale. The evolution of these complexes towards the final products of gasification, namely $\mathrm{CO}$ and $\mathrm{H}_{2}$, was also investigated. Several paths are possible, but all are endothermic (and will be favored by high temperatures). The main point to observe from these schemes is that the release of $\mathrm{CO}$ and $\mathrm{H}_{2}$ after adsorption of one single water molecule involves participation of several surface sites (carbon atoms) on either zig-zag or armchair edges, and results in drastic reconfiguration of the carbon skeleton (replacement of an aromatic 6-atoms ring by a 5-member cycle). These observations will be used later.

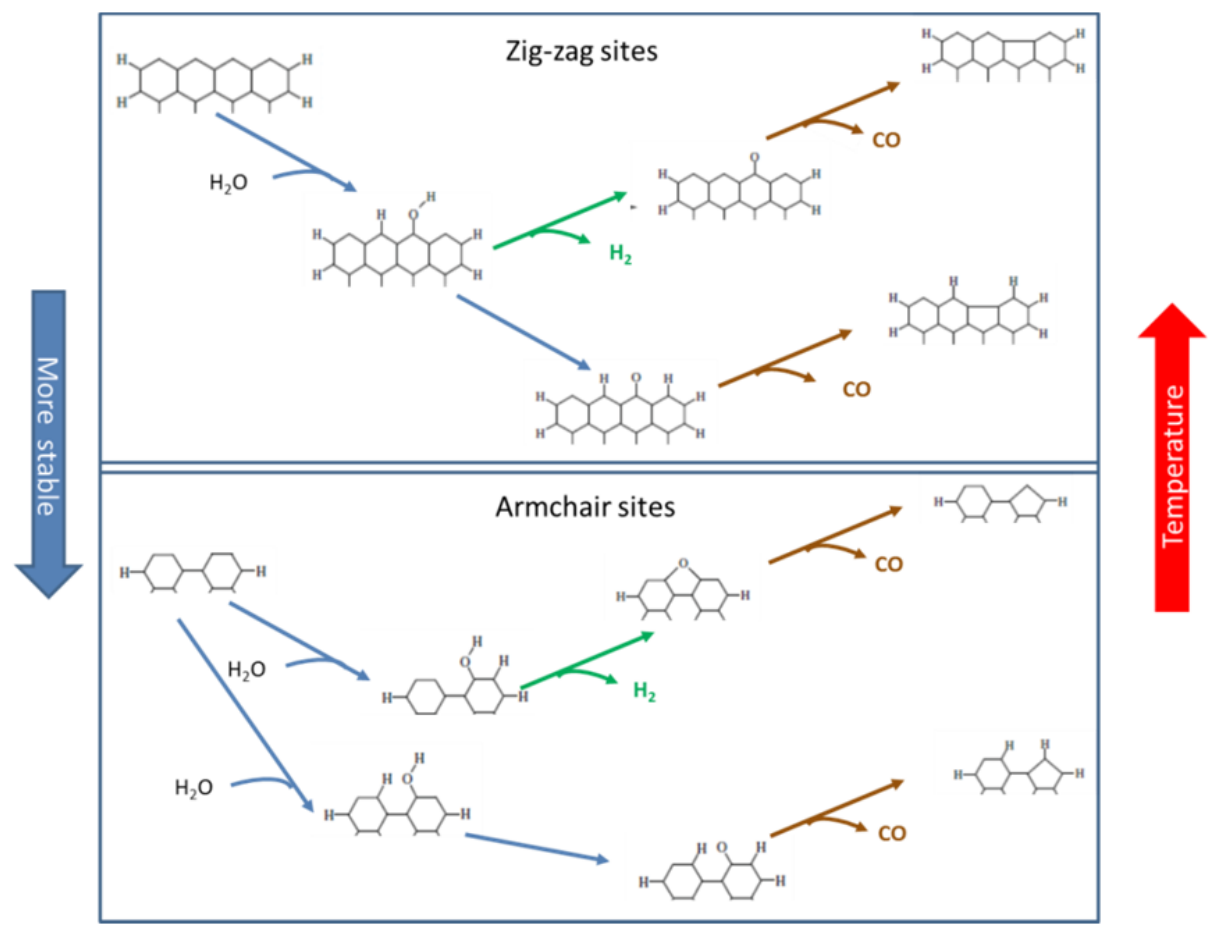

Figure 4: $\quad$ Schematic diagram of surface complexes formed by chemisorption of water at exposed zig-zag and armchair sites on graphene, and of their subsequent transformations during graphite gasification. Adapted from [52].

Espinal et al. [52] calculated the overall energetics of water reactions on clean graphite surface. They found that the global process for the reactions shown in Fig. 4 is exothermic when CO desorption occurs after the dissociation of $\mathrm{H}_{2} \mathrm{O}$ either on zig-zag or armchair sites. When hydrogen evolution was also considered, the global process of $\mathrm{H}_{2}$ evolution and $\mathrm{CO}$ desorption is exothermic for zig-zag sites (Fig. 4, top panel) but endothermic for armchair sites (Fig. 4, bottom panel). In reality, the number of exposed active sites on "clean" graphite is small unless they were formed by prior high temperature treatment and pyrolysis steps. Of most significant importance are the reactions occurring on hydrogen-saturated or preoxidized surfaces. These reactions are summarized in Figure 5. 


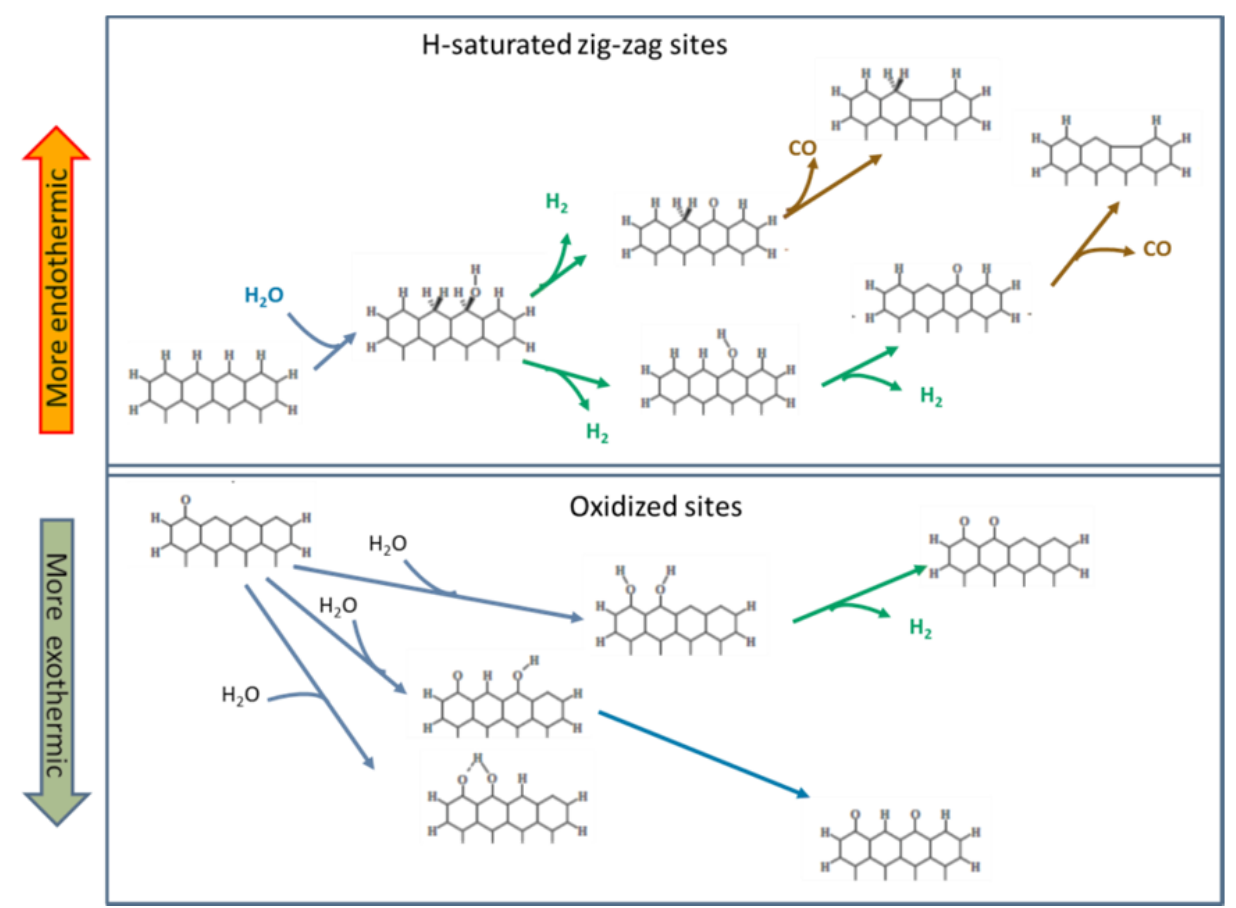

Figure 5: $\quad$ Schematic diagram of surface complexes formed by adsorption of water on hydrogen saturated and oxygen-containing zig-zag sites on graphene edges, and of their subsequent transformations during graphite gasification. Adapted from [52]

The bottom panel in this figure shows that water adsorption and dissociation on a pre-oxidized surface is even more exothermic than on the clean surface. This suggests that oxidized surfaces can be more reactive towards water than clean surfaces, possible because oxygen containing groups can form hydrogen bonds with $\mathrm{H}_{2} \mathrm{O}$ molecules that would lower the energy barrier to dissociative chemisorption [52]. We found out that this feature explains some of our recent observations (to be discussed later). On the other hand, dissociation of water on a hydrogen-saturated surface is endothermic (as often observed in experiments) and requires more energy than the reaction of water with clean surface. The top panel of Fig. 5 shows the diagram of these reactions. The retardation by hydrogen of gasification by water is explained by the fact that $\mathrm{H}_{2}$ molecules compete with $\mathrm{H}_{2} \mathrm{O}$ for the same active sites [52].

\subsection{COOPERATIVE BEHAVIOR IN REACTION KINETICS}

The main conclusion from the above discussion is that reaction of water with graphite is a complex process, that can occur on numerous routes (of which only a few were listed above) which involve a multitude of surface sites. After each reaction step, be it chemisorption and dissociation of $\mathrm{H}_{2} \mathrm{O}$, surface spillover of $\mathrm{H}$ atoms, release of $\mathrm{H}_{2}$ or desorption of $\mathrm{CO}$, the configuration of surface sites changes, carbon bonds are broken, and new bonds are formed. These changes are not localized to single carbon atoms. Because of the $\pi$ electrons delocalization in graphite, chemical transformations occurring at one carbon site modify the chemical environment of the neighboring carbon atoms. These processes are too complex 
to be treated individually, yet they need to be considered for a more accurate model development. An important aspect of the new model should be inclusion of cooperative behavior between active sites on carbon, and the correlation between separate chemical events.

Cooperative behavior is a fundamental property of molecular interactions and binding phenomena in biological systems [53]. Many polymers and proteins exhibit cooperativity, whereby their ligands bind in a non-independent, interacting way. After binding an oxygen molecule on hemoglobin, the probability of binding a second molecule increases. This is a well-known example of positive cooperativity. Conversely, polyelectrolyte polymers binding ligands by electrostatic interactions see their binding probability decrease after binding the first ligands. This is an example of negative cooperativity. According to some scholars $[53,54]$ there is a close analogy between collective behaviors in chemical kinetics, biochemistry, cybernetics, neuron interactions and other interdisciplinary fields. The property of cooperativity links descriptions of chemical systems at the individual atom (or molecule) level with the macroscopic behavior observed in real systems, either macromolecules, organisms, microbes, etc. The common property in these systems is the occurrence of "active sites". As the occupancy of these sites increases the interaction between sites can lead to increased affinity for further binding (positive cooperativity) or to retardation of further binding (negative cooperativity).

Chemical kinetics of elementary step reactions is derived from the mass action law that postulates that the reaction rates of elementary processes are proportional with the reactant concentrations raised to a power defined by stoichiometry coefficients. The global rate equation is derived by combining these simple rules with the steady state hypothesis, according to which the forward and reverse reactions occur with equal rate. This is how the global kinetic equations for graphite oxidation, Eqs. (1) - (3), where derived in the LH model. An equation of similar form describes the dependence of enzymatic reaction rates on the concentration of substrates in enzyme catalysis; it is known as the Michaelis-Menten equation for non-cooperative enzymatic reactions [55]:

$$
v=\frac{v_{\max }[S]}{K_{M}+[S]}
$$

where [S] is the substrate (ligand) concentration and $K_{M}$ is a combined rate constant. This equation is formally equivalent with the rate equations for graphite oxidation based on the LH model, such as Eq. (3), in the particular case of no product inhibition $\left(P_{\mathrm{H} 2}=0\right)$. The rate response to ligand concentration variations is described by a hyperbola (Fig. 6). A similar variation is predicted by the LH model for the relationship between oxidation rate and oxidant concentration.

Enzymatic kinetics has numerous examples of cooperative effects, where Eq. (7) fails to reproduce the data. In these cases, the variation of rate versus changes in substrate concentration is a sigmoidal curve (Fig. 6). This type of variation is described by the following empirical equation proposed by Hill:

$$
v=\frac{v_{\max }[S]^{m}}{K_{d}+[S]^{m}}
$$

where $K_{d}$ is a dissociation constant and $m$ formally represents the number of binding sites available per enzyme unit (the Hill parameter):

$$
\mathrm{E}+\mathrm{m} \mathrm{S} \longleftrightarrow \mathrm{ES}_{\mathrm{m}}
$$

Recalling the chemical kinetics theory definition introduced by Eq. (4) above, one can also regard $m$ from scheme (VI) as the apparent reaction order in Eq. (8). Fitting the Hill equation to real data rarely gives integer $m$ values, as expected if $m$ was the stoichiometric coefficient in an elementary reaction step. The Hill equation may not be an accurate description of elementary step mechanisms, but it is very useful in describing cooperative enzymatic systems because variations of $m$ provide a needed flexibility [55]. 
Figure 6 compares rate of enzymatic reactions versus concentration relationship typical for lack of cooperativity (hyperbola) and for positive cooperativity (sigmoid curves) with various $m$ values.
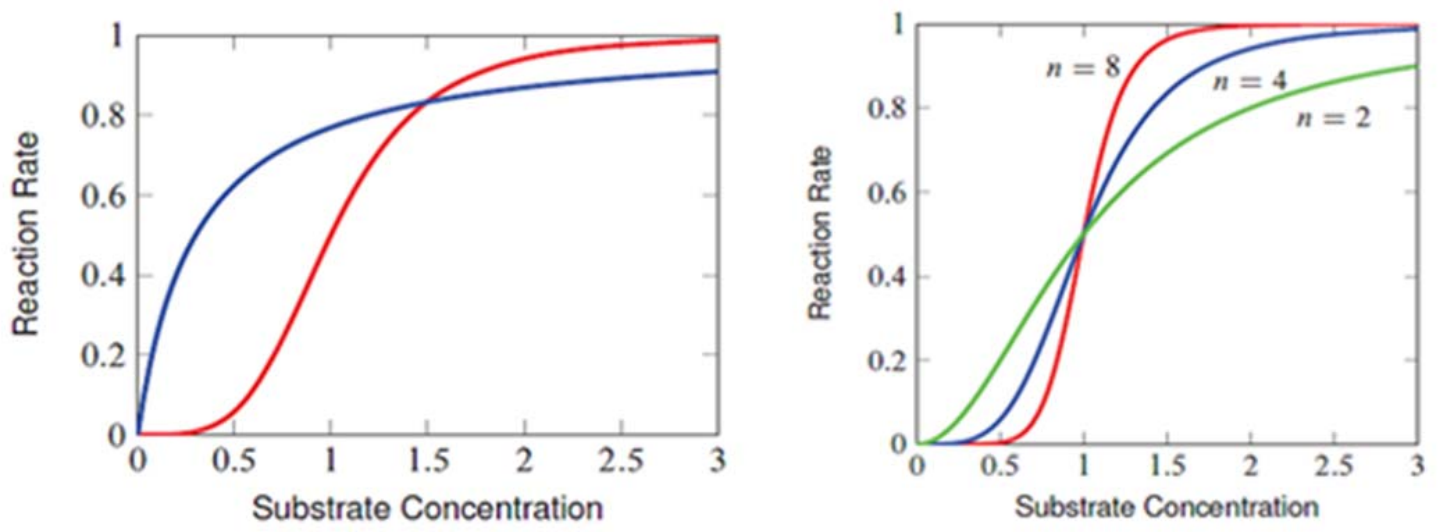

Figure 6: Left: Comparison between hyperbolic and sigmoidal dependence of reaction rate versus ligand concentration indicating lack of cooperativity (blue hyperbola line) and positive cooperativity (red sigmoid curve), respectively. Right: By varying the Hill parameter, sigmoid curves are able to describe a multitude of positive cooperative phenomena. Adapted from [55].

\subsection{ENHANCED KINETIC MODEL FOR GRAPHITE OXIDATION}

\subsubsection{Site Cooperativity and Apparent Reaction Order}

Fitting the LH model to experimental data on IG110 oxidation collected during 2015-2016 was more difficult than fitting the model to PCEA and NBG-17 data. It was shown in Fig. 1 that deviations from the LH model appear to be larger for graphite IG-110 than for the other grades. Deviations appear mostly at high temperatures. To understand the cause of temperature effects, we plotted in Figure 7 the apparent reaction order $(m)$ calculated with Eq. (4) from the experimental data against the values predicted by the LH model with best fit parameters.

Figure 7 shows big differences between the trends predicted by the LH model and the experimentally observed variations of $m$. The LH model predicts a linear increase of the apparent reaction order with temperature. In contrast, the apparent reaction order obtained directly from experimental data (as the slope of $\ln ($ Rate $)$ versus $\ln \left(P_{\mathrm{H} 2 \mathrm{O}}\right)$ plots $)$ describes a sigmoid curve with values between 0 and 1 . Interestingly, while IG-110 data spread over the full range of the sigmoid, NBG-17 data cover only the lower and middle ranges and PCEA data only the top range. In contrast, both variants of the LH predictions for graphite H-451 (based on digitized data from ref. [7]) show descending trends versus temperature; the values calculated directly from experimental observations are close to the predictions for the "low water" model at $\mathrm{P}_{\mathrm{H} 2 \mathrm{O}}<300 \mathrm{~Pa}$.

Other researchers observed that the apparent reaction order may vary during carbon oxidation. Querini and Fung [56] studied temperature-programmed oxidation (TPO) of highly coked catalysts and noted that coke reaction order can increase from near 0 to 1 . Analyzing kinetics of charcoal and graphite oxidation at low $\mathrm{O}_{2}$ partial pressure from TPO experiments, Li and Brown [57] used an exponential function to fit the observed variation of carbon reaction order on the fraction of unreacted carbon. 

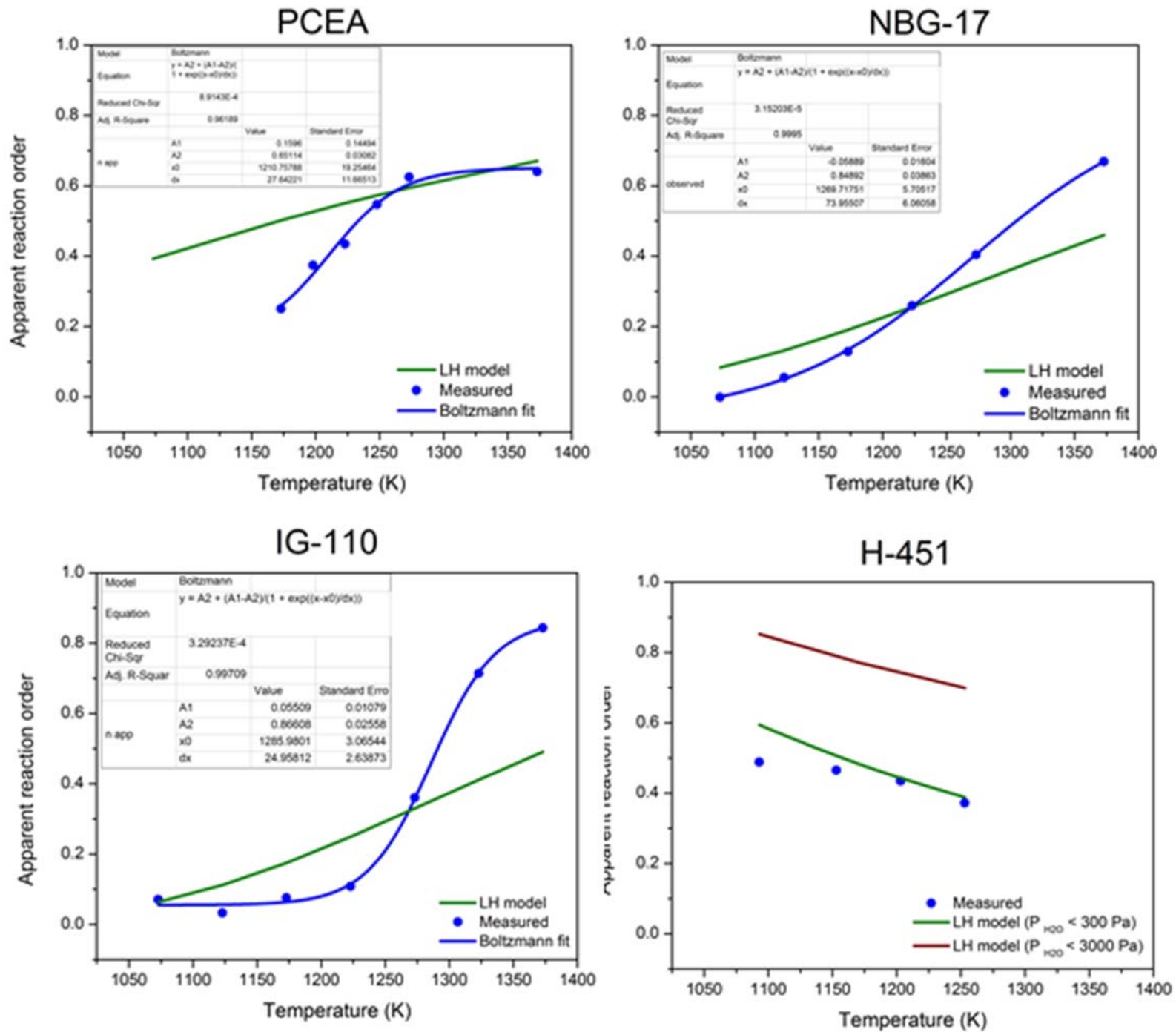

Figure 7: $\quad$ Temperature dependence of apparent reaction order calculated directly from experimental data compared with model predictions based on best fit LH parameters. Data for graphite grades PCEA, NBG-17 and IG-110 were obtained at ORNL and for graphite $\mathrm{H}-451$ were derived by digitizing the plots from ref. [7]. Experimental data points were fitted with the Boltzmann cumulative distribution function.

We fitted the sigmoid temperature variations of apparent reaction order obtained from experiments (fig. 7) with the Boltzmann distribution function:

$$
m(T)=m_{\max }+\frac{m_{\min }-m_{\max }}{1+\exp \left(\frac{T-T_{o}}{\Delta T}\right)} \approx m_{\max } \frac{\exp \left(\frac{T-T_{o}}{\theta}\right)}{1+\exp \left(\frac{T-T_{o}}{\theta}\right)} \quad\left(\text { assume } m_{\min }=0\right)
$$

The cumulative Boltzmann distribution, Eq. (9), represents the probability distribution of apparent reaction order values $(m)$ as a function of temperature. Here $m_{\max }$ and $m_{\min }$ are the upper and lower limits 
of $m$ (in the experimental range) and $0 \leq m_{\min }<m_{\max } ; T_{o}$ is the temperature corresponding to the inflection point of the sigmoid curve and $\theta$ is the slope at $T_{o}$. Recall that the apparent reaction order is defined by the reaction stoichiometry. In the particular case of graphite gasification by moisture, the global equation can be written as:

$$
\mathrm{C}_{\mathrm{f}}+\mathrm{m} \mathrm{H}_{2} \mathrm{O} \rightarrow \ldots . \rightarrow \mathrm{x} \mathrm{C}_{\mathrm{f}}+\mathrm{y} \mathrm{CO}+\mathrm{z} \mathrm{H}_{2}
$$

Because of formal similarity between schemes (VI) and (VII) we borrowed concepts from enzyme kinetics and applied them to graphite oxidation kinetics. The Hill coefficient, $m$, in Scheme (VI) is a variable stoichiometric coefficient in enzyme kinetics. In Scheme (VII) the stoichiometric coefficient $m$ represents mechanistically the average number of $\mathrm{H}_{2} \mathrm{O}$ molecules reacted per active carbon site. The global rate equation is proportional with $P_{\mathrm{H} 2 \mathrm{O}}$ raised to the $m$-th power, as in Eq. (4) above, which is repeated here:

$$
\text { Rate }(T) \cong k\left(P_{H 2 O}\right)^{m} \cong A \exp \left(-\frac{E}{R T}\right)\left(P_{H 2 O}\right)^{m(T)}
$$

In classical kinetics the temperature effect is expressed by the Arrhenius activation law: The rate constant $k$ is the product of the frequency factor $A$ and of the exponential function derived from the Boltzmann distribution of energy. Only those $\mathrm{H}_{2} \mathrm{O}$ molecules impinging on the surface with energy higher than a threshold activation energy $E$ will react.

The experimental data shown in Figure 7 demonstrate that the apparent reaction order $m$ (or the stoichiometry of global oxidation reaction) also depends on temperature, and that dependence is described by a Boltzmann distribution. This empirical observation can be interpreted by observing that $1 / \mathrm{m}$ in Scheme (VII) is the average number of surface sites that participate in reaction with one $\mathrm{H}_{2} \mathrm{O}$ molecule. This number is large at low temperatures (when $m$ is small) and drops with the increase of temperature $(m$ increases). This suggests that the cooperativity between surface sites able to participate in gasification by water is temperature-dependent, and follows the Boltzmann distribution function. In other words, increasing the temperature modifies the conditions at graphite surface and enhances the reactivity of surface sites: more and more sites that were stable at low temperatures become reactive at higher temperatures.

With this assumption the global rate equation should be written as

$$
\text { Rate }(T) \cong k(T) P_{H 2 O}^{m(T)} \cong A \exp \left(-\frac{E}{R T}\right) P_{H 2 O}^{m(T)}
$$

where $m(T)$ is the Boltzmann distribution function and $k$ is an oversimplified notation for the composed kinetic constants that support the LH model.

\subsubsection{Enhanced LH Model with Boltzmann Activation of Surface Sites}

Returning to the LH model for graphite gasification by water, we modified the classical LH equation, repeated below,

$$
\operatorname{Rate}\left(P_{H 2 O}, P_{H 2}, T\right)=\frac{k_{1} P_{H 2 O}}{1+k_{2}\left(P_{H 2}\right)^{n}+k_{3} P_{H 2 O}}
$$

by replacing $P_{\mathrm{H} 2 \mathrm{O}}$ at the numerator and denominator by $P_{H 2 O}{ }^{m(T)}$. The new rate equation for the enhanced LH model that includes site cooperativity is then written as: 


$$
\operatorname{Rate}\left(P_{H 2 O}, P_{H 2}, T\right)=\frac{k_{1}\left(P_{H 2 O}\right)^{m(T)}}{1+k_{2}\left(P_{H 2}\right)^{n}+k_{3}\left(P_{H 2 O}\right)^{m(T)}}
$$

where it is assumed that $n=0.5$ (the exponent of $P_{H_{2}}$ ) and the Arrhenius relationship holds for all three rate constants $k_{i}$. The $m(T)$ exponent is modeled as the Boltzmann distribution function. The explicit form of Eq. (11) is as follows:

$$
\operatorname{Rate}\left(P_{H 2 O}, P_{H 2}, T\right)=\frac{A_{1} \exp \left(-\frac{E_{1}}{R T}\right)\left(P_{H 2 O}\right)\left[m_{\max }+\frac{m_{\min }-m_{\max }}{1+\exp \left(\frac{T-T_{O}}{\theta}\right)}\right]}{1+A_{2} \exp \left(-\frac{E_{2}}{R T}\right)\left(P_{H 2}\right)^{n_{+}} A_{3} \exp \left(-\frac{E_{1}}{R T}\right)\left(P_{H 2 O}\right)\left[m_{\max }+\frac{m_{\min }-m_{\max }}{1+\exp \left(\frac{T-T_{O}}{\theta}\right)}\right]}
$$

This 10-parameter equation of the LH model enhanced with the Boltzmann distribution function will be called Boltzmann-enhanced Langmuir-Hinshelwood (BLH) model. The new model was fitted to all experimental data points measured during 2015-2016 for graphite IG-110. The same model was then fit to data measured previously for graphite PCEA and NBG-17, and to data for graphite H-451 obtained by digitization of the plots in the 1978 GA report [7]. In general, the enhanced 10-parameters BLH model provides better fit than the 6-parameters classical LH variant.

\subsubsection{Testing the Boltzmann-enhanced LH Model}

Data analysis and statistical treatment was performed by Dr. Robert Mee at the University of Tennessee, Knoxville, TN. The estimation of parameters was done by the maximum likelihood estimation (MLE) method, which is a standard approach used in statistics. It is an indispensable modeling technique for non-linear modeling with non-normal data that offers sufficiency, consistency, efficiency, and parametrization invariance [58]. When applied to a set of data in combination with a parametrized model, MLE approach is able to simultaneously estimate the parameters that represent all data. The analysis returns parameters values, standard errors for estimates and correlations between estimates. This is essential for understanding the uncertainty in the parameters estimates.

In our analysis we found that not all experimental data were usable for parameters estimate. A preliminary validation step was performed after data collection was complete. Some data points were rejected because of experimental errors or unexpected events during experiments. All "negative oxidation rate" data (highlighted red in the Annex) were obviously wrong and were rejected. In general these were coming from measurements at low temperatures (mostly at $800{ }^{\circ} \mathrm{C}$, a few at $850{ }^{\circ} \mathrm{C}$ ) where oxidation rates are very slow and the relative error of weight loss measurements is higher. Some other data points were rejected because they were clearly in error with the rest of the data based on an empirical response surface model. Data rejected were coming from experiments perturbed by various reasons, either because of flow rate variations, gas composition instability, or other experimental errors. Valid observations retained for analysis were about $85-90 \%$ of the bulk of total data collected for each graphite grade.

Analysis of valid data was performed by using the SAS Institute procedure MLMIXED for estimation of the 10 parameters of the enhanced LH model. The rate equation was rewritten in logarithmic form as follows: 


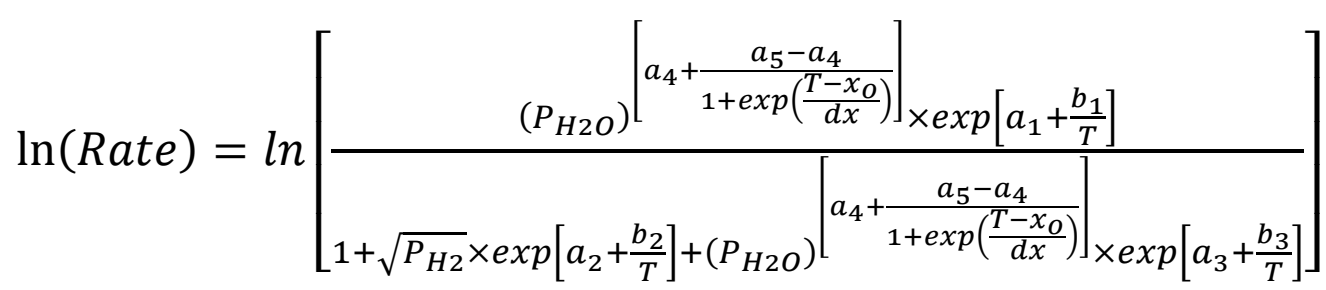

The following notations link Eqs. (12) and (13):

$$
\begin{array}{lll}
a_{i}=\ln \left(A_{i}\right) ; i=1,2,3 & \text { so that } & A_{i}=\exp \left(a_{i}\right) ; i=1,2,3 \\
b_{i}=-\frac{E_{i}}{R} ; i=1,2,3 ; R=8.314 & \text { so that } & E_{i}=-8.314 \times b_{i}
\end{array}
$$

and also $a_{4}=m_{\max } ; a_{5}=m_{\min } ; x_{o}=T_{o} ; d x=\theta$. He variables are $P_{H 2 O}(\mathrm{~Pa}), P_{H 2}(\mathrm{~Pa})$, and $T(\mathrm{~K})$. The units for $A_{i}$ include pressure units $(\mathrm{Pa})$ raised to a negative power equal to the appropriate value of the exponent defining the apparent kinetic order. In addition, the units of $A_{1}$ also include inverse time $\left(\mathrm{s}^{-1}\right)$. All $E_{i}$ have the units of $\mathrm{R}, \mathrm{J} / \mathrm{mol}$. The unit of Rate is $\mathrm{s}^{-1}$. Rates are calculated as

$$
\text { Rate }=\left(1 / m_{o}\right) \times\left(\frac{\Delta m}{\Delta t}\right)
$$

where $\Delta m / \Delta t$ is the rate of weight loss $(\mathrm{mg} / \mathrm{s})$ at isothermal and constant gas composition conditions, and $m_{o}(\mathrm{mg})$ is the apparent specimen weight at the beginning of isothermal constant conditions. The apparent specimen weight changes slightly when temperature, gas composition and flow rate change, but it is constant during isothermal and constant flow conditions. Corrections were made for every segment of constant conditions, starting from the known weight of the dry specimen at the beginning of the experiment. 


\section{RESULTS}

\subsection{GRAPHITE IG-110}

As mentioned above, fitting the LH model to experimental data for graphite IG-110 was more difficult than LH fitting of PCEA and NBG-17 experimental data. Special attention was given to collecting data at low temperatures $\left(800\right.$ and $\left.850{ }^{\circ} \mathrm{C}\right)$ and low water vapor pressure $(5-10 \mathrm{~Pa})$ because these conditions are the closest to the normal operating conditions of HTGR (temperature range about 400 $-900{ }^{\circ} \mathrm{C}$ and $\mathrm{P}_{\mathrm{H} 2 \mathrm{O}}<1 \mathrm{~Pa}$ ) and practical for experiments. Because of the higher relative error of these measurements, the rate of rejections was higher for slow oxidation rates.

In typical runs the gas composition $\left(P_{\mathrm{H} 2 \mathrm{O}}\right.$ and $\left.P_{\mathrm{H} 2}\right)$ was kept constant and the temperature was raised in $50{ }^{\circ} \mathrm{C}$ increments (Method 1). In Figure 8 below, each Method 1 data point was collected on a different day, using a different graphite specimen. This day-to-day variation and differences between specimens as expected produces the scatter seen in these plots about the blue curves at low temperatures. In an effort to increase the precision of the pressure effect at low temperatures, Method 2 was attempted. In this procedure, each specimen was run at constant temperature, and only $P_{H 2 O}$ was varied. As expected, this did reduce the scatter about the red curves, since measurements by Method 2 were taken using the same specimen on the same day. However, an unexpected result was observed. When we started at $800{ }^{\circ} \mathrm{C}$ with $\mathrm{P}_{\mathrm{H} 2 \mathrm{O}}=200 \mathrm{~Pa}$ and repeatedly lowered the pressure at constant temperature to take additional measurements, the results showed an inexplicable increase in oxidation rate. A similar effect was observed when the Method 2 procedure was repeated at $850{ }^{\circ} \mathrm{C}$ (as shown in Figure 8) and $900{ }^{\circ} \mathrm{C}$ (not shown).
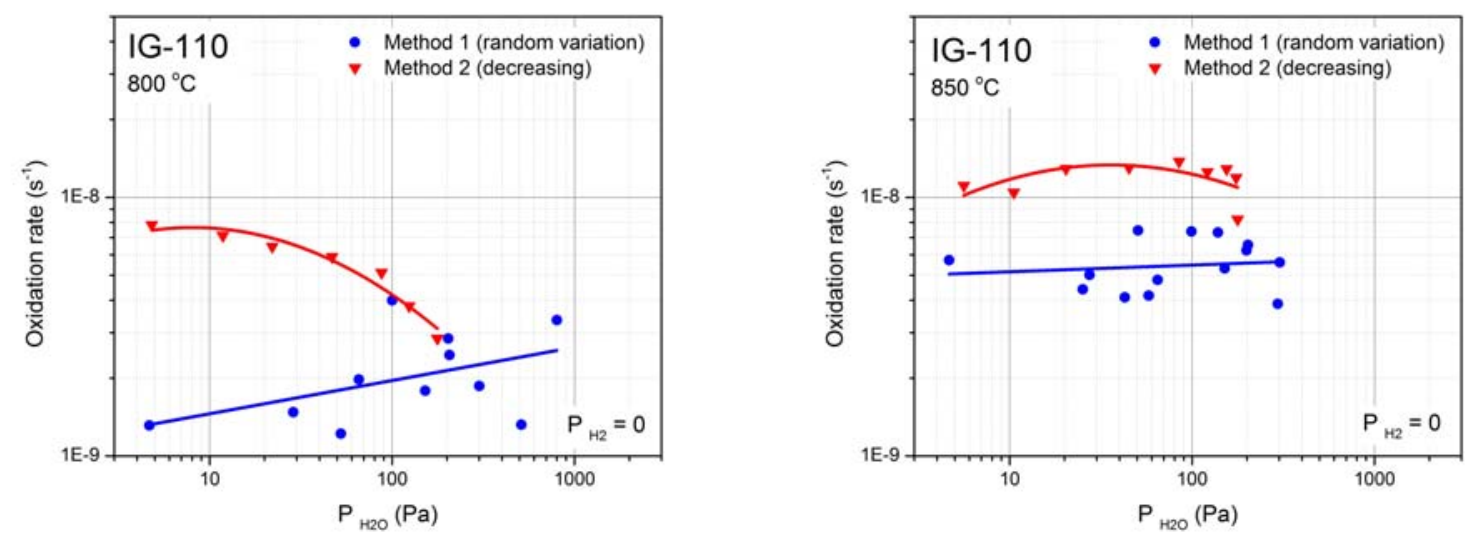

Figure 8: $\quad$ Experimental evidence of site cooperativity effects: Oxidation rates measured according to Method 1 (random $P_{H 2 O}$ variation from multiple specimens) follow an increasing trend with $P_{H 2 O}$, albeit scattered, while rates measured according to Method 2 (continuous $P_{\mathrm{H} 2 \mathrm{O}}$ decrease on the same specimen) are higher and show a trend reversed to that expected. 
This puzzling fact indicates that a certain "memory effect" was triggered on the graphite surface when the oxidation conditions changed from more aggressive at higher $P_{\mathrm{H} 2 \mathrm{O}}$ to less aggressive at lower $P_{\mathrm{H} 2 \mathrm{O}}$. The surface reactivity of aggressively oxidized surfaces did not drop, as expected, when $P_{H 2 O}$ was lowered at constant $T$. On the contrary, the rates increased. Figure 8 shows examples of this "memory effect". A similar observation was reported by Binford and Eyring [31] the reactivity of samples oxidized aggressively at high temperature continued even after lowering the graphite temperature by about $500{ }^{\circ} \mathrm{C}$. This is experimental proof of the reality of cooperativity between active sites. Dynamic changes on the graphite surface are not necessarily reversible (in about $12 \mathrm{~h}$ timeframe). Our results confirm theoretical conclusions by Espinal et al. [52] that heavily oxidized surfaces can be more reactive than clean surfaces toward reactions with water. The explanation is that oxygenated species on graphite surface (from aggressive oxidation at higher $P_{\mathrm{H}_{2} \mathrm{O}}$ ) act as centers for water clustering and migration in pores, and thus favors further chemisorption of water by lowering the barrier to $\mathrm{H}_{2} \mathrm{O}$ dissociation. After we obtained evidence of the irreversibility of dynamic changes, all data collected in Method 2 were dropped from the MLE analysis.

All physical parameters of IG-110 specimens and their change after oxidation are listed in Annex 1. All oxidation rate values and their corresponding experimental conditions are reported in Annex 2. From a total of 308 data points, 29 observations were rejected because they were either affected by experimental errors, instrumental instability, or simply the oxidation rate values were zero or negative. Another lot of 70 data points were collected with Method 2 procedure and could not be used for model fitting. In the lot of valid observations, 103 data points measured in $\mathrm{H}_{2} \mathrm{O} / \mathrm{He}$ mixtures and 106 data points measured in $\left(\mathrm{H}_{2} \mathrm{O}+\mathrm{H}_{2}\right) / \mathrm{He}$ mixtures were retained.

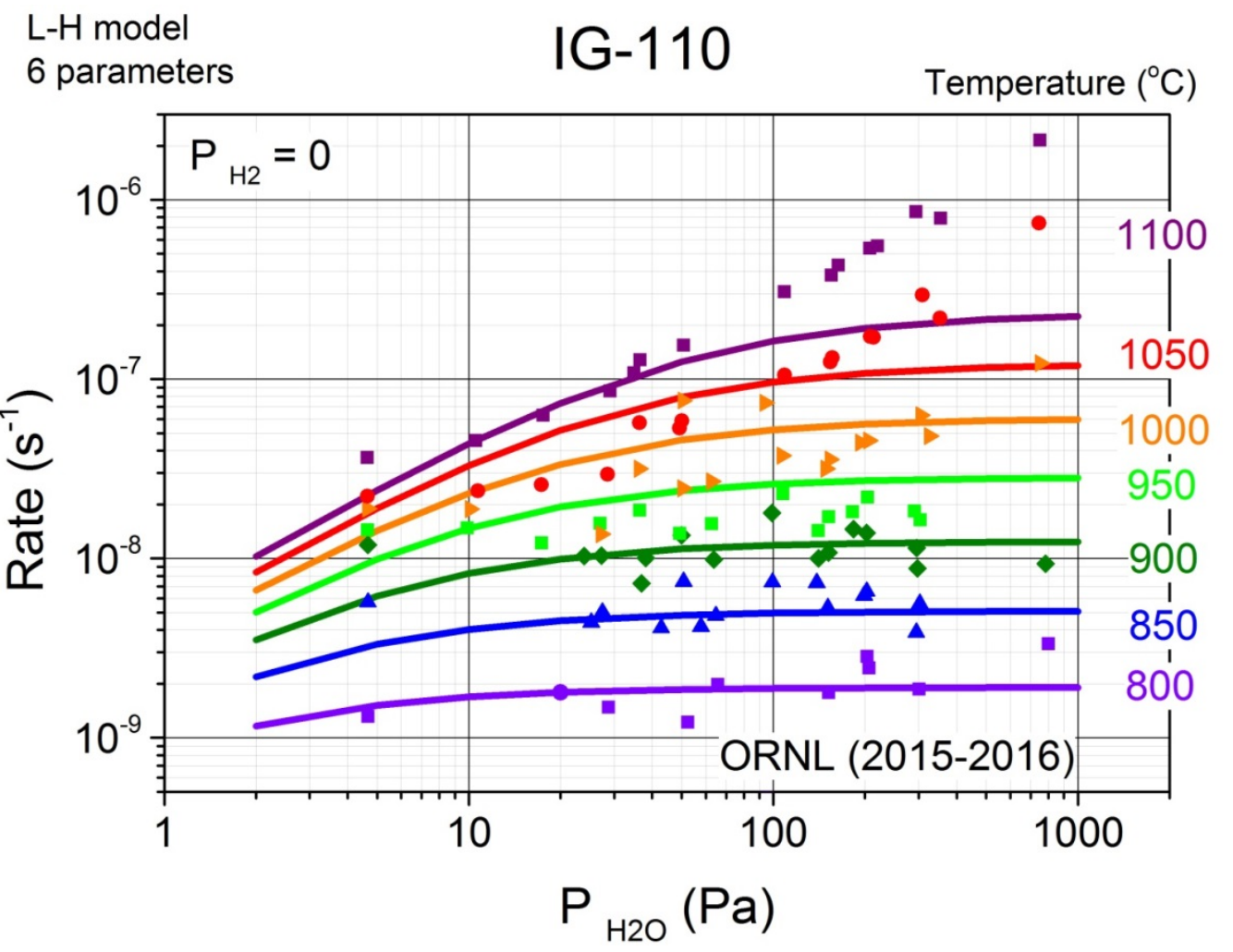

Figure 9: $\quad$ Oxidation rates measured for graphite IG-110 and the trends predicted by LH model with 6 parameters. Deviations are visible at high temperature and high water vapor pressure. 
The best fit LH parameters for graphite IG-110 are shown in Table 1:

Table 1

Best fit LH parameters for graphite IG-110

$$
\begin{aligned}
& A_{1}=8.29 \times 10^{-6} \mathrm{~Pa}^{-1} \mathrm{~s}^{-1} \\
& A_{2}=4.18 \times 10^{-8} \mathrm{~Pa}^{-1 / 2} \\
& E_{1}=85.75 \mathrm{~kJ} / \mathrm{mol} \\
& A_{3}=6.29 \times 10^{-11} \mathrm{~Pa}^{-1} \\
& E_{2}=-193.23 \mathrm{~kJ} / \mathrm{mol} \\
& n=0.5 \\
& E_{3}=-210.53 \mathrm{~kJ} / \mathrm{mol}
\end{aligned}
$$

Figure 9 show shows that the trends calculated with the best fitted LH parameters do not reproduce faithfully the measured data. Large deviations are seen at high pressures and high temperatures, where predicted rates are lower than the observed rates. The LH model predicts that the apparent reaction order is larger at low $P_{\mathrm{H} 2 \mathrm{O}}$ and smaller at high $P_{\mathrm{H} 2 \mathrm{O}}$. Accordingly, the LH trends in Fig. 9 (continuous lines) change the slope before $P_{\mathrm{H} 2 \mathrm{O}}=100 \mathrm{~Pa}$, but the observed rates do not follow this trend. Figure 10 compares all measured rates versus the LH model prediction. The correlation is not as good as expected.

\section{LH model}

\section{6 parameters}

\section{IG-110}

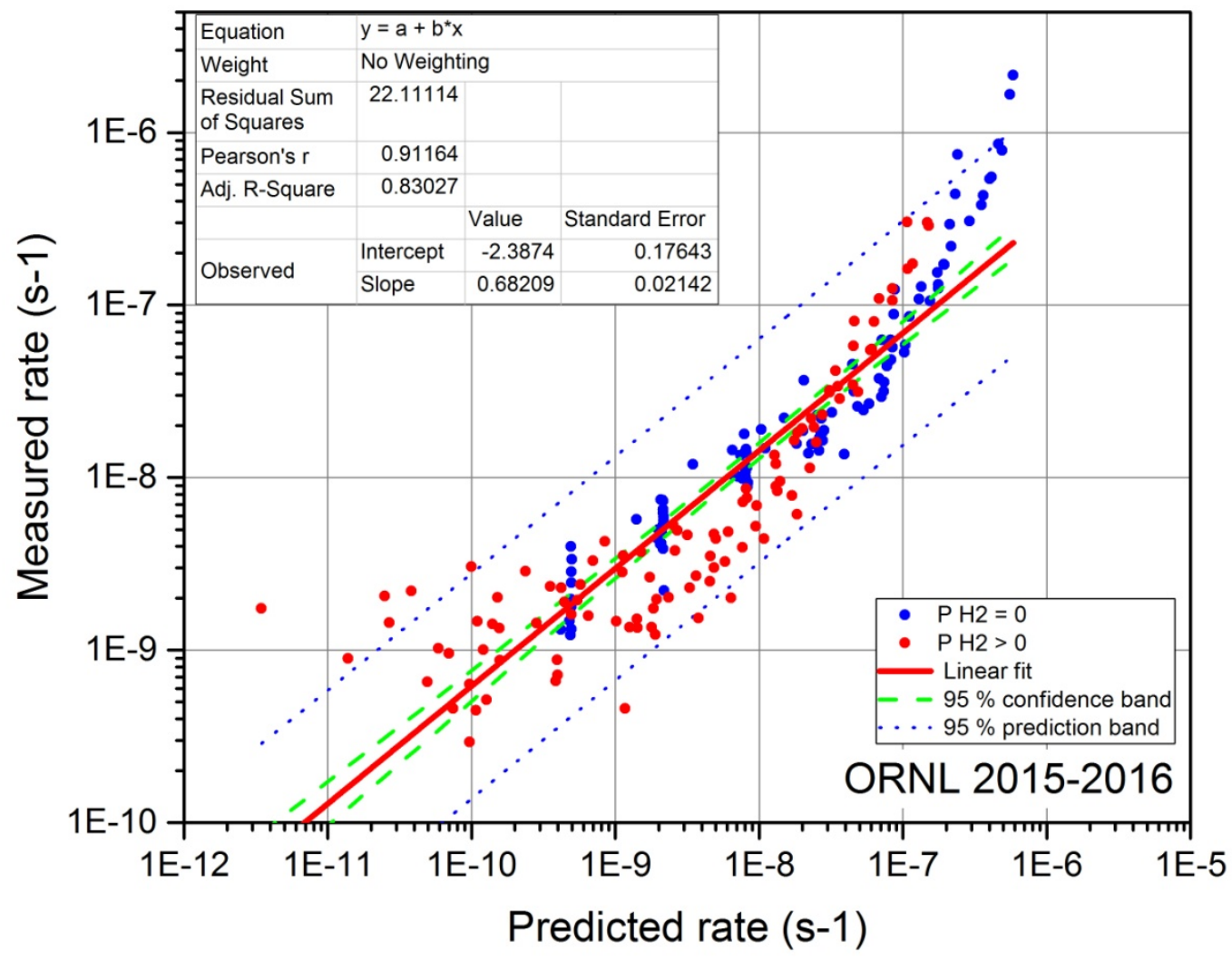

Figure 10: $\quad$ Comparison between rates measured for oxidation of IG-110 graphite and rates predicted by the $\mathrm{LH}$ model. Data shown include measurements in $\mathrm{H}_{2} \mathrm{O} / \mathrm{He}$ and $\left(\mathrm{H}_{2} \mathrm{O}+\mathrm{H}_{2}\right) / \mathrm{He}$ mixtures. 
The fact that fitting of 6-parameters LH model was not very successful for IG-110 is shown by the $\log -\log$ plot of measured and predicted rates in Figure 10. Large deviations are seen for fast rates at $\mathrm{H}_{2}-$ free conditions and for slow rates in presence of $\mathrm{H}_{2}$.

A much better agreement between experimental measurements and model predictions was obtained with the Boltzmann-enhanced LH model, introduced by Eqs. (12) and (13) above. Figure 11 compares the trends predicted at $P_{\mathrm{H} 2}=0$ with the experimentally measured rates.

\section{$\begin{array}{lll}\text { Enhanced BLH model } & \text { IG-110 } & \text { Temperature }\left({ }^{\circ} \mathrm{C}\right) \\ 10 \text { parameters } & \end{array}$}

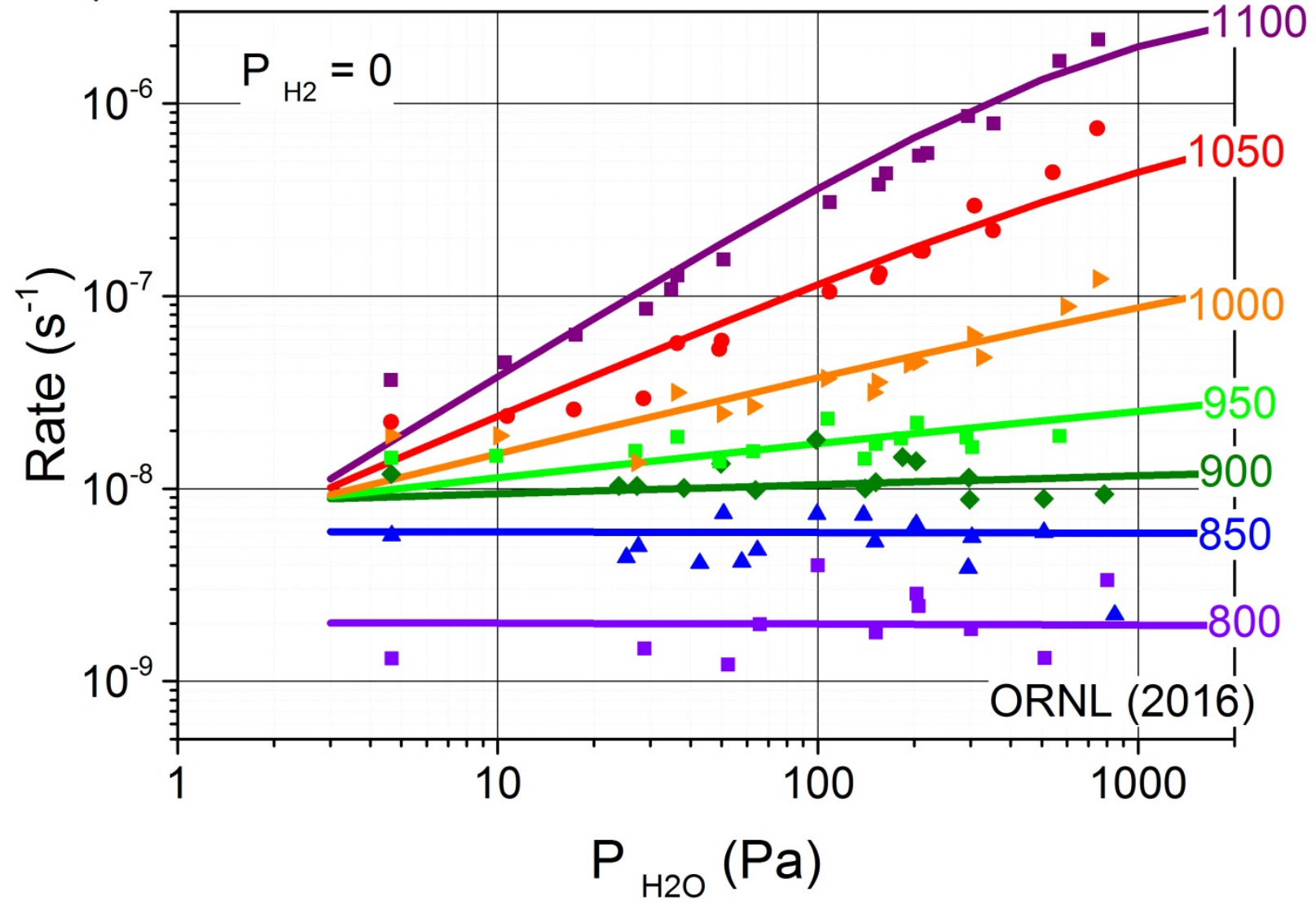

Figure 11: Oxidation rates measured for graphite IG-110 and the trends predicted by the Boltzmannenhanced LH model (10 parameters). This model fits the data better, including observations at high temperature and high water pressure.

Table 2

Best fit parameters for graphite IG-110 using the Boltzmann-enhanced LH model

$$
\begin{array}{lll}
A_{1}=7.64 \times 10^{-12} \mathrm{~Pa}^{-1} \mathrm{~s}^{-1} & E_{1}=-70.55 \mathrm{~kJ} / \mathrm{mol} & m_{\max }=1.5 \\
A_{2}=1.88 \times 10^{-2} \mathrm{~Pa}^{-1 / 2} & E_{2}=-39.61 \mathrm{~kJ} / \mathrm{mol} & m_{\min }=0 \\
\mathrm{~A}_{3}=6.07 \times 10^{-18} \mathrm{~Pa}^{-1} & \mathrm{E}_{3}=-373.52 \mathrm{~kJ} / \mathrm{mol} & T_{o}=1327 \mathrm{~K} \\
& n=0.5 & \theta=34.2 \mathrm{~K}
\end{array}
$$


Figure 12 compares rate measured versus rate predictions using the Boltzmann-enhanced LH model for this graphite. The linear fit in the log-log coordinates of Fig. 12 is of better quality than the corresponding fit shown in Fig. 10. This demonstrates that the enhanced model that includes site cooperativity and Boltzmann activation is able to more faithfully reproduce the experimental data over more than three ranges.

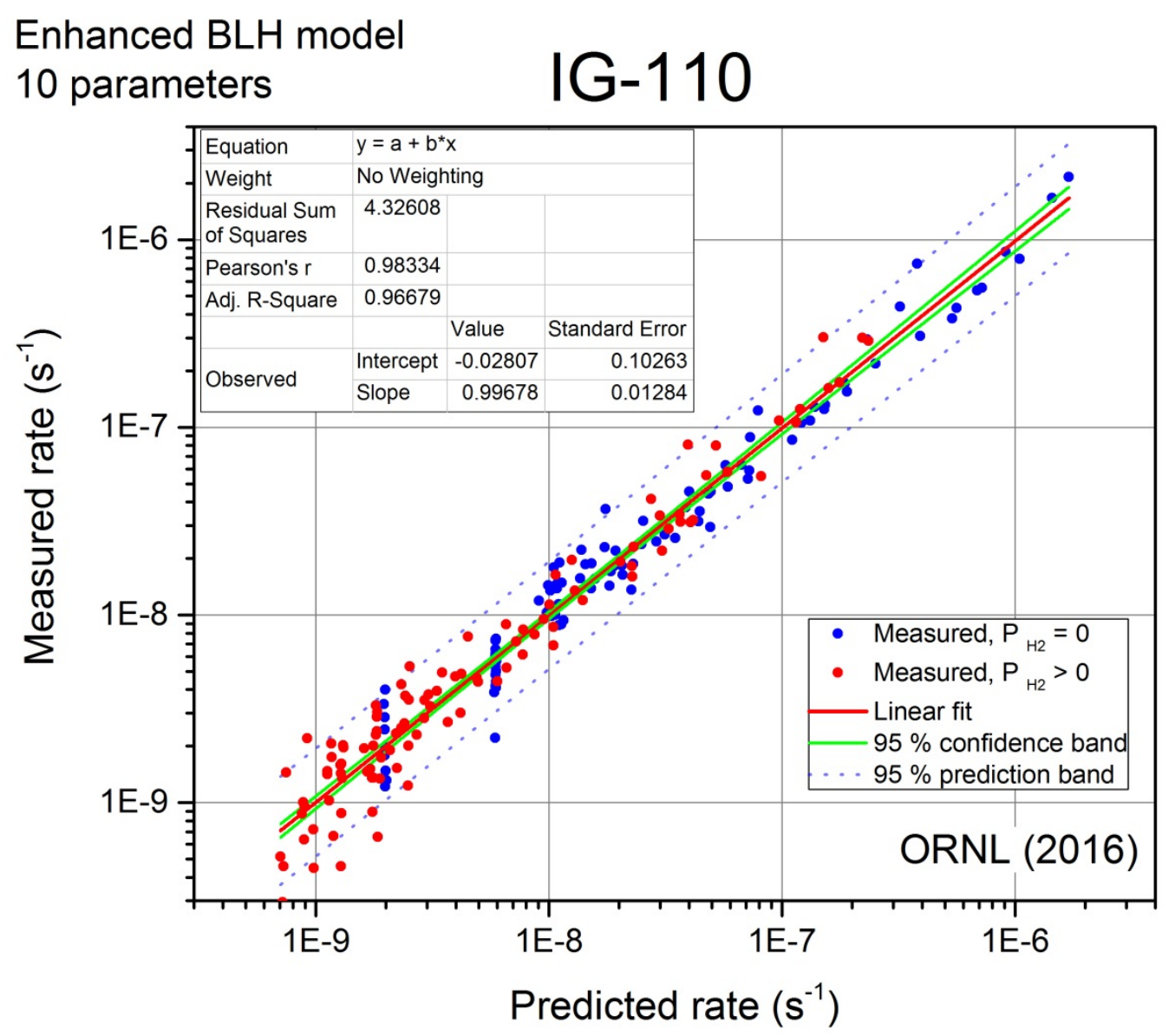

Figure 12: Comparison between rates measured for oxidation of IG-110 graphite and the rates predicted by the Boltzmann-enhanced LH model. Data shown include measurements in $\mathrm{H}_{2} \mathrm{O} / \mathrm{He}$ and $\left(\mathrm{H}_{2} \mathrm{O}+\mathrm{H}_{2}\right) / \mathrm{He}$ mixtures.

\subsection{GRAPHITE NBG-17}

In the 2015 report on oxidation by moisture of graphite NBG-17 [13] we acknowledged that the LH model did not fit correctly all experimental data. The valid data lot consisted of 269 data points of which 195 were from measurements in moist He only and 74 were measurements in moist He with added 
hydrogen. A number of 34 data points were invalidated because of the reasons explained above. Figure 13 shows the fit of LH model for data collected at $\mathrm{P}_{\mathrm{H} 2}=0$ and $\mathrm{P}_{\mathrm{H} 2}=26 \mathrm{~Pa}$. The same data were refitted using the augmented model with site cooperativity. The fit shown in Fig. 14 is a better model for experimental data.

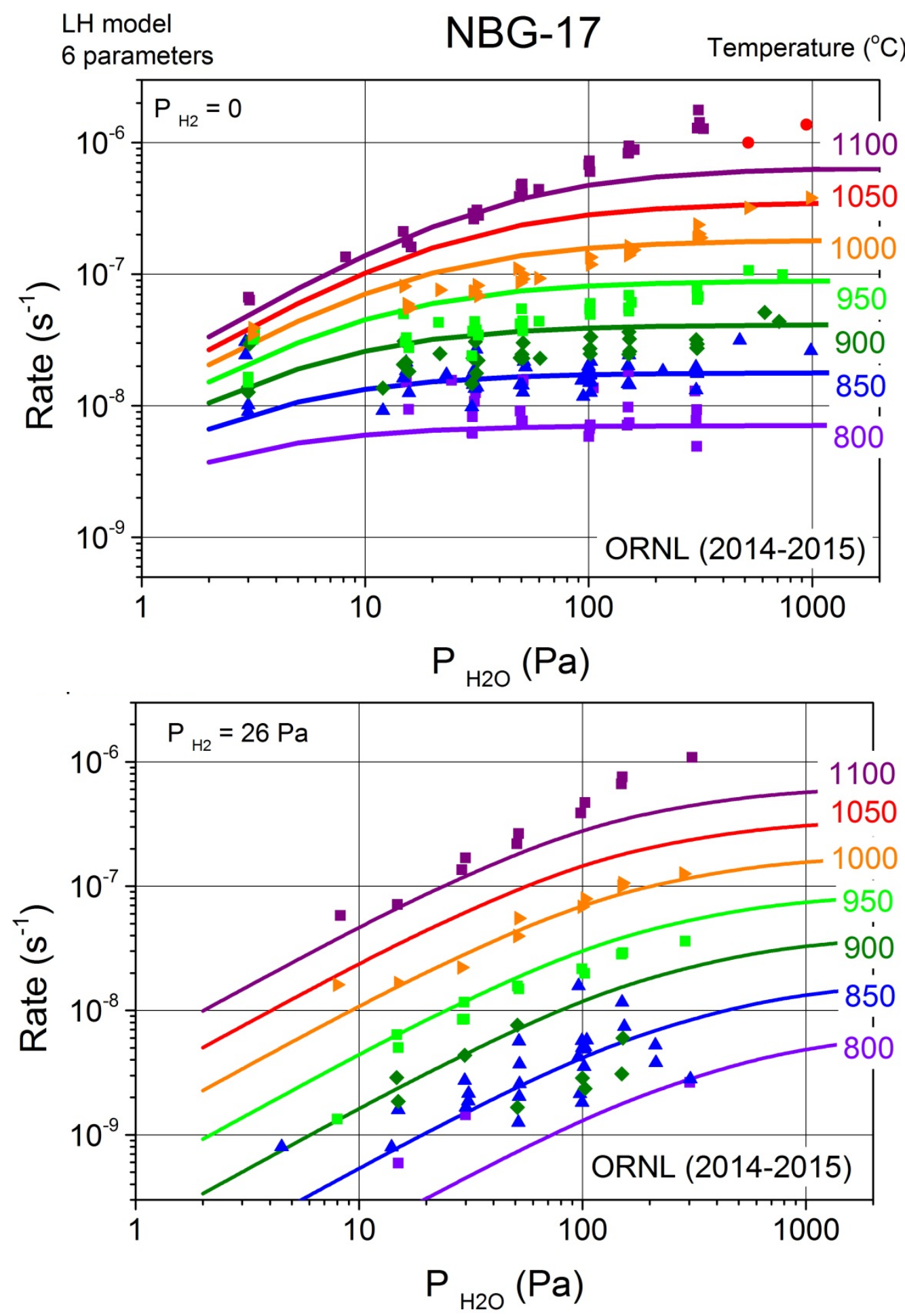

Figure 13: Fit of LH model to oxidation data for graphite NBG-17 at $P_{H 2}=0$ and $P_{H 2}=26 \mathrm{~Pa}$. 

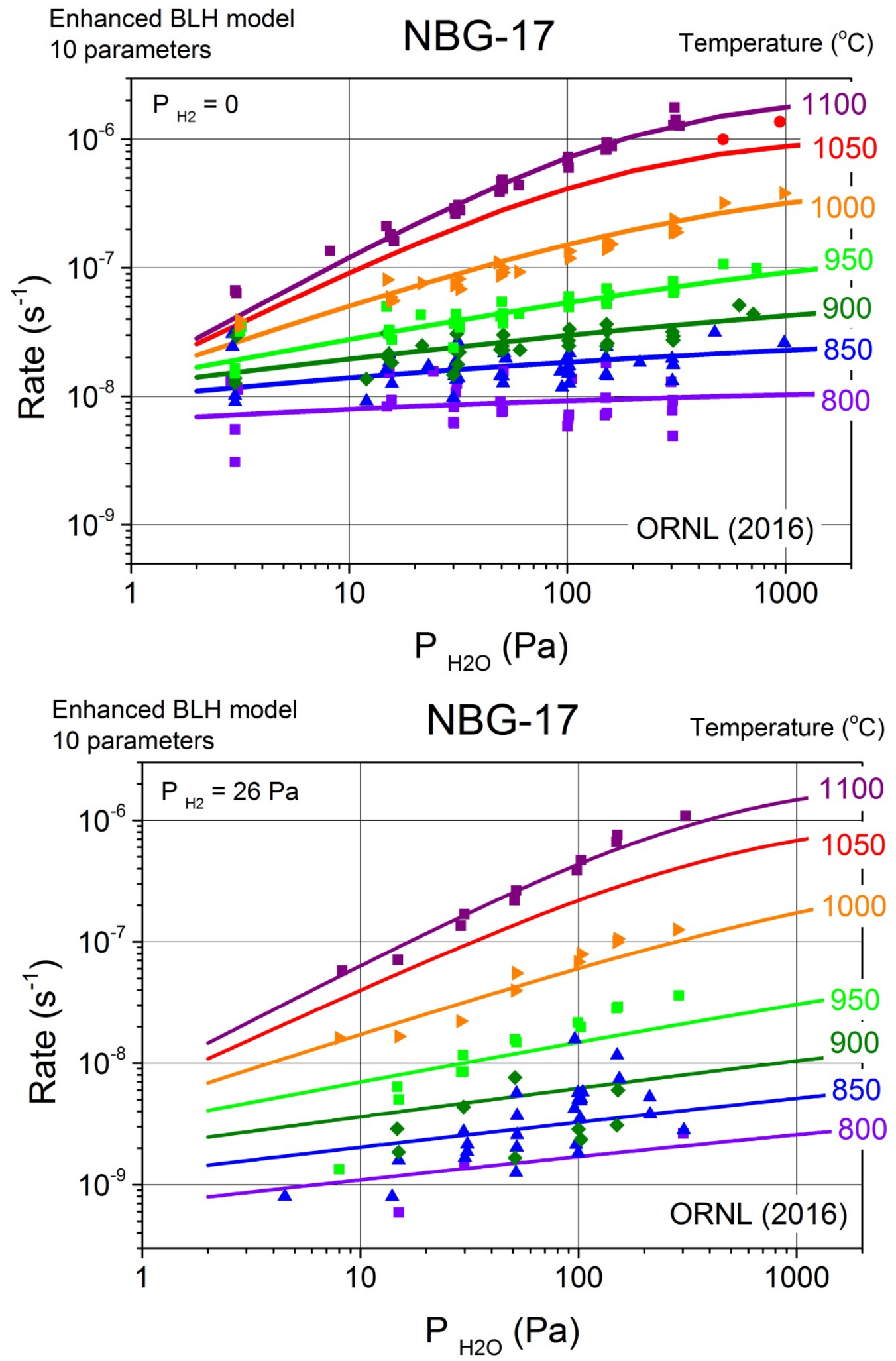

Figure 14: $\quad$ Fit of Boltzmann-enhanced LH model to oxidation data collected for graphite NBG-17 at $P_{\mathrm{H} 2}=0$ and $P_{\mathrm{H} 2}=26 \mathrm{~Pa}$. 
Figure 15 compares the goodness of fit of the two models. The superiority of the Boltzmann-enhanced LH model is reflected in the lower scatter of the log-log comparison of measured versus predicted results, and the narrower prediction and confidence bands of the plots.
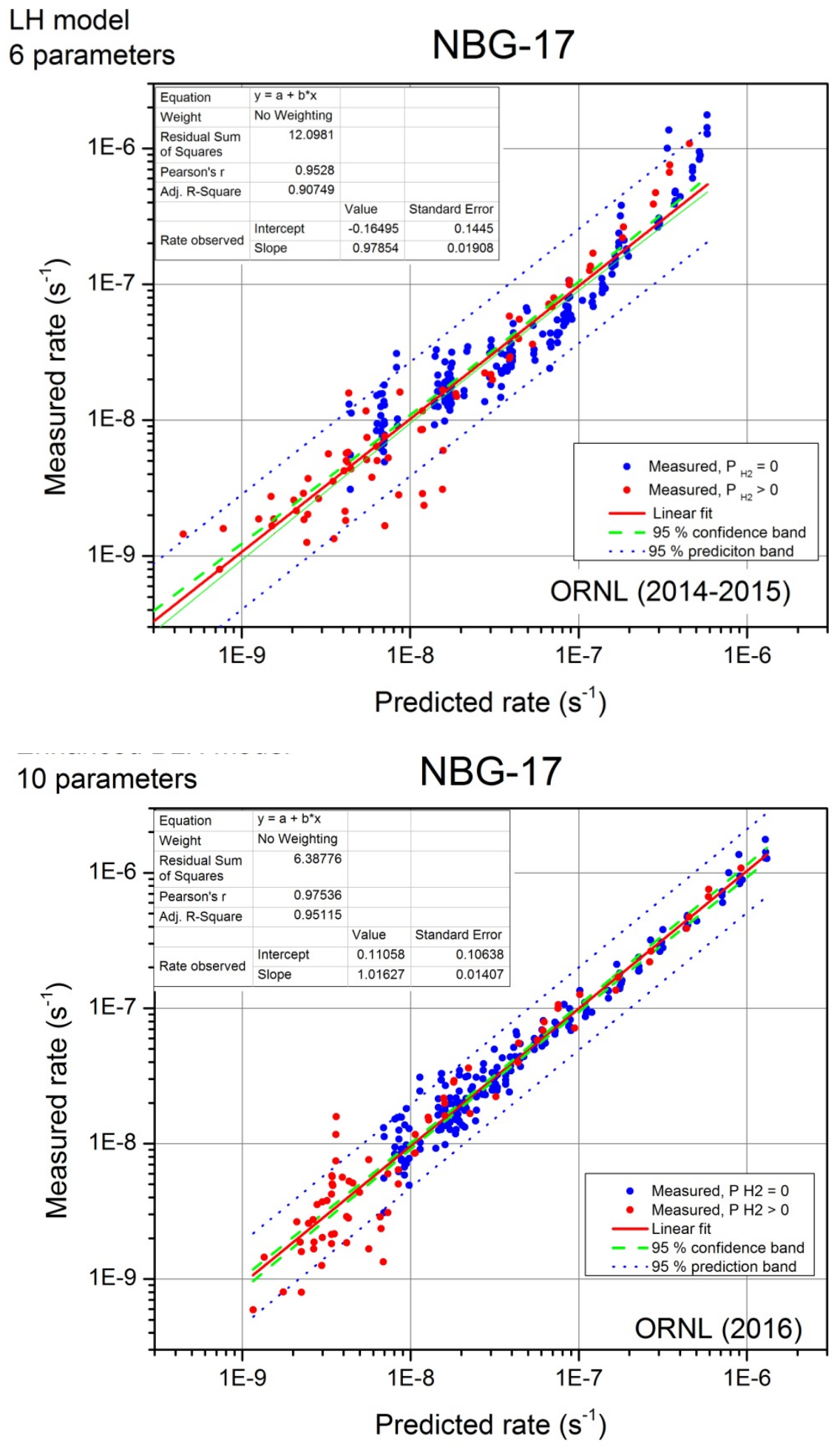

Figure 15: Goodness of fit comparison between the LH model and the Boltzmann-enhanced LH model applied to graphite NBG-17oxidation by moisture. 
The parameters used for the LH fit (2014) and Boltzmann-enhanced LH fit (2016) of graphite NBG-17 oxidation data are listed below.

Table 3

Best fit LH parameters for graphite NBG-17 [13]

$$
\begin{aligned}
& A_{1}=3.85 \times 10^{-6} \mathrm{~Pa}^{-1} \mathrm{~s}^{-1} \\
& E_{1}=61.464 \mathrm{~kJ} / \mathrm{mol} \\
& A_{2}=4.00 \times 10^{-8} \mathrm{~Pa}^{-1} \\
& A_{3}=5.79 \times 10^{-7} \mathrm{~Pa}^{-1} \\
& E_{2}=-186.561 \mathrm{~kJ} / \mathrm{mol} \\
& n=0.5 \\
& E_{3}=-122.827 \mathrm{~kJ} / \mathrm{mol}
\end{aligned}
$$

Table 4

Best fit parameters for graphite IG-110 using the Boltzmann-enhanced LH model

\begin{tabular}{|ccl}
\hline$A_{1}=4.3 \times 10^{-8} \mathrm{~Pa}^{-1} \mathrm{~s}^{-1}$ & $E_{1}=11.37 \mathrm{~kJ} / \mathrm{mol}$ & $m_{\max }=0.93$ \\
$A_{2}=3.9 \times 10^{-6} \mathrm{~Pa}^{-1 / 2}$ & $E_{2}=-121.70 \mathrm{~kJ} / \mathrm{mol}$ & $m_{\min }=0.23$ \\
$A_{3}=1.2 \times 10^{-10} \mathrm{~Pa}^{-1}$ & $E_{3}=-203.18 \mathrm{~kJ} / \mathrm{mol}$ & $T_{o}=1275 \mathrm{~K}$ \\
& $n=0.5$ & $\theta=32.5 \mathrm{~K}$
\end{tabular}

\subsection{GRAPHITE PCEA}

From a total to 355 data points, the lot of valid oxidation data for graphite PCEA [12] consisted of

\begin{tabular}{|c|c|}
\hline$A_{1}=5.9 \times 10^{-1} \mathrm{~Pa}^{-1} \mathrm{~s}^{-1}$ & $E_{1}=198.68 \mathrm{~kJ} / \mathrm{mol}$ \\
\hline $\begin{array}{l}A_{2}=5.4 \times 10^{9} \mathrm{~Pa}^{-1 / 2} \\
A_{3}=4.0 \times 10^{-4} \mathrm{~Pa}^{-1}\end{array}$ & $\begin{array}{l}E_{2}=279.54 \mathrm{~kJ} / \mathrm{mol} \\
E_{3}=-38.98 \mathrm{~kJ} / \mathrm{mol}\end{array}$ \\
\hline
\end{tabular}
144 data points measured at $P_{\mathrm{H} 2}=0$ and 48 data points measured at $30 \mathrm{~Pa}<P_{\mathrm{H} 2}<150 \mathrm{~Pa}$. All physical measurements data and oxidation rate data measured for graphite PCEA are presented in Annex 5 and 6. The parameters used for the LH fit (2013) and Boltzmann-enhanced LH fit (2016) of graphite PCEA oxidation data are listed in Tables 5 and 6.

Table 5

Best fit LH parameters for graphite PCEA [12]

Table 6

Best fit parameters for graphite PCEA using the Boltzmann-enhanced LH model

$$
\begin{array}{lcl}
A_{1}=5.9 \times 10^{-2} \mathrm{~Pa}^{-1} \mathrm{~s}^{-1} & E_{1}=161.71 \mathrm{~kJ} / \mathrm{mol} & m_{\max }=0.64 \\
A_{2}=2.1 \times 10^{5} \mathrm{~Pa}^{-1 / 2} & E_{2}=166.79 \mathrm{~kJ} / \mathrm{mol} & m_{\min }=0.44 \\
A_{3}=1.4 \times 10^{-15} \mathrm{~Pa}^{-1} & E_{3}=-292.64 \mathrm{~kJ} / \mathrm{mol} & T_{o}=1283 \mathrm{~K} \\
& n=0.5 & \theta=10.8 \mathrm{~K}
\end{array}
$$

Figure 16 shows the LH model fit and the enhanced model fit of oxidation data for graphite PCEA. The LH trend lines change slope as $\mathrm{P}_{\mathrm{H} 2 \mathrm{O}}$ increases, while the enhanced model predicts constant slope. Figure 17 compares the goodness of fit in LH and augmented model. For this graphite the augmented model did not improve substantially the agreement with the experimental data, but the shape of the fit is quite different. 

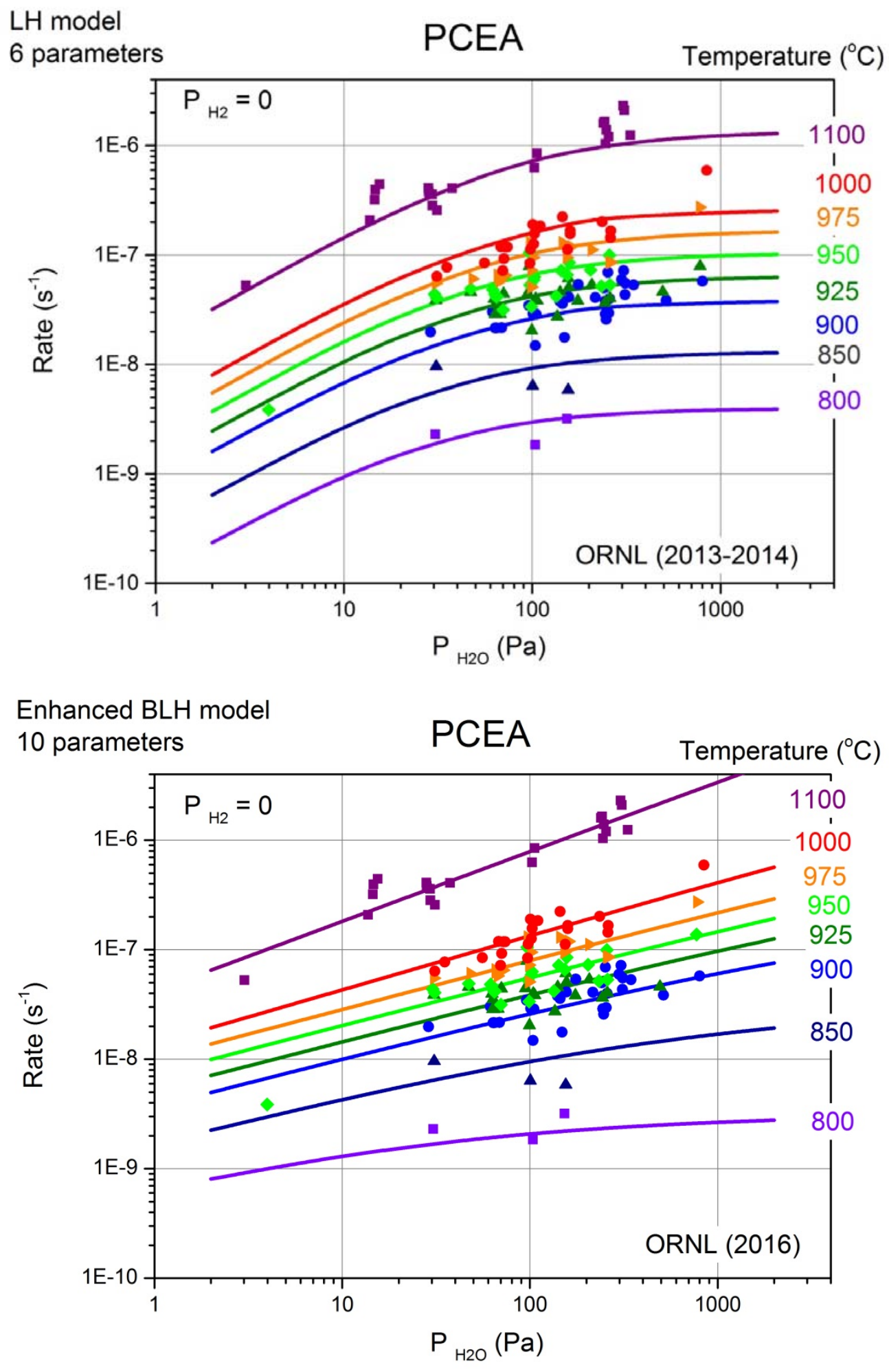

Figure 16: Fit of PCEA oxidation data using the LH model (top panel) and the Boltzmann-enhanced LH model (bottom panel) 
LH model

6 parameters

\section{PCEA}

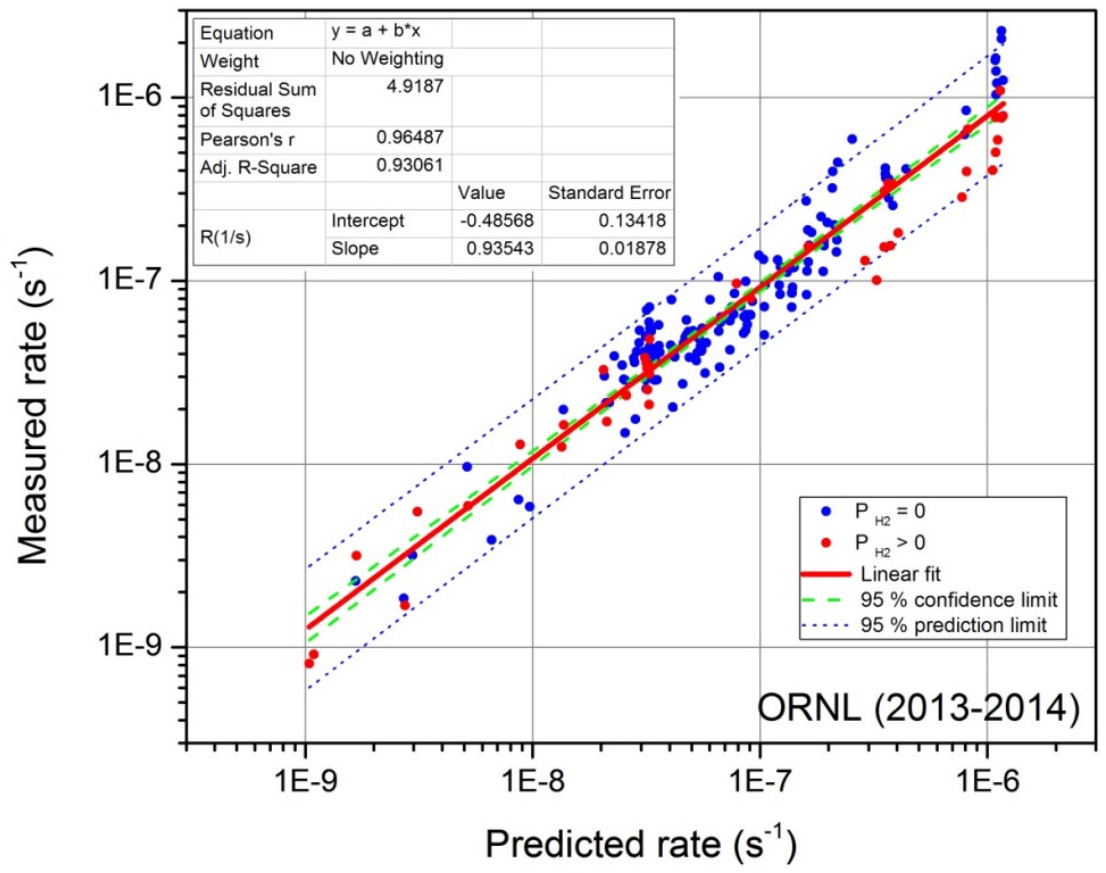

Enhanced BLH model 10 parameters

PCEA

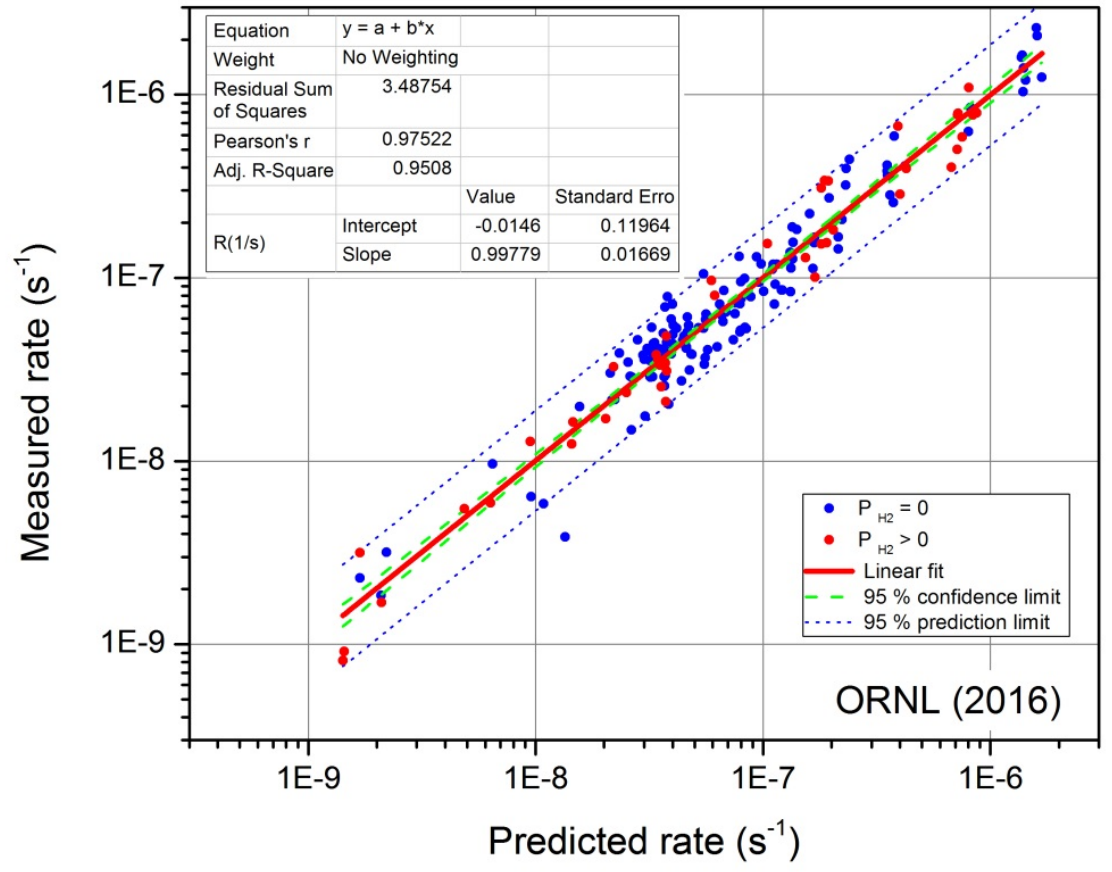

Figure 17: Goodness of fit comparison between LH model and Boltzmann-enhanced LH model applied to graphite PCEA oxidation by moisture 


\subsection{GRAPHITE H-451}

The enhanced model was less successful in fitting the digitized data [7] available for graphite H-451. Figure 18 compares experimental and predicted data by the "low water" LH model and by the Boltzmannenhanced LH model. The fitting parameters are comparable but the slope of the BLH model line is not close to 1 , as it should be for good fitting.
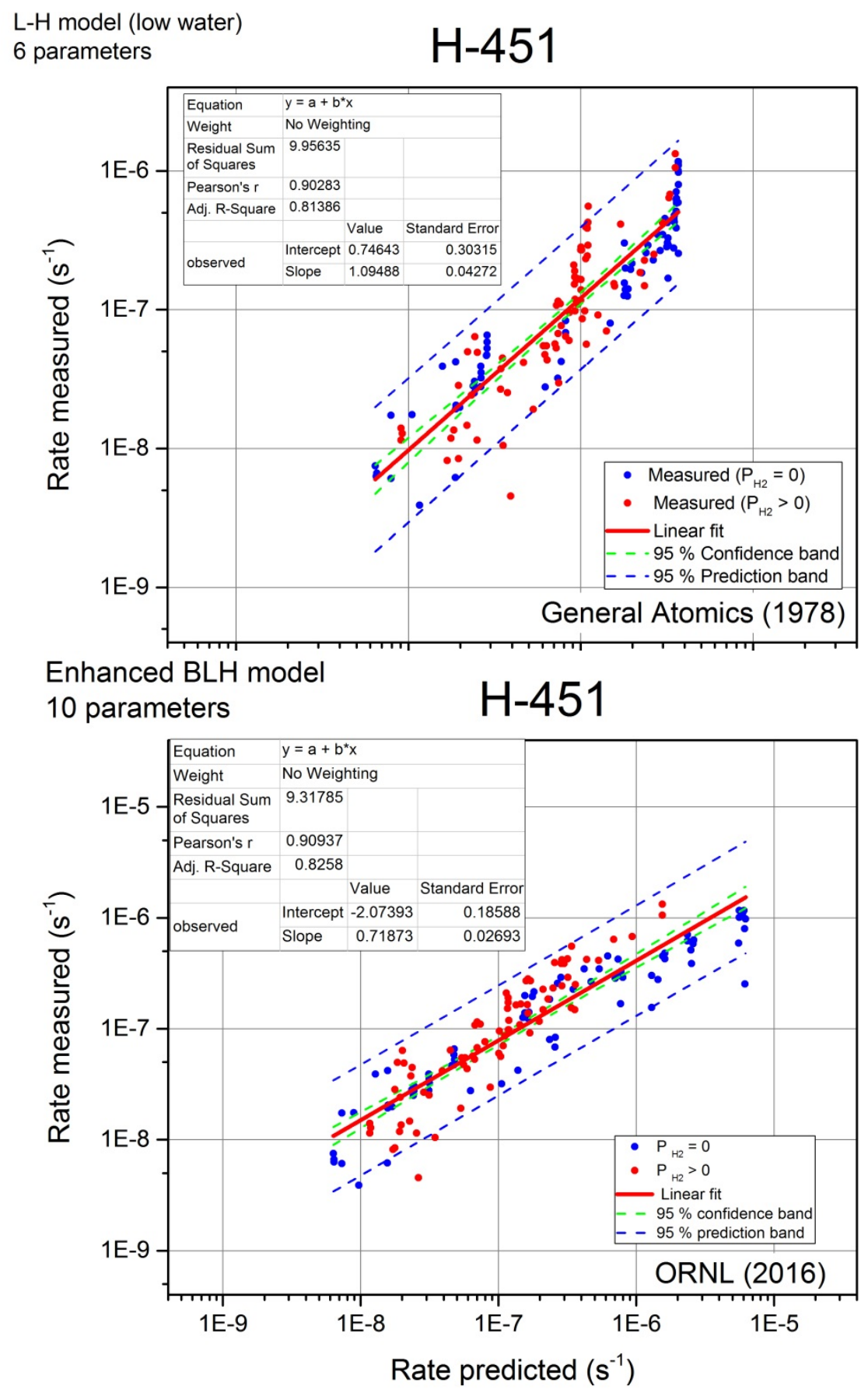

Figure 18: Goodness of fit comparison between LH and Boltzmann-enhanced LH applied to graphite $\mathrm{H}-451$ oxidation by moisture [7] 
The parameters used for fitting oxidation of H-451 graphite by the LH model ("low water" [7]) and the Boltzmann-enhanced LH model are shown in Tables 7 and 8.

\section{Table 7}

Best fit LH parameters for graphite H-451 (“low water" variant [7])

$$
\begin{aligned}
& A_{1}=2.0 \times 10^{3} \mathrm{~Pa}^{-1} \mathrm{~s}^{-1} \\
& A_{2}=1.1 \times 10^{2} \mathrm{~Pa}^{-1 / 2} \\
& A_{3}=2.0 \times 10^{2} \mathrm{~Pa}^{-1} \\
& E_{1}=274.00 \mathrm{~kJ} / \mathrm{mol} \\
& E_{2}=74.66 \mathrm{~kJ} / \mathrm{mol} \\
& n=0.75 \\
& E_{3}=95.85 \mathrm{~kJ} / \mathrm{mol}
\end{aligned}
$$

Table 8

Best fit parameters for graphite H-451 using the Boltzmann-enhanced LH model

$$
\begin{aligned}
& A_{1}=6.6 \times 10^{-4} \mathrm{~Pa}^{-1} \mathrm{~s}^{-1} \\
& A_{2}=9.2 \times 10^{6} \mathrm{~Pa}^{-1 / 2} \\
& A_{3}=22.7 \mathrm{~Pa}^{-1} \\
& \begin{array}{c}
E_{1}=121.42 \mathrm{~kJ} / \mathrm{mol} \\
E_{2}=180.359 \mathrm{~kJ} / \mathrm{mol} \\
E_{3}=84.38 \mathrm{~kJ} / \mathrm{mol} \\
n=0.5
\end{array} \\
& m_{\max }=1 \\
& m_{\min }=0.44 \\
& T_{o}=1194 \mathrm{~K} \\
& \theta=51.8 \mathrm{~K}
\end{aligned}
$$

\subsection{COMPARISON OF THE TWO MODELS}

Table 9 compares the residual sum of squares (RSS), Pearson's $\rho$ parameter and the adjusted Rsquare parameter of observed and predicted rate plots, for each graphite grade and the two kinetic models available, the classical LH and the enhanced BLH model. All parameters are collected from the log-log plots shown in Figures 10 and 12 (for IG-110), 15 (for NBG-17), 17 (for PCEA) and 18 (for H-451).

Table 9

Comparison of scattered regression plots between observed and model-predicted rates

\begin{tabular}{lrrrrrrrr}
\hline & \multicolumn{2}{c}{ IG-110 } & \multicolumn{2}{c}{ NBG-17 } & \multicolumn{2}{c}{ PCEA } & \multicolumn{2}{c}{ H-451 } \\
\cline { 2 - 9 } & \multicolumn{1}{c}{ LH } & \multicolumn{1}{c}{ B LH } & \multicolumn{1}{c}{ LH } & \multicolumn{1}{c}{ B LH } & \multicolumn{1}{c}{ LH } & B LH & LH & B LH \\
\hline \hline Residual sum of squares & 22.11 & 4.32 & 12.09 & 6.38 & 4.92 & 3.49 & 9.956 & 9.317 \\
Pearson's $\rho$ & 0.911 & 0.983 & 0.953 & 0.975 & 0.965 & 0.975 & 0.903 & 0.909 \\
Adjusted R-square & 0.83 & 0.967 & 0.907 & 0.951 & 0.931 & 0.951 & 0.814 & 0.826 \\
\hline
\end{tabular}

For each grade, the RSS corresponding to the BLH model is always smaller than that of the LH model. A small RSS indicates a tight fit of the model to the data. The Pearson's correlation parameter $\rho$ and the adjusted $\mathrm{R}^{2}$ correlation coefficient of linear regressions in the double logarithmic scale reflect a measure of correlation between observed and predicted oxidation rates. Most values are higher than 0.95 for the new graphite grades, showing good correlation (with the singular exception of LH model applied to graphite IG-110). Again, the BLH model shows systematically better correlations for each grade of graphite, although the improvement is not equal for all grades. The correlation is weaker, however, for graphite H-451 based on the digitized values from the 1978 report [7]. 


\section{DISCUSSION}

The results presented above indicate that the Boltzmann-enhanced LH model is able to better reproduce the experimental oxidation rates by moisture measured for several grades of nuclear graphite. Noticeably, the Boltzmann-enhanced LH model fits the deviations from the LH model, observed in general at high temperatures and high $P_{\mathrm{H} 2 \mathrm{O}}$, where measured rates are faster than what the classical LH model predicts.

The improvement is due to the recognition of the fact that active sites on graphite surface are not identical, not isolated, and their number is not constant. These principles are at the basis of classical Langmuir- and Langmuir - Hinshelwood models that have numerous applications in gas adsorption and heterogeneous catalysis. However, these models do not correctly represent the complex surface of graphite (or carbon) materials. The reactive surface sites on graphite are located mostly at the edge atoms of graphene sheets, or (in a lesser extent) at defects and dislocations on basal planes. The edge sites are not equivalent: zig-zag sites have high density of single electron states, and therefore high reactivity, while such states are absent in armchair sites. Figure 19 shows atomic resolution scanning tunneling microscopy (STM) images of nanoholes in graphene structures [59] and illustrate these differences. The brighter spots represent zig-zag sites with localized $\pi$ state electrons that enhance tunneling in STM. The less luminous spots correspond to armchair sites, with no such states.
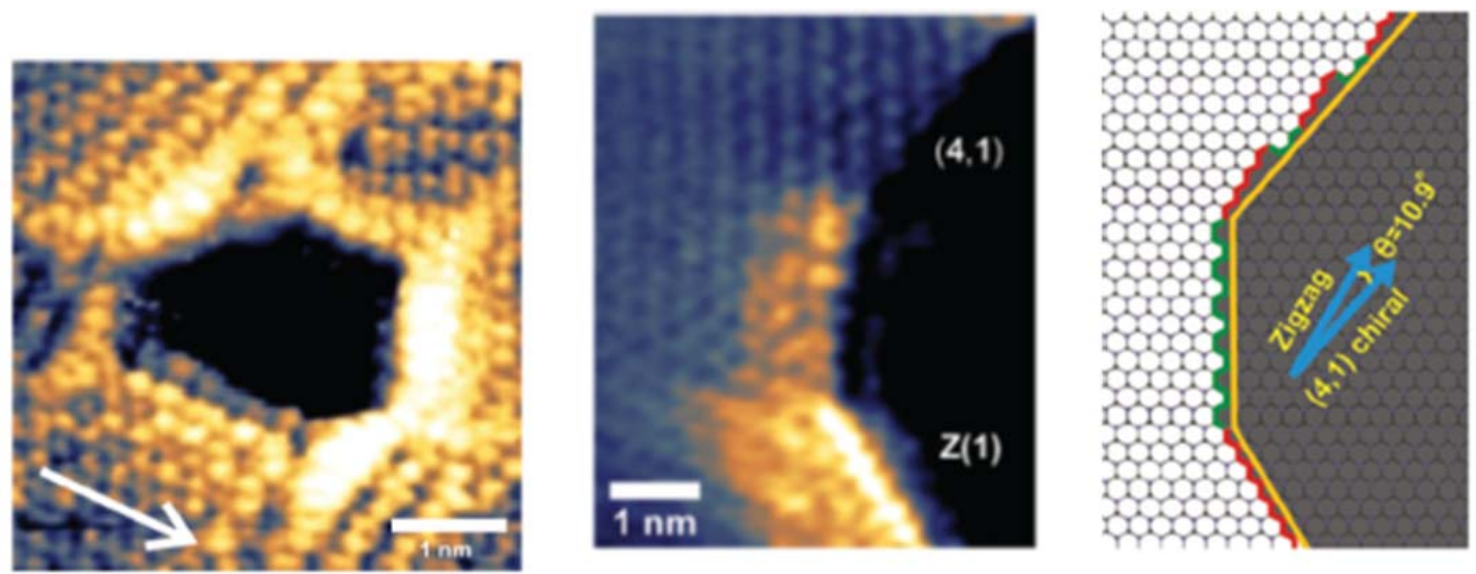

Figure 19: Visualization of electronic states localized at edge carbon atoms of graphene with different number of hydrogen atoms. Zig-zag atoms have local density of states if no $\mathrm{H}$ atoms are attached (left and center panel) or no localized states if $\mathrm{H}$ atoms are attached (center panel). Armchair atoms do not have local density of states (left panel) but partial bonding of $\mathrm{H}$ atoms enhances the local density of states at the boundary (center panel). The nanohole (left panel) has mostly zig-zag edges stabilized by spontaneous reconstruction [59].

Adding to the structural variety of atomic positions in graphene, and to defect creation and annihilation through physical actions (temperature, neutron irradiation), the delocalized $\pi$ electrons link neighboring carbon atoms and mediate interactions between distant sites. Figure 19 shows very vividly how chemical changes occurring at some edge carbon sites propagate and modify the density of states of other, quite distant carbon sites. Bonding of $\mathrm{H}$ atoms on zig-zag edges extinguishes the localized states on that edge, while partial hydrogenation of armchair sites enhances the density of states. The inductive effect of functional groups in aromatic compounds, which is well known in organic chemistry, cannot be neglected in graphite chemistry. 
Computational chemistry results cited above [52] support the proposal that water chemisorbs dissociatively on graphite edges, and chemisorbed states stabilize through rearrangement and migration of hydrogen atoms. The surface complexes formed by water chemisorption have a multitude of transformation routes, most of them being endothermic, which means they are favored by temperature. The multitude of surface complex transformations, beginning with water chemisorption and ending with elimination of $\mathrm{H}_{2}$ and $\mathrm{CO}$, and the fact that they do not occur in isolation, justifies the using of the cooperativity concept. It is known that temperature has an important role in reconstruction of carbon skeleton, even in the absence of chemical changes. When chemical changes are triggered by temperature (desorption of less stable surface complexes), temperature becomes an important factor that controls the number and reactivity of active surface sites, and therefore the global stoichiometry of gasification processes. The Boltzmann-enhanced LH model incorporates the effect of temperature through the variable stoichiometric coefficient $m(T)$ which is modeled by a Gauss distribution function. In this way, the temperature control of graphite gasification rate occurs via two independent mechanisms: on one hand, water molecule impinging the surface must have energy above a certain threshold (the activation energy) in order to successfully initiate a chemical reaction. The higher the temperature, the more "activated" molecules will collide on the surface. On the other hand, the configuration of surface sites and their reactivity change with temperature. Desorption of stable complexes will leave vacant sites as the temperature increases. Higher density of vacant sites will cause faster turnover at constant pressure, and will also increase the electronic interactions between sites. This second mechanism of reactivity (and stoichiometry) controlled by temperature is introduced in the enhanced model by the Boltzmann distribution function. It shows the "activation" of surface sites on the increase of temperature. Formally, $m(T)$ is also an apparent reaction order for the global oxidation reaction. The microstructure differences between graphite grades (and the associated diversity of local structures at the nanoscale) determine various shapes of the $m(T)$ function, as shown by the slope variation of $\ln ($ Rate $)$ versus $\ln \left(P_{H 2 O}\right)$ curves.

The Boltzmann-enhanced LH model proposed here offers a robust, comprehensive mathematical equation that fits kinetic data collected over large variations of experimental conditions (temperature, gas composition). The classic LH model may still fit data over narrower ranges of conditions. Moreover, the structural properties of each graphite grade determine that the Boltzmann-enhanced LH model is not equally successful for all grades. The IG-110 data could not be fitted without the enhanced model. This is a fine grade graphite (about $20-40 \mu \mathrm{m}$ grain size) with a higher than average BET surface area and one single class of fine pores (about $0.01 \mu \mathrm{m}$ diameter). The other two grades have larger grain sizes $(0.8$ $\mathrm{mm}$ ), smaller BET surface areas and bimodal pore size distribution (larger pores of about $20 \mu \mathrm{m}$ diameter and narrower pores of about $0.02 \mu \mathrm{m}$ diameter) [60]. At this time we can only speculate that differences in oxidation kinetics by water reflect the degree of surface sites exposure in microstructure.

Being a better tool for modeling graphite oxidation kinetics, the Boltzmann-enhanced LH is in no way able to provide information on the mechanism of elementary steps. In fact, kinetics models are not regarded as sources of reaction mechanisms; on the contrary, they are rather used to validate mechanisms postulated independently, on different foundations. The parameters returned by fitting should not be compared using kinetic notions that are popular for reactions in gas phase. They are just fitting parameters and represent "apparent" (i.e. model-dependent) constants. For that reason, the occurrence of non-positive terms under the exponential sign is not paradoxical. As we have seen, even early applications of LH model for graphite oxidation by moisture contain examples of negative "activation energies". Moreover, reactions with negative activation energies are not impossible and do occur even though the elementary steps that compose the global process have non-negative activation energies [61]. 


\section{SUMMARY AND CONCLUSION}

Graphite will undergo extremely slow, but continuous, oxidation by traces of moisture that will be present, albeit at very low levels, in the helium coolant of HTGR. This chronic oxidation may cause degradation of mechanical strength and thermal properties of graphite components, if a porous oxidation layer develops on the surface and then penetrates deeper in the bulk of graphite components during the lifetime of the reactor. The current research on graphite chronic oxidation is motivated by the acute need to understand the behavior of each graphite grade during prolonged exposure to high temperature chemical attack by moisture. The goal is to provide the elements needed to develop predictive models for long-time oxidation behavior of graphite components in the cooling helium of HTGR.

The tasks derived from this goal are structured on three directions:

(1) Oxidation rate measurements in conditions of kinetic control in order to determine and validate a comprehensive model suitable for prediction of intrinsic oxidation rates as a function of temperature and oxidant gas composition;

(2) Characterization of effective diffusivity of water vapor in the graphite pore system in order to account for the in-pore transport of moisture through the particular graphite microstructure;

(3) Development and validation of a predictive model for the penetration depth of the oxidized layer, in order to assess the risk of oxidation caused damage of particular graphite grades after prolonged exposure to the environment of helium coolant in HTGR.

The most important - and most time consuming - of these tasks is the measurement of oxidation rates in accelerated oxidation tests (but still under kinetic control) and the development of a reliable kinetic model. Because of that, this report is focused on the progress of kinetic measurements, validation of results, and improvement of the available models. Analysis of current and past results obtained with three grades of graphite showed that the classical Langmuir-Hinshelwood model cannot reproduce all data with a unique set of parameters. Starting from here, we propose a modification of the LH model that includes temperature activation of surface sites, modeled as a Boltzmann activation function. The enhanced Boltzmann-Langmuir-Hinshelwood model (BLH) was tested successfully on three grades of graphite. The model is a robust, comprehensive mathematical function that allows better fitting of experimental results collected over a wide range of temperature and partial pressures of water vapor and hydrogen. We found that the new model did improve the accuracy of data fitting for all three grades of graphite, although at different rates. The BLH model was essential for fitting oxidation of IG-110 graphite, but could not be used with the data for graphite H-451 extracted from the GA report [7].

Current activities still need to analyze the oxidized layer profile in graphite NBG-17, for which kinetic and water diffusivity results are now available. Combining kinetic and transport results will allow us to confirm (or not) the viability of the predictive model for the maximum penetration of the oxidation and its temperature dependence, which is an important goal of this research. At this time we have only checked the validity of the model and obtained confirmation only for PCEA graphite [18]. This task will be completed during FY 2016.

In the near future we plan to complete effective diffusivity measurements for graphite IG-110 and to prepare oxidized samples at 5-6 \% weight loss for oxidized layer profile characterization. Combining kinetic results on IG-110 (now available) with effective diffusivity and oxidized layer profile will provide one more verification point of the predictive model.

We also plan to use the thermogravimetric equipment and the mass spectrometer available at ORNL for measurements of the desorption energy distribution function, $f\left(E_{\text {des }}\right)$, of surface complexes formed by water on several grades of graphite (IG-110, NBG-17, PCEA). Then we will try to use this information in

a variant of the stochastic oxidation model proposed by other researchers $[43,44]$ for modeling of graphite gasification by air.

The long term plan is to extend these studies to graphite grades 2114 and 2160 produced by Mersen. 
This page was intentionally left blank 


\section{REFERENCES}

1. M P Kissane, A review of radionuclide behavior in the primary system of a very-high temperature reactor, Nucl. Eng. Design, 239 (2009) 3076-3091.

2. $\mathrm{X} \mathrm{Yu}, \mathrm{S} \mathrm{Yu}$, Analysis of fuel element matrix graphite corrosion in HTR-PM for normal operating conditions, Nucl. Eng. Design, 240 (2010) 738-743.

3. E R Corwin, Generation IV Reactors Integrated Materials Technology Program Plan: Focus on Very High Temperature Reactor Materials, ORNL/TM-2008/129 (2008).

4. M Fechter, Graphite Oxidation Modeling for a 250 MW Pebble Bed Reactor, ORNL presentation, July 2010.

5. B Castle, NGNP Reactor Coolant Chemistry Control Study, INL/EXT-10-10533.

6. R N Wright, Kinetics of Gas Reactions and Environmental Degradation in NGNP Helium, INL/EXT-06-11494.

7. C Velasquez, G Hightower, R Burnette, The Oxidation of H-451 Graphite by Steam. Part 1: Reaction Kinetics, General Atomic Company, GA-A14951 (1978).

8. M B Richards, Reaction of nuclear grade graphite with low concentrations of steam in the helium coolant of an MHTGR, Energy 15 (1990) 729-739

9. C. I. Contescu, T. Guldan, P. Wang, T. D. Burchell, The effect of microstructure on air oxidation resistance of nuclear graphite, Carbon 50 (2012) 3354-3366.

10. C I Contescu, Microstructure effect on air oxidation behavior of three nuclear grade materials: NBG-18, PCEA, and IG-110, ORNL/TM-2011/324 (2011)

11. C. I. Contescu, T. D. Burchell, R. W. Mee, Accelerated oxidation studies of PCEA nuclear graphite by low concentrations of water and hydrogen in helium, ORNL/TM-2013/524 (2013).

12. C.I. Contescu, R.W. Mee, P. Wang, A.V. Romanova, T.D. Burchell, oxidation of PCEA nuclear graphite by low water concentrations in helium, J. Nucl. Mater. 453 (2014) 225-232

13. C.I. Contescu, T.D. Burchell, R.W. Mee, Kinetics of chronic oxidation of NBG-17 nuclear graphite by water vapor, ORNL/TM-2015/142 (2015).

14. C.I. Contescu, T.D. Burchell, Water vapor transport in nuclear graphite, ORNL/TM-2015/88 (2015).

15. D Miller, I Lewis, M Santana, Isotropic graphite from needle coke, http://acs.omnibooksonline.com/data/papers/2004_K003.pdf (accessed January 5, 2015)

16. P Beghein, G Berlioux, B du Mesnildot, F Hiltmannm M Melin, NBG-17 - An improved graphite grade for HTRs and VHTRs, Nucl. Eng. Des. 251 (2012) 146-149

17. "Standard test method for water vapor diffusion resistance and air flow resistance of clothing materials using the dynamic moisture permeation cell", ASTM F2298-03 (reapproved 2009).

18. C. Contescu, J. Kane, R. Mee, A, Bontorno, N. Gallego, T. Burchell, W. Windes, Reactivity differences between graphite grades during long time exposure in the helium coolant, INGSM-16, International Nuclear Graphite Specialists Meeting, Nottingham, UK, September 13-17, 2015.

19. J Gadsby, C N Hinshelwood, K W Sykes, Kinetics of the reactions of steam-carbon system, Proc Roy Soc (London) A 187 (1946) 129-151.

20. R C Giberson, J P Walker, Reaction of nuclear graphite with water vapor. Part I: Effect of hydrogen and water vapor partial pressure, Carbon 3 (1966) 521-525

21. F J Long, K W Sykes, The mechanism of steam-carbon reaction, Proc. Roy Soc. (London) A 193 (1948) 377-399 
22. J Gadsby, F J Long, P Sleightholmm K W Sykes, The mechanism of the carbon dioxide - carbon reaction, Proc Roy Soc (London) A 193 (1948) 357-376

23. Graphite Design Handbook, General Atomics Company, DOE-HTGR-88111/Rev 0 (September 1988)

24. H F Johnstone, C Y Chen, D S Scott, Kinetics of the steam-carbon reaction in porous graphite tubes, Ind. Eng. Chem. 44 (1952) 1564-

25. J D Blackwood, F McGrory, The carbon-steam reaction at high pressure, Australian J Chem $\mathbf{1 1}$ (1958) 16-33

26. J E Antill, K A Peakall, Attack of graphite by an oxidizing gas at low partial pressures and high temperatures, J. Nucl Mater 2 (1960) 31-38

27. K Huttinger, Mechanism of water vapor gasification at high hydrogen levels, Carbon 26 (1988) 79-87

28. R T Yang, K L Yang, Kinetics and mechanism of the carbon-steam reaction on the monolayer and multilayer edges of graphite, Carbon 23 (1985) 537-547

29. L G Overholser, J P Blakely, Oxidation of graphite by low concentration of water vapor and crabon dioxide in helium, Carbon 2 (1965) 385-394

30. J P Blakely, L GL Overholser, Oxidation of ATJ graphite by low concentrations of water vapor and carbon dioxide in helium, Carbon 3 (1965) 269-275

31. J S Binford, H Eyring, Kinetics of the steam-carbon reaction, J Phys Chem 60 (1956) 486-491

32. R F Strickland-Constable, The interaction of carbon filaments at high temperatures with nitrous oxide, carbon dioxide and water vapor, Trans. Faraday Soc. 43 (1947) 769-778

33. P Magne, RF Sauvageot, X Duval, Etude de la formation d'un complexe de surface graphie-eau relation avec la reaction d'oxydation, Carbon 11 (1973) 485-495

34. R F Strickland-Constable, Interaction of steam and charcoal at low pressures, Proc. Roy Soc (London) A 189 (1947) 1-10

35. G Blyholder, H Eyring, Kinetics of the steam-carbon reaction, J Phys Chem 63 (1959) 693-696

36. D R Olander, T R Acharaya, A Z Ullman, Reactions of modulated molecular beams with pyrolytic graphite. IV Water vapor, J Chem Phys 67 (1977) 3549-3562

37. K Miura, T Morimoto, Adsorption sites for water on graphite: 4. Chemisorption of water on graphite at room temperature, Langmuir 4 (1988) 1283-1288

38. M G Lussier, Z Zhang, D J Miller, Characterizing rate inhibition in steam/hydrogen gasification via analysis of adsorbed hydrogen, Carbon 36 (1998) 1361-1369

39. B S Haynes, A turnover model for carbon reactivity. I. Development, Combust. Flame, 126 (2001) 1421-1432

40. A E Lear, T C Brown, B S Haynes, Formation of metastable oxide complexes during the oxidation of carbons at low temperatures, $33^{\text {rd }}$ Symposium (International) on Combustion. The Combustion Institute (1990) 1191-1197

41. A Sibbra, T G. Newbury, B S Haynes, The reactions of hydrogen and carbon monoxide with surface-bound oxides on carbon, Combust. Flame 120 (2000) 515-525

42. B S Haynes, T G Newbury, Oxyreactivity of carbon surface oxides, Proc. Combust. Inst. 28 (2000) 2197-2203

43. R H Hurt, J M Calo, Semi-global intrinsic kinetics for char combustion modeling, Combust. Flame 125 (2001) 1138-1149

44. R H Hurt, B S Haynes, On the origin of power-law kinetics in carbon oxidation, Proc. Combust. 
Inst. 30 (2005) 2161-2168

45. M S El-Genk, J-M Tournier, Development and validation of a model for the chemical kinetics of graphite oxidation, J. Nucl. Mat. 411 (2011) 193-207

46. B Marchon, J Carrazza, H Heinemann, G A Somorjai, TPD and XPS studies of $)_{2}, \mathrm{CO}_{2}$, and $\mathrm{H}_{2} \mathrm{O}$ adsorption on clean polycrystalline graphite, Carbon 26 (1988) 507-514

47. V J Garcia, J M Briceno-Valero, L Martinez, Kinetic parameters from a single thermal desorption spectrum, Surf Sci 339 (1995) 189-193

48. M Battacharya, W G Devi, P S Mazumdar, Determination of kinetic parameters from temperature programmed desorption curves, Appl Surf Sci 218 (2003) 1-6

49. M C Ma, B S Haynes, Surface heterogeneity in the formation and decomposition of carbon surface oxides. $26^{\text {th }}$ Symposium (International) on Combustion / The Combustion Institute (1996) 3119-3125

50. A Allouche, Y Ferro, Dissociative adsorption of small molecules at vacancies on the graphite (0001) surface, Carbon 44 (2006) 3320-3327

51. P Cabrera-Sanfelix, G B Darling, Dissociative adsorption of water at vacancy defects in graphite, J. Phys Chem C 111 (2007) 18258-18263

52. J F Espinal, F Mondragon, $\mathrm{T}$ N Truong, Thermodynamic evaluation of steam gasification mechanisms of carbonaceous materials, Carbon 47 (2009) 3010-3018

53. E Agliari, A Barra, R Burioni, A Di Biasio, G. Uguzzoni, Collective behaviours: from biochemical kinetics to electronic circuits, Sci. Rep. 3 (2013) 3458; doi:10.1038/srep0.458

54. A Di Biasio, E Agliari, A Barra, R Burioni, Mean-field cooperativity in chemical kinetics, Theor. Chem. Acc. 131 (2012) 1104; doi: 10.1007/s00214-012-1104-3

55. http://sys-bio.org/wp-content/uploads/downloads/2012/03/CB_Chapter3.pdf (accessed April 26, 2016)

56. C A Querini, S C Fung, Coke characterization by temperature-programmed techniques, Catal. Today 37 (1997) 277-283

57. C Li, T C Brown, Carbon oxidation kinetics from evolved carbon oxide analysis during temperature-programmed oxidation, Carbon 39 (2001) 725-732

58. I J Myung, Tutorial on maximum likelihood estimation, J. Math Psychology 47 (2003) 90-100

59. M Ziatdinov, S Fuji, K Kusabe, M Kiguchi, T Mori, T Enoki, Visualization of electronic states on atomically smooth graphitic edhs with different types of hydrogen termination, Phys Rev B 87 (2013) 115427

60. T Burchell, S Nunn, J Strizak, M Williams, AGC-1 sister specimen testing data report, ORNL/TM-2009/025

61. L E Revell, B E Williamson, Why are some reactions slower at higher temperatures ?, J Chem Educ 90 (2013) 1024-1027 


\section{ANNEXES}

PHYSICAL MEASUREMENTS AND TEST CONDITIONS 
PHYSICAL MEASUREMENTS ON GRAPHITE IG-110 SPECIMENS BEFORE AND AFTER TESTS

\begin{tabular}{|c|c|c|c|c|c|c|c|c|c|c|c|c|}
\hline \multirow[b]{2}{*}{ Test Date } & \multirow[b]{2}{*}{ Specimen ID } & \multicolumn{4}{|c|}{ Before test } & \multicolumn{2}{|c|}{ Test Conditions } & \multicolumn{4}{|c|}{ After test } & \multirow[b]{2}{*}{ Method } \\
\hline & & Weight mg & $\begin{array}{c}\text { Average L } \\
\mathrm{mm}\end{array}$ & $\begin{array}{c}\text { Average D } \\
\mathrm{mm}\end{array}$ & $\begin{array}{l}\text { Density } \\
\mathrm{g} / \mathrm{cm} 3\end{array}$ & $\mathrm{P} \mathrm{H} 2 \mathrm{OPa}$ & $\mathrm{P} \mathrm{H} 2 \mathrm{~Pa}$ & Weight mg & Average L mm & $\begin{array}{c}\text { Average D } \\
\mathrm{mm}\end{array}$ & Density $\mathrm{g} / \mathrm{cm} 3$ & \\
\hline $3 / 2 / 2015$ & IG-1 & 464.71 & 20.02 & 4.00 & 1.849 & $100 ; 50$ & 0 & 456.37 & 20.01 & 3.99 & 1.822 & 1 \\
\hline $3 / 10 / 2015$ & IG-2 & 462.88 & 19.92 & 4.10 & 1.765 & $100 ; 51$ & 0 & 459.61 & 19.90 & 4.08 & 1.769 & 1 \\
\hline $3 / 11 / 2015$ & IG-3 & 452.82 & 20.09 & 4.03 & 1.772 & $100 ; 52$ & 0 & 445.21 & 20.07 & 4.02 & 1.752 & 1 \\
\hline $3 / 18 / 2015$ & IG-4 & 453.25 & 20.00 & 4.05 & 1.764 & 300, air & 0 & 445.71 & 19.98 & 4.04 & 1.744 & 1 \\
\hline $3 / 27 / 2015$ & IG-5 & 456.12 & 20.07 & 4.04 & 1.778 & 300 (bad) & 0 & 448.59 & 20.06 & 4.02 & 1.762 & 1 \\
\hline $3 / 31 / 2015$ & IG-6 & 461.91 & 20.05 & 4.06 & 1.783 & 300 (bad) & 0 & 454.45 & 20.05 & 4.07 & 1.746 & 1 \\
\hline $4 / 8 / 2015$ & IG-7 & 463.58 & 19.95 & 4.08 & 1.778 & 30 & 0 & 462.45 & 19.92 & 4.07 & 1.782 & 1 \\
\hline $4 / 13 / 2015$ & IG-8 & 451.83 & 20.04 & 4.03 & 1.765 & 50 & 0 & 450.3 & 20.05 & 4.03 & 1.766 & 1 \\
\hline 4/19/2015 & IG-9 & 458.7 & 19.96 & 4.06 & 1.776 & 100 & 0 & 455.91 & 19.95 & 4.06 & 1.763 & 1 \\
\hline $4 / 28 / 2015$ & IG-10 & 467.94 & 20.06 & 4.08 & 1.786 & 200 & 0 & 463.56 & 20.05 & 4.09 & 1.760 & 1 \\
\hline $4 / 30 / 2015$ & IG-11 & 452.27 & 20.01 & 4.03 & 1.773 & 25 & 0 & 451.42 & 19.99 & 4.02 & 1.782 & 1 \\
\hline $5 / 4 / 2015$ & IG-12 & 449.18 & 20.03 & 4.02 & 1.771 & 5 & 0 & 448.33 & 20.04 & 4.02 & 1.762 & 1 \\
\hline $5 / 7 / 2015$ & IG-13 & 450.92 & 20.16 & 4.02 & 1.767 & $50 ; 30$ & 0 & 449.32 & 20.17 & 4.01 & 1.764 & 1 \\
\hline $5 / 13 / 2015$ & IG-14 & 458.71 & 20.12 & 4.05 & 1.770 & 300 & 0 & 452.97 & 20.12 & 4.04 & 1.760 & 1 \\
\hline $5 / 27 / 2015$ & IG-15 & 453.86 & 20.18 & 4.02 & 1.776 & 50 & 0 & 452.53 & 20.17 & 4.02 & 1.767 & 1 \\
\hline $5 / 29 / 2015$ & IG-16 & 458.61 & 19.98 & 4.06 & 1.771 & 150 & 0 & 455.53 & 19.98 & 4.07 & 1.758 & 1 \\
\hline $6 / 2 / 2015$ & IG-17 & 454.02 & 20.25 & 4.02 & 1.766 & 200 & 0 & 449.82 & 20.26 & 4.02 & 1.755 & 1 \\
\hline $6 / 8 / 2015$ & IG-18 & 453.84 & 20.09 & 4.02 & 1.782 & 200 & 20 & 451.47 & 20.09 & 4.02 & 1.773 & 1 \\
\hline $6 / 10 / 2015$ & IG-19 & 457.44 & 20.16 & 4.03 & 1.779 & 100 & 20 & 456.37 & 20.16 & 4.03 & 1.777 & 1 \\
\hline $6 / 12 / 2015$ & IG-20 & 447.79 & 20.09 & 4.02 & 1.756 & 50 & 20 & 447.1 & 20.08 & 4.02 & 1.758 & 1 \\
\hline $6 / 13 / 2015$ & IG-21 & 459.88 & 20.12 & 4.06 & 1.770 & 25 & 20 & 459.38 & 20.12 & 4.05 & 1.771 & 1 \\
\hline $6 / 15 / 2015$ & IG-22 & 462.15 & 20.08 & 4.07 & 1.774 & 100 & 50 & 461.55 & 20.07 & 4.07 & 1.771 & 1 \\
\hline $6 / 19 / 2015$ & IG-23 & 452.72 & 20.14 & 4.03 & 1.764 & 50 & 50 & 452.2 & 20.16 & 4.03 & 1.762 & 1 \\
\hline $6 / 30 / 2015$ & IG-24 & 461.93 & 19.93 & 4.09 & 1.763 & 150 & 50 & 460.7 & 19.92 & 4.09 & 1.764 & 1 \\
\hline $7 / 2 / 2015$ & IG-25 & 450.75 & 20.09 & 4.02 & 1.771 & 200 & 50 & 449.55 & 20.09 & 4.01 & 1.772 & 1 \\
\hline $7 / 8 / 2015$ & IG-26 & 452.81 & 20.14 & 4.02 & 1.776 & 300 & 50 & 450.79 & 20.14 & 4.02 & 1.768 & 1 \\
\hline $7 / 27 / 2015$ & IG-27 & 451.25 & 20.11 & 4.02 & 1.769 & 300 & 100 & 450.06 & 20.11 & 4.03 & 1.758 & 1 \\
\hline $8 / 13 / 2015$ & IG-28 & 449.77 & 20.07 & 4.00 & 1.781 & 100 & 100 & 449.21 & 20.08 & 4.02 & 1.767 & 1 \\
\hline
\end{tabular}




\begin{tabular}{|c|c|c|c|c|c|c|c|c|c|c|c|c|}
\hline \multirow[b]{2}{*}{ Test Date } & \multirow[b]{2}{*}{ Specimen ID } & \multicolumn{4}{|c|}{ Before test } & \multicolumn{2}{|c|}{ Test Conditions } & \multicolumn{4}{|c|}{ After test } & \multirow[b]{2}{*}{ Methoc } \\
\hline & & Weight mg & $\begin{array}{c}\text { Average L } \\
\mathrm{mm}\end{array}$ & $\begin{array}{c}\text { Average D } \\
\mathrm{mm}\end{array}$ & $\begin{array}{l}\text { Density } \\
\mathrm{g} / \mathrm{cm} 3\end{array}$ & $\mathrm{P} \mathrm{H} 2 \mathrm{OPa}$ & $\mathrm{P} \mathrm{H} 2 \mathrm{~Pa}$ & Weight mg & Average $\mathrm{L} \mathrm{mm}$ & $\begin{array}{c}\text { Average D } \\
\mathrm{mm}\end{array}$ & Density g/cm3 & \\
\hline $8 / 18 / 2015$ & IG-29 & 453.23 & 20.08 & 4.02 & 1.777 & increasing & 0 & 452.47 & 20.08 & 4.03 & 1.768 & 2 \\
\hline $8 / 24 / 2015$ & IG-30 & 452.98 & 20.21 & 4.02 & 1.771 & increasing & 0 & 451.17 & 20.21 & 4.00 & 1.777 & 2 \\
\hline $8 / 31 / 2015$ & IG-31 & 457.81 & 19.89 & 4.08 & 1.764 & decreasing & 0 & 455.85 & 19.89 & 4.07 & 1.764 & 2 \\
\hline $9 / 4 / 2015$ & IG-32 & 452.47 & 20.21 & 4.01 & 1.777 & increasing & 0 & 450.03 & 20.21 & 4.00 & 1.770 & 2 \\
\hline $9 / 28 / 2015$ & IG-33 & 455.39 & 20.14 & 4.02 & 1.782 & decreasing & 0 & 454.44 & 20.14 & 4.02 & 1.781 & 2 \\
\hline $10 / 2 / 2015$ & IG-34 & 455.79 & 20.12 & 4.03 & 1.776 & decreasing & 0 & 452.97 & 20.11 & 4.02 & 1.773 & 2 \\
\hline $10 / 8 / 2015$ & IG-35 & 455.15 & 20.16 & 4.03 & 1.775 & random & 0 & 450.46 & 20.15 & 4.02 & 1.764 & 2 \\
\hline $11 / 2 / 2015$ & IG-36 & 450.82 & 20.06 & 4.03 & 1.765 & random & 0 & 443.82 & 20.06 & 4.01 & 1.752 & 2 \\
\hline $11 / 6 / 2015$ & IG-37 & 448.76 & 20.22 & 3.99 & 1.774 & random & 0 & 447.2 & 20.22 & 3.99 & 1.769 & 2 \\
\hline $11 / 18 / 2015$ & IG-38 & 466.41 & 20.07 & 4.07 & 1.784 & random & 0 & 464.34 & 20.08 & 4.08 & 1.773 & 2 \\
\hline $3 / 7 / 2016$ & IG-39 & 450.09 & 20.04 & 4.03 & 1.766 & 200 & 100 & 448.74 & 20.03 & 4.03 & 1.762 & 1 \\
\hline $3 / 9 / 2016$ & IG-40 & 452.74 & 20.02 & 4.04 & 1.769 & 150 & 100 & 451.9 & 20.01 & 4.03 & 1.769 & 1 \\
\hline $3 / 12 / 2016$ & IG-41 & 452.09 & 20.04 & 4.03 & 1.772 & 50 & 100 & 451.75 & 20.04 & 4.03 & 1.765 & 1 \\
\hline $3 / 13 / 2016$ & IG-42 & 456.13 & 19.93 & 4.06 & 1.769 & 0 & 20 & 455.89 & 19.94 & 4.06 & 1.772 & 1 \\
\hline $3 / 16 / 2016$ & IG-43 & 450.29 & 20.06 & 4.03 & 1.759 & 150 & 20 & 448.04 & 20.08 & 4.02 & 1.760 & 1 \\
\hline $3 / 17 / 2016$ & IG-44 & 462.12 & 20.08 & 4.07 & 1.768 & 500 & 0 & 449.98 & 20.06 & 4.06 & 1.735 & 1 \\
\hline $3 / 19 / 2016$ & IG-45 & 455.29 & 20.08 & 4.03 & 1.781 & 300 & 0 & 447.55 & 20.07 & 4.02 & 1.761 & 1 \\
\hline $3 / 24 / 2016$ & IG-46 & 455.33 & 20.21 & 4.01 & 1.784 & 1000 & 0 & 432.93 & 20.19 & 4.00 & 1.709 & 1 \\
\hline
\end{tabular}


ANNEX 2

LOG OF EXPERIMENTAL RESULTS - GRAPHITE IG-110

\begin{tabular}{|c|c|c|c|c|c|c|c|c|c|c|c|c|c|c|c|c|c|}
\hline \multirow{2}{*}{$\begin{array}{l}\text { Exp data } \\
\text { number }\end{array}$} & \multirow[b]{2}{*}{ Test Date } & \multirow[b]{2}{*}{ Specimen ID } & \multicolumn{2}{|c|}{$\mathrm{H} 2 \mathrm{O}$ Pressure } & & \multirow{2}{*}{$\begin{array}{c}\text { Temperatur } \\
\mathrm{e}\end{array}$} & \multicolumn{2}{|c|}{ Weight } & \multicolumn{2}{|c|}{ Time in the Test } & \multirow[b]{2}{*}{ Rate } & \multicolumn{2}{|c|}{ Weight loss \% } & \multicolumn{2}{|c|}{ Sample preparaton } & \multirow{2}{*}{$\begin{array}{l}\text { Wt loss in } \\
\text { outgassing }\end{array}$} & \multirow[b]{2}{*}{ Notes } \\
\hline & & & target & actual $^{8}$ & H2 Pressure & & before & after & before & after & & before & after & duration & temperature & & \\
\hline & & & $\mathrm{Pa}$ & $\mathrm{Pa}$ & $\mathrm{Pa}$ & ${ }^{\circ} \mathrm{C}$ & $\mathrm{mg}$ & $\mathrm{mg}$ & $\mathrm{hr}$ & $\mathrm{hr}$ & $s^{-1}$ & $\%$ & $\%$ & $\mathrm{~h}$ & ${ }^{\circ} \mathrm{C}$ & $\mathrm{mg}$ & \\
\hline \multicolumn{18}{|c|}{ METHOD 1 (constant gas composition, incremental temepratures) 212 data } \\
\hline 16 & $3 / 10 / 15$ & IG-2 & 150 & 139 & 0 & 850 & 461.94 & 461.90 & 8.71 & 11.42 & $7.32 \mathrm{E}-09$ & 0.20 & 0.20 & 2 & 1200 & 0.028 & \\
\hline 17 & $3 / 10 / 15$ & IG-2 & 150 & 141 & 0 & 900 & 461.84 & 461.80 & 11.94 & 14.46 & $1.00 \mathrm{E}-08$ & 0.22 & 0.23 & 2 & 1200 & 0.028 & \\
\hline 18 & $3 / 10 / 15$ & IG-2 & 150 & 140 & 0 & 950 & 461.72 & 461.66 & 15.11 & 17.59 & $1.43 \mathrm{E}-08$ & 0.25 & 0.26 & 2 & 1200 & 0.028 & \\
\hline 19 & $3 / 10 / 15$ & IG-2 & 150 & 149 & 0 & 1000 & 461.58 & 461.45 & 17.99 & 20.56 & $3.16 \mathrm{E}-08$ & 0.27 & 0.30 & 2 & 1200 & 0.028 & \\
\hline 20 & $3 / 10 / 15$ & IG-2 & 150 & 156 & 0 & 1050 & 461.33 & 460.76 & 21.09 & 23.70 & $1.31 \mathrm{E}-07$ & 0.33 & 0.45 & 2 & 1200 & 0.028 & \\
\hline 21 & $3 / 10 / 15$ & IG-2 & 150 & 163 & 1 & 1100 & 460.51 & 458.59 & 24.13 & 26.80 & $4.33 \mathrm{E}-07$ & 0.51 & 0.92 & 2 & 1200 & 0.028 & \\
\hline 23 & $3 / 12 / 15$ & IG-3 & 30 & 43 & 0 & 850 & 451.29 & 451.27 & 8.69 & 11.54 & $4.10 \mathrm{E}-09$ & 0.17 & 0.18 & 2 & 1200 & 0.013 & \\
\hline 27 & $3 / 12 / 15$ & IG-3 & 30 & 17 & 0 & 1050 & 450.85 & 450.74 & 21.04 & 23.84 & 2.57E- 08 & 0.27 & 0.29 & 2 & 1200 & 0.013 & \\
\hline 28 & $3 / 12 / 15$ & IG-3 & 30 & 18 & 0 & 1100 & 450.65 & 450.35 & 24.07 & 26.95 & $6.29 \mathrm{E}-08$ & 0.31 & 0.38 & 2 & 1200 & 0.013 & \\
\hline 30 & $4 / 8 / 15$ & IG-7 & 30 & 27 & 0 & 850 & 463.14 & 463.11 & 8.71 & 11.46 & $5.02 \mathrm{E}-09$ & 0.01 & 0.02 & 2 & 1200 & 0.376 & \\
\hline 31 & $4 / 8 / 15$ & IG-7 & 30 & 27 & 0 & 900 & 463.11 & 463.06 & 11.75 & 14.59 & $1.03 \mathrm{E}-08$ & 0.02 & 0.03 & 2 & 1200 & 0.376 & \\
\hline 32 & $4 / 8 / 15$ & IG-7 & 30 & 27 & 0 & 950 & 463.06 & 462.99 & 14.82 & 17.69 & $1.57 \mathrm{E}-08$ & 0.03 & 0.04 & 2 & 1200 & 0.376 & \\
\hline 33 & $4 / 8 / 15$ & IG-7 & 30 & 27 & 0 & 1000 & 462.99 & 462.93 & 17.95 & 20.76 & $1.37 \mathrm{E}-08$ & 0.04 & 0.06 & 2 & 1200 & 0.376 & \\
\hline 34 & $4 / 8 / 15$ & IG-7 & 30 & 29 & 0 & 1050 & 462.93 & 462.79 & 21.09 & 23.76 & 2.94E-08 & 0.06 & 0.09 & 2 & 1200 & 0.376 & \\
\hline 35 & $4 / 8 / 15$ & IG-7 & 30 & 29 & 1 & 1100 & 462.79 & 462.37 & 24.02 & 26.96 & 8.57E-08 & 0.09 & 0.18 & 2 & 1200 & 0.376 & \\
\hline 36 & $4 / 13 / 15$ & IG-8 & 50 & 52 & 0 & 800 & 451.33 & 451.33 & 5.87 & 8.39 & $1.22 \mathrm{E}-09$ & -0.11 & -0.11 & 2 & 1200 & 0.497 & \\
\hline 37 & $4 / 13 / 15$ & IG-8 & 50 & 51 & 0 & 850 & 451.33 & 451.29 & 8.71 & 11.52 & $7.45 \mathrm{E}-09$ & -0.11 & -0.10 & 2 & 1200 & 0.497 & \\
\hline 38 & $4 / 13 / 15$ & IG-8 & 50 & 50 & 0 & 900 & 451.29 & 451.23 & 11.78 & 14.66 & $1.35 \mathrm{E}-08$ & -0.10 & -0.09 & 2 & 1200 & 0.497 & \\
\hline 39 & $4 / 13 / 15$ & IG-8 & 50 & 49 & 0 & 950 & 451.23 & 451.16 & 14.82 & 17.89 & $1.38 \mathrm{E}-08$ & -0.09 & -0.07 & 2 & 1200 & 0.497 & \\
\hline 40 & $4 / 13 / 15$ & IG-8 & 50 & 50 & 0 & 1000 & 451.16 & 451.06 & 18.21 & 20.79 & $2.46 \mathrm{E}-08$ & -0.07 & -0.05 & 2 & 1200 & 0.497 & \\
\hline 41 & $4 / 13 / 15$ & IG-8 & 50 & 50 & 0 & 1050 & 451.06 & 450.80 & 21.06 & 23.83 & $5.87 \mathrm{E}-08$ & -0.05 & 0.01 & 2 & 1200 & 0.497 & \\
\hline 42 & $4 / 13 / 15$ & IG-8 & 50 & 51 & 1 & 1100 & 450.80 & 450.09 & 24.13 & 26.93 & $1.55 \mathrm{E}-07$ & 0.01 & 0.17 & 2 & 1200 & 0.497 & \\
\hline 43 & $4 / 19 / 15$ & IG-9 & 100 & 100 & 0 & 800 & 458.15 & 458.14 & 5.67 & 8.25 & $3.99 \mathrm{E}-09$ & -0.11 & -0.11 & 2 & 1200 & 0.526 & \\
\hline 44 & $4 / 19 / 15$ & IG-9 & 100 & 99 & 0 & 850 & 458.14 & 458.10 & 8.71 & 11.42 & $7.38 \mathrm{E}-09$ & -0.11 & -0.10 & 2 & 1200 & 0.526 & \\
\hline 45 & $4 / 19 / 15$ & IG-9 & 100 & 99 & 0 & 900 & 458.10 & 458.02 & 11.78 & 14.59 & $1.79 \mathrm{E}-08$ & -0.10 & -0.09 & 2 & 1200 & 0.526 & \\
\hline 46 & $4 / 19 / 15$ & IG-9 & 100 & 107 & 0 & 950 & 458.02 & 457.97 & 14.82 & 16.19 & $2.30 \mathrm{E}-08$ & -0.09 & -0.07 & 2 & 1200 & 0.526 & \\
\hline 47 & $4 / 19 / 15$ & IG-9 & 100 & 107 & 0 & 1000 & 457.97 & 457.81 & 18.05 & 20.56 & $3.75 \mathrm{E}-08$ & -0.07 & -0.04 & 2 & 1200 & 0.526 & \\
\hline 48 & $4 / 19 / 15$ & IG-9 & 100 & 109 & 0 & 1050 & 457.81 & 457.32 & 20.96 & 23.83 & $1.05 \mathrm{E}-07$ & -0.04 & 0.07 & 2 & 1200 & 0.526 & \\
\hline 49 & $4 / 19 / 15$ & IG-9 & 100 & 109 & 0 & 1100 & 457.32 & 455.88 & 24.06 & 26.90 & 3.07E-07 & 0.07 & 0.38 & 2 & 1200 & 0.526 & \\
\hline 50 & $4 / 28 / 15$ & IG-10 & 200 & 206 & 0 & 800 & 467.47 & 467.46 & 5.90 & 8.32 & 2.46E-09 & -0.10 & -0.10 & 2 & 1200 & 0.010 & \\
\hline 51 & $4 / 28 / 15$ & IG-10 & 200 & 199 & 0 & 850 & 467.46 & 467.43 & 8.74 & 11.22 & $6.23 \mathrm{E}-09$ & -0.10 & -0.09 & 2 & 1200 & 0.010 & \\
\hline 52 & $4 / 28 / 15$ & $\mathrm{IG}-10$ & 200 & 184 & 0 & 900 & 467.43 & 467.37 & 11.85 & 14.46 & $1.46 \mathrm{E}-08$ & -0.09 & -0.08 & 2 & 1200 & 0.010 & \\
\hline 53 & $4 / 28 / 15$ & IG-10 & 200 & 182 & 0 & 950 & 467.37 & 467.28 & 14.82 & 17.53 & $1.82 \mathrm{E}-08$ & -0.08 & -0.06 & 2 & 1200 & 0.010 & \\
\hline 54 & $4 / 28 / 15$ & IG-10 & 200 & 193 & 0 & 1000 & 467.28 & 467.08 & 17.95 & 20.69 & 4.43E-08 & -0.06 & -0.02 & 2 & 1200 & 0.010 & \\
\hline 55 & $4 / 28 / 15$ & IG-10 & 200 & 213 & 0 & 1050 & 467.08 & 466.29 & 21.02 & 23.76 & $1.71 \mathrm{E}-07$ & -0.02 & 0.15 & 2 & 1200 & 0.010 & \\
\hline 56 & $4 / 28 / 15$ & $\mathrm{IG}-10$ & 200 & 220 & 0 & 1100 & 466.29 & 463.62 & 24.09 & 26.96 & $5.54 \mathrm{E}-07$ & 0.15 & 0.72 & 2 & 1200 & 0.010 & \\
\hline 57 & $4 / 30 / 15$ & IG-11 & 25 & 29 & 0 & 800 & 451.77 & 451.77 & 5.48 & 8.39 & $1.48 \mathrm{E}-09$ & -0.11 & -0.11 & 2 & 1200 & 0.025 & \\
\hline 58 & $4 / 30 / 15$ & IG-11 & 25 & 25 & 0 & 850 & 451.77 & 451.75 & 8.71 & 11.36 & $4.41 \mathrm{E}-09$ & -0.11 & -0.10 & 2 & 1200 & 0.025 & \\
\hline 59 & $4 / 30 / 15$ & IG-11 & 25 & 24 & 0 & 900 & 451.75 & 451.70 & 11.78 & 14.58 & $1.03 \mathrm{E}-08$ & -0.10 & -0.09 & 2 & 1200 & 0.025 & \\
\hline 60 & $4 / 30 / 15$ & IG-11 & 25 & 10 & 0 & 950 & 451.70 & 451.64 & 15.14 & 17.63 & $1.48 \mathrm{E}-08$ & -0.09 & -0.08 & 2 & 1200 & 0.025 & \\
\hline 61 & $4 / 30 / 15$ & IG-11 & 25 & 10 & 0 & 1000 & 451.64 & 451.56 & 17.95 & 20.73 & $1.88 \mathrm{E}-08$ & -0.08 & -0.06 & 2 & 1200 & 0.025 & \\
\hline 62 & $4 / 30 / 15$ & IG-11 & 25 & 11 & 0 & 1050 & 451.56 & 451.45 & 21.02 & 23.76 & $2.38 \mathrm{E}-08$ & -0.06 & -0.04 & 2 & 1200 & 0.025 & \\
\hline 63 & $4 / 30 / 15$ & $\mid \mathrm{G}-11$ & 25 & 11 & 0 & 1100 & 451.45 & 451.25 & 24.13 & 26.83 & $4.54 \mathrm{E}-08$ & -0.04 & 0.01 & 2 & 1200 & 0.025 & \\
\hline 64 & $5 / 4 / 15$ & IG-12 & 3 & 5 & 0 & 800 & 448.64 & 448.63 & 5.40 & 8.23 & $1.31 \mathrm{E}-09$ & -0.12 & -0.12 & 2 & 1200 & 0.036 & \\
\hline 65 & $5 / 4 / 15$ & IG-12 & 3 & 5 & 0 & 850 & 448.63 & 448.61 & 8.76 & 11.36 & $5.72 \mathrm{E}-09$ & -0.12 & -0.11 & 2 & 1200 & 0.036 & \\
\hline 66 & $5 / 4 / 15$ & IG-12 & 3 & 5 & 0 & 900 & 448.61 & 448.56 & 11.77 & 14.52 & $1.19 \mathrm{E}-08$ & -0.11 & -0.10 & 2 & 1200 & 0.036 & \\
\hline 67 & $5 / 4 / 15$ & $\mathrm{IG}-12$ & 3 & 5 & 0 & 950 & 448.56 & 448.49 & 14.89 & 17.51 & $1.44 \mathrm{E}-08$ & -0.10 & -0.09 & 2 & 1200 & 0.036 & \\
\hline 68 & $5 / 4 / 15$ & IG-12 & 3 & 5 & 0 & 1000 & 448.49 & 448.41 & 17.93 & 20.80 & $1.90 \mathrm{E}-08$ & -0.09 & -0.07 & 2 & 1200 & 0.036 & \\
\hline 69 & $5 / 4 / 15$ & IG-12 & 3 & 5 & 0 & 1050 & 448.41 & 448.31 & 21.01 & 23.80 & $2.22 \mathrm{E}-08$ & -0.07 & -0.05 & 2 & 1200 & 0.036 & \\
\hline & & & 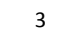 & & & & & & & & & & & & & & \\
\hline
\end{tabular}




\begin{tabular}{|c|c|c|c|c|c|c|c|c|c|c|c|c|c|c|c|c|c|}
\hline \multirow{2}{*}{$\begin{array}{l}\text { Exp data } \\
\text { number }\end{array}$} & \multirow[b]{2}{*}{ Test Date } & \multirow[b]{2}{*}{ Specimen ID } & \multicolumn{2}{|c|}{$\mathrm{H} 2 \mathrm{O}$ Pressure } & & \multirow{2}{*}{$\begin{array}{c}\text { Temperatur } \\
\mathrm{e}\end{array}$} & \multicolumn{2}{|c|}{ Weight } & \multicolumn{2}{|c|}{ Time in the Test } & \multirow[b]{2}{*}{ Rate } & \multicolumn{2}{|c|}{ Weight loss \% } & \multicolumn{2}{|c|}{ Sample preparaton } & \multirow{2}{*}{$\begin{array}{l}\text { Wt loss in } \\
\text { outgassing }\end{array}$} & \multirow{3}{*}{ Notes } \\
\hline & & & target & actual $^{\text {\& }}$ & H2 Pressure & & before & after & before & after & & before & after & duration & temperature & & \\
\hline & & & $\mathrm{Pa}$ & $\mathrm{Pa}$ & $\mathrm{Pa}$ & ${ }^{\circ} \mathrm{C}$ & $\mathrm{mg}$ & $\mathrm{mg}$ & $\mathrm{hr}$ & $\mathrm{hr}$ & $s^{-1}$ & $\%$ & $\%$ & $\mathrm{~h}$ & ${ }^{\circ} \mathrm{C}$ & $\mathrm{mg}$ & \\
\hline 71 & $5 / 8 / 15$ & IG-13 & 50 & 95 & 0 & 800 & 450.90 & 450.89 & 5.71 & 8.39 & $\begin{array}{l}4.60 \mathrm{E}-10 \\
\end{array}$ & -0.01 & -0.01 & 2 & 1200 & 0.024 & \\
\hline 72 & $5 / 8 / 15$ & IG-13 & 50 & 58 & 0 & 850 & 450.89 & 450.88 & 8.76 & 11.42 & 4.17E-09 & -0.01 & 0.00 & 2 & 1200 & 0.024 & \\
\hline 73 & $5 / 8 / 15$ & IG-13 & 50 & 38 & 0 & 900 & 450.88 & 450.83 & 11.75 & 14.56 & $1.01 \mathrm{E}-08$ & 0.00 & 0.01 & 2 & 1200 & 0.024 & \\
\hline 74 & $5 / 8 / 15$ & IG-13 & 50 & 36 & 0 & 950 & 450.83 & 450.75 & 14.85 & 17.63 & $1.86 \mathrm{E}-08$ & 0.01 & 0.03 & 2 & 1200 & 0.024 & \\
\hline 75 & $5 / 8 / 15$ & IG-13 & 50 & 36 & 0 & 1000 & 450.75 & 450.60 & 17.89 & 20.79 & $3.17 \mathrm{E}-08$ & 0.03 & 0.06 & 2 & 1200 & 0.024 & \\
\hline 76 & $5 / 8 / 15$ & IG-13 & 50 & 36 & 0 & 1050 & 450.60 & 450.34 & 21.02 & 23.83 & $5.70 \mathrm{E}-08$ & 0.06 & 0.12 & 2 & 1200 & 0.024 & \\
\hline 77 & $5 / 8 / 15$ & IG-13 & 50 & 36 & 1 & 1100 & 450.34 & 449.74 & 24.02 & 26.90 & $1.28 \mathrm{E}-07$ & 0.12 & 0.25 & 2 & 1200 & 0.024 & \\
\hline 79 & $5 / 13 / 15$ & IG-14 & 300 & 303 & 0 & 850 & 458.18 & 458.15 & 8.71 & 11.52 & $5.61 \mathrm{E}-09$ & -0.12 & -0.11 & 2 & 1200 & 0.037 & \\
\hline 80 & $5 / 13 / 15$ & IG-14 & 300 & 296 & 0 & 900 & 458.15 & 458.10 & 11.78 & 14.59 & $1.14 \mathrm{E}-08$ & -0.11 & -0.10 & 2 & 1200 & 0.037 & \\
\hline 81 & $5 / 13 / 15$ & IG-14 & 300 & 291 & 0 & 950 & 458.10 & 458.01 & 14.85 & 17.69 & $1.84 \mathrm{E}-08$ & -0.10 & -0.08 & 2 & 1200 & 0.037 & \\
\hline 82 & $5 / 13 / 15$ & IG-14 & 300 & 326 & 0 & 1000 & 458.01 & 457.79 & 17.92 & 20.73 & $4.81 \mathrm{E}-08$ & -0.08 & -0.04 & 2 & 1200 & 0.037 & \\
\hline 83 & $5 / 13 / 15$ & IG-14 & 300 & 352 & 0 & 1050 & 457.79 & 456.77 & 20.93 & 23.76 & $2.19 \mathrm{E}-07$ & -0.04 & 0.19 & 2 & 1200 & 0.037 & \\
\hline 84 & $5 / 13 / 15$ & IG-14 & 300 & 354 & 0 & 1100 & 456.77 & 453.05 & 24.06 & 26.93 & $7.88 \mathrm{E}-07$ & 0.19 & 1.00 & 2 & 1200 & 0.037 & \\
\hline 85 & $5 / 27 / 15$ & IG-15 & 50 & 66 & 0 & 800 & 453.27 & 453.26 & 5.84 & 8.32 & $1.98 \mathrm{E}-09$ & -0.13 & -0.13 & 2 & 1200 & 0.034 & \\
\hline 86 & $5 / 27 / 15$ & IG-15 & 50 & 65 & 0 & 850 & 453.26 & 453.24 & 8.78 & 11.46 & $4.80 \mathrm{E}-09$ & -0.13 & -0.12 & 2 & 1200 & 0.034 & \\
\hline 87 & $5 / 27 / 15$ & IG-15 & 50 & 64 & 0 & 900 & 453.24 & 453.20 & 11.88 & 14.49 & $9.86 \mathrm{E}-09$ & -0.12 & -0.11 & 2 & 1200 & 0.034 & \\
\hline 88 & $5 / 27 / 15$ & IG-15 & 50 & 63 & 0 & 950 & 453.20 & 453.13 & 14.92 & 17.59 & $1.56 \mathrm{E}-08$ & -0.11 & -0.10 & 2 & 1200 & 0.034 & \\
\hline 89 & $5 / 27 / 15$ & IG-15 & 50 & 63 & 0 & 1000 & 453.13 & 453.01 & 18.02 & 20.69 & $2.69 \mathrm{E}-08$ & -0.10 & -0.07 & 2 & 1200 & 0.034 & \\
\hline 90 & $5 / 27 / 15$ & IG-15 & 50 & 49 & 0 & 1050 & 453.01 & 452.77 & 21.02 & 23.83 & $5.32 \mathrm{E}-08$ & -0.07 & -0.02 & 2 & 1200 & 0.034 & \\
\hline 91 & $5 / 27 / 15$ & IG-15 & 50 & 35 & 0 & 1100 & 452.77 & 452.27 & 24.09 & 26.90 & $1.09 \mathrm{E}-07$ & -0.02 & 0.09 & 2 & 1200 & 0.034 & \\
\hline 92 & $5 / 29 / 15$ & IG-16 & 150 & 152 & 0 & 800 & 458.07 & 458.06 & 5.61 & 8.32 & $1.79 \mathrm{E}-09$ & -0.12 & -0.12 & 2 & 1200 & 0.031 & \\
\hline 93 & $5 / 29 / 15$ & IG-16 & 150 & 151 & 0 & 850 & 451.24 & 451.24 & 8.78 & 11.52 & $5.31 \mathrm{E}-09$ & -0.12 & -0.11 & 2 & 1200 & 0.031 & \\
\hline 94 & $5 / 29 / 15$ & IG-16 & 150 & 152 & 0 & 900 & 451.24 & 451.23 & 11.81 & 14.56 & $1.08 \mathrm{E}-08$ & -0.11 & -0.10 & 2 & 1200 & 0.031 & \\
\hline 95 & $5 / 29 / 15$ & IG-16 & 150 & 152 & 0 & 950 & 451.23 & 451.22 & 14.85 & 17.66 & $1.71 \mathrm{E}-08$ & -0.10 & -0.08 & 2 & 1200 & 0.031 & \\
\hline 96 & $5 / 29 / 15$ & IG-16 & 150 & 153 & 0 & 1000 & 451.22 & 451.19 & 17.89 & 20.66 & $3.57 \mathrm{E}-08$ & -0.08 & -0.05 & 2 & 1200 & 0.031 & \\
\hline 97 & $5 / 29 / 15$ & IG-16 & 150 & 154 & 0 & 1050 & 451.19 & 451.05 & 21.02 & 23.76 & $1.25 \mathrm{E}-07$ & -0.05 & 0.08 & 2 & 1200 & 0.031 & \\
\hline 98 & $5 / 29 / 15$ & IG-16 & 150 & 155 & 0 & 1100 & 451.05 & 450.26 & 24.02 & 26.83 & $3.81 \mathrm{E}-07$ & 0.08 & 0.46 & 2 & 1200 & 0.031 & \\
\hline 99 & $6 / 2 / 15$ & IG-17 & 200 & 203 & 0 & 800 & 453.49 & 453.48 & 5.22 & 8.45 & $2.84 \mathrm{E}-09$ & -0.12 & -0.11 & 2 & 1200 & 0.526 & \\
\hline 100 & $6 / 2 / 15$ & IG-17 & 200 & 203 & 0 & 850 & 453.48 & 453.45 & 8.71 & 11.42 & $6.55 \mathrm{E}-09$ & -0.11 & -0.11 & 2 & 1200 & 0.526 & \\
\hline 101 & $6 / 2 / 15$ & IG-17 & 200 & 203 & 0 & 900 & 453.45 & 453.39 & 11.75 & 14.62 & $1.39 \mathrm{E}-08$ & -0.11 & -0.09 & 2 & 1200 & 0.526 & \\
\hline 102 & $6 / 2 / 15$ & IG-17 & 200 & 204 & 0 & 950 & 453.39 & 453.28 & 14.82 & 17.66 & $2.20 \mathrm{E}-08$ & -0.09 & -0.07 & 2 & 1200 & 0.526 & \\
\hline 103 & $6 / 2 / 15$ & IG-17 & 200 & 205 & 0 & 1000 & 453.28 & 453.07 & 17.92 & 20.76 & 4.55E-08 & -0.07 & -0.02 & 2 & 1200 & 0.526 & \\
\hline 104 & $6 / 2 / 15$ & IG-17 & 200 & 208 & 0 & 1050 & 453.07 & 452.30 & 20.99 & 23.73 & $1.73 \mathrm{E}-07$ & -0.02 & 0.15 & 2 & 1200 & 0.526 & \\
\hline 105 & $6 / 2 / 15$ & IG-17 & 200 & 207 & 0 & 1100 & 452.30 & 449.79 & 24.06 & 26.93 & $5.37 \mathrm{E}-07$ & 0.15 & 0.70 & 2 & 1200 & 0.526 & \\
\hline 107 & $6 / 8 / 15$ & IG-18 & 20 & 204 & 17 & 850 & 453.83 & 453.81 & 8.68 & 11.46 & $3.30 \mathrm{E}-09$ & -0.02 & -0.01 & 2 & 1200 & 0.063 & \\
\hline 108 & $6 / 8 / 15$ & IG-18 & 20 & 203 & 17 & 900 & 453.81 & 453.79 & 11.75 & 14.62 & $5.33 \mathrm{E}-09$ & -0.01 & -0.01 & 2 & 1200 & 0.063 & \\
\hline 109 & $6 / 8 / 15$ & IG-18 & 20 & 203 & 17 & 950 & 453.79 & 453.75 & 14.75 & 17.63 & $7.65 \mathrm{E}-09$ & -0.01 & 0.00 & 2 & 1200 & 0.063 & \\
\hline 110 & $6 / 8 / 15$ & IG-18 & 20 & 203 & 17 & 1000 & 453.75 & 453.66 & 17.95 & 20.79 & $1.96 \mathrm{E}-08$ & 0.00 & 0.02 & 2 & 1200 & 0.063 & \\
\hline 111 & $6 / 8 / 15$ & IG-18 & 20 & 204 & 17 & 1050 & 453.66 & 453.29 & 20.96 & 23.83 & $8.00 \mathrm{E}-08$ & 0.02 & 0.10 & 2 & 1200 & 0.063 & \\
\hline 112 & $6 / 8 / 15$ & IG-18 & 20 & 202 & 17 & 1100 & 453.29 & 451.91 & 24.16 & 26.96 & $3.00 \mathrm{E}-07$ & 0.10 & 0.40 & 2 & 1200 & 0.063 & \\
\hline 113 & $6 / 10 / 15$ & IG-19 & 100 & 113 & 17 & 800 & 457.41 & 457.41 & 6.07 & 7.31 & 1.47E-09 & -0.01 & -0.01 & 2 & 1200 & 0.028 & \\
\hline 114 & $6 / 10 / 15$ & IG-19 & 100 & 104 & 17 & 850 & 457.41 & 457.40 & 8.78 & 11.42 & $2.30 \mathrm{E}-09$ & -0.01 & 0.00 & 2 & 1200 & 0.028 & \\
\hline 115 & $6 / 10 / 15$ & IG-19 & 100 & 104 & 17 & 900 & 457.40 & 457.38 & 11.78 & 14.56 & $3.71 \mathrm{E}-09$ & 0.00 & 0.00 & 2 & 1200 & 0.028 & \\
\hline 116 & $6 / 10 / 15$ & IG-19 & 100 & 103 & 17 & 950 & 457.38 & 457.36 & 14.92 & 17.63 & $4.71 \mathrm{E}-09$ & 0.00 & 0.01 & 2 & 1200 & 0.028 & \\
\hline 117 & $6 / 10 / 15$ & IG-19 & 100 & 103 & 17 & 1000 & 457.36 & 457.32 & 17.95 & 20.69 & 9.53E-09 & 0.01 & 0.01 & 2 & 1200 & 0.028 & \\
\hline 118 & $6 / 10 / 15$ & IG-19 & 100 & 103 & 17 & 1050 & 457.32 & 457.19 & 20.96 & 23.73 & 2.87E-08 & 0.01 & 0.04 & 2 & 1200 & 0.028 & \\
\hline 119 & $6 / 10 / 15$ & IG-19 & 100 & 103 & 17 & 1100 & 457.19 & 456.69 & 24.02 & 26.87 & $1.06 \mathrm{E}-07$ & 0.04 & 0.15 & 2 & 1200 & 0.028 & \\
\hline 120 & $6 / 12 / 15$ & IG-20 & 20 & 53 & 17 & 800 & 447.75 & 447.74 & 6.00 & 8.42 & $1.03 \mathrm{E}-09$ & -0.01 & -0.01 & 2 & 1200 & 0.038 & \\
\hline 121 & $6 / 12 / 15$ & IG-20 & 20 & 53 & 17 & 850 & 447.74 & 447.73 & 8.68 & 11.49 & 2.87E-09 & -0.01 & -0.01 & 2 & 1200 & 0.038 & \\
\hline 122 & $6 / 12 / 15$ & IG-20 & 20 & 52 & 17 & 900 & 447.73 & 447.71 & 11.68 & 14.59 & $4.26 \mathrm{E}-09$ & -0.01 & 0.00 & 2 & 1200 & 0.038 & \\
\hline 123 & $6 / 12 / 15$ & IG-20 & 20 & 52 & 17 & 950 & 447.71 & 447.69 & 14.82 & 17.59 & 4.93E-09 & 0.00 & 0.00 & 2 & 1200 & 0.038 & \\
\hline 124 & $6 / 12 / 15$ & IG-20 & 20 & 53 & 17 & 1000 & 447.69 & 447.65 & 17.92 & 20.76 & $7.21 \mathrm{E}-09$ & 0.00 & 0.01 & 2 & 1200 & 0.038 & \\
\hline 125 & $6 / 12 / 15$ & IG-20 & 20 & 52 & 17 & 1050 & 447.65 & 447.56 & 20.93 & 23.86 & $1.93 \mathrm{E}-08$ & 0.01 & 0.03 & 2 & 1200 & 0.038 & \\
\hline
\end{tabular}




\begin{tabular}{|c|c|c|c|c|c|c|c|c|c|c|c|c|c|c|c|c|c|}
\hline \multirow{2}{*}{$\begin{array}{l}\text { Exp data } \\
\text { number }\end{array}$} & \multirow[b]{2}{*}{ Test Date } & \multirow[b]{2}{*}{ Specimen ID } & \multicolumn{2}{|c|}{$\mathrm{H} 2 \mathrm{O}$ Pressure } & & \multirow{2}{*}{$\begin{array}{c}\text { Temperatur } \\
\mathrm{e}\end{array}$} & \multicolumn{2}{|c|}{ Weight } & \multicolumn{2}{|c|}{ Time in the Test } & \multirow[b]{2}{*}{ Rate } & \multicolumn{2}{|c|}{ Weight loss \% } & \multicolumn{2}{|c|}{ Sample preparaton } & \multirow{2}{*}{$\begin{array}{l}\text { Wt loss in } \\
\text { outgassing }\end{array}$} & \multirow[b]{2}{*}{ Notes } \\
\hline & & & target & actual $^{\&}$ & H2 Pressure & & before & after & before & after & & before & after & duration & temperature & & \\
\hline & & & $\mathrm{Pa}$ & $\mathrm{Pa}$ & $\mathrm{Pa}$ & ${ }^{\circ} \mathrm{C}$ & $\mathrm{mg}$ & $\mathrm{mg}$ & $\mathrm{hr}$ & $\mathrm{hr}$ & $s^{-1}$ & $\%$ & $\%$ & $\mathrm{~h}$ & ${ }^{\circ} \mathrm{C}$ & $\mathrm{mg}$ & \\
\hline 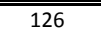 & "6/12/15 & IG-20 & 20 & $\overline{c 52}$ & 17 & "1100 & (447.56 & $\begin{array}{l}447.30 \\
\end{array}$ & 23.99 & 26.83 & (5.79E-08 & \begin{tabular}{c|}
0.03 \\
\end{tabular} & 0.09 & $\overline{22}$ & 1200 & 0.038 & \\
\hline 127 & $6 / 14 / 15$ & IG-21 & 20 & 21 & 17 & 800 & 459.53 & 459.52 & 5.81 & 8.45 & $2.06 \mathrm{E}-09$ & -0.08 & -0.08 & 2 & 1200 & 0.035 & \\
\hline 128 & $6 / 14 / 15$ & IG-21 & 20 & 21 & 17 & 850 & 459.52 & 459.50 & 8.68 & 11.46 & $3.04 \mathrm{E}-09$ & -0.08 & -0.07 & 2 & 1200 & 0.035 & \\
\hline 129 & $6 / 14 / 15$ & $\mid G-21$ & 20 & 21 & 17 & 900 & 459.50 & 459.49 & 11.75 & 14.59 & $2.34 \mathrm{E}-09$ & -0.07 & -0.07 & 2 & 1200 & 0.035 & \\
\hline 130 & $6 / 14 / 15$ & IG-21 & 20 & 21 & 17 & 950 & 459.49 & 459.48 & 14.85 & 17.63 & $2.83 \mathrm{E}-09$ & -0.07 & -0.07 & 2 & 1200 & 0.035 & \\
\hline 131 & $6 / 14 / 15$ & $\mid G-21$ & 20 & 20 & 17 & 1000 & 459.48 & 459.46 & 17.92 & 20.79 & $4.63 \mathrm{E}-09$ & -0.07 & -0.06 & 2 & 1200 & 0.035 & \\
\hline 132 & $6 / 14 / 15$ & $\mid G-21$ & 20 & 20 & 17 & 1050 & 459.46 & 459.42 & 20.96 & 23.83 & $8.64 \mathrm{E}-09$ & -0.06 & -0.05 & 2 & 1200 & 0.035 & \\
\hline 133 & $6 / 14 / 15$ & IG-21 & 20 & 20 & 17 & 1100 & 459.42 & 459.33 & 24.02 & 26.90 & $1.83 \mathrm{E}-08$ & -0.05 & -0.03 & 2 & 1200 & 0.035 & \\
\hline 134 & $6 / 15 / 15$ & IG-22 & 100 & 103 & 44 & 800 & 462.12 & 462.12 & 5.25 & 8.39 & $9.57 \mathrm{E}-10$ & -0.01 & 0.00 & 2 & 1200 & 0.028 & \\
\hline 135 & $6 / 15 / 15$ & IG-22 & 100 & 103 & 44 & 850 & 462.12 & 462.11 & 8.58 & 11.52 & $1.43 \mathrm{E}-09$ & 0.00 & 0.00 & 2 & 1200 & 0.028 & \\
\hline 136 & $6 / 15 / 15$ & IG-22 & 100 & 103 & 44 & 900 & 462.11 & 462.10 & 11.75 & 14.62 & $1.47 \mathrm{E}-09$ & 0.00 & 0.00 & 2 & 1200 & 0.028 & \\
\hline 137 & $6 / 15 / 15$ & IG-22 & 100 & 104 & 44 & 950 & 462.10 & 462.09 & 14.82 & 17.69 & $2.30 \mathrm{E}-09$ & 0.00 & 0.00 & 2 & 1200 & 0.028 & \\
\hline 138 & $6 / 15 / 15$ & IG-22 & 100 & 103 & 44 & 1000 & 462.09 & 462.07 & 17.92 & 20.79 & $5.24 \mathrm{E}-09$ & 0.00 & 0.01 & 2 & 1200 & 0.028 & \\
\hline 139 & $6 / 15 / 15$ & IG-22 & 100 & 104 & 44 & 1050 & 462.07 & 461.99 & 20.96 & 23.89 & $1.60 \mathrm{E}-08$ & 0.01 & 0.02 & 2 & 1200 & 0.028 & \\
\hline 140 & $6 / 15 / 15$ & IG-22 & 100 & 104 & 44 & 1100 & 461.99 & 461.73 & 24.06 & 26.93 & $5.49 \mathrm{E}-08$ & 0.02 & 0.08 & 2 & 1200 & 0.028 & \\
\hline 141 & $6 / 19 / 15$ & IG-23 & 50 & 52 & 42 & 800 & 452.69 & 452.68 & 5.61 & 8.39 & $2.21 \mathrm{E}-09$ & -0.01 & -0.01 & 2 & 1200 & 0.035 & \\
\hline 142 & $6 / 19 / 15$ & IG-23 & 50 & 51 & 42 & 850 & 452.68 & 452.67 & 8.78 & 11.52 & $2.02 \mathrm{E}-09$ & -0.01 & 0.00 & 2 & 1200 & 0.035 & \\
\hline 143 & 6/19/15 & IG-23 & 50 & 51 & 42 & 900 & 452.67 & 452.66 & 11.75 & 14.59 & $1.94 \mathrm{E}-09$ & 0.00 & 0.00 & 2 & 1200 & 0.035 & \\
\hline 144 & $6 / 19 / 15$ & IG-23 & 50 & 51 & 42 & 950 & 452.66 & 452.65 & 14.88 & 17.66 & $2.65 \mathrm{E}-09$ & 0.00 & 0.00 & 2 & 1200 & 0.035 & \\
\hline 145 & $6 / 19 / 15$ & IG-23 & 50 & 51 & 42 & 1000 & 452.65 & 452.63 & 17.95 & 20.73 & $4.41 \mathrm{E}-09$ & 0.00 & 0.01 & 2 & 1200 & 0.035 & \\
\hline 146 & $6 / 19 / 15$ & IG-23 & 50 & 51 & 42 & 1050 & 452.63 & 452.57 & 20.96 & 23.83 & $1.20 \mathrm{E}-08$ & 0.01 & 0.02 & 2 & 1200 & 0.035 & \\
\hline 147 & $6 / 19 / 15$ & IG-23 & 50 & 51 & 42 & 1100 & 452.57 & 452.43 & 24.09 & 26.90 & $3.12 \mathrm{E}-08$ & 0.02 & 0.05 & 2 & 1200 & 0.035 & \\
\hline 148 & $6 / 30 / 15$ & IG-24 & 150 & 152 & 43 & 800 & 461.92 & 461.91 & 6.46 & 8.35 & $6.36 \mathrm{E}-10$ & 0.00 & 0.00 & 2 & 1200 & 0.034 & \\
\hline 149 & $6 / 30 / 15$ & IG-24 & 150 & 150 & 43 & 850 & 461.91 & 461.91 & 8.68 & 11.42 & $8.78 \mathrm{E}-10$ & 0.00 & 0.00 & 2 & 1200 & 0.034 & \\
\hline 150 & $6 / 30 / 15$ & IG-24 & 150 & 151 & 43 & 900 & 461.91 & 461.90 & 11.75 & 14.53 & $1.51 \mathrm{E}-09$ & 0.00 & 0.00 & 2 & 1200 & 0.034 & \\
\hline 151 & $6 / 30 / 15$ & IG-24 & 150 & 150 & 43 & 950 & 461.90 & 461.89 & 14.85 & 17.59 & $3.51 \mathrm{E}-09$ & 0.00 & 0.00 & 2 & 1200 & 0.034 & \\
\hline 152 & $6 / 30 / 15$ & IG-24 & 150 & 151 & 43 & 1000 & 461.89 & 461.85 & 17.89 & 20.69 & $8.38 \mathrm{E}-09$ & 0.00 & 0.01 & 2 & 1200 & 0.034 & \\
\hline 153 & $6 / 30 / 15$ & IG-24 & 150 & 151 & 43 & 1050 & 461.85 & 461.69 & 20.96 & 23.83 & $3.37 \mathrm{E}-08$ & 0.01 & 0.05 & 2 & 1200 & 0.034 & \\
\hline 154 & 6/30/15 & IG-24 & 150 & 151 & 43 & 1100 & 461.69 & 461.13 & 24.13 & 26.83 & $1.25 \mathrm{E}-07$ & 0.05 & 0.17 & 2 & 1200 & 0.034 & \\
\hline 155 & $7 / 2 / 15$ & IG-25 & 200 & 202 & 43 & 800 & 450.74 & 450.73 & 6.00 & 8.45 & $1.01 \mathrm{E}-09$ & 0.00 & 0.00 & 2 & 1200 & 0.028 & \\
\hline 156 & $7 / 2 / 15$ & IG-25 & 200 & 202 & 43 & 850 & 450.73 & 450.73 & 8.74 & 11.42 & $1.61 \mathrm{E}-09$ & 0.00 & 0.00 & 2 & 1200 & 0.028 & \\
\hline 157 & $7 / 2 / 15$ & IG-25 & 200 & 200 & 43 & 900 & 450.73 & 450.72 & 11.81 & 14.53 & $1.36 \mathrm{E}-09$ & 0.00 & 0.00 & 2 & 1200 & 0.028 & \\
\hline 158 & $7 / 2 / 15$ & IG-25 & 200 & 201 & 43 & 950 & 450.72 & 450.70 & 14.82 & 17.66 & $3.26 \mathrm{E}-09$ & 0.00 & 0.00 & 2 & 1200 & 0.028 & \\
\hline 159 & $7 / 2 / 15$ & IG-25 & 200 & 200 & 43 & 1000 & 450.70 & 450.67 & 17.99 & 20.73 & $7.87 \mathrm{E}-09$ & 0.00 & 0.01 & 2 & 1200 & 0.028 & \\
\hline 160 & $7 / 2 / 15$ & IG-25 & 200 & 200 & 43 & 1050 & 450.67 & 450.51 & 20.99 & 23.80 & $3.44 \mathrm{E}-08$ & 0.01 & 0.05 & 2 & 1200 & 0.028 & \\
\hline 161 & $7 / 2 / 15$ & IG-25 & 200 & 202 & 43 & 1100 & 450.51 & 449.78 & 24.13 & 26.90 & $1.62 \mathrm{E}-07$ & 0.05 & 0.21 & 2 & 1200 & 0.028 & \\
\hline 162 & $7 / 8 / 15$ & IG-26 & 300 & 293 & 44 & 800 & 452.79 & 452.79 & 5.58 & 8.39 & $8.73 \mathrm{E}-10$ & 0.00 & 0.00 & 2 & 1200 & 0.035 & \\
\hline 163 & $7 / 8 / 15$ & IG-26 & 300 & 292 & 44 & 850 & 452.79 & 452.78 & 8.71 & 11.42 & $1.58 \mathrm{E}-09$ & 0.00 & 0.00 & 2 & 1200 & 0.035 & \\
\hline 164 & $7 / 8 / 15$ & IG-26 & 300 & 291 & 44 & 900 & 452.78 & 452.77 & 11.82 & 14.56 & $2.02 \mathrm{E}-09$ & 0.00 & 0.00 & 2 & 1200 & 0.035 & \\
\hline 165 & $7 / 8 / 15$ & IG-26 & 300 & 289 & 44 & 950 & 452.77 & 452.75 & 14.82 & 17.63 & $3.93 \mathrm{E}-09$ & 0.00 & 0.00 & 2 & 1200 & 0.035 & \\
\hline 166 & $7 / 8 / 15$ & IG-26 & 300 & 291 & 44 & 1000 & 452.75 & 452.70 & 17.92 & 20.73 & $1.14 \mathrm{E}-08$ & 0.00 & 0.02 & 2 & 1200 & 0.035 & \\
\hline 167 & $7 / 8 / 15$ & IG-26 & 300 & 295 & 44 & 1050 & 452.70 & 452.45 & 21.02 & 23.83 & $5.55 \mathrm{E}-08$ & 0.02 & 0.07 & 2 & 1200 & 0.035 & \\
\hline 168 & $7 / 8 / 15$ & IG-26 & 300 & 305 & 44 & 1100 & 452.45 & 451.09 & 24.09 & 26.98 & $2.89 \mathrm{E}-07$ & 0.07 & 0.37 & 2 & 1200 & 0.035 & \\
\hline 169 & $7 / 27 / 15$ & IG-27 & 300 & 307 & 87 & 800 & 451.24 & 451.24 & 6.00 & 8.39 & $5.15 \mathrm{E}-10$ & 0.00 & 0.00 & 2 & 1200 & 0.033 & \\
\hline 171 & $7 / 27 / 15$ & IG-27 & 300 & 317 & 87 & 900 & 451.24 & 451.23 & 11.72 & 14.53 & $1.97 \mathrm{E}-09$ & 0.00 & 0.00 & 2 & 1200 & 0.033 & \\
\hline 172 & $7 / 27 / 15$ & IG-27 & 300 & 320 & 87 & 950 & 451.23 & 451.22 & 14.92 & 17.68 & $2.01 \mathrm{E}-09$ & 0.00 & 0.00 & 2 & 1200 & 0.033 & \\
\hline 173 & $7 / 27 / 15$ & IG-27 & 300 & 313 & 87 & 1000 & 451.22 & 451.19 & 17.92 & 20.73 & $6.13 \mathrm{E}-09$ & 0.00 & 0.01 & 2 & 1200 & 0.033 & \\
\hline 174 & $7 / 27 / 15$ & IG-27 & 300 & 309 & 87 & 1050 & 451.19 & 451.05 & 20.93 & 23.73 & $3.14 \mathrm{E}-08$ & 0.01 & 0.04 & 2 & 1200 & 0.033 & \\
\hline 175 & $7 / 27 / 15$ & IG-27 & 300 & 301 & 87 & 1100 & 451.05 & 450.26 & 24.09 & 26.87 & $1.73 \mathrm{E}-07$ & 0.04 & 0.21 & 2 & 1200 & 0.033 & \\
\hline 178 & $8 / 13 / 15$ & IG-28 & 100 & 101 & 86 & 900 & 449.74 & 449.74 & 11.75 & 14.56 & $2.20 \mathrm{E}-10$ & -0.01 & -0.01 & 2 & 1200 & 0.029 & \\
\hline 179 & $8 / 13 / 15$ & IG-28 & 100 & 77 & 86 & 950 & 449.74 & 449.73 & 14.82 & 17.66 & $1.74 \mathrm{E}-09$ & -0.01 & -0.01 & 2 & 1200 & 0.029 & \\
\hline 180 & $8 / 13 / 15$ & IG-28 & 100 & 69 & 86 & 1000 & 449.73 & 449.72 & 17.89 & 20.76 & $3.01 \mathrm{E}-09$ & -0.01 & 0.00 & 2 & 1200 & 0.029 & \\
\hline 181 & $8 / 13 / 15$ & IG-28 & 100 & 69 & 86 & 1050 & 449.72 & 449.65 & 20.99 & 23.83 & $1.35 \mathrm{E}-08$ & 0.00 & 0.01 & 2 & 1200 & 0.029 & \\
\hline
\end{tabular}




\begin{tabular}{|c|c|c|c|c|c|c|c|c|c|c|c|c|c|c|c|c|c|}
\hline \multirow{2}{*}{$\begin{array}{l}\text { Exp data } \\
\text { number }\end{array}$} & \multirow[b]{2}{*}{ Test Date } & \multirow[b]{2}{*}{ Specimen ID } & \multicolumn{2}{|c|}{$\mathrm{H} 2 \mathrm{O}$ Pressure } & & \multirow{2}{*}{$\begin{array}{c}\text { Temperatur } \\
\mathrm{e}\end{array}$} & \multicolumn{2}{|c|}{ Weight } & \multicolumn{2}{|c|}{ Time in the Test } & \multirow[b]{2}{*}{ Rate } & \multicolumn{2}{|c|}{ Weight loss \% } & \multicolumn{2}{|c|}{ Sample preparaton } & \multirow{2}{*}{$\begin{array}{l}\text { Wt loss in } \\
\text { outgassing }\end{array}$} & \multirow{3}{*}{ Notes } \\
\hline & & & target & actual $^{\circledR}$ & H2 Pressure & & before & after & before & after & & before & after & duration & temperature & & \\
\hline & & & $\mathrm{Pa}$ & $\mathrm{Pa}$ & $\mathrm{Pa}$ & ${ }^{\circ} \mathrm{C}$ & $\mathrm{mg}$ & $\mathrm{mg}$ & $\mathrm{hr}$ & $\mathrm{hr}$ & $s^{-1}$ & $\%$ & $\%$ & $\mathrm{~h}$ & ${ }^{\circ} \mathrm{C}$ & $\mathrm{mg}$ & \\
\hline 182 & $8 / 13 / 15$ & IG-28 & 100 & 70 & 86 & 1100 & 449.65 & 449.50 & 24.02 & 26.93 & $\begin{array}{ll}3.21 \mathrm{E}-08 \\
\end{array}$ & 0.01 & 0.05 & 2 & 1200 & 0.029 & \\
\hline 254 & $3 / 7 / 16$ & IG 39 & 200 & 213 & 85 & 800 & 449.44 & 449.44 & 6.29 & 8.39 & $2.94 \mathrm{E}-10$ & -0.15 & -0.14 & 2 & 1200 & 0.023 & \\
\hline 255 & $3 / 7 / 16$ & IG 39 & 200 & 214 & 85 & 850 & 449.44 & 449.44 & 8.81 & 11.39 & $7.19 \mathrm{E}-10$ & -0.14 & -0.14 & 2 & 1200 & 0.023 & \\
\hline 256 & $3 / 7 / 16$ & IG 39 & 200 & 213 & 85 & 900 & 449.44 & 449.43 & 11.81 & 14.56 & $1.35 \mathrm{E}-09$ & -0.14 & -0.14 & 2 & 1200 & 0.023 & \\
\hline 257 & $3 / 7 / 16$ & IG 39 & 200 & 209 & 85 & 950 & 449.43 & 449.42 & 14.88 & 17.59 & $2.51 \mathrm{E}-09$ & -0.14 & -0.14 & 2 & 1200 & 0.023 & \\
\hline 258 & $3 / 7 / 16$ & IG 39 & 200 & 205 & 85 & 1000 & 449.42 & 449.38 & 17.95 & 20.73 & $8.89 \mathrm{E}-09$ & -0.14 & -0.13 & 2 & 1200 & 0.023 & \\
\hline 259 & $3 / 7 / 16$ & IG 39 & 200 & 200 & 85 & 1050 & 449.38 & 449.19 & 21.02 & 23.80 & $4.16 \mathrm{E}-08$ & -0.13 & -0.09 & 2 & 1200 & 0.023 & \\
\hline 260 & $3 / 7 / 16$ & IG 39 & 200 & 201 & 85 & 1100 & 449.19 & 443.99 & 24.09 & 26.90 & $1.14 \mathrm{E}-06$ & -0.09 & 1.07 & 2 & 1200 & 0.023 & \\
\hline 261 & $3 / 9 / 16$ & IG-40 & 150 & 155 & 85 & 800 & 452.21 & 452.21 & 7.05 & 8.39 & $4.58 \mathrm{E}-10$ & -0.12 & -0.12 & 2 & 1200 & 0.023 & \\
\hline 262 & $3 / 9 / 16$ & IG-40 & 150 & 161 & 85 & 850 & 452.21 & 452.21 & 8.71 & 11.42 & $0.00 E+00$ & -0.12 & -0.12 & 2 & 1200 & 0.023 & \\
\hline 263 & $3 / 9 / 16$ & IG-40 & 150 & 168 & 85 & 900 & 452.21 & 452.21 & 11.85 & 14.53 & $4.58 \mathrm{E}-10$ & -0.12 & -0.12 & 2 & 1200 & 0.023 & \\
\hline 264 & $3 / 9 / 16$ & IG-40 & 150 & 168 & 85 & 950 & 452.21 & 452.20 & 14.85 & 17.66 & $1.53 \mathrm{E}-09$ & -0.12 & -0.12 & 2 & 1200 & 0.023 & \\
\hline 265 & $3 / 9 / 16$ & IG-40 & 150 & 165 & 85 & 1000 & 452.20 & 452.18 & 17.92 & 20.69 & $4.44 \mathrm{E}-09$ & -0.12 & -0.11 & 2 & 1200 & 0.023 & \\
\hline 266 & $3 / 9 / 16$ & IG-40 & 150 & 157 & 85 & 1050 & 452.18 & 452.07 & 20.99 & 23.83 & $2.31 \mathrm{E}-08$ & -0.11 & -0.09 & 2 & 1200 & 0.023 & \\
\hline 267 & $3 / 9 / 16$ & IG-40 & 150 & 162 & 85 & 1100 & 452.07 & 451.57 & 24.09 & 26.93 & $1.09 \mathrm{E}-07$ & -0.09 & 0.02 & 2 & 1200 & 0.023 & \\
\hline 268 & $3 / 12 / 16$ & IG-41 & 50 & 51 & 86 & 800 & 452.09 & 452.09 & 6.75 & 8.45 & $1.45 \mathrm{E}-09$ & 0.00 & 0.00 & 2 & 1200 & 0.027 & \\
\hline 269 & $3 / 12 / 16$ & IG-41 & 50 & 50 & 86 & 850 & 452.09 & 452.09 & 8.68 & 11.42 & $4.48 \mathrm{E}-10$ & 0.00 & 0.00 & 2 & 1200 & 0.027 & \\
\hline 270 & $3 / 12 / 16$ & IG-41 & 50 & 50 & 85 & 900 & 452.09 & 452.08 & 11.81 & 14.59 & $6.63 \mathrm{E}-10$ & 0.00 & 0.00 & 2 & 1200 & 0.027 & \\
\hline 271 & $3 / 12 / 16$ & IG-41 & 50 & 51 & 85 & 950 & 452.08 & 452.08 & 14.82 & 17.53 & $1.36 \mathrm{E}-09$ & 0.00 & 0.00 & 2 & 1200 & 0.027 & \\
\hline 272 & $3 / 12 / 16$ & IG-41 & 50 & 51 & 85 & 1000 & 452.08 & 452.06 & 17.95 & 20.69 & 2.69E-09 & 0.00 & 0.01 & 2 & 1200 & 0.027 & \\
\hline 273 & $3 / 12 / 16$ & IG-41 & 50 & 51 & 85 & 1050 & 452.06 & 452.03 & 21.12 & 23.80 & $6.88 \mathrm{E}-09$ & 0.01 & 0.01 & 2 & 1200 & 0.027 & \\
\hline 274 & $3 / 12 / 16$ & IG-41 & 50 & 51 & 85 & 1100 & 452.03 & 451.94 & 24.16 & 26.87 & $2.20 \mathrm{E}-08$ & 0.01 & 0.03 & 2 & 1200 & 0.027 & \\
\hline 275 & $3 / 13 / 2016$ & IG-42 & 0 & 3 & 20 & 800 & 455.54 & 455.53 & 5.63 & 8.42 & $1.75 \mathrm{E}-09$ & -0.130 & -0.128 & 2 & 1200 & 0.03 & \\
\hline 276 & $3 / 13 / 2016$ & IG-42 & 0 & 3 & 20 & 850 & 455.53 & 455.53 & 8.76 & 11.49 & $8.93 E-10$ & -0.128 & -0.127 & 2 & 1200 & 0.03 & \\
\hline 277 & $3 / 13 / 2016$ & IG-42 & 0 & 3 & 20 & 900 & 455.53 & 455.52 & 11.76 & 14.55 & $6.56 \mathrm{E}-10$ & -0.127 & -0.127 & 2 & 1200 & 0.03 & \\
\hline 278 & $3 / 13 / 2016$ & IG-42 & 0 & 3 & 20 & 950 & 455.52 & 455.52 & 14.86 & 17.59 & $1.34 \mathrm{E}-09$ & -0.127 & -0.126 & 2 & 1200 & 0.03 & \\
\hline 279 & $3 / 13 / 2016$ & IG-42 & 0 & 3 & 20 & 1000 & 455.52 & 455.51 & 17.89 & 20.77 & $1.91 \mathrm{E}-09$ & -0.126 & -0.124 & 2 & 1200 & 0.03 & \\
\hline 280 & $3 / 13 / 2016$ & IG-42 & 0 & 3 & 20 & 1050 & 455.51 & 455.49 & 21.05 & 23.81 & $3.54 \mathrm{E}-09$ & -0.124 & -0.120 & 2 & 1200 & 0.03 & \\
\hline 281 & $3 / 13 / 2016$ & IG-42 & 0 & 3 & 20 & 1100 & 455.49 & 455.48 & 24.11 & 25.89 & $3.77 \mathrm{E}-09$ & -0.120 & -0.118 & 2 & 1200 & 0.03 & \\
\hline 282 & $3 / 16 / 16$ & IG-43 & 150 & 153 & 17 & 800 & 449.69 & 449.69 & 6.23 & 8.39 & $1.42 \mathrm{E}-09$ & -0.13 & -0.13 & 2 & 1200 & 0.020 & \\
\hline 283 & $3 / 16 / 16$ & IG-43 & 150 & 152 & 17 & 850 & 449.69 & 449.68 & 9.01 & 11.36 & $2.39 \mathrm{E}-09$ & -0.13 & -0.13 & 2 & 1200 & 0.020 & \\
\hline 284 & $3 / 16 / 16$ & IG-43 & 150 & 135 & 17 & 900 & 449.68 & 449.67 & 11.88 & 14.46 & $1.23 \mathrm{E}-09$ & -0.13 & -0.13 & 2 & 1200 & 0.020 & \\
\hline 285 & $3 / 16 / 16$ & IG-43 & 150 & 135 & 17 & 950 & 449.67 & 449.65 & 15.08 & 17.63 & $4.84 \mathrm{E}-09$ & -0.13 & -0.12 & 2 & 1200 & 0.020 & \\
\hline 286 & $3 / 16 / 16$ & IG-43 & 150 & 134 & 17 & 1000 & 449.65 & 449.58 & 18.02 & 20.66 & $1.64 \mathrm{E}-08$ & -0.12 & -0.11 & 2 & 1200 & 0.020 & \\
\hline 287 & $3 / 16 / 16$ & IG-43 & 150 & 134 & 17 & 1050 & 449.58 & 449.24 & 20.98 & 23.60 & $8.09 \mathrm{E}-08$ & -0.11 & -0.03 & 2 & 1200 & 0.020 & \\
\hline 288 & $3 / 16 / 16$ & IG-43 & 150 & 134 & 17 & 1100 & 449.24 & 447.95 & 24.22 & 26.87 & $3.02 \mathrm{E}-07$ & -0.03 & 0.26 & 2 & 1200 & 0.020 & \\
\hline 289 & $3 / 17 / 16$ & IG-44 & 500 & 511 & 0 & 800 & 461.67 & 461.67 & 5.51 & 8.24 & $1.32 \mathrm{E}-09$ & -0.10 & -0.10 & 2 & 1200 & 0.022 & \\
\hline 290 & $3 / 17 / 16$ & IG-44 & 500 & 508 & 0 & 850 & 461.67 & 461.64 & 8.70 & 11.33 & $5.95 \mathrm{E}-09$ & -0.10 & -0.09 & 2 & 1200 & 0.022 & \\
\hline 291 & $3 / 17 / 16$ & IG-44 & 500 & 507 & 0 & 900 & 461.64 & 461.60 & 11.92 & 14.49 & $8.90 \mathrm{E}-09$ & -0.09 & -0.08 & 2 & 1200 & 0.022 & \\
\hline 292 & $3 / 17 / 16$ & IG-44 & 500 & 569 & 0 & 950 & 461.60 & 461.52 & 14.91 & 17.48 & $1.87 \mathrm{E}-08$ & -0.08 & -0.06 & 2 & 1200 & 0.022 & \\
\hline 293 & $3 / 17 / 16$ & IG-44 & 500 & 598 & 0 & 1000 & 461.52 & 461.16 & 18.19 & 20.67 & $8.83 \mathrm{E}-08$ & -0.06 & 0.01 & 2 & 1200 & 0.022 & \\
\hline 294 & $3 / 17 / 16$ & IG-44 & 500 & 542 & 0 & 1050 & 461.16 & 459.74 & 21.09 & 23.04 & $4.39 \mathrm{E}-07$ & 0.01 & 0.32 & 2 & 1200 & 0.022 & \\
\hline 295 & $3 / 17 / 16$ & IG-44 & 500 & 568 & 0 & 1100 & 459.74 & 454.61 & 24.27 & 26.13 & $1.67 \mathrm{E}-06$ & 0.32 & 1.44 & 2 & 1200 & 0.022 & \\
\hline 296 & $3 / 19 / 16$ & IG-45 & 300 & 301 & 0 & 800 & 454.73 & 454.72 & 5.55 & 7.84 & $1.87 \mathrm{E}-09$ & -0.12 & -0.12 & 2 & 1200 & 0.018 & \\
\hline 297 & $3 / 19 / 16$ & IG-45 & 300 & 295 & 0 & 850 & 454.72 & 454.70 & 8.84 & 11.36 & $3.88 \mathrm{E}-09$ & -0.12 & -0.12 & 2 & 1200 & 0.018 & \\
\hline 298 & $3 / 19 / 16$ & IG-45 & 300 & 298 & 0 & 900 & 454.70 & 454.67 & 12.16 & 14.45 & $8.80 \mathrm{E}-09$ & -0.12 & -0.11 & 2 & 1200 & 0.018 & \\
\hline 299 & $3 / 19 / 16$ & IG-45 & 300 & 303 & 0 & 950 & 454.67 & 454.60 & 14.97 & 17.58 & $1.64 \mathrm{E}-08$ & -0.11 & -0.10 & 2 & 1200 & 0.018 & \\
\hline 300 & $3 / 19 / 16$ & IG-45 & 300 & 305 & 0 & 1000 & 454.60 & 454.34 & 18.09 & 20.61 & $6.28 \mathrm{E}-08$ & -0.10 & -0.04 & 2 & 1200 & 0.018 & \\
\hline 301 & $3 / 19 / 16$ & IG-45 & 300 & 308 & 0 & 1050 & 454.34 & 453.15 & 21.19 & 23.67 & $2.94 \mathrm{E}-07$ & -0.04 & 0.22 & 2 & 1200 & 0.018 & \\
\hline 302 & $3 / 19 / 16$ & IG-45 & 300 & 295 & 0 & 1100 & 453.15 & 450.35 & 24.09 & 26.09 & $8.58 \mathrm{E}-07$ & 0.22 & 0.84 & 2 & 1200 & 0.018 & \\
\hline 303 & $3 / 24 / 16$ & IG-46 & 1000 & 801 & 0 & 800 & 455.36 & 455.34 & 5.51 & 8.24 & $3.35 \mathrm{E}-09$ & 0.01 & 0.01 & 2 & 1200 & 0.028 & \\
\hline 304 & $3 / 24 / 16$ & IG-46 & 1000 & 846 & 0 & 850 & 455.34 & 455.34 & 9.91 & 10.46 & $2.22 \mathrm{E}-09$ & 0.01 & 0.01 & 2 & 1200 & 0.028 & \\
\hline 305 & $3 / 24 / 16$ & IG-46 & 1000 & 785 & 0 & 900 & 455.34 & 455.30 & 11.98 & 14.46 & $9.35 \mathrm{E}-09$ & 0.01 & 0.02 & 2 & 1200 & 0.028 & \\
\hline
\end{tabular}




\begin{tabular}{|c|c|c|c|c|c|c|c|c|c|c|c|c|c|c|c|c|c|}
\hline \multirow{2}{*}{$\begin{array}{l}\text { Exp data } \\
\text { number }\end{array}$} & \multirow[b]{2}{*}{ Test Date } & \multirow[b]{2}{*}{ Specimen ID } & \multicolumn{2}{|c|}{$\mathrm{H} 2 \mathrm{O}$ Pressure } & \multirow{2}{*}{\multicolumn{2}{|c|}{ H2 Pressure $\begin{array}{c}\text { Temperatur } \\
\mathrm{e}\end{array}$}} & \multicolumn{2}{|c|}{ Weight } & \multicolumn{2}{|c|}{ Time in the Test } & \multirow[b]{2}{*}{ Rate } & \multicolumn{2}{|c|}{ Weight loss \% } & \multicolumn{2}{|c|}{ Sample preparaton } & \multirow{2}{*}{$\begin{array}{l}\text { Wt loss in } \\
\text { outgassing }\end{array}$} & \multirow[b]{2}{*}{ Notes } \\
\hline & & & target & actual $^{\&}$ & & & before & after & before & after & & before & after & duration & temperature & & \\
\hline & & & $\mathrm{Pa}$ & $\mathrm{Pa}$ & $\mathrm{Pa}$ & ${ }^{\circ} \mathrm{C}$ & $\mathrm{mg}$ & $\mathrm{mg}$ & $\mathrm{hr}$ & $\mathrm{hr}$ & $s^{-1}$ & $\%$ & $\%$ & $\mathrm{~h}$ & ${ }^{\circ} \mathrm{C}$ & $\mathrm{mg}$ & \\
\hline 307 & $3 / 24 / 16$ & IG-46 & 1000 & 753 & 0 & 1000 & 455.30 & 454.86 & 18.16 & 20.37 & $1.23 \mathrm{E}-07$ & 0.02 & 0.12 & 2 & 1200 & 0.028 & \\
\hline 308 & $3 / 24 / 16$ & IG-46 & 1000 & 746 & 0 & 1050 & 454.86 & 452.48 & 21.74 & 23.69 & $7.43 \mathrm{E}-07$ & 0.12 & 0.64 & 2 & 1200 & 0.028 & \\
\hline 309 & $3 / 24 / 16$ & IG-46 & 1000 & 751 & 0 & 1100 & 452.48 & 450.52 & 24.14 & 24.70 & $2.15 \mathrm{E}-06$ & 0.64 & 1.07 & 2 & 1200 & 0.028 & \\
\hline \multicolumn{18}{|c|}{ METHOD 2 (variable gas composition at constant temperature) 70 data } \\
\hline 183 & $8 / 18 / 15$ & IG-29 & variable & 4 & 0 & 800 & 453.20 & 453.16 & 7.18 & 21.30 & $2.00 \mathrm{E}-09$ & -0.01 & 0.00 & 2 & 1200 & 0.031 & increasing \\
\hline 184 & $8 / 18 / 15$ & IG-29 & variable & 11 & 0 & 800 & 453.16 & 453.09 & 22.39 & 34.20 & $3.32 \mathrm{E}-09$ & 0.00 & 0.02 & 2 & 1200 & 0.031 & increasing \\
\hline 185 & $8 / 18 / 15$ & IG-29 & variable & 22 & 0 & 800 & 453.09 & 453.01 & 35.56 & 46.69 & $4.30 \mathrm{E}-09$ & 0.02 & 0.04 & 2 & 1200 & 0.031 & increasing \\
\hline 186 & $8 / 18 / 15$ & IG-29 & variable & 47 & 0 & 800 & 453.01 & 452.94 & 47.91 & 58.09 & $4.64 \mathrm{E}-09$ & 0.04 & 0.05 & 2 & 1200 & 0.031 & increasing \\
\hline 187 & $8 / 18 / 15$ & IG-29 & variable & 86 & 0 & 800 & 452.94 & 452.84 & 59.31 & 71.12 & $5.19 \mathrm{E}-09$ & 0.05 & 0.07 & 2 & 1200 & 0.031 & increasing \\
\hline 188 & $8 / 18 / 15$ & IG-29 & variable & 122 & 0 & 800 & 452.84 & 452.76 & 73.43 & 82.53 & $5.53 \mathrm{E}-09$ & 0.07 & 0.09 & 2 & 1200 & 0.031 & increasing \\
\hline 189 & $8 / 18 / 15$ & IG-29 & variable & 176 & 0 & 800 & 452.76 & 452.70 & 83.89 & 89.91 & $5.71 \mathrm{E}-09$ & 0.09 & 0.10 & 2 & 1200 & 0.031 & increasing \\
\hline 190 & $8 / 24 / 15$ & IG-30 & variable & 4 & 0 & 850 & 452.66 & 452.60 & 5.72 & 11.21 & $6.26 \mathrm{E}-09$ & -0.07 & -0.06 & 2 & 1200 & 0.026 & decreasing \\
\hline 191 & $8 / 24 / 15$ & IG-30 & variable & 11 & 0 & 850 & 452.60 & 452.40 & 11.77 & 22.28 & $1.16 \mathrm{E}-08$ & -0.06 & -0.01 & 2 & 1200 & 0.026 & decreasing \\
\hline 192 & $8 / 24 / 15$ & IG-30 & variable & 21 & 0 & 850 & 452.40 & 452.19 & 23.29 & 32.35 & $1.42 \mathrm{E}-08$ & -0.01 & 0.03 & 2 & 1200 & 0.026 & decreasing \\
\hline 193 & $8 / 24 / 15$ & IG-30 & variable & 45 & 0 & 850 & 452.19 & 451.90 & 34.22 & 46.27 & $1.48 \mathrm{E}-08$ & 0.03 & 0.10 & 2 & 1200 & 0.026 & decreasing \\
\hline 194 & $8 / 24 / 15$ & IG-30 & variable & 86 & 0 & 850 & 451.90 & 451.65 & 47.59 & 57.81 & $1.49 \mathrm{E}-08$ & 0.10 & 0.15 & 2 & 1200 & 0.026 & decreasing \\
\hline 195 & $8 / 24 / 15$ & IG-30 & variable & 121 & 0 & 850 & 451.65 & 451.44 & 59.24 & 70.15 & $1.23 \mathrm{E}-08$ & 0.15 & 0.20 & 2 & 1200 & 0.026 & decreasing \\
\hline 197 & $8 / 24 / 15$ & IG-30 & variable & 174 & 0 & 850 & 451.44 & 451.20 & 70.68 & 82.66 & $1.21 \mathrm{E}-08$ & 0.20 & 0.25 & 2 & 1200 & 0.026 & decreasing \\
\hline 198 & $8 / 31 / 15$ & IG-31 & variable & 178 & 0 & 850 & 457.82 & 457.72 & 6.38 & 13.47 & $8.22 \mathrm{E}-09$ & 0.00 & 0.02 & 2 & 1200 & 0.035 & decreasing \\
\hline 199 & $8 / 31 / 15$ & IG-31 & variable & 175 & 0 & 850 & 457.72 & 457.55 & 13.47 & 22.18 & $1.19 \mathrm{E}-08$ & 0.02 & 0.06 & 2 & 1200 & 0.035 & decreasing \\
\hline 200 & $8 / 31 / 15$ & $\mid G-31$ & variable & 155 & 0 & 850 & 457.55 & 457.38 & 23.19 & 31.3 & $1.29 \mathrm{E}-08$ & 0.06 & 0.10 & 2 & 1200 & 0.035 & decreasing \\
\hline 201 & $8 / 31 / 15$ & IG-31 & variable & 121 & 0 & 850 & 457.38 & 457.28 & 31.3 & 35.95 & $1.25 \mathrm{E}-08$ & 0.10 & 0.12 & 2 & 1200 & 0.035 & decreasing \\
\hline 202 & $8 / 31 / 15$ & IG-31 & variable & 85 & 0 & 850 & 457.28 & 457.04 & 36.49 & 47.08 & $1.38 \mathrm{E}-08$ & 0.12 & 0.17 & 2 & 1200 & 0.035 & decreasing \\
\hline 203 & $8 / 31 / 15$ & IG-31 & variable & 45 & 0 & 850 & 457.04 & 456.78 & 48.01 & 60.33 & $1.30 \mathrm{E}-08$ & 0.17 & 0.23 & 2 & 1200 & 0.035 & decreasing \\
\hline 204 & $8 / 31 / 15$ & $\mid G-31$ & variable & 20 & 0 & 850 & 456.78 & 456.61 & 61.48 & 69.67 & $1.29 \mathrm{E}-08$ & 0.23 & 0.27 & 2 & 1200 & 0.035 & decreasing \\
\hline 205 & $8 / 31 / 15$ & IG-31 & variable & 11 & 0 & 850 & 456.61 & 456.40 & 72.33 & 84.61 & $1.05 \mathrm{E}-08$ & 0.27 & 0.31 & 2 & 1200 & 0.035 & decreasing \\
\hline 206 & $8 / 31 / 15$ & IG-31 & variable & 6 & 0 & 850 & 456.40 & 456.24 & 85.79 & 94.34 & $1.11 \mathrm{E}-08$ & 0.31 & 0.35 & 2 & 1200 & 0.035 & decreasing \\
\hline 207 & 9/4/15 & IG-32 & variable & 5 & 0 & 900 & 452.42 & 452.33 & 6.16 & 11.03 & $1.21 \mathrm{E}-08$ & -0.01 & 0.01 & 2 & 1200 & 0.039 & increasing \\
\hline 208 & $9 / 4 / 15$ & IG-32 & variable & 13 & 0 & 900 & 452.33 & 452.07 & 11.73 & 23.90 & $1.30 \mathrm{E}-08$ & 0.01 & 0.07 & 2 & 1200 & 0.039 & increasing \\
\hline 209 & $9 / 4 / 15$ & IG-32 & variable & 23 & 0 & 900 & 452.07 & 451.80 & 24.82 & 36.93 & $1.38 \mathrm{E}-08$ & 0.07 & 0.13 & 2 & 1200 & 0.039 & increasing \\
\hline 210 & $9 / 4 / 15$ & IG-32 & variable & 48 & 0 & 900 & 451.80 & 451.58 & 39.06 & 47.79 & $1.54 \mathrm{E}-08$ & 0.13 & 0.18 & 2 & 1200 & 0.039 & increasing \\
\hline 211 & $9 / 4 / 15$ & IG-32 & variable & 90 & 0 & 900 & 451.58 & 451.26 & 48.82 & 59.98 & $1.76 \mathrm{E}-08$ & 0.18 & 0.25 & 2 & 1200 & 0.039 & increasing \\
\hline 212 & $9 / 4 / 15$ & IG-32 & variable & 126 & 0 & 900 & 451.26 & 450.94 & 61.14 & 71.56 & $1.87 \mathrm{E}-08$ & 0.25 & 0.32 & 2 & 1200 & 0.039 & increasing \\
\hline 213 & $9 / 4 / 15$ & IG-32 & variable & 180 & 0 & 900 & 450.94 & 450.60 & 72.71 & 82.90 & $2.04 \mathrm{E}-08$ & 0.32 & 0.39 & 2 & 1200 & 0.039 & increasing \\
\hline 214 & 9/4/15 & IG-32 & variable & 206 & 0 & 900 & 450.60 & 450.43 & 83.94 & 86.72 & $2.11 \mathrm{E}-08$ & 0.39 & 0.43 & 2 & 1200 & 0.039 & increasing \\
\hline 215 & 9/28/2015 & IG-33 & variable & 177 & 0 & 800 & 455.35 & 455.30 & 7.08 & 19.7 & $2.85 \mathrm{E}-09$ & -0.008 & 0.005 & 2 & 1200 & 0.039 & decreasing \\
\hline 216 & $9 / 28 / 2015$ & IG-33 & variable & 124 & 0 & 800 & 455.30 & 455.23 & 20.53 & 30.96 & $3.80 \mathrm{E}-09$ & 0.005 & 0.019 & 2 & 1200 & 0.039 & decreasing \\
\hline 217 & 9/28/2015 & IG-33 & variable & 87 & 0 & 800 & 455.23 & 455.14 & 31.68 & 42.53 & $5.12 \mathrm{E}-09$ & 0.019 & 0.039 & 2 & 1200 & 0.039 & decreasing \\
\hline 218 & 9/28/2015 & IG-33 & variable & 47 & 0 & 800 & 455.14 & 455.02 & 43.27 & 55.18 & $5.89 \mathrm{E}-09$ & 0.039 & 0.065 & 2 & 1200 & 0.039 & decreasing \\
\hline 219 & $9 / 28 / 2015$ & IG-33 & variable & 22 & 0 & 800 & 455.02 & 454.91 & 56.07 & 66.57 & $6.45 \mathrm{E}-09$ & 0.065 & 0.089 & 2 & 1200 & 0.039 & decreasing \\
\hline 220 & 9/28/2015 & IG-33 & variable & 12 & 0 & 800 & 454.91 & 454.78 & 68.17 & 79.74 & $7.12 \mathrm{E}-09$ & 0.089 & 0.119 & 2 & 1200 & 0.039 & decreasing \\
\hline 221 & 9/28/2015 & IG-33 & variable & 5 & 0 & 800 & 454.78 & 454.67 & 80.87 & 89.22 & $7.83 \mathrm{E}-09$ & 0.119 & 0.142 & 2 & 1200 & 0.039 & decreasing \\
\hline 222 & $10 / 2 / 15$ & IG-34 & variable & 159 & 0 & 900 & 455.76 & 455.64 & 6.47 & 11.48 & $1.46 \mathrm{E}-08$ & -0.01 & 0.02 & 2 & 1200 & 0.028 & decreasing \\
\hline 223 & $10 / 2 / 15$ & IG-34 & variable & 109 & 0 & 900 & 455.64 & 455.33 & 12.27 & 23.53 & $1.69 \mathrm{E}-08$ & 0.02 & 0.09 & 2 & 1200 & 0.028 & decreasing \\
\hline 224 & $10 / 2 / 15$ & IG-34 & variable & 82 & 0 & 900 & 455.33 & 454.98 & 24.16 & 36.20 & $1.80 \mathrm{E}-08$ & 0.09 & 0.17 & 2 & 1200 & 0.028 & decreasing \\
\hline 225 & $10 / 2 / 15$ & IG-34 & variable & 46 & 0 & 900 & 454.98 & 454.67 & 36.91 & 47.00 & $1.88 \mathrm{E}-08$ & 0.17 & 0.24 & 2 & 1200 & 0.028 & decreasing \\
\hline 226 & $10 / 2 / 15$ & IG-34 & variable & 22 & 0 & 900 & 454.67 & 454.37 & 49.03 & 58.66 & $1.86 \mathrm{E}-08$ & 0.24 & 0.30 & 2 & 1200 & 0.028 & decreasing \\
\hline 227 & $10 / 2 / 15$ & IG-34 & variable & 12 & 0 & 900 & 454.37 & 454.18 & 59.59 & 66.07 & $1.79 \mathrm{E}-08$ & 0.30 & 0.34 & 2 & 1200 & 0.028 & decreasing \\
\hline 228 & $10 / 8 / 15$ & IG-35 & variable & 5 & 0 & 950 & 455.11 & 454.98 & 5.46 & 10.87 & $1.46 \mathrm{E}-08$ & -0.01 & 0.02 & 2 & 1200 & 0.040 & random \\
\hline 229 & $10 / 8 / 15$ & IG-35 & variable & 13 & 0 & 950 & 454.98 & 454.64 & 11.43 & 21.69 & $2.04 \mathrm{E}-08$ & 0.02 & 0.10 & 2 & 1200 & 0.040 & random \\
\hline 230 & $10 / 8 / 15$ & IG-35 & variable & 23 & 0 & 950 & 454.64 & 454.17 & 23.80 & 34.33 & $2.73 \mathrm{E}-08$ & 0.10 & 0.20 & 2 & 1200 & 0.040 & random \\
\hline 231 & $10 / 8 / 15$ & IG-35 & variable & 47 & 0 & 950 & 454.17 & 453.53 & 35.02 & 47.58 & $3.14 \mathrm{E}-08$ & 0.20 & 0.34 & 2 & 1200 & 0.040 & random \\
\hline
\end{tabular}




\begin{tabular}{|c|c|c|c|c|c|c|c|c|c|c|c|c|c|c|c|c|c|}
\hline \multirow{2}{*}{$\begin{array}{l}\text { Exp data } \\
\text { number }\end{array}$} & \multirow[b]{2}{*}{ Test Date } & \multirow[b]{2}{*}{ Specimen ID } & \multicolumn{2}{|c|}{ H2O Pressure } & \multirow[b]{2}{*}{ H2 Pressure } & \multirow{2}{*}{$\begin{array}{c}\text { Temperatur } \\
\mathrm{e}\end{array}$} & \multicolumn{2}{|c|}{ Weight } & \multicolumn{2}{|c|}{ Time in the Test } & \multirow[b]{2}{*}{ Rate } & \multicolumn{2}{|c|}{ Weight loss \% } & \multicolumn{2}{|c|}{ Sample preparaton } & \multirow{2}{*}{$\begin{array}{l}\text { Wt loss in } \\
\text { outgassing }\end{array}$} & \multirow[b]{2}{*}{ Notes } \\
\hline & & & target & actual $^{8}$ & & & before & after & before & after & & before & after & duration & $\overline{\text { temperature }}$ & & \\
\hline & & & $\mathrm{Pa}$ & $\mathrm{Pa}$ & $\mathrm{Pa}$ & ${ }^{\circ} \mathrm{C}$ & $\mathrm{mg}$ & $\mathrm{mg}$ & $\mathrm{hr}$ & $\mathrm{hr}$ & $s^{-1}$ & $\%$ & $\%$ & $\mathrm{~h}$ & ${ }^{\circ} \mathrm{C}$ & $\mathrm{mg}$ & \\
\hline 232 & 10/8/15 & IG-35 & "variable & 87 & 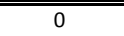 & 950 & (453.53 & (452.96 & (48.44 & (58.19 & 3.52E-08 & 0.34 & 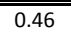 & 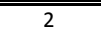 & 1200 & 0.040 & $\begin{array}{l}\text { random } \\
\end{array}$ \\
\hline 233 & $10 / 8 / 15$ & IG-35 & variable & 123 & 0 & 950 & 452.96 & 452.22 & 59.40 & 70.26 & $4.20 \mathrm{E}-08$ & 0.46 & 0.63 & 2 & 1200 & 0.040 & random \\
\hline 234 & $10 / 8 / 15$ & IG-35 & variable & 175 & 0 & 950 & 452.22 & 451.28 & 70.92 & 81.81 & $5.30 \mathrm{E}-08$ & 0.63 & 0.83 & 2 & 1200 & 0.040 & random \\
\hline 235 & $10 / 8 / 15$ & IG-35 & variable & 5 & 0 & 950 & 451.28 & 451.06 & 83.02 & 88.93 & $2.31 \mathrm{E}-08$ & 0.83 & 0.88 & 2 & 1200 & 0.040 & random \\
\hline 236 & $11 / 2 / 15$ & IG-36 & variable & 4 & 0 & 1000 & 450.76 & 450.62 & 6.19 & 10.24 & $2.01 \mathrm{E}-08$ & -0.01 & 0.01 & 2 & 1200 & 0.066 & random \\
\hline 237 & $11 / 2 / 15$ & IG-36 & variable & 12 & 0 & 1000 & 450.62 & 450.18 & 11.41 & 21.89 & $2.61 \mathrm{E}-08$ & 0.01 & 0.11 & 2 & 1200 & 0.066 & random \\
\hline 238 & $11 / 2 / 15$ & IG-36 & variable & 22 & 0 & 1000 & 450.18 & 449.63 & 23.13 & 32.91 & $3.50 \mathrm{E}-08$ & 0.11 & 0.24 & 2 & 1200 & 0.066 & random \\
\hline 239 & $11 / 2 / 15$ & IG-36 & variable & 46 & 0 & 1000 & 449.63 & 448.73 & 34.93 & 45.18 & $5.39 \mathrm{E}-08$ & 0.24 & 0.43 & 2 & 1200 & 0.066 & random \\
\hline 240 & $11 / 2 / 15$ & IG-36 & variable & 35 & 0 & 1000 & 448.73 & 448.03 & 46.41 & 51.69 & $8.18 \mathrm{E}-08$ & 0.43 & 0.59 & 2 & 1200 & 0.066 & random \\
\hline 241 & $11 / 2 / 15$ & IG-36 & variable & 119 & 0 & 1000 & 448.03 & 447.12 & 52.82 & 58.20 & $1.05 \mathrm{E}-07$ & 0.59 & 0.79 & 2 & 1200 & 0.066 & random \\
\hline 242 & $11 / 2 / 15$ & IG-36 & variable & 12 & 0 & 1000 & 447.12 & 446.44 & 59.01 & 69.23 & $4.11 \mathrm{E}-08$ & 0.79 & 0.94 & 2 & 1200 & 0.066 & random \\
\hline 243 & $11 / 2 / 15$ & IG-36 & variable & 46 & 0 & 1000 & 446.44 & 445.31 & 70.20 & 79.47 & $7.64 \mathrm{E}-08$ & 0.94 & 1.19 & 2 & 1200 & 0.066 & random \\
\hline 244 & $11 / 2 / 15$ & IG-36 & variable & 4 & 0 & 1000 & 445.31 & 444.89 & 80.28 & 88.84 & $3.06 \mathrm{E}-08$ & 1.19 & 1.29 & 2 & 1200 & 0.066 & random \\
\hline 245 & $11 / 6 / 15$ & IG-37 & variable & 168 & 0 & 850 & 447.97 & 447.89 & 6.08 & 11.17 & $9.98 \mathrm{E}-09$ & -0.01 & 0.01 & 2 & 1200 & 0.037 & random \\
\hline 246 & $11 / 6 / 15$ & IG-37 & variable & 4 & 0 & 850 & 447.89 & 447.61 & 11.75 & 25.28 & $1.29 \mathrm{E}-08$ & 0.01 & 0.07 & 2 & 1200 & 0.037 & random \\
\hline 247 & $11 / 18 / 15$ & IG-38 & variable & 3 & 0 & 900 & 466.43 & 466.19 & 5.74 & 19.34 & $1.05 \mathrm{E}-08$ & 0.00 & 0.06 & 2 & 1200 & 0.031 & random \\
\hline 248 & $11 / 18 / 15$ & IG-38 & variable & 44 & 0 & 900 & 466.19 & 465.97 & 20.32 & 31.22 & $1.16 \mathrm{E}-08$ & 0.06 & 0.10 & 2 & 1200 & 0.031 & random \\
\hline 249 & $11 / 18 / 15$ & IG-38 & variable & 10 & 0 & 900 & 465.97 & 465.80 & 32.43 & 42.21 & $1.08 \mathrm{E}-08$ & 0.10 & 0.14 & 2 & 1200 & 0.031 & random \\
\hline 250 & $11 / 18 / 15$ & IG-38 & variable & 19 & 0 & 900 & 465.80 & 465.57 & 45.51 & 55.57 & $1.32 \mathrm{E}-08$ & 0.14 & 0.19 & 2 & 1200 & 0.031 & random \\
\hline 251 & $11 / 18 / 15$ & IG-38 & variable & 117 & 0 & 900 & 465.57 & 465.34 & 57.23 & 67.51 & $1.36 \mathrm{E}-08$ & 0.19 & 0.24 & 2 & 1200 & 0.031 & random \\
\hline 252 & $11 / 18 / 15$ & IG-38 & variable & 83 & 0 & 900 & 465.34 & 465.06 & 68.91 & 80.37 & $1.45 \mathrm{E}-08$ & 0.24 & 0.30 & 2 & 1200 & 0.031 & random \\
\hline 253 & $11 / 18 / 15$ & IG-38 & variable & 167 & 0 & 900 & 465.06 & 464.87 & 81.39 & 88.90 & $1.53 \mathrm{E}-08$ & 0.30 & 0.34 & 2 & 1200 & 0.031 & random \\
\hline \multicolumn{18}{|c|}{26 DATA REJECTED } \\
\hline 1 & $3 / 3 / 15$ & IG-1 & 100 & 95 & 0 & 800 & 464.54 & 464.52 & 7.01 & 8.42 & $1.23 \mathrm{E}-08$ & -0.06 & -0.05 & 1 & 1200 & 0.264 & Unstable \\
\hline 2 & $3 / 3 / 15$ & IG-1 & 100 & 93 & 0 & 850 & 464.45 & 464.41 & 8.78 & 11.39 & $9.17 \mathrm{E}-09$ & -0.05 & -0.04 & 1 & 1200 & 0.264 & Unstable \\
\hline 3 & $3 / 3 / 15$ & IG-1 & 100 & 94 & 0 & 900 & 464.34 & 464.28 & 11.85 & 14.43 & $1.32 \mathrm{E}-08$ & -0.04 & -0.03 & 1 & 1200 & 0.264 & Unstable \\
\hline 4 & $3 / 3 / 15$ & IG-1 & 100 & 94 & 0 & 950 & 464.20 & 464.05 & 14.88 & 17.59 & 3.33E-08 & -0.03 & 0.00 & 1 & 1200 & 0.264 & Unstable \\
\hline 5 & $3 / 3 / 15$ & IG-1 & 100 & 94 & 0 & 1000 & 463.95 & 463.62 & 17.95 & 20.60 & 7.39E-08 & 0.00 & 0.07 & 1 & 1200 & 0.264 & Unstable \\
\hline 6 & $3 / 3 / 15$ & IG-1 & 100 & 97 & 0 & 1050 & 463.44 & 462.63 & 21.09 & 23.60 & $1.95 \mathrm{E}-07$ & 0.07 & 0.25 & 1 & 1200 & 0.264 & Unstable \\
\hline 7 & $3 / 3 / 15$ & IG-1 & 100 & 98 & 0 & 1100 & 462.28 & 460.07 & 24.16 & 26.87 & $4.89 \mathrm{E}-07$ & 0.25 & 0.73 & 1 & 1200 & 0.264 & Unstable \\
\hline 8 & $3 / 4 / 15$ & IG-1(2) & 50 & 52 & 0 & 800 & 461.56 & 461.55 & 7.54 & 8.35 & $8.92 \mathrm{E}-09$ & -0.07 & -0.07 & 1 & 1200 & $\mathrm{n} / \mathrm{a}$ & Unstable \\
\hline 9 & $3 / 4 / 15$ & IG-1(2) & 50 & 49 & 0 & 850 & 461.48 & 461.44 & 8.71 & 11.42 & $9.33 \mathrm{E}-09$ & -0.05 & -0.04 & 1 & 1200 & $n / a$ & Unstable \\
\hline 10 & $3 / 4 / 15$ & IG-1(2) & 50 & 49 & 0 & 900 & 461.37 & 461.30 & 11.75 & 14.49 & $1.41 \mathrm{E}-08$ & -0.03 & -0.01 & 1 & 1200 & $\mathrm{n} / \mathrm{a}$ & Unstable \\
\hline 11 & $3 / 4 / 15$ & IG-1(2) & 50 & 51 & 0 & 950 & 461.24 & 461.12 & 14.85 & 17.63 & 2.69E-08 & 0.00 & 0.03 & 1 & 1200 & $\mathrm{n} / \mathrm{a}$ & Unstable \\
\hline 12 & $3 / 4 / 15$ & IG-1(2) & 50 & 50 & 0 & 1000 & 461.00 & 460.67 & 17.99 & 20.63 & 7.60E-08 & 0.05 & 0.13 & 1 & 1200 & $\mathrm{n} / \mathrm{a}$ & Unstable \\
\hline 13 & $3 / 4 / 15$ & IG-1(2) & 50 & 50 & 0 & 1050 & 460.54 & 459.75 & 20.99 & 23.80 & $1.68 \mathrm{E}-07$ & 0.15 & 0.32 & 1 & 1200 & $n / a$ & Unstable \\
\hline 14 & $3 / 4 / 15$ & IG-1(2) & 50 & 48 & 0 & 1100 & 459.49 & 457.90 & 24.22 & 26.90 & $3.60 \mathrm{E}-07$ & 0.38 & 0.73 & 1 & 1200 & $\mathrm{n} / \mathrm{a}$ & Unstable \\
\hline 15 & $3 / 10 / 15$ & IG-2 & 150 & 138 & 0 & 800 & 462.12 & 462.00 & 5.02 & 8.32 & $2.30 \mathrm{E}-08$ & 0.16 & 0.18 & 2 & 1200 & 0.028 & Unstable \\
\hline 22 & $3 / 12 / 15$ & IG-3 & 30 & 35 & 0 & 800 & 451.43 & 451.35 & 5.04 & 8.44 & $1.43 \mathrm{E}-08$ & 0.14 & 0.16 & 2 & 1200 & 0.013 & Unstable \\
\hline 24 & $3 / 12 / 15$ & IG-3 & 30 & 37 & 0 & 900 & 451.21 & 451.17 & 11.70 & 14.58 & 7.27E-09 & 0.19 & 0.20 & 2 & 1200 & 0.013 & Unstable \\
\hline 25 & $3 / 12 / 15$ & IG-3 & 30 & 17 & 0 & 950 & 451.10 & 451.04 & 14.85 & 17.68 & $1.22 \mathrm{E}-08$ & 0.21 & 0.23 & 2 & 1200 & 0.013 & Unstable \\
\hline 26 & $3 / 12 / 15$ & IG-3 & 30 & 17 & 0 & 1000 & 450.97 & 450.92 & 17.93 & 20.81 & $9.62 \mathrm{E}-09$ & 0.24 & 0.25 & 2 & 1200 & 0.013 & Unstable \\
\hline 29 & $4 / 8 / 15$ & IG-7 & 30 & 29 & 0 & 800 & 463.20 & 463.14 & 5.31 & 8.39 & $1.32 \mathrm{E}-08$ & 0.00 & 0.01 & 2 & 1200 & 0.376 & Unstable \\
\hline 78 & $5 / 13 / 15$ & IG-14 & 300 & 318 & 0 & 800 & 458.17 & 458.18 & 6.42 & 8.39 & $-2.15 \mathrm{E}-09$ & -0.12 & -0.12 & 2 & 1200 & 0.037 & Negative rate \\
\hline 106 & $6 / 8 / 15$ & $\mathrm{IG}-18$ & 20 & 190 & 15 & 800 & 453.84 & 453.83 & 6.23 & 8.42 & $3.91 \mathrm{E}-09$ & -0.02 & -0.02 & 2 & 1200 & 0.063 & Unstable \\
\hline 170 & $7 / 27 / 15$ & IG-27 & 300 & 310 & 87 & 850 & 451.24 & 451.24 & 8.78 & 11.42 & $0.00 E+00$ & 0.00 & 0.00 & 2 & 1200 & 0.033 & Zero rate \\
\hline 176 & $8 / 13 / 15$ & IG-28 & 100 & 110 & 86 & 800 & 449.74 & 449.74 & 6.20 & 8.45 & $0.00 E+00$ & -0.01 & -0.01 & 2 & 1200 & 0.029 & Negative rate \\
\hline 177 & $8 / 13 / 15$ & IG-28 & 100 & 103 & 86 & 850 & 449.74 & 449.74 & 8.68 & 11.52 & $-2.17 E-10$ & -0.01 & -0.01 & 2 & 1200 & 0.029 & Negative rate \\
\hline 306 & $3 / 24 / 16$ & IG-46 & 1000 & unstable & $\begin{array}{c}0 \\
0\end{array}$ & $\begin{array}{l}030 \\
950\end{array}$ & 455.30 & 455.30 & $\begin{array}{l}0.00 \\
0.00\end{array}$ & $\begin{array}{l}11.02 \\
0.00\end{array}$ & \#DIV/0! & $\begin{array}{l}-0.01 \\
0.02\end{array}$ & $\begin{array}{l}-0.01 \\
0.02\end{array}$ & 2 & 1200 & 0.028 & Unstable \\
\hline
\end{tabular}




\section{PHYSICAL MEASUREMENTS ON GRAPHITE NBG-17 SPECIMENS BEFORE AND AFTER TESTS}

\begin{tabular}{|c|c|c|c|c|c|c|c|c|c|c|c|c|}
\hline \multirow[b]{2}{*}{ Test Date } & \multirow[b]{2}{*}{ Specimen ID } & \multicolumn{4}{|c|}{ Before test } & \multicolumn{2}{|c|}{ Test Conditions } & \multicolumn{4}{|c|}{ After test } & \multirow[b]{2}{*}{ Notes } \\
\hline & & Weight mg & $\begin{array}{c}\text { Average } \mathrm{L} \\
\mathrm{mm}\end{array}$ & $\begin{array}{c}\text { Average D } \\
\mathrm{mm}\end{array}$ & $\begin{array}{c}\text { Density } \\
\mathrm{g} / \mathrm{cm} 3 \\
\end{array}$ & $\mathrm{PH} 2 \mathrm{OPa}$ & $\mathrm{P} \mathrm{H} 2 \mathrm{~Pa}$ & Weight mg & Average $\mathrm{L} \mathrm{mm}$ & $\begin{array}{c}\text { Average D } \\
\mathrm{mm}\end{array}$ & Density g/cm3 & \\
\hline $11 / 25 / 201$ & WG1-1 & 466.32 & 20.01 & 3.98 & 1.870 & 3 & 0 & 462.60 & 20.01 & 3.98 & 1.856 & 856 \\
\hline $11 / 26 / 201$ & WG1-2 & 464.58 & 20.05 & 3.97 & 1.871 & 3 & 0 & 463.60 & 20.23 & 3.97 & 1.849 & 849 \\
\hline $12 / 3 / 201$ & WG1-3 & 465.13 & 20.03 & 3.98 & 1.867 & 3 & 0 & 449.25 & 20.03 & 3.97 & & 309 exp. error \\
\hline $12 / 5 / 201$ & WG1-4 & 465.63 & 20.04 & 3.98 & 1.870 & 100 & 0 & 460.99 & 20.03 & 3.97 & & 858 waiting in furnace \\
\hline $12 / 16 / 201$ & WG1-5 & 464.92 & 20.00 & 3.99 & 1.859 & 100 & 0 & 459.77 & 20.00 & 3.99 & 1.840 & 840 \\
\hline $12 / 17 / 201$ & WG1-6 & 472.14 & 20.03 & 4.01 & 1.871 & 50 & 0 & 468.67 & 20.04 & 4.01 & 1.855 & 855 \\
\hline $12 / 18 / 201$ & WG1-7 & 452.7 & 19.86 & 3.98 & 1.831 & 30 & 0 & 449.98 & 19.88 & 3.98 & 1.821 & 821 \\
\hline $1 / 2 / 201$ & WG1-8 & 456.55 & 20.05 & 3.98 & 1.832 & 150 & 0 & 450.72 & 20.05 & 3.97 & 1.814 & 814 \\
\hline $1 / 6 / 201$ & WG1-9 & 465.68 & 20.01 & 3.99 & 1.866 & 300 & 0 & 456.19 & 20.01 & 3.98 & 1.831 & 831 \\
\hline $1 / 7 / 201$ & WG1-10 & 467.68 & 19.99 & 3.99 & 1.869 & 15 & 0 & 465.65 & 19.99 & 3.99 & 1.862 & 362 \\
\hline $1 / 8 / 201$ & WG1-11 & 465.53 & 20.05 & 3.98 & 1.867 & 30 & 0 & 463.01 & 20.05 & 3.98 & 1.858 & 858 \\
\hline $1 / 9 / 201$ & WG1-12 & 464.35 & 20.04 & 3.98 & 1.860 & 15 & 0 & 462.4 & 20.04 & 3.98 & 1.853 & 353 \\
\hline $1 / 13 / 201$ & WG1-13 & 469.68 & 19.98 & 4.00 & 1.869 & 50 & 0 & 466.11 & 19.97 & 4.00 & 1.859 & 859 \\
\hline $1 / 14 / 201$ & 4 WG1-14 & 472.23 & 20.04 & 4.01 & 1.862 & 150 & 0 & 465.88 & 20.04 & 4.01 & 1.842 & 842 \\
\hline $1 / 15 / 201$ & 4 WG1-15 & 465.1 & 20.04 & 3.99 & 1.856 & 300 & 0 & 456.8 & 20.04 & 3.98 & 1.833 & 833 \\
\hline $1 / 16 / 201$ & WG1-16 & 469.56 & 19.99 & 4.01 & 1.862 & 100 & 0 & 465.96 & 19.98 & 4.00 & & $356 \mathrm{H} 2 \mathrm{O}$ not constant \\
\hline $1 / 21 / 201$ & AG3-1 & 438.68 & 20.00 & 3.99 & 1.753 & 50 & 0 & 434.8 & 20.01 & 3.98 & 1.748 & 748 \\
\hline $1 / 22 / 201$ & AG3-2 & 462.65 & 20.06 & 4.00 & 1.839 & 30 & 0 & 459.87 & 20.06 & 3.98 & 1.841 & 841 \\
\hline $1 / 23 / 201$ & AG3-3 & 465.83 & 20.09 & 3.99 & 1.851 & 15 & 0 & 464.25 & 20.09 & 3.98 & 1.854 & 854 \\
\hline $1 / 24 / 201$ & AG3-4 & 470.17 & 20.02 & 4.00 & 1.869 & 100 & 0 & 465.59 & 20.02 & 4.00 & 1.852 & 352 \\
\hline $1 / 27 / 201$ & AG3-5 & 454.19 & 20.01 & 3.99 & 1.812 & 300 & 0 & 442.98 & 20.00 & 3.98 & 1.777 & 777 \\
\hline $1 / 28 / 201$ & AG3-6 & 464.52 & 20.06 & 4.00 & 1.844 & 150 & 0 & 458.65 & 20.06 & 3.99 & 1.830 & 830 \\
\hline $2 / 5 / 201$ & AG3-7 & 464.52 & 20.08 & 3.99 & 1.855 & 300 & 0 & 456.02 & 20.08 & 3.98 & 1.825 & 825 \\
\hline $2 / 6 / 201$ & AG3-8 & 463.04 & 19.91 & 3.98 & 1.872 & 150 & 0 & 456.39 & 19.93 & 3.97 & 1.847 & 847 \\
\hline $2 / 10 / 201$ & AG3-9 & 455.72 & 19.90 & 3.98 & 1.840 & 15 & 0 & 452.73 & 19.91 & 3.97 & & 836 He flow stopped \\
\hline $2 / 11 / 201$ & AG3-10 & 463.36 & 19.97 & 3.98 & 1.869 & 30 & 0 & 460.81 & 19.97 & 3.98 & 1.855 & 855 \\
\hline $2 / 14 / 201$ & AG3-11 & 464.43 & 20.02 & 3.99 & 1.856 & 50 & 0 & 460.31 & 20.03 & 3.98 & 1.847 & 847 \\
\hline $2 / 15 / 201$ & 4 AG3-12 & 457.97 & 20.00 & 3.99 & 1.836 & 100 & 0 & 452.59 & 20.00 & 3.98 & 1.822 & 322 \\
\hline
\end{tabular}




\begin{tabular}{|c|c|c|c|c|c|c|c|c|c|c|c|c|}
\hline \multirow[b]{2}{*}{ Test Date } & \multirow[b]{2}{*}{ Specimen ID } & \multicolumn{4}{|c|}{ Before test } & \multicolumn{2}{|c|}{ Test Conditions } & \multicolumn{4}{|c|}{ After test } & \multirow[b]{2}{*}{ Notes } \\
\hline & & Weight mg & $\begin{array}{c}\text { Average L } \\
\mathrm{mm}\end{array}$ & $\begin{array}{c}\text { Average D } \\
\mathrm{mm}\end{array}$ & $\begin{array}{c}\text { Density } \\
\mathrm{g} / \mathrm{cm} 3\end{array}$ & $\mathrm{P} \mathrm{H} 2 \mathrm{O} \mathrm{Pa}$ & 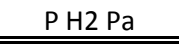 & Weight mg & Average $\mathrm{L} \mathrm{mm}$ & $\begin{array}{c}\text { Average D } \\
\mathrm{mm}\end{array}$ & Density g/cm3 & \\
\hline $2 / 16 / 201$ & AG3-13 & 442.65 & 20.03 & 4.00 & 1.756 & 0 & 0 & 441.12 & 20.03 & 4.01 & 1.748 & \\
\hline $2 / 17 / 201$ & AG3-14 & 465.53 & 20.05 & 4.00 & 1.848 & 0 & 0 & 464.2 & 20.05 & 3.99 & 1.848 & \\
\hline $3 / 5 / 201$ & AG3-15 & 463.73 & 20.09 & 3.99 & 1.846 & 15 & 30 & 462.79 & 20.09 & 3.99 & 1.842 & \\
\hline $3 / 6 / 201$ & AG3-16 & 471.69 & 19.96 & 4.02 & 1.866 & 30 & 30 & 470.47 & 19.96 & 4.02 & 1.859 & \\
\hline $3 / 7 / 201$ & AG3-17 & 467.5 & 19.95 & 3.99 & 1.871 & 50 & 30 & 465.71 & 19.95 & 3.99 & 1.870 & \\
\hline $3 / 10 / 201$ & AG3-18 & 464.33 & 19.99 & 3.99 & 1.860 & 100 & 30 & 463.49 & & & & He flow stopped \\
\hline $3 / 14 / 201$ & AG3-19 & 460.88 & 19.97 & 3.99 & 1.849 & 100 & 30 & 457.88 & 19.95 & 3.99 & 1.837 & \\
\hline $3 / 25 / 201$ & AG3-20 & 453.58 & 20.09 & 3.98 & 1.814 & 150 & 30 & 448.41 & 20.09 & 3.98 & 1.797 & \\
\hline $3 / 27 / 201$ & AG3-21 & 467.18 & 19.99 & 4.02 & 1.842 & 300 & 30 & 457.54 & 19.99 & 4.02 & 1.808 & \\
\hline $3 / 31 / 201$ & AG3-22 & 456.19 & 19.83 & 3.98 & 1.846 & 15 & 0 & 454.09 & 19.83 & 3.98 & 1.844 & $14 \mathrm{H} 2 \mathrm{O}$ not constant \\
\hline $4 / 1 / 201$ & WG1-17 & 468.16 & 19.98 & 4.00 & 1.862 & 100 & 30 & 464.68 & 19.99 & 4.00 & 1.850 & \\
\hline $4 / 2 / 201$ & WG1-18 & 468.16 & 20.01 & 3.99 & 1.868 & 50 & 30 & 462.35 & 20.01 & 3.99 & 1.847 & \\
\hline $4 / 3 / 201$ & WG1-19 & 464.23 & 20.04 & 3.99 & 1.856 & 30 & 30 & 462.7 & 20.04 & 3.98 & 1.852 & \\
\hline $4 / 4 / 201$ & WG1-20 & 465.3 & 20.03 & 3.98 & 1.865 & 150 & 30 & 460.74 & 20.04 & 3.98 & 1.846 & \\
\hline $4 / 7 / 201$ & WG1-21 & 466.16 & 20.03 & 3.99 & 1.861 & 300 & 30 & 459.19 & 20.01 & 3.99 & 1.839 & \\
\hline $4 / 8 / 201$ & WG1-22 & 457.51 & 19.80 & 3.99 & 1.844 & 15 & 30 & 456.71 & 19.81 & 3.99 & 1.845 & $15 \mathrm{H} 2 \mathrm{O}$ not constant \\
\hline $4 / 9 / 201$ & WG1-23 & 470.38 & 20.01 & 4.00 & 1.871 & 3 & 100 & 469.74 & 20.02 & 4.01 & 1.863 & $53 \mathrm{H} 2$ only \\
\hline $6 / 30 / 201$ & WG1-24 & 465.29 & 20.07 & 3.99 & 1.853 & 500 & 0 & 442.02 & 20.07 & 3.98 & 1.774 & \\
\hline $7 / 1 / 201$ & WG1-25 & 465.38 & 20.05 & 3.98 & 1.868 & 1000 & 0 & 430.71 & 20.04 & 3.96 & 1.742 & $12 \mathrm{H} 2 \mathrm{O}$ not constant \\
\hline $7 / 3 / 201$ & WG1-26 & 468.94 & 20.00 & 4.00 & 1.866 & 750 & 0 & 467.95 & 19.99 & 4.00 & 1.861 & 51 exp. Error \\
\hline $7 / 29 / 201$ & WG1-27 & 467.87 & 20.02 & 3.99 & 1.865 & 100 & 30 & 465.72 & 20.01 & 3.99 & 1.861 & $1 \mathrm{H} 2$ not constant \\
\hline $8 / 4 / 201$ & WG1-28 & 466.22 & 20.01 & 3.99 & 1.863 & 100 & 30 & 464.77 & 20.02 & 3.98 & 1.864 & $84 \mathrm{H} 2$ not constant \\
\hline $8 / 8 / 201$ & WG1-29 & 466.01 & 20.03 & 3.98 & 1.868 & $100-200$ & variable & 464.6 & 20.04 & 3.99 & 1.853 & 33 variable conditions \\
\hline $8 / 12 / 201$ & WG1-30 & 466.83 & 20.04 & 4.00 & 1.859 & $30-50$ & variable & 465.87 & 20.03 & 3.99 & 1.860 & 50 variable conditions \\
\hline $8 / 15 / 201$ & WG1-31 & 470.25 & 19.99 & 4.01 & 1.868 & vary & 25 & 469.58 & 19.99 & 4.01 & 1.861 & 51 variable conditions \\
\hline $8 / 25 / 201$ & WG1-32 & 456.9 & 20.02 & 4.00 & 1.818 & 15 & 26 & 456.34 & 20.03 & 4.00 & 1.816 & $16 \mathrm{~T}=800-850-900-950$ \\
\hline $9 / 3 / 201$ & WG1-33 & 463.92 & 20.06 & 3.98 & 1.857 & 30 & 26 & 463.15 & 20.05 & 3.98 & 1.861 & $51 \mathrm{~T}=800-850-900-950$ \\
\hline $12 / 18 / 201$ & WG1-34 & 468.30 & 20.01 & 3.99 & 1.869 & $30,15,3$ & 0 & 464.8 & 20.02 & 4.00 & 1.850 & $50 \mathrm{~T}=800-850-900-950$ \\
\hline
\end{tabular}


LOG OF EXPERIMENTAL RESULTS - GRAPHITE NBG-17

\begin{tabular}{|c|c|c|c|c|c|c|c|c|c|c|c|c|c|c|c|c|c|}
\hline \multirow{2}{*}{$\begin{array}{l}\text { Exp data } \\
\text { number }\end{array}$} & \multirow[b]{2}{*}{ Test Date } & \multirow[b]{2}{*}{ Specimen ID } & \multicolumn{2}{|c|}{ H2O Pressure } & \multirow{2}{*}{$\begin{array}{c}\mathrm{H} 2 \\
\text { Pressure }\end{array}$} & \multirow{2}{*}{$\begin{array}{c}\text { Temperat } \\
\text { ure }\end{array}$} & \multicolumn{2}{|c|}{ Weight } & \multicolumn{2}{|c|}{ Time in the test } & \multirow[b]{2}{*}{ Rate } & \multicolumn{2}{|c|}{ Weight loss \% } & \multicolumn{2}{|c|}{ Sample preparaton } & \multirow{2}{*}{$\begin{array}{l}\text { Wt loss in } \\
\text { outgassing }\end{array}$} & \multirow{3}{*}{ _Notes } \\
\hline & & & target & actual $^{\text {\& }}$ & & & before & after & before & after & & before & after & duration & temperature & & \\
\hline & & & $\mathrm{Pa}$ & $\mathrm{Pa}$ & $\mathrm{Pa}$ & oC & $\mathrm{mg}$ & $\mathrm{mg}$ & $\mathrm{hr}$ & $\mathrm{hr}$ & $s^{-1}$ & $\%$ & $\%$ & $\mathrm{~h}$ & ${ }^{\circ} \mathrm{C}$ & $\mathrm{mg}$ & \\
\hline 1 & $12 / 16 / 2013$ & WG1-5 & 100 & 100 & 0 & 800 & 465.07 & 465.04 & 4.60 & 7.36 & $5.84 \mathrm{E}-09$ & -0.03 & -0.03 & 1 & 1200 & 0.18 & \\
\hline 2 & $12 / 16 / 2013$ & WG1-5 & 100 & 101 & 0 & 850 & 464.99 & 464.91 & 7.70 & 10.46 & $1.71 \mathrm{E}-08$ & -0.01 & 0.00 & 1 & 1200 & 0.18 & \\
\hline 3 & $12 / 16 / 2013$ & WG1-5 & 100 & 101 & 0 & 900 & 464.84 & 464.72 & 10.91 & 13.56 & $2.73 \mathrm{E}-08$ & 0.02 & 0.04 & 1 & 1200 & 0.18 & \\
\hline 4 & $12 / 16 / 2013$ & WG1-5 & 100 & 101 & 0 & 950 & 464.66 & 464.41 & 13.78 & 16.55 & $5.42 \mathrm{E}-08$ & 0.06 & 0.11 & 1 & 1200 & 0.18 & \\
\hline 5 & $12 / 16 / 2013$ & WG1-5 & 100 & 101 & 0 & 1000 & 464.30 & 463.68 & 16.94 & 19.68 & $1.35 \mathrm{E}-07$ & 0.13 & 0.27 & 1 & 1200 & 0.18 & \\
\hline 6 & $12 / 16 / 2013$ & WG1-5 & 100 & 100 & 0 & 1100 & 463.29 & 460.17 & 20.12 & 22.86 & $6.81 \mathrm{E}-07$ & 0.35 & 1.02 & 1 & 1200 & 0.18 & \\
\hline 7 & $12 / 17 / 2013$ & WG1-6 & 50 & 50 & 0 & 800 & 471.18 & 471.14 & 4.21 & 7.34 & $7.53 \mathrm{E}-09$ & 0.17 & 0.18 & 1 & 1200 & 0.15 & \\
\hline 8 & $12 / 17 / 2013$ & WG1-6 & 50 & 51 & 0 & 850 & 471.07 & 471.02 & 7.81 & 10.46 & $1.27 \mathrm{E}-08$ & 0.19 & 0.21 & 1 & 1200 & 0.15 & \\
\hline 9 & $12 / 17 / 2013$ & WG1-6 & 50 & 50 & 0 & 900 & 470.96 & 470.85 & 10.82 & 13.51 & $2.46 \mathrm{E}-08$ & 0.22 & 0.24 & 1 & 1200 & 0.15 & \\
\hline 10 & $12 / 17 / 2013$ & WG1-6 & 50 & 51 & 0 & 950 & 470.74 & 470.57 & 13.90 & 16.57 & $3.71 \mathrm{E}-08$ & 0.27 & 0.30 & 1 & 1200 & 0.15 & \\
\hline 11 & $12 / 17 / 2013$ & WG1-6 & 50 & 51 & 0 & 1000 & 470.46 & 470.05 & 17.02 & 19.68 & $9.21 \mathrm{E}-08$ & 0.32 & 0.41 & 1 & 1200 & 0.15 & \\
\hline 12 & $12 / 17 / 2013$ & WG1-6 & 50 & 51 & 0 & 1100 & 469.75 & 467.86 & 20.15 & 22.86 & $4.11 \mathrm{E}-07$ & 0.47 & 0.87 & 1 & 1200 & 0.15 & \\
\hline 13 & $12 / 18 / 2013$ & WG1-7 & 30 & 30 & 0 & 800 & 451.65 & 451.63 & 4.52 & 6.61 & $6.18 \mathrm{E}-09$ & 0.20 & 0.20 & 2 & 1200 & 0.15 & \\
\hline 14 & $12 / 18 / 2013$ & WG1-7 & 30 & 30 & 0 & 850 & 451.54 & 451.47 & 7.89 & 10.43 & $1.77 \mathrm{E}-08$ & 0.22 & 0.24 & 2 & 1200 & 0.15 & \\
\hline 15 & $12 / 18 / 2013$ & WG1-7 & 30 & 30 & 0 & 900 & 451.40 & 451.31 & 10.94 & 13.48 & $2.30 \mathrm{E}-08$ & 0.25 & 0.27 & 2 & 1200 & 0.15 & \\
\hline 16 & $12 / 18 / 2013$ & WG1-7 & 30 & 30 & 0 & 950 & 451.24 & 451.08 & 13.95 & 16.57 & $3.69 \mathrm{E}-08$ & 0.29 & 0.32 & 2 & 1200 & 0.15 & \\
\hline 17 & $12 / 18 / 2013$ & WG1-7 & 30 & 30 & 0 & 1000 & 450.99 & 450.67 & 17.02 & 19.70 & 7.33E-08 & 0.34 & 0.42 & 2 & 1200 & 0.15 & \\
\hline 18 & $12 / 18 / 2013$ & WG1-7 & 30 & 30 & 0 & 1100 & 450.48 & 449.25 & 20.04 & 22.66 & $2.90 \mathrm{E}-07$ & 0.46 & 0.73 & 2 & 1200 & 0.15 & \\
\hline 19 & $1 / 2 / 2014$ & WG1-8 & 150 & 152 & 0 & 800 & 455.29 & 455.26 & 4.85 & 7.39 & $7.45 \mathrm{E}-09$ & 0.23 & 0.23 & 2 & 1200 & 0.22 & \\
\hline 20 & $1 / 2 / 2014$ & WG1-8 & 150 & 153 & 0 & 850 & 455.21 & 455.15 & 7.84 & 10.38 & $1.44 \mathrm{E}-08$ & 0.25 & 0.26 & 2 & 1200 & 0.22 & \\
\hline 21 & $1 / 2 / 2014$ & WG1-8 & 150 & 153 & 0 & 900 & 455.08 & 454.97 & 10.85 & 13.51 & $2.59 \mathrm{E}-08$ & 0.27 & 0.30 & 2 & 1200 & 0.22 & \\
\hline 22 & $1 / 2 / 2014$ & WG1-8 & 150 & 152 & 0 & 950 & 454.90 & 454.67 & 13.93 & 16.57 & $5.25 \mathrm{E}-08$ & 0.31 & 0.36 & 2 & 1200 & 0.22 & \\
\hline 23 & $1 / 2 / 2014$ & WG1-8 & 150 & 151 & 0 & 1000 & 454.57 & 453.93 & 16.94 & 19.73 & $1.40 \mathrm{E}-07$ & 0.39 & 0.53 & 2 & 1200 & 0.22 & \\
\hline 24 & $1 / 2 / 2014$ & WG1-8 & 150 & 150 & 0 & 1100 & 453.47 & 449.73 & 20.18 & 22.94 & $8.30 \mathrm{E}-07$ & 0.63 & 1.45 & 2 & 1200 & 0.22 & \\
\hline 25 & $1 / 6 / 2014$ & WG1-9 & 300 & 303 & 0 & 800 & 464.463 & 464.427 & 4.46 & 7.24 & $7.74 \mathrm{E}-09$ & 0.21 & 0.22 & 2 & 1200 & 0.22 & \\
\hline 26 & $1 / 6 / 2014$ & WG1-9 & 300 & 302 & 0 & 850 & 464.367 & 464.31 & 7.80 & 10.38 & $1.32 \mathrm{E}-08$ & 0.24 & 0.25 & 2 & 1200 & 0.22 & \\
\hline 27 & $1 / 6 / 2014$ & WG1-9 & 300 & 304 & 0 & 900 & 464.248 & 464.125 & 10.80 & 13.47 & $2.76 \mathrm{E}-08$ & 0.26 & 0.29 & 2 & 1200 & 0.22 & \\
\hline 28 & $1 / 6 / 2014$ & WG1-9 & 300 & 307 & 0 & 950 & 464.045 & 463.729 & 13.69 & 16.64 & $6.41 \mathrm{E}-08$ & 0.30 & 0.37 & 2 & 1200 & 0.22 & \\
\hline 29 & $1 / 6 / 2014$ & WG1-9 & 300 & 309 & 0 & 1000 & 463.582 & 462.677 & 17.03 & 19.70 & 2.03E-07 & 0.40 & 0.60 & 2 & 1200 & 0.22 & \\
\hline 30 & $1 / 6 / 2014$ & WG1-9 & 300 & 314 & 0 & 1100 & 462.139 & 455.456 & 20.09 & 22.92 & $1.42 \mathrm{E}-06$ & 0.71 & 2.15 & 2 & 1200 & 0.22 & \\
\hline 31 & $1 / 7 / 2014$ & WG1-10 & 15 & 15 & 0 & 800 & 466.664 & 466.628 & 4.71 & 7.28 & $8.34 \mathrm{E}-09$ & 0.18 & 0.19 & 2 & 1200 & 0.16 & \\
\hline 32 & $1 / 7 / 2014$ & WG1-10 & 15 & 15 & 0 & 850 & 466.571 & 466.5 & 7.81 & 10.41 & $1.63 \mathrm{E}-08$ & 0.20 & 0.22 & 2 & 1200 & 0.16 & \\
\hline 33 & $1 / 7 / 2014$ & WG1-10 & 15 & 15 & 0 & 900 & 466.44 & 466.348 & 10.85 & 13.51 & 2.06E-08 & 0.23 & 0.25 & 2 & 1200 & 0.16 & \\
\hline 34 & $1 / 7 / 2014$ & WG1-10 & 15 & 15 & 0 & 950 & 466.279 & 466.141 & 13.95 & 16.63 & 3.07E-08 & 0.27 & 0.29 & 2 & 1200 & 0.16 & \\
\hline 35 & $1 / 7 / 2014$ & WG1-10 & 15 & 15 & 0 & 1000 & 466.07 & 465.81 & 16.91 & 19.70 & $5.55 \mathrm{E}-08$ & 0.31 & 0.37 & 2 & 1200 & 0.16 & \\
\hline
\end{tabular}




\begin{tabular}{|c|c|c|c|c|c|c|c|c|c|c|c|c|c|c|c|c|c|}
\hline \multirow{3}{*}{$\begin{array}{c}\text { Exp data } \\
\text { number }\end{array}$} & \multirow[b]{3}{*}{ Test Date } & \multirow[b]{3}{*}{ Specimen ID } & \multirow{2}{*}{\multicolumn{2}{|c|}{ H2O Pressure }} & \multirow{3}{*}{$\begin{array}{c}\mathrm{H} 2 \\
\text { Pressure } \\
\end{array}$} & \multirow{3}{*}{$\begin{array}{c}\text { Temperat } \\
\text { ure }\end{array}$} & \multirow{2}{*}{\multicolumn{2}{|c|}{ Weight }} & \multirow{2}{*}{\multicolumn{2}{|c|}{ Time in the test }} & \multirow[b]{3}{*}{ Rate } & \multirow{2}{*}{\multicolumn{2}{|c|}{ Weight loss \% }} & \multirow{2}{*}{\multicolumn{2}{|c|}{ Sample preparaton }} & \multirow{3}{*}{$\begin{array}{l}\text { Wt loss in } \\
\text { outgassing }\end{array}$} & \multirow[b]{3}{*}{ Notes } \\
\hline & & & & & & & & & & & & & & & & & \\
\hline & & & target & actual $^{\&}$ & & & before & after & before & after & & before & after & duration & temperature & & \\
\hline & & & $\mathrm{Pa}$ & $\mathrm{Pa}$ & $\mathrm{Pa}$ & $\mathrm{OC}$ & $\mathrm{mg}$ & $\mathrm{mg}$ & $\mathrm{hr}$ & $\mathrm{hr}$ & $\mathrm{s}^{-1}$ & $\%$ & $\%$ & $\mathrm{~h}$ & ${ }^{\circ} \mathrm{C}$ & $\mathrm{mg}$ & \\
\hline 36 & $1 / 7 / 2014$ & WG1-10 & 15 & 15 & 0 & 1100 & 465.629 & 464.813 & 20.07 & 22.86 & $1.74 \mathrm{E}-07$ & 0.40 & 0.58 & 2 & 1200 & 0.16 & \\
\hline 37 & $1 / 8 / 2014$ & WG1-11 & 30 & 30 & 0 & 800 & 464.557 & 464.518 & 4.63 & 7.45 & 8.27E-09 & 0.18 & 0.19 & 2 & 1200 & 0.14 & \\
\hline 38 & $1 / 8 / 2014$ & WG1-11 & 30 & 30 & 0 & 850 & 464.465 & 464.398 & 7.73 & 10.49 & $1.45 \mathrm{E}-08$ & 0.20 & 0.21 & 2 & 1200 & 0.14 & \\
\hline 39 & $1 / 8 / 2014$ & WG1-11 & 30 & 32 & 0 & 900 & 464.339 & 464.234 & 10.80 & 13.64 & $2.21 \mathrm{E}-08$ & 0.23 & 0.25 & 2 & 1200 & 0.14 & \\
\hline 40 & $1 / 8 / 2014$ & WG1-11 & 30 & 32 & 0 & 950 & 464.176 & 464.012 & 13.81 & 16.66 & 3.44E-08 & 0.26 & 0.30 & 2 & 1200 & 0.14 & \\
\hline 41 & $1 / 8 / 2014$ & WG1-11 & 30 & 32 & 0 & 1000 & 463.939 & 463.613 & 16.88 & 19.73 & $6.85 \mathrm{E}-08$ & 0.31 & 0.38 & 2 & 1200 & 0.14 & \\
\hline 42 & $1 / 8 / 2014$ & WG1-11 & 30 & 32 & 0 & 1100 & 463.406 & 462.082 & 20.07 & 22.91 & $2.79 \mathrm{E}-07$ & 0.43 & 0.71 & 2 & 1200 & 0.14 & \\
\hline 44 & $1 / 9 / 2014$ & WG1-12 & 15 & 15 & 0 & 850 & 463.261 & 463.181 & 7.87 & 10.46 & $1.85 \mathrm{E}-08$ & 0.20 & 0.22 & 2 & 1200 & 0.14 & \\
\hline 45 & $1 / 9 / 2014$ & WG1-12 & 15 & 15 & 0 & 900 & 463.123 & 463.021 & 10.77 & 13.62 & $2.15 \mathrm{E}-08$ & 0.23 & 0.26 & 2 & 1200 & 0.14 & \\
\hline 46 & $1 / 9 / 2014$ & WG1-12 & 15 & 15 & 0 & 950 & 462.956 & 462.812 & 13.90 & 16.52 & 3.30E-08 & 0.27 & 0.30 & 2 & 1200 & 0.14 & \\
\hline 47 & $1 / 9 / 2014$ & WG1-12 & 15 & 15 & 0 & 1000 & 462.727 & 462.455 & 16.94 & 19.70 & $5.92 \mathrm{E}-08$ & 0.32 & 0.38 & 2 & 1200 & 0.14 & \\
\hline 48 & $1 / 9 / 2014$ & WG1-12 & 15 & 16 & 0 & 1100 & 462.185 & 461.413 & 20.34 & 22.89 & $1.82 \mathrm{E}-07$ & 0.44 & 0.60 & 2 & 1200 & 0.14 & \\
\hline 49 & $1 / 13 / 2014$ & WG1-13 & 50 & 49 & 0 & 800 & 468.56 & 468.515 & 4.54 & 7.47 & $9.10 \mathrm{E}-09$ & 0.20 & 0.21 & 2 & 1200 & 0.16 & \\
\hline 50 & $1 / 13 / 2014$ & WG1-13 & 50 & 49 & 0 & 850 & 468.461 & 468.393 & 7.67 & 10.46 & 1.45E-08 & 0.22 & 0.24 & 2 & 1200 & 0.16 & \\
\hline 51 & $1 / 13 / 2014$ & WG1-13 & 50 & 49 & 0 & 900 & 468.334 & 468.224 & 10.74 & 13.56 & $2.31 \mathrm{E}-08$ & 0.25 & 0.28 & 2 & 1200 & 0.16 & \\
\hline 52 & $1 / 13 / 2014$ & WG1-13 & 50 & 49 & 0 & 950 & 468.158 & 467.956 & 13.81 & 16.66 & $4.21 \mathrm{E}-08$ & 0.29 & 0.33 & 2 & 1200 & 0.16 & \\
\hline 53 & $1 / 13 / 2014$ & WG1-13 & 50 & 49 & 0 & 1000 & 467.881 & 467.458 & 16.86 & 19.76 & 8.66E-08 & 0.35 & 0.44 & 2 & 1200 & 0.16 & \\
\hline 54 & $1 / 13 / 2014$ & WG1-13 & 50 & 49 & 0 & 1100 & 467.205 & 465.372 & 20.09 & 22.89 & $3.89 \mathrm{E}-07$ & 0.49 & 0.88 & 2 & 1200 & 0.16 & \\
\hline 55 & $1 / 14 / 2014$ & WG1-14 & 150 & 149 & 0 & 800 & 471.241 & 471.21 & 4.82 & 7.39 & 7.11E-09 & 0.18 & 0.19 & 2 & 1200 & 0.15 & \\
\hline 56 & $1 / 14 / 2014$ & WG1-14 & 150 & 150 & 0 & 850 & 471.156 & 471.062 & 7.67 & 10.43 & $2.01 \mathrm{E}-08$ & 0.20 & 0.22 & 2 & 1200 & 0.15 & \\
\hline 57 & $1 / 14 / 2014$ & WG1-14 & 150 & 152 & 0 & 900 & 470.999 & 470.845 & 10.74 & 13.56 & $3.22 \mathrm{E}-08$ & 0.23 & 0.26 & 2 & 1200 & 0.15 & \\
\hline 58 & $1 / 14 / 2014$ & WG1-14 & 150 & 155 & 0 & 950 & 470.771 & 470.485 & 13.84 & 16.60 & $6.11 \mathrm{E}-08$ & 0.28 & 0.34 & 2 & 1200 & 0.15 & \\
\hline 59 & $1 / 14 / 2014$ & WG1-14 & 150 & 158 & 0 & 1000 & 470.358 & 469.646 & 16.99 & 19.73 & $1.53 \mathrm{E}-07$ & 0.37 & 0.52 & 2 & 1200 & 0.15 & \\
\hline 60 & $1 / 14 / 2014$ & WG1-14 & 150 & 160 & 0 & 1100 & 469.237 & 465.093 & 20.09 & 22.86 & 8.86E-07 & 0.60 & 1.48 & 2 & 1200 & 0.15 & \\
\hline 61 & $1 / 15 / 2014$ & WG1-15 & 300 & 304 & 0 & 800 & 464.077 & 464.053 & 4.36 & 7.28 & 4.92E-09 & 0.19 & 0.19 & 2 & 1200 & 0.15 & \\
\hline 62 & $1 / 15 / 2014$ & WG1-15 & 300 & 306 & 0 & 850 & 463.994 & 463.914 & 7.75 & 10.45 & 1.77E-08 & 0.21 & 0.22 & 2 & 1200 & 0.15 & \\
\hline 63 & $1 / 15 / 2014$ & WG1-15 & 300 & 306 & 0 & 900 & 463.846 & 463.726 & 10.89 & 13.51 & $2.74 \mathrm{E}-08$ & 0.24 & 0.26 & 2 & 1200 & 0.15 & \\
\hline 64 & $1 / 15 / 2014$ & WG1-15 & 300 & 310 & 0 & 950 & 463.648 & 463.337 & 13.84 & 16.60 & $6.75 \mathrm{E}-08$ & 0.28 & 0.35 & 2 & 1200 & 0.15 & \\
\hline 65 & $1 / 15 / 2014$ & WG1-15 & 300 & 316 & 0 & 1000 & 463.207 & 462.319 & 16.96 & 19.77 & 1.90E-07 & 0.37 & 0.57 & 2 & 1200 & 0.15 & \\
\hline 66 & $1 / 15 / 2014$ & WG1-15 & 300 & 327 & 0 & 1100 & 461.341 & 456.033 & 20.37 & 22.88 & 1.27E-06 & 0.78 & 1.92 & 2 & 1200 & 0.15 & \\
\hline 67 & $1 / 16 / 2014$ & WG1-16 & 100 & 101 & 0 & 800 & 468.502 & 468.471 & 4.60 & 7.34 & $6.71 \mathrm{E}-09$ & 0.19 & 0.20 & 2 & 1200 & 0.16 & \\
\hline 68 & $1 / 16 / 2014$ & WG1-16 & 100 & 101 & 0 & 850 & 468.417 & 468.344 & 7.61 & 10.49 & $1.50 \mathrm{E}-08$ & 0.21 & 0.22 & 2 & 1200 & 0.16 & \\
\hline 69 & $1 / 16 / 2014$ & WG1-16 & 100 & 61 & 0 & 900 & 468.286 & 468.177 & 10.74 & 13.56 & 2.29E-08 & 0.24 & 0.26 & 2 & 1200 & 0.16 & \\
\hline 70 & $1 / 16 / 2014$ & WG1-16 & 100 & 60 & 0 & 950 & 468.109 & 467.901 & 13.81 & 16.63 & $4.38 \mathrm{E}-08$ & 0.28 & 0.32 & 2 & 1200 & 0.16 & \\
\hline 71 & 1/16/2014 & WG1-16 & 100 & 60 & 0 & 1000 & 467.825 & 467.375 & 16.86 & 19.73 & 9.31E-08 & 0.34 & 0.43 & 2 & 1200 & 0.16 & \\
\hline 72 & $1 / 16 / 2014$ & WG1-16 & 100 & 60 & 0 & 1100 & 467.09 & 465.026 & 20.12 & 22.91 & 4.40E-07 & 0.49 & 0.93 & 2 & 1200 & 0.16 & \\
\hline 73 & $1 / 21 / 2014$ & AG3-1 & 50 & 51 & 0 & 800 & 437.532 & 437.501 & 4.82 & 7.39 & 7.66E-09 & 0.22 & 0.23 & 2 & 1200 & 0.19 & \\
\hline 74 & $1 / 21 / 2014$ & AG3-1 & 50 & 51 & 0 & 850 & 437.447 & 437.384 & 7.73 & 10.52 & $1.43 \mathrm{E}-08$ & 0.24 & 0.25 & 2 & 1200 & 0.19 & \\
\hline 75 & $1 / 21 / 2014$ & AG3-1 & 50 & 51 & 0 & 900 & 437.327 & 437.226 & 10.77 & 13.56 & 2.30E-08 & 0.27 & 0.29 & 2 & 1200 & 0.19 & \\
\hline 76 & $1 / 21 / 2014$ & AG3-1 & 50 & 51 & 0 & 950 & 437.166 & 436.967 & 13.76 & 16.63 & $4.41 \mathrm{E}-08$ & 0.30 & 0.35 & 2 & 1200 & 0.19 & \\
\hline
\end{tabular}




\begin{tabular}{|c|c|c|c|c|c|c|c|c|c|c|c|c|c|c|c|c|c|}
\hline \multirow{3}{*}{$\begin{array}{c}\text { Exp data } \\
\text { number }\end{array}$} & \multirow[b]{3}{*}{ Test Date } & \multirow[b]{3}{*}{ Specimen ID } & \multirow{2}{*}{\multicolumn{2}{|c|}{ H2O Pressure }} & \multirow{3}{*}{$\begin{array}{c}\mathrm{H} 2 \\
\text { Pressure } \\
\end{array}$} & \multirow{3}{*}{$\begin{array}{c}\text { Temperat } \\
\text { ure }\end{array}$} & \multirow{2}{*}{\multicolumn{2}{|c|}{ Weight }} & \multirow{2}{*}{\multicolumn{2}{|c|}{ Time in the test }} & \multirow[b]{3}{*}{ Rate } & \multirow{2}{*}{\multicolumn{2}{|c|}{ Weight loss \% }} & \multirow{2}{*}{\multicolumn{2}{|c|}{ Sample preparaton }} & \multirow{3}{*}{$\begin{array}{l}\text { Wt loss in } \\
\text { outgassing }\end{array}$} & \multirow[b]{3}{*}{ Notes } \\
\hline & & & & & & & & & & & & & & & & & \\
\hline & & & target & actual $^{\&}$ & & & before & after & before & after & & before & after & duration & temperature & & \\
\hline & & & $\mathrm{Pa}$ & $\mathrm{Pa}$ & $\mathrm{Pa}$ & $\mathrm{OC}$ & $\mathrm{mg}$ & $\mathrm{mg}$ & $\mathrm{hr}$ & $\mathrm{hr}$ & $\mathrm{s}^{-1}$ & $\%$ & $\%$ & $\mathrm{~h}$ & ${ }^{\circ} \mathrm{C}$ & $\mathrm{mg}$ & \\
\hline 77 & $1 / 21 / 2014$ & AG3-1 & 50 & 51 & 0 & 1000 & 436.877 & 436.445 & 16.94 & 19.70 & 9.95E-08 & 0.37 & 0.47 & 2 & 1200 & 0.19 & \\
\hline 78 & $1 / 21 / 2014$ & AG3-1 & 50 & 50 & 0 & 1100 & 436.103 & 434.047 & 20.21 & 22.91 & $4.85 \mathrm{E}-07$ & 0.54 & 1.01 & 2 & 1200 & 0.19 & \\
\hline 79 & $1 / 22 / 2014$ & AG3-2 & 30 & 31 & 0 & 800 & 461.685 & 461.629 & 4.79 & 7.47 & $1.26 \mathrm{E}-08$ & 0.18 & 0.19 & 2 & 1200 & 0.13 & \\
\hline 80 & $1 / 22 / 2014$ & AG3-2 & 30 & 32 & 0 & 850 & 461.578 & 461.513 & 7.70 & 10.52 & $1.39 \mathrm{E}-08$ & 0.20 & 0.22 & 2 & 1200 & 0.13 & \\
\hline 81 & $1 / 22 / 2014$ & AG3-2 & 30 & 32 & 0 & 900 & 461.436 & 461.355 & 10.80 & 13.56 & 1.77E-08 & 0.23 & 0.25 & 2 & 1200 & 0.13 & \\
\hline 82 & $1 / 22 / 2014$ & AG3-2 & 30 & 31 & 0 & 950 & 461.296 & 461.113 & 13.76 & 16.69 & $3.76 \mathrm{E}-08$ & 0.26 & 0.30 & 2 & 1200 & 0.13 & \\
\hline 83 & $1 / 22 / 2014$ & AG3-2 & 30 & 32 & 0 & 1000 & 461.038 & 460.649 & 16.91 & 19.76 & $8.22 \mathrm{E}-08$ & 0.32 & 0.40 & 2 & 1200 & 0.13 & \\
\hline 84 & $1 / 22 / 2014$ & AG3-2 & 30 & 32 & 0 & 1100 & 460.432 & 458.989 & 20.07 & 22.91 & 3.07E-07 & 0.45 & 0.76 & 2 & 1200 & 0.13 & \\
\hline 85 & $1 / 23 / 2014$ & AG3-3 & 15 & 16 & 0 & 800 & 464.874 & 464.831 & 4.61 & 7.34 & $9.41 \mathrm{E}-09$ & 0.18 & 0.19 & 2 & 1200 & 0.13 & \\
\hline 86 & $1 / 23 / 2014$ & AG3-3 & 15 & 16 & 0 & 850 & 464.774 & 464.714 & 7.71 & 10.56 & $1.26 \mathrm{E}-08$ & 0.20 & 0.21 & 2 & 1200 & 0.13 & \\
\hline 87 & $1 / 23 / 2014$ & AG3-3 & 15 & 16 & 0 & 900 & 464.659 & 464.573 & 10.77 & 13.59 & $1.82 \mathrm{E}-08$ & 0.22 & 0.24 & 2 & 1200 & 0.13 & \\
\hline 88 & $1 / 23 / 2014$ & AG3-3 & 15 & 16 & 0 & 950 & 464.511 & 464.381 & 13.86 & 16.68 & $2.76 \mathrm{E}-08$ & 0.26 & 0.28 & 2 & 1200 & 0.13 & \\
\hline 89 & $1 / 23 / 2014$ & AG3-3 & 15 & 16 & 0 & 1000 & 464.311 & 464.053 & 16.91 & 19.70 & $5.53 \mathrm{E}-08$ & 0.30 & 0.35 & 2 & 1200 & 0.13 & \\
\hline 90 & $1 / 23 / 2014$ & AG3-3 & 15 & 16 & 0 & 1100 & 463.865 & 463.312 & 20.10 & 22.16 & $1.61 \mathrm{E}-07$ & 0.39 & 0.51 & 2 & 1200 & 0.13 & \\
\hline 91 & $1 / 24 / 2014$ & AG3-4 & 100 & 102 & 0 & 800 & 469.193 & 469.17 & 5.49 & 7.39 & 7.17E-09 & 0.18 & 0.19 & 2 & 1200 & 0.12 & \\
\hline 92 & $1 / 24 / 2014$ & AG3-4 & 100 & 102 & 0 & 850 & 469.117 & 469.058 & 7.76 & 10.52 & 1.27E-08 & 0.20 & 0.21 & 2 & 1200 & 0.12 & \\
\hline 93 & $1 / 24 / 2014$ & AG3-4 & 100 & 102 & 0 & 900 & 468.994 & 468.883 & 10.91 & 13.56 & $2.48 \mathrm{E}-08$ & 0.23 & 0.25 & 2 & 1200 & 0.12 & \\
\hline 94 & $1 / 24 / 2014$ & AG3-4 & 100 & 102 & 0 & 950 & 468.812 & 468.577 & 13.87 & 16.69 & 4.94E-08 & 0.26 & 0.31 & 2 & 1200 & 0.12 & \\
\hline 95 & $1 / 24 / 2014$ & AG3-4 & 100 & 102 & 0 & 1000 & 468.489 & 467.919 & 16.91 & 19.76 & 1.19E-07 & 0.33 & 0.45 & 2 & 1200 & 0.12 & \\
\hline 96 & $1 / 24 / 2014$ & AG3-4 & 100 & 101 & 0 & 1100 & 467.573 & 464.765 & 20.12 & 22.89 & $6.02 \mathrm{E}-07$ & 0.53 & 1.12 & 2 & 1200 & 0.12 & \\
\hline 97 & $1 / 27 / 2014$ & AG3-5 & 300 & 299 & 0 & 800 & 453.06 & 453.005 & 4.77 & 7.38 & $1.29 \mathrm{E}-08$ & 0.20 & 0.22 & 2 & 1200 & 0.20 & \\
\hline 98 & $1 / 27 / 2014$ & AG3-5 & 300 & 302 & 0 & 850 & 452.941 & 452.858 & 7.86 & 10.44 & 1.97E-08 & 0.23 & 0.25 & 2 & 1200 & 0.20 & \\
\hline 99 & $1 / 27 / 2014$ & AG3-5 & 300 & 303 & 0 & 900 & 452.797 & 452.651 & 10.74 & 13.55 & 3.19E-08 & 0.26 & 0.29 & 2 & 1200 & 0.20 & \\
\hline 100 & $1 / 27 / 2014$ & AG3-5 & 300 & 306 & 0 & 950 & 452.579 & 452.211 & 13.80 & 16.67 & 7.87E-08 & 0.31 & 0.39 & 2 & 1200 & 0.20 & \\
\hline 101 & $1 / 27 / 2014$ & AG3-5 & 300 & 308 & 0 & 1000 & 452.083 & 450.983 & 16.94 & 19.78 & $2.38 \mathrm{E}-07$ & 0.42 & 0.66 & 2 & 1200 & 0.20 & \\
\hline 102 & $1 / 27 / 2014$ & AG3-5 & 300 & 310 & 0 & 1100 & 450.657 & 442.425 & 19.98 & 22.86 & 1.76E-06 & 0.73 & 2.55 & 2 & 1200 & 0.20 & \\
\hline 103 & $1 / 28 / 2014$ & AG3-6 & 150 & 150 & 0 & 800 & 463.513 & 463.468 & 4.63 & 7.39 & 9.77E-09 & 0.19 & 0.20 & 2 & 1200 & 0.15 & \\
\hline 104 & $1 / 28 / 2014$ & AG3-6 & 150 & 150 & 0 & 850 & 463.416 & 463.346 & 7.61 & 10.46 & 1.47E-08 & 0.21 & 0.22 & 2 & 1200 & 0.15 & \\
\hline 105 & $1 / 28 / 2014$ & AG3-6 & 150 & 151 & 0 & 900 & 463.289 & 463.175 & 10.74 & 13.51 & 2.47E-08 & 0.23 & 0.26 & 2 & 1200 & 0.15 & \\
\hline 106 & $1 / 28 / 2014$ & AG3-6 & 150 & 151 & 0 & 950 & 463.107 & 462.841 & 13.78 & 16.66 & $5.54 \mathrm{E}-08$ & 0.27 & 0.33 & 2 & 1200 & 0.15 & \\
\hline 107 & $1 / 28 / 2014$ & AG3-6 & 150 & 151 & 0 & 1000 & 462.763 & 462.042 & 16.83 & 19.81 & $1.45 \mathrm{E}-07$ & 0.35 & 0.50 & 2 & 1200 & 0.15 & \\
\hline 108 & $1 / 28 / 2014$ & AG3-6 & 150 & 151 & 0 & 1100 & 461.647 & 457.782 & 20.12 & 22.91 & $8.34 \mathrm{E}-07$ & 0.59 & 1.42 & 2 & 1200 & 0.15 & \\
\hline 109 & $2 / 5 / 2014$ & AG3-7 & 300 & 305 & 0 & 800 & 463.67 & 463.623 & 4.33 & 7.34 & 9.35E-09 & 0.20 & 0.21 & 2 & 1200 & 0.16 & \\
\hline 110 & $2 / 5 / 2014$ & AG3-7 & 300 & 306 & 0 & 850 & 463.565 & 463.484 & 7.67 & 10.43 & $1.76 \mathrm{E}-08$ & 0.22 & 0.24 & 2 & 1200 & 0.16 & \\
\hline 111 & $2 / 5 / 2014$ & AG3-7 & 300 & 306 & 0 & 900 & 463.42 & 463.286 & 10.81 & 13.54 & 2.94E-08 & 0.25 & 0.28 & 2 & 1200 & 0.16 & \\
\hline 112 & $2 / 5 / 2014$ & AG3-7 & 300 & 306 & 0 & 950 & 463.206 & 462.891 & 13.87 & 16.63 & $6.84 \mathrm{E}-08$ & 0.30 & 0.36 & 2 & 1200 & 0.16 & \\
\hline 113 & $2 / 5 / 2014$ & AG3-7 & 300 & 305 & 0 & 1000 & 462.783 & 461.878 & 16.90 & 19.79 & $1.88 \mathrm{E}-07$ & 0.39 & 0.58 & 2 & 1200 & 0.16 & \\
\hline 114 & $2 / 5 / 2014$ & AG3-7 & 300 & 307 & 0 & 1100 & 461.696 & 455.617 & 19.93 & 22.77 & $1.29 \mathrm{E}-06$ & 0.62 & 1.93 & 2 & 1200 & 0.16 & \\
\hline 115 & $2 / 6 / 2014$ & AG3-8 & 150 & 150 & 0 & 800 & 461.912 & 461.838 & 4.88 & 7.34 & $1.81 \mathrm{E}-08$ & 0.20 & 0.22 & 2 & 1200 & 0.20 & \\
\hline 116 & $2 / 6 / 2014$ & AG3-8 & 150 & 152 & 0 & 850 & 461.778 & 461.666 & 7.70 & 10.46 & 2.44E-08 & 0.23 & 0.25 & 2 & 1200 & 0.20 & \\
\hline
\end{tabular}




\begin{tabular}{|c|c|c|c|c|c|c|c|c|c|c|c|c|c|c|c|c|c|}
\hline \multirow{3}{*}{$\begin{array}{c}\text { Exp data } \\
\text { number }\end{array}$} & \multirow[b]{3}{*}{ Test Date } & \multirow[b]{3}{*}{ Specimen ID } & \multirow{2}{*}{\multicolumn{2}{|c|}{ H2O Pressure }} & \multirow{3}{*}{$\begin{array}{c}\mathrm{H} 2 \\
\text { Pressure } \\
\end{array}$} & \multirow{3}{*}{$\begin{array}{c}\text { Temperat } \\
\text { ure }\end{array}$} & \multirow{2}{*}{\multicolumn{2}{|c|}{ Weight }} & \multirow{2}{*}{\multicolumn{2}{|c|}{ Time in the test }} & \multirow[b]{3}{*}{ Rate } & \multirow{2}{*}{\multicolumn{2}{|c|}{ Weight loss \% }} & \multirow{2}{*}{\multicolumn{2}{|c|}{ Sample preparaton }} & \multirow{3}{*}{$\begin{array}{l}\text { Wt loss in } \\
\text { outgassing }\end{array}$} & \multirow[b]{3}{*}{ Notes } \\
\hline & & & & & & & & & & & & & & & & & \\
\hline & & & target & actual $^{\&}$ & & & before & after & before & after & & before & after & duration & temperature & & \\
\hline & & & $\mathrm{Pa}$ & $\mathrm{Pa}$ & $\mathrm{Pa}$ & $\mathrm{OC}$ & $\mathrm{mg}$ & $\mathrm{mg}$ & $\mathrm{hr}$ & $\mathrm{hr}$ & $\mathrm{s}^{-1}$ & $\%$ & $\%$ & $\mathrm{~h}$ & ${ }^{\circ} \mathrm{C}$ & $\mathrm{mg}$ & \\
\hline 117 & $2 / 6 / 2014$ & AG3-8 & 150 & 151 & 0 & 900 & 461.601 & 461.432 & 10.77 & 13.56 & 3.65E-08 & 0.27 & 0.30 & 2 & 1200 & 0.20 & \\
\hline 118 & $2 / 6 / 2014$ & AG3-8 & 150 & 152 & 0 & 950 & 461.353 & 461.04 & 13.87 & 16.60 & $6.90 \mathrm{E}-08$ & 0.32 & 0.39 & 2 & 1200 & 0.20 & \\
\hline 119 & $2 / 6 / 2014$ & AG3-8 & 150 & 151 & 0 & 1000 & 460.937 & 460.182 & 16.88 & 19.68 & $1.62 \mathrm{E}-07$ & 0.41 & 0.57 & 2 & 1200 & 0.20 & \\
\hline 120 & $2 / 6 / 2014$ & AG3-8 & 150 & 152 & 0 & 1100 & 459.642 & 455.378 & 20.18 & 22.91 & $9.44 \mathrm{E}-07$ & 0.69 & 1.61 & 2 & 1200 & 0.20 & \\
\hline 121 & $2 / 10 / 2014$ & AG3-9 & 15 & 15 & 0 & 800 & 460.261 & 460.211 & 5.35 & 7.34 & $1.52 \mathrm{E}-08$ & 0.25 & 0.26 & 2 & 1200 & 0.32 & \\
\hline 122 & $2 / 10 / 2014$ & AG3-9 & 15 & 15 & 0 & 850 & 460.149 & 460.049 & 7.70 & 10.52 & $2.14 \mathrm{E}-08$ & 0.27 & 0.29 & 2 & 1200 & 0.32 & \\
\hline 123 & $2 / 10 / 2014$ & AG3-9 & 15 & 15 & 0 & 900 & 459.986 & 459.846 & 10.80 & 13.53 & $3.10 \mathrm{E}-08$ & 0.31 & 0.34 & 2 & 1200 & 0.32 & \\
\hline 124 & $2 / 10 / 2014$ & AG3-9 & 15 & 15 & 0 & 950 & 459.777 & 459.533 & 13.78 & 16.74 & $4.98 \mathrm{E}-08$ & 0.35 & 0.40 & 2 & 1200 & 0.32 & \\
\hline 125 & $2 / 10 / 2014$ & AG3-9 & 15 & 15 & 0 & 1000 & 459.462 & 459.092 & 16.97 & 19.73 & 8.10E-08 & 0.42 & 0.50 & 2 & 1200 & 0.32 & \\
\hline 126 & $2 / 10 / 2014$ & AG3-9 & 15 & 15 & 0 & 1100 & 458.882 & 457.906 & 20.09 & 22.89 & $2.11 \mathrm{E}-07$ & 0.55 & 0.76 & 2 & 1200 & 0.32 & \\
\hline 127 & $2 / 11 / 2014$ & AG3-10 & 30 & 31 & 0 & 800 & 462.401 & 462.351 & 4.52 & 7.31 & $1.08 \mathrm{E}-08$ & 0.18 & 0.19 & 2 & 1200 & 0.14 & \\
\hline 128 & $2 / 11 / 2014$ & AG3-10 & 30 & 31 & 0 & 850 & 462.288 & 462.166 & 7.76 & 10.49 & 2.69E-08 & 0.20 & 0.23 & 2 & 1200 & 0.14 & \\
\hline 129 & $2 / 11 / 2014$ & AG3-10 & 30 & 31 & 0 & 900 & 462.106 & 461.963 & 10.77 & 13.56 & $3.08 \mathrm{E}-08$ & 0.24 & 0.27 & 2 & 1200 & 0.14 & \\
\hline 130 & 2/11/2014 & AG3-10 & 30 & 31 & 0 & 950 & 461.896 & 461.687 & 13.81 & 16.69 & 4.36E-08 & 0.29 & 0.33 & 2 & 1200 & 0.14 & \\
\hline 131 & 2/11/2014 & AG3-10 & 30 & 31 & 0 & 1000 & 461.613 & 461.259 & 16.88 & 19.76 & 7.40E-08 & 0.35 & 0.42 & 2 & 1200 & 0.14 & \\
\hline 132 & 2/11/2014 & AG3-10 & 30 & 31 & 0 & 1100 & 461.047 & 459.807 & 20.09 & 22.94 & $2.62 \mathrm{E}-07$ & 0.47 & 0.74 & 2 & 1200 & 0.14 & \\
\hline 133 & $2 / 14 / 2014$ & AG3-11 & 50 & 51 & 0 & 800 & 463.228 & 463.159 & 4.77 & 7.42 & $1.56 \mathrm{E}-08$ & 0.22 & 0.23 & 2 & 1200 & 0.20 & \\
\hline 134 & $2 / 14 / 2014$ & AG3-11 & 50 & 51 & 0 & 850 & 463.099 & 463.003 & 7.76 & 10.41 & 2.17E-08 & 0.24 & 0.26 & 2 & 1200 & 0.20 & \\
\hline 135 & $2 / 14 / 2014$ & AG3-11 & 50 & 51 & 0 & 900 & 462.932 & 462.8 & 10.88 & 13.51 & 3.01E-08 & 0.28 & 0.31 & 2 & 1200 & 0.20 & \\
\hline 136 & $2 / 14 / 2014$ & AG3-11 & 50 & 50 & 0 & 950 & 462.723 & 462.472 & 13.84 & 16.60 & $5.46 \mathrm{E}-08$ & 0.33 & 0.38 & 2 & 1200 & 0.20 & \\
\hline 137 & $2 / 14 / 2014$ & AG3-11 & 50 & 48 & 0 & 1000 & 462.379 & 461.866 & 16.88 & 19.68 & 1.10E-07 & 0.40 & 0.51 & 2 & 1200 & 0.20 & \\
\hline 138 & $2 / 14 / 2014$ & AG3-11 & 50 & 50 & 0 & 1100 & 461.565 & 459.353 & 20.09 & 22.91 & $4.72 \mathrm{E}-07$ & 0.57 & 1.05 & 2 & 1200 & 0.20 & \\
\hline 139 & $2 / 15 / 2014$ & AG3-12 & 100 & 105 & 0 & 800 & 456.892 & 456.821 & 4.24 & 7.39 & 1.37E-08 & 0.19 & 0.21 & 2 & 1200 & 0.20 & \\
\hline 140 & $2 / 15 / 2014$ & AG3-12 & 100 & 102 & 0 & 850 & 456.767 & 456.665 & 7.64 & 10.49 & $2.18 \mathrm{E}-08$ & 0.22 & 0.24 & 2 & 1200 & 0.20 & \\
\hline 141 & $2 / 15 / 2014$ & AG3-12 & 100 & 102 & 0 & 900 & 456.603 & 456.445 & 10.74 & 13.62 & $3.34 \mathrm{E}-08$ & 0.26 & 0.29 & 2 & 1200 & 0.20 & \\
\hline 142 & $2 / 15 / 2014$ & AG3-12 & 100 & 102 & 0 & 950 & 456.373 & 456.093 & 13.84 & 16.69 & $5.98 \mathrm{E}-08$ & 0.31 & 0.37 & 2 & 1200 & 0.20 & \\
\hline 143 & $2 / 15 / 2014$ & AG3-12 & 100 & 102 & 0 & 1000 & 455.999 & 455.387 & 16.91 & 19.68 & $1.35 \mathrm{E}-07$ & 0.39 & 0.52 & 2 & 1200 & 0.20 & \\
\hline 144 & $2 / 15 / 2014$ & AG3-12 & 100 & 101 & 0 & 1100 & 454.91 & 451.662 & 20.21 & 22.94 & 7.26E-07 & 0.63 & 1.34 & 2 & 1200 & 0.20 & \\
\hline 145 & 2/16/2014 & AG3-13 & 3 & 3 & 0 & 800 & 441.532 & 441.472 & 4.04 & 7.39 & 1.13E-08 & 0.22 & 0.23 & 2 & 1200 & 0.15 & \\
\hline 146 & $2 / 16 / 2014$ & AG3-13 & 3 & 3 & 0 & 850 & 441.414 & 441.273 & 7.61 & 10.49 & $3.08 \mathrm{E}-08$ & 0.25 & 0.28 & 2 & 1200 & 0.15 & \\
\hline 147 & $2 / 16 / 2014$ & AG3-13 & 3 & 3 & 0 & 900 & 441.207 & 441.06 & 10.74 & 13.56 & $3.28 \mathrm{E}-08$ & 0.29 & 0.33 & 2 & 1200 & 0.15 & \\
\hline 148 & $2 / 16 / 2014$ & AG3-13 & 3 & 3 & 0 & 950 & 440.988 & 440.848 & 13.87 & 16.63 & 3.20E-08 & 0.34 & 0.37 & 2 & 1200 & 0.15 & \\
\hline 149 & 2/16/2014 & AG3-13 & 3 & 3 & 0 & 1000 & 440.774 & 440.6 & 16.94 & 19.76 & 3.89E-08 & 0.39 & 0.43 & 2 & 1200 & 0.15 & \\
\hline 150 & $2 / 16 / 2014$ & AG3-13 & 3 & 3 & 0 & 1100 & 440.452 & 440.148 & 20.07 & 22.94 & $6.68 \mathrm{E}-08$ & 0.46 & 0.53 & 2 & 1200 & 0.15 & \\
\hline 151 & $2 / 17 / 2014$ & AG3-14 & 3 & 3 & 0 & 800 & 464.54 & 464.468 & 4.07 & 7.36 & $1.31 \mathrm{E}-08$ & 0.18 & 0.20 & 2 & 1200 & 0.15 & \\
\hline 152 & $2 / 17 / 2014$ & AG3-14 & 3 & 3 & 0 & 850 & 464.406 & 464.291 & 7.70 & 10.52 & 2.44E-08 & 0.21 & 0.24 & 2 & 1200 & 0.15 & \\
\hline 153 & $2 / 17 / 2014$ & AG3-14 & 3 & 3 & 0 & 900 & 464.24 & 464.096 & 10.71 & 13.64 & 2.94E-08 & 0.25 & 0.28 & 2 & 1200 & 0.15 & \\
\hline 154 & $2 / 17 / 2014$ & AG3-14 & 3 & 3 & 0 & 950 & 464.033 & 463.873 & 13.81 & 16.57 & 3.47E-08 & 0.29 & 0.32 & 2 & 1200 & 0.15 & \\
\hline 155 & $2 / 17 / 2014$ & AG3-14 & 3 & 3 & 0 & 1000 & 463.795 & 463.636 & 16.91 & 19.65 & 3.48E-08 & 0.34 & 0.38 & 2 & 1200 & 0.15 & \\
\hline 156 & $2 / 17 / 2014$ & AG3-14 & 3 & 3 & 0 & 1100 & 463.477 & 463.178 & 20.07 & 22.89 & 6.35E-08 & 0.41 & 0.47 & 2 & 1200 & 0.15 & \\
\hline
\end{tabular}




\begin{tabular}{|c|c|c|c|c|c|c|c|c|c|c|c|c|c|c|c|c|c|}
\hline \multirow{3}{*}{$\begin{array}{c}\text { Exp data } \\
\text { number }\end{array}$} & \multirow[b]{3}{*}{ Test Date } & \multirow[b]{3}{*}{ Specimen ID } & \multirow{2}{*}{\multicolumn{2}{|c|}{ H2O Pressure }} & \multirow{3}{*}{$\begin{array}{c}\mathrm{H} 2 \\
\text { Pressure } \\
\end{array}$} & \multirow{3}{*}{$\begin{array}{c}\text { Temperat } \\
\text { ure }\end{array}$} & \multirow{2}{*}{\multicolumn{2}{|c|}{ Weight }} & \multirow{2}{*}{\multicolumn{2}{|c|}{ Time in the test }} & \multirow[b]{3}{*}{ Rate } & \multirow{2}{*}{\multicolumn{2}{|c|}{ Weight loss \% }} & \multirow{2}{*}{\multicolumn{2}{|c|}{ Sample preparaton }} & \multirow{3}{*}{$\begin{array}{l}\text { Wt loss in } \\
\text { outgassing }\end{array}$} & \multirow[b]{3}{*}{ Notes } \\
\hline & & & & & & & & & & & & & & & & & \\
\hline & & & target & actual $^{\&}$ & & & before & after & before & after & & before & after & duration & temperature & & \\
\hline & & & $\mathrm{Pa}$ & $\mathrm{Pa}$ & $\mathrm{Pa}$ & $\mathrm{OC}$ & $\mathrm{mg}$ & $\mathrm{mg}$ & $\mathrm{hr}$ & $\mathrm{hr}$ & $\mathrm{s}^{-1}$ & $\%$ & $\%$ & $\mathrm{~h}$ & ${ }^{\circ} \mathrm{C}$ & $\mathrm{mg}$ & \\
\hline 157 & $3 / 31 / 2014$ & AG3-22 & 15 & 24 & 0 & 800 & 454.981 & 454.911 & 4.68 & 7.42 & $1.56 \mathrm{E}-08$ & 0.22 & 0.23 & 2 & 1200 & 0.21 & \\
\hline 158 & $3 / 31 / 2014$ & AG3-22 & 15 & 23 & 0 & 850 & 454.85 & 454.772 & 7.73 & 10.49 & $1.73 \mathrm{E}-08$ & 0.25 & 0.27 & 2 & 1200 & 0.21 & \\
\hline 159 & $3 / 31 / 2014$ & AG3-22 & 15 & 22 & 0 & 900 & 454.707 & 454.595 & 10.88 & 13.62 & $2.50 \mathrm{E}-08$ & 0.28 & 0.30 & 2 & 1200 & 0.21 & \\
\hline 160 & $3 / 31 / 2014$ & AG3-22 & 15 & 21 & 0 & 950 & 454.524 & 454.33 & 13.87 & 16.63 & 4.30E-08 & 0.32 & 0.36 & 2 & 1200 & 0.21 & \\
\hline 161 & $3 / 31 / 2014$ & AG3-22 & 15 & 22 & 0 & 1000 & 454.249 & 453.891 & 16.88 & 19.76 & 7.60E-08 & 0.38 & 0.46 & 2 & 1200 & 0.21 & \\
\hline 162 & $3 / 31 / 2014$ & AG3-22 & 15 & 8 & 0 & 1100 & 453.658 & 453.042 & 20.12 & 22.91 & $1.35 \mathrm{E}-07$ & 0.51 & 0.64 & 2 & 1200 & 0.21 & \\
\hline 164 & $3 / 5 / 2014$ & AG3-15 & 30 & 15 & 26 & 850 & 462.701 & 462.703 & 7.78 & 10.43 & $-4.53 \mathrm{E}-10$ & 0.19 & 0.19 & 2 & 1200 & 0.16 & \\
\hline 165 & $3 / 5 / 2014$ & AG3-15 & 30 & 15 & 26 & 900 & 462.652 & 462.639 & 10.85 & 13.56 & $2.88 \mathrm{E}-09$ & 0.20 & 0.20 & 2 & 1200 & 0.16 & \\
\hline 166 & $3 / 5 / 2014$ & AG3-15 & 30 & 15 & 26 & 950 & 462.584 & 462.555 & 13.87 & 16.60 & $6.38 \mathrm{E}-09$ & 0.21 & 0.22 & 2 & 1200 & 0.16 & \\
\hline 167 & $3 / 5 / 2014$ & AG3-15 & 30 & 15 & 26 & 1000 & 462.494 & 462.419 & 16.97 & 19.68 & $1.66 \mathrm{E}-08$ & 0.23 & 0.25 & 2 & 1200 & 0.16 & \\
\hline 168 & $3 / 5 / 2014$ & AG3-15 & 30 & 15 & 26 & 1100 & 462.271 & 461.95 & 20.12 & 22.83 & 7.12E-08 & 0.28 & 0.35 & 2 & 1200 & 0.16 & \\
\hline 172 & $3 / 6 / 2014$ & AG3-16 & 30 & 29 & 26 & 950 & 470.614 & 470.576 & 13.98 & 16.63 & 8.46E-09 & 0.20 & 0.21 & 2 & 1200 & 0.12 & \\
\hline 173 & $3 / 6 / 2014$ & AG3-16 & 30 & 29 & 26 & 1000 & 470.51 & 470.406 & 16.99 & 19.76 & $2.22 \mathrm{E}-08$ & 0.22 & 0.25 & 2 & 1200 & 0.12 & \\
\hline 174 & $3 / 6 / 2014$ & AG3-16 & 30 & 29 & 26 & 1100 & 470.222 & 469.564 & 20.07 & 22.94 & 1.35E-07 & 0.29 & 0.42 & 2 & 1200 & 0.12 & \\
\hline 176 & 3/7/2014 & AG3-17 & 50 & 52 & 26 & 850 & 466.444 & 466.438 & 7.70 & 10.55 & $1.25 \mathrm{E}-09$ & 0.19 & 0.19 & 2 & 1200 & 0.15 & \\
\hline 177 & $3 / 7 / 2014$ & AG3-17 & 50 & 51 & 26 & 900 & 466.385 & 466.35 & 10.77 & 13.51 & 7.61E-09 & 0.21 & 0.21 & 2 & 1200 & 0.15 & \\
\hline 178 & $3 / 7 / 2014$ & AG3-17 & 50 & 51 & 26 & 950 & 466.29 & 466.215 & 13.84 & 16.69 & 1.57E-08 & 0.23 & 0.24 & 2 & 1200 & 0.15 & \\
\hline 179 & $3 / 7 / 2014$ & AG3-17 & 50 & 51 & 26 & 1000 & 466.148 & 465.958 & 16.91 & 19.76 & 3.97E-08 & 0.26 & 0.30 & 2 & 1200 & 0.15 & \\
\hline 180 & $3 / 7 / 2014$ & AG3-17 & 50 & 51 & 26 & 1100 & 465.767 & 464.757 & 20.09 & 22.84 & 2.19E-07 & 0.34 & 0.55 & 2 & 1200 & 0.15 & \\
\hline 182 & $3 / 14 / 2014$ & AG3-19 & 100 & 100 & 26 & 850 & 459.711 & 459.703 & 7.87 & 10.52 & $1.82 \mathrm{E}-09$ & 0.21 & 0.21 & 2 & 1200 & 0.22 & \\
\hline 183 & $3 / 14 / 2014$ & AG3-19 & 100 & 100 & 26 & 900 & 459.652 & 459.639 & 10.77 & 13.51 & 2.87E-09 & 0.22 & 0.22 & 2 & 1200 & 0.22 & \\
\hline 184 & $3 / 14 / 2014$ & AG3-19 & 100 & 99 & 26 & 950 & 459.575 & 459.478 & 13.95 & 16.66 & $2.16 \mathrm{E}-08$ & 0.24 & 0.26 & 2 & 1200 & 0.22 & \\
\hline 185 & $3 / 14 / 2014$ & AG3-19 & 100 & 99 & 26 & 1000 & 459.401 & 459.086 & 16.94 & 19.73 & $6.83 \mathrm{E}-08$ & 0.27 & 0.34 & 2 & 1200 & 0.22 & \\
\hline 186 & $3 / 14 / 2014$ & AG3-19 & 100 & 98 & 26 & 1100 & 458.788 & 458.109 & 20.18 & 21.24 & $3.88 \mathrm{E}-07$ & 0.41 & 0.55 & 2 & 1200 & 0.22 & \\
\hline 189 & $3 / 25 / 2014$ & AG3-20 & 150 & 152 & 26 & 900 & 452.222 & 452.195 & 10.74 & 13.51 & 5.99E-09 & 0.25 & 0.26 & 2 & 1200 & 0.22 & \\
\hline 190 & $3 / 25 / 2014$ & AG3-20 & 150 & 151 & 26 & 950 & 452.137 & 451.999 & 13.78 & 16.69 & $2.91 \mathrm{E}-08$ & 0.27 & 0.30 & 2 & 1200 & 0.22 & \\
\hline 191 & $3 / 25 / 2014$ & AG3-20 & 150 & 151 & 26 & 1000 & 451.926 & 451.421 & 16.86 & 19.79 & $1.06 \mathrm{E}-07$ & 0.32 & 0.43 & 2 & 1200 & 0.22 & \\
\hline 192 & $3 / 25 / 2014$ & AG3-20 & 150 & 151 & 26 & 1100 & 451.018 & 447.52 & 20.15 & 23.00 & 7.56E-07 & 0.52 & 1.29 & 2 & 1200 & 0.22 & \\
\hline 195 & $4 / 1 / 2014$ & WG1-17 & 100 & 103 & 26 & 900 & 466.935 & 466.924 & 10.80 & 13.58 & $2.35 \mathrm{E}-09$ & 0.22 & 0.22 & 2 & 1200 & 0.17 & \\
\hline 196 & $4 / 1 / 2014$ & WG1-17 & 100 & 102 & 26 & 950 & 466.865 & 466.77 & 13.78 & 16.63 & $1.98 \mathrm{E}-08$ & 0.23 & 0.25 & 2 & 1200 & 0.17 & \\
\hline 197 & $4 / 1 / 2014$ & WG1-17 & 100 & 103 & 26 & 1000 & 466.697 & 466.318 & 16.88 & 19.73 & 7.92E-08 & 0.27 & 0.35 & 2 & 1200 & 0.17 & \\
\hline 198 & $4 / 1 / 2014$ & WG1-17 & 100 & 103 & 26 & 1100 & 466.064 & 463.773 & 20.07 & 22.97 & $4.71 \mathrm{E}-07$ & 0.41 & 0.90 & 2 & 1200 & 0.17 & \\
\hline 201 & $4 / 2 / 2014$ & WG1-18 & 50 & 51 & 26 & 900 & 463.309 & 463.301 & 10.71 & 13.59 & 1.67E-09 & 0.22 & 0.22 & 2 & 1200 & 0.18 & \\
\hline 202 & $4 / 2 / 2014$ & WG1-18 & 50 & 52 & 26 & 950 & 463.244 & 463.173 & 13.84 & 16.69 & 1.49E-08 & 0.23 & 0.25 & 2 & 1200 & 0.18 & \\
\hline 203 & $4 / 2 / 2014$ & WG1-18 & 50 & 52 & 26 & 1000 & 463.103 & 462.838 & 16.91 & 19.79 & $5.52 \mathrm{E}-08$ & 0.27 & 0.32 & 2 & 1200 & 0.18 & \\
\hline 204 & $4 / 2 / 2014$ & WG1-18 & 50 & 52 & 26 & 1100 & 462.635 & 461.385 & 20.07 & 22.91 & 2.64E-07 & 0.37 & 0.64 & 2 & 1200 & 0.18 & \\
\hline 208 & $4 / 3 / 2014$ & WG1-19 & 30 & 30 & 26 & 950 & 463.009 & 462.969 & 13.82 & 16.64 & $8.51 \mathrm{E}-09$ & 0.23 & 0.24 & 2 & 1200 & 0.17 & \\
\hline 210 & $4 / 3 / 2014$ & WG1-19 & 30 & 30 & 26 & 1100 & 462.525 & 461.739 & 20.10 & 22.89 & 1.69E-07 & 0.33 & 0.50 & 2 & 1200 & 0.17 & \\
\hline 213 & $4 / 4 / 2014$ & WG1-20 & 150 & 150 & 26 & 900 & 464.163 & 464.149 & 10.85 & 13.56 & $3.09 \mathrm{E}-09$ & 0.21 & 0.21 & 2 & 1200 & 0.15 & \\
\hline 214 & $4 / 4 / 2014$ & WG1-20 & 150 & 150 & 26 & 950 & 464.086 & 463.955 & 13.87 & 16.63 & $2.84 \mathrm{E}-08$ & 0.23 & 0.26 & 2 & 1200 & 0.15 & \\
\hline
\end{tabular}




\begin{tabular}{|c|c|c|c|c|c|c|c|c|c|c|c|c|c|c|c|c|c|}
\hline \multirow{3}{*}{$\begin{array}{c}\text { Exp data } \\
\text { number }\end{array}$} & \multirow[b]{3}{*}{ Test Date } & \multirow[b]{3}{*}{ Specimen ID } & \multirow{2}{*}{\multicolumn{2}{|c|}{ H2O Pressure }} & \multirow{3}{*}{$\begin{array}{c}\mathrm{H} 2 \\
\text { Pressure } \\
\end{array}$} & \multirow{3}{*}{$\begin{array}{c}\text { Temperat } \\
\text { ure }\end{array}$} & \multirow{2}{*}{\multicolumn{2}{|c|}{ Weight }} & \multirow{2}{*}{\multicolumn{2}{|c|}{ Time in the test }} & \multirow[b]{3}{*}{ Rate } & \multirow{2}{*}{\multicolumn{2}{|c|}{ Weight loss \% }} & \multirow{2}{*}{\multicolumn{2}{|c|}{ Sample preparaton }} & \multirow{3}{*}{$\begin{array}{l}\text { Wt loss in } \\
\text { outgassing }\end{array}$} & \multirow[b]{3}{*}{ Notes } \\
\hline & & & & & & & & & & & & & & & & & \\
\hline & & & target & actual $^{\&}$ & & & before & after & before & after & & before & after & duration & temperature & & \\
\hline & & & $\mathrm{Pa}$ & $\mathrm{Pa}$ & $\mathrm{Pa}$ & $\mathrm{OC}$ & $\mathrm{mg}$ & $\mathrm{mg}$ & $\mathrm{hr}$ & $\mathrm{hr}$ & $\mathrm{s}^{-1}$ & $\%$ & $\%$ & $\mathrm{~h}$ & ${ }^{\circ} \mathrm{C}$ & $\mathrm{mg}$ & \\
\hline 215 & $4 / 4 / 2014$ & WG1-20 & 150 & 150 & 26 & 1000 & 463.875 & 463.425 & 16.88 & 19.59 & 9.94E-08 & 0.27 & 0.37 & 2 & 1200 & 0.15 & \\
\hline 216 & $4 / 4 / 2014$ & WG1-20 & 150 & 149 & 26 & 1100 & 462.8 & 459.953 & 20.37 & 22.94 & $6.65 \mathrm{E}-07$ & 0.50 & 1.12 & 2 & 1200 & 0.15 & \\
\hline 217 & $4 / 7 / 2014$ & WG1-21 & 300 & 303 & 26 & 800 & 464.971 & 464.961 & 5.13 & 7.39 & 2.64E-09 & 0.21 & 0.22 & 2 & 1200 & 0.19 & \\
\hline 218 & $4 / 7 / 2014$ & WG1-21 & 300 & 304 & 26 & 850 & 464.906 & 464.893 & 7.67 & 10.43 & $2.81 \mathrm{E}-09$ & 0.23 & 0.23 & 2 & 1200 & 0.19 & \\
\hline 220 & $4 / 7 / 2014$ & WG1-21 & 300 & 289 & 26 & 950 & 464.763 & 464.589 & 13.84 & 16.72 & $3.61 \mathrm{E}-08$ & 0.26 & 0.30 & 2 & 1200 & 0.19 & \\
\hline 221 & $4 / 7 / 2014$ & WG1-21 & 300 & 284 & 26 & 1000 & 464.502 & 463.907 & 16.91 & 19.73 & $1.26 \mathrm{E}-07$ & 0.32 & 0.44 & 2 & 1200 & 0.19 & \\
\hline 222 & $4 / 7 / 2014$ & WG1-21 & 300 & 309 & 26 & 1100 & 463.309 & 458.402 & 20.23 & 22.94 & 1.09E-06 & 0.57 & 1.62 & 2 & 1200 & 0.19 & \\
\hline 225 & $4 / 8 / 2014$ & WG1-22 & 15 & 8 & 26 & 950 & 456.228 & 456.222 & 13.87 & 16.60 & $1.34 \mathrm{E}-09$ & 0.24 & 0.24 & 2 & 1200 & 0.17 & \\
\hline 226 & $4 / 8 / 2014$ & WG1-22 & 15 & 8 & 26 & 1000 & 456.161 & 456.086 & 16.97 & 19.81 & $1.61 \mathrm{E}-08$ & 0.26 & 0.27 & 2 & 1200 & 0.17 & \\
\hline 227 & $4 / 8 / 2014$ & WG1-22 & 15 & 8 & 25 & 1100 & 455.946 & 455.677 & 20.07 & 22.89 & $5.81 \mathrm{E}-08$ & 0.30 & 0.36 & 2 & 1200 & 0.17 & \\
\hline 234 & $6 / 30 / 2014$ & WG1-24 & 500 & 475 & 0 & 850 & 463.864 & 463.718 & 3.99 & 6.77 & $3.14 \mathrm{E}-08$ & 0.25 & 0.28 & 2 & 1200 & 0.25 & \\
\hline 235 & $6 / 30 / 2014$ & WG1-24 & 500 & 614 & 0 & 900 & 463.645 & 463.403 & 7.07 & 9.90 & $5.12 \mathrm{E}-08$ & 0.30 & 0.35 & 2 & 1200 & 0.25 & \\
\hline 236 & $6 / 30 / 2014$ & WG1-24 & 500 & 520 & 0 & 950 & 463.316 & 462.816 & 10.12 & 12.93 & $1.07 \mathrm{E}-07$ & 0.37 & 0.48 & 2 & 1200 & 0.25 & \\
\hline 237 & $6 / 30 / 2014$ & WG1-24 & 500 & 520 & 0 & 1000 & 462.648 & 461.181 & 13.25 & 16.01 & $3.19 \mathrm{E}-07$ & 0.51 & 0.83 & 2 & 1200 & 0.25 & \\
\hline 238 & $6 / 30 / 2014$ & WG1-24 & 500 & 519 & 0 & 1050 & 460.878 & 456.168 & 16.27 & 19.11 & 1.00E-06 & 0.89 & 1.91 & 2 & 1200 & 0.25 & \\
\hline 240 & $7 / 1 / 2014$ & WG1-25 & 1000 & 988 & 0 & 850 & 464.032 & 463.951 & 4.46 & 6.31 & $2.62 \mathrm{E}-08$ & 0.25 & 0.27 & 2 & 1200 & 0.18 & \\
\hline 241 & $7 / 1 / 2014$ & WG1-25 & 1000 & 712 & 0 & 900 & 464.156 & 463.95 & 7.58 & 10.39 & 4.39E-08 & 0.22 & 0.27 & 2 & 1200 & 0.18 & \\
\hline 242 & $7 / 1 / 2014$ & WG1-25 & 1000 & 738 & 0 & 950 & 463.683 & 463.353 & 11.44 & 13.43 & 9.93E-08 & 0.33 & 0.40 & 2 & 1200 & 0.18 & \\
\hline 243 & $7 / 1 / 2014$ & WG1-25 & 1000 & 981 & 0 & 1000 & 463.183 & 461.502 & 13.76 & 16.41 & 3.80E-07 & 0.43 & 0.79 & 2 & 1200 & 0.18 & \\
\hline 244 & $7 / 1 / 2014$ & WG1-25 & 1000 & 944 & 0 & 1050 & 460.798 & 454.859 & 16.99 & 19.61 & 1.37E-06 & 0.95 & 2.22 & 2 & 1200 & 0.18 & \\
\hline 247 & $7 / 30 / 2014$ & WG1-27 & 100 & 95 & 0 & 850 & 466.431 & 466.355 & 4.17 & 8.00 & $1.18 \mathrm{E}-08$ & 0.25 & 0.20 & 1 & 1200 & 0.26 & \\
\hline 248 & $7 / 30 / 2014$ & WG1-27 & 100 & 98 & 26 & 850 & 465.3 & 465.263 & 10.39 & 20.73 & $2.14 \mathrm{E}-09$ & 0.49 & 0.50 & 1 & 1200 & 0.26 & \\
\hline 249 & $7 / 30 / 2014$ & WG1-27 & 100 & 96 & 22 & 850 & 465.253 & 465.137 & 21.64 & 26.02 & $1.58 \mathrm{E}-08$ & 0.50 & 0.56 & 1 & 1200 & 0.26 & \\
\hline 250 & $7 / 30 / 2014$ & WG1-27 & 100 & 96 & 25 & 850 & 465.093 & 465.033 & 28.92 & 37.39 & 4.23E-09 & 0.54 & 0.55 & 1 & 1200 & 0.26 & \\
\hline 251 & $7 / 30 / 2014$ & WG1-27 & 100 & 93 & 0 & 850 & 465.014 & 464.769 & 38.64 & 48.00 & 1.56E-08 & 0.56 & 0.61 & 1 & 1200 & 0.26 & \\
\hline 252 & $8 / 6 / 2014$ & WG1-28 & 100 & 100 & 0 & 850 & 464.83 & 464.582 & 3.22 & 10.97 & $1.91 \mathrm{E}-08$ & 0.26 & 0.31 & 2 & 1200 & 0.17 & \\
\hline 253 & $8 / 6 / 2014$ & WG1-28 & 100 & 100 & 25 & 850 & 464.511 & 464.435 & 12.35 & 21.41 & $5.02 \mathrm{E}-09$ & 0.33 & 0.35 & 2 & 1200 & 0.17 & \\
\hline 254 & $8 / 6 / 2014$ & WG1-28 & 100 & 100 & 0 & 850 & 464.428 & 464.312 & 21.88 & 25.35 & 2.00E-08 & 0.35 & 0.37 & 2 & 1200 & 0.17 & \\
\hline 255 & $8 / 6 / 2014$ & WG1-28 & 100 & 99 & 26 & 850 & 464.3 & 464.229 & 25.78 & 33.22 & $5.71 \mathrm{E}-09$ & 0.37 & 0.39 & 2 & 1200 & 0.17 & \\
\hline 256 & $8 / 8 / 2014$ & WG1-29 & 100 & 102 & 0 & 850 & 466.76 & 466.582 & 3.26 & 10.19 & $1.53 \mathrm{E}-08$ & 0.22 & 0.26 & 1 & 1200 & 0.07 & \\
\hline 257 & $8 / 8 / 2014$ & WG1-29 & 100 & 102 & 13 & 850 & 466.544 & 466.454 & 12.07 & 22.56 & 5.11E-09 & 0.27 & 0.29 & 1 & 1200 & 0.07 & \\
\hline 258 & $8 / 8 / 2014$ & WG1-29 & 100 & 102 & 25 & 850 & 466.444 & 466.414 & 24.44 & 28.09 & 4.89E-09 & 0.29 & 0.30 & 1 & 1200 & 0.07 & \\
\hline 259 & $8 / 8 / 2014$ & WG1-29 & 100 & 102 & 42 & 850 & 466.407 & 466.368 & 28.93 & 35.49 & 3.54E-09 & 0.30 & 0.31 & 1 & 1200 & 0.07 & \\
\hline 260 & $8 / 8 / 2014$ & WG1-29 & 100 & 102 & 0 & 850 & 466.351 & 466.078 & 36.90 & 46.27 & $1.74 \mathrm{E}-08$ & 0.31 & 0.37 & 1 & 1200 & 0.07 & \\
\hline 261 & $8 / 8 / 2014$ & WG1-29 & 200 & 215 & 0 & 850 & 466.024 & 465.787 & 47.49 & 55.17 & $1.84 \mathrm{E}-08$ & 0.38 & 0.43 & 1 & 1200 & 0.07 & \\
\hline 262 & $8 / 8 / 2014$ & WG1-29 & 200 & 213 & 44 & 850 & 465.753 & 465.682 & 56.95 & 68.10 & 3.80E-09 & 0.44 & 0.45 & 1 & 1200 & 0.07 & \\
\hline 263 & $8 / 8 / 2014$ & WG1-29 & 200 & 212 & 21 & 850 & 465.661 & 465.59 & 70.72 & 78.78 & 5.25E-09 & 0.46 & 0.47 & 1 & 1200 & 0.07 & \\
\hline 264 & $8 / 12 / 2014$ & WG1-30 & 100 & 31 & 0 & 850 & 465.485 & 465.392 & 3.15 & 7.24 & 1.36E-08 & 0.26 & 0.28 & 1 & 1200 & 0.144 & \\
\hline 265 & 8/12/2014 & WG1-30 & 100 & 31 & 13 & 850 & 465.377 & 465.368 & 8.70 & 11.20 & 2.15E-09 & 0.28 & 0.28 & 1 & 1200 & 0.144 & \\
\hline 266 & $8 / 12 / 2014$ & WG1-30 & 100 & 31 & 25 & 850 & 465.365 & 465.339 & 11.74 & 20.03 & 1.87E-09 & 0.28 & 0.29 & 1 & 1200 & 0.144 & \\
\hline
\end{tabular}




\begin{tabular}{|c|c|c|c|c|c|c|c|c|c|c|c|c|c|c|c|c|c|}
\hline \multirow{3}{*}{$\begin{array}{l}\text { Exp data } \\
\text { number }\end{array}$} & \multirow[b]{3}{*}{ Test Date } & \multirow[b]{3}{*}{ Specimen ID } & \multirow{2}{*}{\multicolumn{2}{|c|}{$\mathrm{H} 2 \mathrm{O}$ Pressure }} & \multirow{3}{*}{$\begin{array}{c}\mathrm{H} 2 \\
\text { Pressure } \\
\end{array}$} & \multirow{3}{*}{$\begin{array}{c}\text { Temperat } \\
\text { ure }\end{array}$} & \multirow{2}{*}{\multicolumn{2}{|c|}{ Weight }} & \multirow{2}{*}{\multicolumn{2}{|c|}{ Time in the test }} & \multirow[b]{3}{*}{ Rate } & \multirow{2}{*}{\multicolumn{2}{|c|}{ Weight loss \% }} & \multirow{2}{*}{\multicolumn{2}{|c|}{ Sample preparaton }} & \multirow{3}{*}{$\begin{array}{c}\text { Wt loss in } \\
\text { outgassing }\end{array}$} & \multirow[b]{3}{*}{ Notes } \\
\hline & & & & & & & & & & & & & & & & & \\
\hline & & & target & actual $^{\&}$ & & & before & after & before & after & & before & after & duration & temperature & & \\
\hline & & & $\mathrm{Pa}$ & $\mathrm{Pa}$ & $\mathrm{Pa}$ & $\mathrm{OC}$ & $\mathrm{mg}$ & $\mathrm{mg}$ & $\mathrm{hr}$ & $\mathrm{hr}$ & $\mathrm{s}^{-1}$ & $\%$ & $\%$ & $\mathrm{~h}$ & ${ }^{\circ} \mathrm{C}$ & $\mathrm{mg}$ & \\
\hline 267 & $8 / 12 / 2014$ & WG1-30 & 100 & 31 & 39 & 850 & 465.338 & 465.326 & 20.52 & 24.36 & $1.87 \mathrm{E}-09$ & 0.29 & 0.29 & 1 & 1200 & 0.144 & \\
\hline 268 & $8 / 12 / 2014$ & WG1-30 & 100 & 31 & 0 & 850 & 465.305 & 465.22 & 26.12 & 28.80 & $1.89 \mathrm{E}-08$ & 0.30 & 0.31 & 1 & 1200 & 0.144 & \\
\hline 269 & $8 / 12 / 2014$ & WG1-30 & 100 & 52 & 0 & 850 & 465.202 & 465.118 & 29.36 & 31.91 & $1.97 \mathrm{E}-08$ & 0.32 & 0.34 & 1 & 1200 & 0.144 & \\
\hline 270 & $8 / 12 / 2014$ & WG1-30 & 100 & 52 & 39 & 850 & 465.105 & 465.094 & 33.01 & 35.56 & $2.58 \mathrm{E}-09$ & 0.34 & 0.34 & 1 & 1200 & 0.144 & \\
\hline 271 & $8 / 12 / 2014$ & WG1-30 & 100 & 52 & 25 & 850 & 465.09 & 465.036 & 36.42 & 45.13 & $3.70 \mathrm{E}-09$ & 0.34 & 0.35 & 1 & 1200 & 0.144 & \\
\hline 272 & $8 / 12 / 2014$ & WG1-30 & 100 & 52 & 13 & 850 & 465.027 & 464.985 & 46.60 & 51.04 & $5.65 \mathrm{E}-09$ & 0.36 & 0.36 & 1 & 1200 & 0.144 & \\
\hline 275 & $8 / 15 / 2014$ & WG1-31 & 15 & 14 & 25 & 850 & 469.05 & 469.042 & 12.39 & 18.33 & $7.98 \mathrm{E}-10$ & 0.23 & 0.24 & 1 & 1200 & 0.097 & \\
\hline 277 & $8 / 15 / 2014$ & WG1-31 & 50 & 52 & 25 & 850 & 469.037 & 469.019 & 22.48 & 27.74 & 2.03E-09 & 0.24 & 0.24 & 1 & 1200 & 0.097 & \\
\hline 278 & $8 / 15 / 2014$ & WG1-31 & 100 & 105 & 26 & 850 & 469.01 & 468.938 & 28.50 & 35.88 & $5.78 \mathrm{E}-09$ & 0.24 & 0.26 & 1 & 1200 & 0.097 & \\
\hline 279 & $8 / 15 / 2014$ & WG1-31 & 30 & 30 & 25 & 850 & 468.937 & 468.911 & 36.89 & 46.14 & 1.67E-09 & 0.26 & 0.26 & 1 & 1200 & 0.097 & \\
\hline 280 & $8 / 15 / 2014$ & WG1-31 & 150 & 150 & 28 & 850 & 468.881 & 468.786 & 46.99 & 51.82 & $1.17 \mathrm{E}-08$ & 0.27 & 0.29 & 1 & 1200 & 0.097 & \\
\hline 281 & $8 / 15 / 2014$ & WG1-31 & 150 & 154 & 28 & 850 & 468.786 & 468.703 & 51.82 & 58.44 & 7.43E-09 & 0.29 & 0.31 & 1 & 1200 & 0.097 & \\
\hline 282 & $8 / 15 / 2014$ & WG1-31 & 3 & 5 & 25 & 850 & 468.721 & 468.706 & 59.62 & 70.73 & $8.00 \mathrm{E}-10$ & 0.30 & 0.31 & 1 & 1200 & 0.097 & \\
\hline 283 & $8 / 25 / 2014$ & WG1-32 & 15 & 15 & 26 & 800 & 455.577 & 455.569 & 5.83 & 14.08 & $5.91 \mathrm{E}-10$ & 0.26 & 0.26 & 2 & 1200 & 0.15 & \\
\hline 284 & $8 / 25 / 2014$ & WG1-32 & 15 & 15 & 26 & 850 & 455.496 & 455.472 & 14.89 & 24.11 & $1.59 \mathrm{E}-09$ & 0.27 & 0.28 & 2 & 1200 & 0.15 & \\
\hline 285 & $8 / 25 / 2014$ & WG1-32 & 15 & 15 & 26 & 900 & 455.393 & 455.365 & 25.13 & 34.36 & $1.85 \mathrm{E}-09$ & 0.30 & 0.30 & 2 & 1200 & 0.15 & \\
\hline 286 & $8 / 25 / 2014$ & WG1-32 & 15 & 15 & 26 & 950 & 455.285 & 455.207 & 34.99 & 44.46 & 5.03E-09 & 0.32 & 0.34 & 2 & 1200 & 0.15 & \\
\hline 287 & 9/3/2014 & WG1-33 & 30 & 30 & 25 & 800 & 462.61 & 462.59 & 6.36 & 14.26 & 1.44E-09 & 0.239 & 0.243 & 2 & 1200 & 0.207 & \\
\hline 288 & $9 / 3 / 2014$ & WG1-33 & 30 & 30 & 25 & 850 & 462.53 & 462.49 & 15.17 & 24.17 & $2.74 \mathrm{E}-09$ & 0.256 & 0.265 & 2 & 1200 & 0.207 & \\
\hline 289 & $9 / 3 / 2014$ & WG1-33 & 30 & 30 & 25 & 900 & 462.42 & 462.35 & 25.08 & 34.45 & $4.36 \mathrm{E}-09$ & 0.279 & 0.294 & 2 & 1200 & 0.207 & \\
\hline 290 & $9 / 3 / 2014$ & WG1-33 & 30 & 30 & 25 & 950 & 462.28 & 462.10 & 35.04 & 44.59 & $1.16 \mathrm{E}-08$ & 0.309 & 0.349 & 2 & 1200 & 0.207 & \\
\hline 291 & $12 / 30 / 2014$ & WG1-34 & 30 & 30 & 0 & 800 & 468.207 & 468.247 & 10.34 & 15.33 & $6.30 \mathrm{E}-09$ & 0.020 & 0.01 & 1 & 1200 & 0.063 & \\
\hline 292 & $12 / 30 / 2014$ & WG1-34 & 30 & 30 & 0 & 850 & 468.235 & 468.143 & 15.82 & 25.31 & $9.81 \mathrm{E}-09$ & 0.014 & 0.03 & 1 & 1200 & 0.063 & \\
\hline 293 & $12 / 30 / 2014$ & WG1-34 & 30 & 30 & 0 & 900 & 468.226 & 468.067 & 26.13 & 35.55 & $1.47 \mathrm{E}-08$ & 0.016 & 0.05 & 1 & 1200 & 0.063 & \\
\hline 294 & $12 / 30 / 2014$ & WG1-34 & 30 & 30 & 0 & 950 & 468.225 & 467.903 & 35.88 & 45.69 & 2.40E-08 & 0.016 & 0.08 & 1 & 1200 & 0.063 & \\
\hline 295 & $1 / 1 / 2015$ & WG1-34 & 12 & 12 & 0 & 850 & 468.307 & 468.226 & 9.69 & 14.45 & $9.22 \mathrm{E}-09$ & 0.00 & 0.02 & 1 & 1200 & 0.06 & \\
\hline 296 & $1 / 1 / 2015$ & WG1-34 & 12 & 12 & 0 & 900 & 468.233 & 468.191 & 14.78 & 19.51 & $1.37 E-08$ & 0.01 & 0.02 & 1 & 1200 & 0.06 & \\
\hline 297 & $1 / 5 / 2015$ & WG1-34 & 3 & 3 & 0 & 800 & 468.273 & 468.253 & 4.42 & 9.45 & $5.54 \mathrm{E}-09$ & 0.01 & 0.02 & 1 & 1200 & 0.092 & \\
\hline 298 & $1 / 5 / 2015$ & WG1-34 & 3 & 3 & 0 & 850 & 468.237 & 468.22 & 9.81 & 14.48 & $1.02 \mathrm{E}-08$ & 0.01 & 0.02 & 1 & 1200 & 0.092 & \\
\hline 299 & $1 / 5 / 2015$ & WG1-34 & 3 & 3 & 0 & 900 & 468.233 & 468.197 & 14.81 & 19.63 & $1.27 \mathrm{E}-08$ & 0.01 & 0.02 & 1 & 1200 & 0.092 & \\
\hline 300 & $1 / 5 / 2015$ & WG1-34 & 3 & 3 & 0 & 950 & 468.229 & 468.181 & 19.93 & 24.60 & $1.51 \mathrm{E}-08$ & 0.01 & 0.02 & 1 & 1200 & 0.092 & \\
\hline 301 & $1 / 7 / 2016$ & WG1-34 & 3 & 3 & 0 & 800 & 468.686 & 468.276 & 5.33 & 9.94 & $3.09 \mathrm{E}-09$ & 0.01 & 0.02 & 1 & 1200 & 0.081 & \\
\hline 302 & $1 / 7 / 2016$ & WG1-34 & 3 & 3 & 0 & 850 & 468.239 & 468.228 & 10.25 & 14.95 & $9.09 E-09$ & 0.01 & 0.02 & 1 & 1200 & 0.081 & \\
\hline 303 & $1 / 7 / 2016$ & WG1-34 & 3 & 3 & 0 & 900 & 468.234 & 468.188 & 15.26 & 20.05 & $1.39 \mathrm{E}-08$ & 0.01 & 0.02 & 1 & 1200 & 0.081 & \\
\hline 304 & $1 / 7 / 2016$ & WG1-34 & 3 & 3 & 0 & 950 & 468.229 & 468.165 & 20.32 & 25.18 & $1.65 \mathrm{E}-08$ & 0.01 & 0.02 & 1 & 1200 & 0.081 & \\
\hline \multicolumn{18}{|c|}{ DATA REJECTED } \\
\hline 239 & $6 / 30 / 2014$ & WG1-24 & 500 & 530 & 0 & 1100 & 455.242 & 441.4 & 19.41 & 22.27 & $2.95 \mathrm{E}-06$ & 2.11 & 5.08 & 2 & 1200 & 0.25 & \\
\hline 245 & $7 / 1 / 2014$ & WG1-25 & 1000 & 702 & 0 & 1100 & 453.542 & 442.934 & 19.95 & 21.74 & 3.63E-06 & 2.51 & 4.79 & 2 & 1200 & 0.18 & \\
\hline 246 & $7 / 1 / 2014$ & WG1-25 & 1000 & 1447 & 0 & 1100 & 442.934 & 430.093 & 21.74 & 22.84 & $7.32 \mathrm{E}-06$ & 4.79 & 7.55 & 2 & 1200 & 0.18 & \\
\hline
\end{tabular}




\begin{tabular}{|c|c|c|c|c|c|c|c|c|c|c|c|c|c|c|c|c|c|}
\hline \multirow{2}{*}{$\begin{array}{l}\text { Exp data } \\
\text { number }\end{array}$} & \multirow[b]{2}{*}{ Test Date } & \multirow[b]{2}{*}{ Specimen ID } & \multicolumn{2}{|c|}{ H2O Pressure } & \multirow{2}{*}{$\begin{array}{c}\mathrm{H} 2 \\
\text { Pressure } \\
\end{array}$} & \multirow{2}{*}{$\begin{array}{c}\text { Temperat } \\
\text { ure }\end{array}$} & \multicolumn{2}{|c|}{ Weight } & \multicolumn{2}{|c|}{ Time in the test } & \multirow[b]{2}{*}{ Rate } & \multicolumn{2}{|c|}{ Weight loss \% } & \multicolumn{2}{|c|}{ Sample preparaton } & \multirow{2}{*}{$\begin{array}{l}\text { Wt loss in } \\
\text { outgassing }\end{array}$} & \multirow[b]{2}{*}{ Notes } \\
\hline & & & target & actual $^{\&}$ & & & before & after & before & after & & before & after & duration & temperature & & \\
\hline & & & $\mathrm{Pa}$ & $\mathrm{Pa}$ & $\mathrm{Pa}$ & $\mathrm{OC}$ & $\mathrm{mg}$ & $\mathrm{mg}$ & $\mathrm{hr}$ & $\mathrm{hr}$ & $\mathrm{s}^{-1}$ & $\%$ & $\%$ & $\mathrm{~h}$ & ${ }^{\circ} \mathrm{C}$ & $\mathrm{mg}$ & \\
\hline 163 & $3 / 5 / 2014$ & AG3-15 & 30 & 15 & 26 & 800 & 462.756 & 462.756 & 4.82 & 7.36 & $0.00 \mathrm{E}+00$ & 0.18 & 0.18 & 2 & 1200 & 0.16 & negative rate \\
\hline 169 & $3 / 6 / 2014$ & AG3-16 & 30 & 30 & 26 & 800 & 470.752 & 470.749 & 4.68 & 7.34 & $6.65 \mathrm{E}-10$ & 0.17 & 0.17 & 2 & 1200 & 0.12 & exp. Errors \\
\hline 170 & $3 / 6 / 2014$ & AG3-16 & 30 & 15 & 25 & 850 & 470.696 & 470.7 & 7.73 & 10.41 & $-8.81 \mathrm{E}-10$ & 0.18 & 0.18 & 2 & 1200 & 0.12 & negative rate \\
\hline 175 & $3 / 7 / 2014$ & AG3-17 & 50 & 52 & 26 & 800 & 466.475 & 466.491 & 4.60 & 7.36 & $-3.45 \mathrm{E}-09$ & 0.19 & 0.18 & 2 & 1200 & 0.15 & negative rate \\
\hline 188 & $3 / 25 / 2014$ & AG3-20 & 150 & 151 & 26 & 850 & 452.259 & 452.272 & 7.67 & 10.43 & $-2.89 \mathrm{E}-09$ & 0.24 & 0.24 & 2 & 1200 & 0.22 & negative rate \\
\hline 193 & $4 / 1 / 2014$ & WG1-17 & 100 & 102 & 26 & 800 & 467.009 & 466.98 & 5.13 & 7.39 & 7.63E-09 & 0.20 & 0.21 & 2 & 1200 & 0.17 & exp. Errors \\
\hline 194 & $4 / 1 / 2014$ & WG1-17 & 100 & 101 & 25 & 850 & 466.953 & 466.985 & 7.70 & 10.46 & $-6.90 \mathrm{E}-09$ & 0.22 & 0.21 & 2 & 1200 & 0.17 & negative rate \\
\hline 199 & $4 / 2 / 2014$ & WG1-18 & 50 & 51 & 26 & 800 & 463.408 & 463.386 & 5.51 & 7.42 & $6.90 \mathrm{E}-09$ & 0.20 & 0.20 & 2 & 1200 & 0.18 & exp. Errors \\
\hline 200 & $4 / 2 / 2014$ & WG1-18 & 50 & 51 & 26 & 850 & 463.34 & 463.361 & 7.70 & 10.55 & $-4.42 \mathrm{E}-09$ & 0.21 & 0.21 & 2 & 1200 & 0.18 & negative rate \\
\hline 205 & $4 / 3 / 2014$ & WG1-19 & 30 & 30 & 26 & 800 & 463.123 & 463.123 & 5.53 & 7.38 & $0.00 E+00$ & 0.20 & 0.20 & 2 & 1200 & 0.17 & negative rate \\
\hline 206 & $4 / 3 / 2014$ & WG1-19 & 30 & 30 & 26 & 850 & 463.075 & 463.114 & 7.68 & 10.47 & $-8.39 \mathrm{E}-09$ & 0.21 & 0.20 & 2 & 1200 & 0.17 & negative rate \\
\hline 207 & $4 / 3 / 2014$ & WG1-19 & 30 & 30 & 26 & 900 & 463.063 & 463.066 & 10.75 & 13.55 & $-6.43 E-10$ & 0.21 & 0.21 & 2 & 1200 & 0.17 & negative rate \\
\hline 209 & $4 / 3 / 2014$ & WG1-19 & 30 & 30 & 26 & 1000 & 465.219 & 462.71 & 16.95 & 19.80 & $5.26 \mathrm{E}-07$ & -0.25 & 0.29 & 2 & 1200 & 0.17 & exp. Errors \\
\hline 211 & 4/4/2014 & WG1-20 & 150 & 152 & 26 & 800 & 464.249 & 464.24 & 4.88 & 7.39 & $2.15 \mathrm{E}-09$ & 0.19 & 0.19 & 2 & 1200 & 0.15 & exp. Errors \\
\hline 212 & $4 / 4 / 2014$ & WG1-20 & 150 & 150 & 26 & 850 & 464.191 & 464.215 & 7.81 & 10.49 & $-5.36 \mathrm{E}-09$ & 0.21 & 0.20 & 2 & 1200 & 0.15 & negative rate \\
\hline 223 & $4 / 8 / 2014$ & WG1-22 & 15 & 22 & 26 & 850 & 456.287 & 456.317 & 7.67 & 10.43 & $-6.62 \mathrm{E}-09$ & 0.23 & 0.22 & 2 & 1200 & 0.17 & negative rate \\
\hline 224 & $4 / 8 / 2014$ & WG1-22 & 15 & 8 & 26 & 900 & 456.266 & 456.283 & 10.74 & 13.59 & $-3.63 E-09$ & 0.23 & 0.23 & 2 & 1200 & 0.17 & negative rate \\
\hline 229 & $4 / 9 / 2014$ & WG1-23 & 30 & 4 & 96 & 850 & 469.615 & 469.638 & 7.69 & 10.45 & $-4.93 \mathrm{E}-09$ & 0.11 & 0.10 & 2 & 1200 & 0.26 & negative rate \\
\hline 230 & $4 / 9 / 2014$ & WG1-23 & 30 & 4 & 96 & 900 & 469.638 & 469.655 & 10.79 & 13.46 & $-3.77 \mathrm{E}-09$ & 0.10 & 0.10 & 2 & 1200 & 0.26 & negative rate \\
\hline 231 & 4/9/2014 & WG1-23 & 30 & 4 & 96 & 950 & 469.634 & 469.655 & 13.89 & 16.62 & $-4.55 E-09$ & 0.10 & 0.10 & 2 & 1200 & 0.26 & negative rate \\
\hline 273 & $8 / 15 / 2014$ & WG1-31 & 3 & 4 & 85 & 850 & 469.07 & 469.062 & 3.49 & 9.17 & $5.21 \mathrm{E}-10$ & 0.23 & 0.23 & 1 & 1200 & 0.097 & exp. Errors \\
\hline 274 & $8 / 15 / 2014$ & WG1-31 & 3 & 4 & 85 & 850 & 469.062 & 469.064 & 9.17 & 11.04 & $-6.33 E-10$ & 0.23 & 0.23 & 1 & 1200 & 0.097 & negative rate \\
\hline 187 & $3 / 25 / 2014$ & AG3-20 & 150 & 152 & 26 & 800 & 452.311 & 452.31 & 5.38 & 7.39 & $3.06 \mathrm{E}-10$ & 0.23 & 0.23 & 2 & 1200 & 0.22 & exp. Errors \\
\hline 219 & $4 / 7 / 2014$ & WG1-21 & 300 & 296 & 26 & 900 & 464.84 & 464.828 & 10.74 & 13.56 & $2.54 \mathrm{E}-09$ & 0.24 & 0.25 & 2 & 1200 & 0.19 & unstable \\
\hline 276 & $8 / 15 / 2014$ & WG1-31 & 15 & 8 & 25 & 850 & 469.042 & 469.041 & 18.33 & 21.72 & $1.75 \mathrm{E}-10$ & 0.24 & 0.24 & 1 & 1200 & 0.097 & exp. Errors \\
\hline 171 & $3 / 6 / 2014$ & AG3-16 & 30 & 29 & 26 & 900 & 470.671 & 470.67 & 12.67 & 13.59 & $6.41 \mathrm{E}-10$ & 0.19 & 0.19 & 2 & 1200 & 0.12 & unstable \\
\hline 228 & $4 / 9 / 2014$ & WG1-23 & 30 & 4 & 96 & 800 & 469.592 & 469.613 & 4.56 & 7.26 & $-4.60 \mathrm{E}-09$ & 0.11 & 0.11 & 2 & 1200 & 0.26 & exp. Errors \\
\hline 232 & $4 / 9 / 2014$ & WG1-23 & 30 & 4 & 96 & 1000 & 469.65 & 469.601 & 16.96 & 19.63 & $1.09 E-08$ & 0.10 & 0.11 & 2 & 1200 & 0.26 & exp. Errors \\
\hline 233 & 4/9/2014 & WG1-23 & 30 & 4 & 96 & 1100 & 469.581 & 469.517 & 20.15 & 22.85 & $1.40 \mathrm{E}-08$ & 0.12 & 0.13 & 2 & 1200 & 0.26 & exp. Errors \\
\hline 181 & $3 / 14 / 2014$ & AG3-19 & 100 & 101 & 26 & 800 & 459.769 & 459.772 & 5.30 & 7.25 & $-9.29 E-10$ & 0.19 & 0.19 & 2 & 1200 & 0.22 & negative rate \\
\hline 43 & $1 / 9 / 2014$ & WG1-12 & 15 & 15 & 0 & 800 & 463.377 & 463.249 & 4.13 & 6.72 & $2.96 \mathrm{E}-08$ & 0.18 & 0.21 & 2 & 1200 & 0.14 & unstable \\
\hline
\end{tabular}




\begin{tabular}{|c|c|c|c|c|c|c|c|c|c|c|c|c|c|}
\hline Experimental data number & Date of test & $\begin{array}{l}\text { Specimen } \\
\text { ID }\end{array}$ & $\begin{array}{l}\text { Weight } \\
\text { (mg) }\end{array}$ & $\begin{array}{c}\text { Before } C \\
\text { Average L } \\
(\mathrm{mm}) \\
\end{array}$ & $\begin{array}{l}\text { xidation } \\
\text { Average D } \\
(\mathrm{mm}) \\
\end{array}$ & $\begin{array}{l}\text { Uensity } \\
\left(\mathrm{g} / \mathrm{cm}^{3}\right) \\
\end{array}$ & Weight (mg) & $\begin{array}{l}\text { After Oxidation } \\
\text { Average } \mathrm{L} \text { Average } \mathrm{D} \\
\begin{array}{cc}(\mathrm{mm}) & (\mathrm{mm}) \\
\end{array}\end{array}$ & $\begin{array}{l}\text { Uensity } \\
\left(\mathrm{g} / \mathrm{cm}^{3}\right)\end{array}$ & $\begin{array}{l}\mathrm{P}_{\mathrm{H} 2 \mathrm{O}} \\
(\mathrm{Pa}) \\
\end{array}$ & $\begin{array}{l}\mathrm{P}_{\mathrm{H} 2} \\
(\mathrm{~Pa}) \\
\end{array}$ & $\begin{array}{c}\text { Weight } \\
\text { loss }\end{array}$ & Notes \\
\hline $2 ; 3 ; 4 ; 5 ; 6$ & $2 / 21 / 2012$ & $\# 1--1$ & 447.6 & & & & 446.8 & & & 100 & 0 & & \\
\hline $7 ; 8 ; 9 ; 10 ; 11$ & $2 / 22 / 2012$ & $\# 1--2$ & 445.3 & & & & 447.1 & & & 70 & 0 & & \\
\hline $12 ; 13 ; 14 ; 15 ; 16$ & $2 / 23 / 2012$ & $\# 1--3$ & 445.1 & & & & 443.3 & & & 150 & 0 & & \\
\hline $17 ; 18 ; 19 ; 20 ; 21$ & $2 / 24 / 2012$ & \#1--4 & 443.5 & & & & 441.7 & & & 250 & 0 & & \\
\hline $22 ; 23 ; 24 ; 25 ; 26$ & $3 / 1 / 2012$ & \#2--1 & 451.1 & & & & 450.4 & & & 100 & 0 & & \\
\hline $27 ; 28 ; 29 ; 30 ; 31$ & $3 / 5 / 2012$ & $\# 2--2$ & 445.8 & & & & 444.9 & & & 70 & 0 & & \\
\hline $32 ; 33 ; 34 ; 35 ; 36$ & $3 / 6 / 2012$ & $\# 2--3$ & 449.7 & & & & 449.0 & & & 100 & 0 & & \\
\hline $37 ; 38 ; 39 ; 40 ; 41$ & $3 / 7 / 2012$ & \#2--4 & & & & & & & & 150 & 0 & & \\
\hline $42 ; 43 ; 44 ; 45 ; 46$ & $3 / 8 / 2012$ & \#3--1 & 446.4 & & & & 444.0 & & & 250 & 0 & & \\
\hline $47 ; 48 ; 49 ; 50 ; 51$ & $3 / 19 / 2012$ & \#3--2 & 446.9 & & & & 445.6 & & & 70 & 0 & & \\
\hline $52 ; 53 ; 54 ; 55 ; 56$ & $3 / 20 / 2012$ & \#3--4 & 448.5 & & & & 447.2 & & & 65 & 0 & & \\
\hline $57 ; 58 ; 59 ; 60 ; 61$ & $3 / 26 / 2012$ & \#3--3 & 445.0 & & & & 443.8 & & & 150 & 0 & & \\
\hline $62 ; 63 ; 64 ; 65 ; 66$ & $4 / 19 / 2012$ & DB1-1 & 444.9 & & & & 443.8 & & & 250 & 0 & & \\
\hline $67 ; 68 ; 69 ; 70 ; 71$ & $4 / 23 / 2012$ & DB1-2 & 443.7 & & & & 441.6 & & & 70 & 0 & & \\
\hline $72 ; 73 ; 74 ; 75 ; 76$ & $4 / 24 / 2012$ & DB1-3 & 445.2 & & & & 444.3 & & & 70 & 0 & & \\
\hline 77; 78; 79; 80; 81 & $4 / 26 / 2012$ & DB1-4 & 446.2 & & & & 444.9 & & & 50 & 0 & & \\
\hline 82; 83; 84; 85; 86; & $5 / 1 / 2012$ & DB1-5 & 447.8 & & & & 446.5 & & & 30 & 0 & & \\
\hline 87; 88; 89; 90; 91 & $5 / 2 / 2012$ & DB2-1 & 450.9 & & & & 448.1 & & & 200 & 0 & & \\
\hline 92; 93; 94; 95; 96 & $5 / 11 / 2012$ & DB2-2 & 444.0 & & & & 442.9 & & & 100 & 0 & & \\
\hline 97; 98; 99; 100; 101 & $5 / 14 / 2012$ & DB2-3 & 443.7 & & & & 442.4 & & & 150 & 0 & & \\
\hline $102 ; 103 ; 104 ; 105 ; 106$ & $5 / 16 / 2012$ & DB2-5 & 448.5 & & & & 446.6 & & & 100 & 0 & & \\
\hline 107; 108; 109; 110; 111 & $5 / 17 / 2012$ & DB2-6 & 444.2 & & & & 442.7 & & & 150 & 0 & & \\
\hline 112; 113; 114; 115; 116 & $5 / 21 / 2012$ & DB2-7 & 445.3 & & & & 444.0 & & & 500 & 0 & & \\
\hline 117; 118; 119; 120; 121 & $5 / 22 / 2012$ & DB2-8 & 447.8 & & & & 444.5 & & & 750 & 0 & & \\
\hline $122 ; 123 ; 124 ; 125 ; 126$ & $5 / 23 / 2012$ & DB3-1 & 444.9 & & & & 444.1 & & & 3 & 0 & & \\
\hline 127; & $5 / 30 / 2012$ & DB3-2 & 443.9 & & & & 442.8 & & & 150 & 0 & & \\
\hline $128 ; 129$ & $5 / 31 / 2012$ & DB3-3 & 444.2 & & & & 443.7 & & & 150 & 0 & & \\
\hline 130;131 & $6 / 27 / 2012$ & DB3-4 & & & & & & & & 75 & 150 & & \\
\hline $133 ; 132$ & $6 / 28 / 2012$ & DB3-5 & & & & & & & & 75 & 100 & & \\
\hline $134 ; 135$ & $7 / 3 / 2012$ & DB3-6 & & & & & & & & 75 & 100 & & \\
\hline
\end{tabular}




\begin{tabular}{|c|c|c|c|c|c|c|c|c|c|c|c|c|c|}
\hline Experimental data number & Date of test & $\begin{array}{l}\text { Specimen } \\
\text { ID }\end{array}$ & $\begin{array}{l}\text { Weight } \\
\text { (mg) }\end{array}$ & $\begin{array}{l}\text { Before O } \\
\text { Average L } \\
(\mathrm{mm})\end{array}$ & $\begin{array}{l}\text { xidation } \\
\text { Average D } \\
(\mathrm{mm})\end{array}$ & $\begin{array}{l}\text { Uensıty } \\
\left(\mathrm{g} / \mathrm{cm}^{3}\right)\end{array}$ & Weight (mg) & $\begin{array}{l}\text { After Ox } \\
\text { Average L } \\
(\mathrm{mm})\end{array}$ & $\begin{array}{l}\text { idation } \\
\text { Average D } \\
(\mathrm{mm})\end{array}$ & $\begin{array}{l}\text { Uensıty } \\
\left(\mathrm{g} / \mathrm{cm}^{3}\right)\end{array}$ & $\begin{array}{l}\mathrm{P}_{\mathrm{H} 2 \mathrm{O}} \\
(\mathrm{Pa})\end{array}$ & $\begin{array}{l}\mathrm{P}_{\mathrm{H} 2} \\
(\mathrm{~Pa})\end{array}$ & $\begin{array}{l}\text { Weight } \\
\text { loss }\end{array}$ \\
\hline $\begin{array}{l}136 ; 137 \\
\end{array}$ & $7 / 7 / 5 / 2012$ & "DB3-7 & "442.5 & 20.01 & 3.95 & 1.804 & 4037.5 & 19.98 & 3.96 & $\begin{array}{l}1.777 \\
\end{array}$ & 30 & 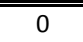 & "1.13\% \\
\hline $138 ; 139$ & $7 / 9 / 2012$ & DB3-8 & 443.3 & 20.01 & 3.96 & 1.798 & 425.2 & 19.99 & 3.91 & 1.771 & 300 & 0 & $4.08 \%$ \\
\hline $140 ; 141$ & $7 / 10 / 2012$ & DB4-1 & 440.2 & 19.98 & 3.97 & 1.776 & 434.2 & 19.95 & 3.96 & 1.767 & 300 & 100 & $1.36 \%$ \\
\hline $142 ; 143$ & $7 / 11 / 2012$ & DB4-2 & 438.5 & 20.04 & 3.94 & 1.792 & 423.9 & 20.01 & 3.92 & 1.755 & 300 & 0 & $3.33 \%$ \\
\hline $144 ; 145$ & $7 / 12 / 2012$ & DB4-3 & 443.4 & 20.01 & 3.98 & 1.785 & 440.0 & 19.99 & 3.96 & 1.790 & 30 & 0 & $0.77 \%$ \\
\hline $146 ; 147$ & $7 / 16 / 2012$ & DB4-4 & 444.4 & 19.97 & 3.98 & 1.786 & 440.9 & 19.95 & 3.97 & 1.787 & 30 & 100 & $0.79 \%$ \\
\hline $148 ; 149$ & $7 / 17 / 2012$ & DB4-5 & 442.4 & 19.82 & 3.98 & 1.792 & 418.1 & 19.78 & 3.94 & 1.738 & 300 & 0 & $5.49 \%$ \\
\hline $150 ; 151$ & $7 / 18 / 2012$ & DB4-6 & 446.8 & 20.00 & 3.97 & 1.805 & 437.3 & 19.98 & 3.96 & 1.782 & 30 & 0 & $2.13 \%$ \\
\hline $152 ; 153$ & $7 / 19 / 2012$ & DB4-7 & 443.7 & 20.00 & 3.97 & 1.790 & 433.4 & 19.98 & 3.95 & 1.771 & 300 & 100 & $2.32 \%$ \\
\hline $154 ; 155$ & $7 / 20 / 2012$ & DB4-8 & 439.9 & 20.06 & 3.94 & 1.797 & 423.1 & 20.02 & 3.91 & 1.758 & 300 & 0 & $3.82 \%$ \\
\hline $156 ; 157$ & $7 / 23 / 2012$ & $\# 10-1$ & 442.1 & 19.94 & 3.97 & 1.788 & 420.2 & 19.92 & 3.95 & 1.726 & 30 & 0 & $4.95 \%$ \\
\hline \multirow[t]{2}{*}{$158 ; 159$} & $7 / 24 / 2012$ & $\# 10-2$ & 440.7 & 20.07 & 3.98 & 1.767 & 436.1 & 20.03 & 3.96 & 1.768 & 30 & 100 & $1.04 \%$ \\
\hline & $7 / 25 / 2012$ & $\# 10-3$ & 445.9 & 20.01 & 3.99 & 1.783 & 328.2 & 19.97 & 3.96 & 1.336 & 300 & 0 & $26.40 \%$ high wt loss \\
\hline $160 ; 161$ & $7 / 26 / 2012$ & $\# 11-1$ & 452.4 & 20.00 & 3.99 & 1.811 & 440.2 & 19.98 & 3.97 & 1.783 & 300 & 0 & $2.70 \%$ \\
\hline $162 ; 163$ & $7 / 30 / 2012$ & $\# 0-1$ & 443.1 & 20.03 & 3.95 & 1.808 & 437.5 & 20.01 & 3.95 & 1.788 & 30 & 0 & $1.26 \%$ \\
\hline \multirow[t]{2}{*}{$164 ; 165$} & $8 / 1 / 2013$ & $\# 0-2$ & 447.5 & 19.98 & 3.99 & 1.788 & 440.0 & 19.94 & 3.98 & 1.778 & 300 & 100 & $1.68 \%$ \\
\hline & $8 / 2 / 2012$ & $\# 0-3$ & 447.3 & 20.11 & 3.98 & 1.793 & 380.0 & 20.02 & 3.98 & 1.528 & 300 & 0 & $15.05 \%$ high wt loss \\
\hline $166 ; 167$ & $8 / 6 / 2012$ & $\# 0-4$ & 443.2 & 20.07 & 3.96 & 1.797 & 431.8 & 20.01 & 3.91 & 1.797 & 300 & 0 & $2.57 \%$ \\
\hline $168 ; 169$ & $8 / 7 / 2012$ & $\# 0-5$ & 444.4 & 19.96 & 3.98 & 1.792 & 438.9 & 19.94 & 3.97 & 1.780 & 30 & 0 & $1.24 \%$ \\
\hline $170 ; 171$ & $8 / 8 / 2012$ & $\# 0-6$ & 454.4 & 19.96 & 3.99 & 1.826 & 453.3 & 19.95 & 3.99 & 1.818 & 30 & 100 & $0.24 \%$ \\
\hline $172 ; 173$ & $8 / 9 / 2012$ & $\# 0-7$ & 447.7 & 19.99 & 3.97 & 1.814 & 416.6 & 19.99 & 3.96 & 1.695 & 300 & 0 & $6.95 \%$ \\
\hline $174 ; 175$ & $8 / 13 / 2012$ & $\# 0-8$ & 442.7 & & & & 434.6 & 20.00 & 3.97 & 1.756 & 30 & 0 & $1.83 \%$ \\
\hline $176 ; 177$ & $8 / 15 / 2012$ & $\# 0-10$ & 455.0 & & & & 445.5 & 20.00 & 3.97 & 1.801 & 300 & 100 & $2.09 \%$ \\
\hline $181 ; 182$ & $8 / 16 / 2012$ & $\# 0-11$ & 442.0 & & & & 438.6 & 20.06 & 3.97 & 1.771 & 30 & 0 & $0.77 \%$ \\
\hline $153 ; 184 ; 185$ & 10/18/2012 & $\# 0-12$ & 443.4 & 20.01 & 3.99 & 1.772 & 417.8 & 20.05 & 3.97 & 1.686 & 300 & 0 & $5.76 \%$ \\
\hline $186 ; 187 ; 188$ & 10/22/2012 & $\# 0-13$ & 445.9 & 20.03 & 3.95 & 1.814 & 443.2 & 20.03 & 3.97 & 1.788 & 30 & 100 & $0.60 \%$ \\
\hline 189; 190; 191 & 10/25/2012 & $\# 0-14$ & 449.9 & 19.96 & 4.02 & 1.779 & 444.5 & 19.95 & 4.01 & 1.761 & 30 & 0 & $1.22 \%$ \\
\hline 192; 196; 194 & $10 / 30 / 2012$ & $\# 0-15$ & 441.6 & 20.01 & 3.96 & 1.789 & 436.7 & 20.00 & 3.95 & 1.786 & 300 & 100 & $1.11 \%$ \\
\hline \multirow{3}{*}{ 195; 196; 197} & $11 / 5 / 2012$ & $\# 0-16$ & 441.9 & 20.02 & 3.95 & 1.803 & 439.8 & 20.03 & 3.97 & 1.770 & 30 & 100 & $0.47 \%$ \\
\hline & $2 / 15 / 2013$ & \#0-17 & 441.3 & 20.00 & 3.97 & 1.779 & 406.1 & 20.00 & 3.98 & 1.636 & 300 & 0 & $7.98 \%$ high wt loss \\
\hline & $2 / 18 / 2013$ & \#0-18 & 446.0 & 19.99 & 3.99 & 1.786 & 364.2 & 19.97 & 3.98 & 1.468 & 300 & 0 & $18.33 \%$ significant pits \\
\hline \multirow[t]{3}{*}{ 198; 199; 200} & $2 / 20 / 2013$ & $\# 0-19$ & 450.1 & 19.99 & 4.00 & 1.791 & 419.2 & 19.98 & 3.99 & 1.680 & 300 & 0 & $6.87 \%$ \\
\hline & $2 / 25 / 2013$ & $\# 0-20$ & 451.2 & 20.01 & 4.00 & 1.792 & 238.8 & 19.91 & 3.86 & 1.027 & 30 & 100 & $47.07 \%$ high wt loss \\
\hline & $3 / 1 / 2013$ & $\# 0-21$ & 441.1 & 20.04 & 3.95 & 1.793 & 431.6 & 20.03 & 3.94 & 1.765 & 300 & 0 & $2.16 \% \mathrm{BO}$ fntc $50 \mathrm{hr}$ \\
\hline 201; 202; 203 & $3 / 5 / 2013$ & $\# 0-22$ & 446.4 & 20.03 & 3.99 & 1.780 & 444.9 & 20.02 & 3.98 & 1.783 & 30 & 100 & $0.34 \%$ \\
\hline $178 ; 179 ; 180$ & $3 / 7 / 2013$ & $\# 0-23$ & 446.7 & 19.98 & 3.99 & 1.789 & 421.2 & 19.97 & 3.98 & 1.697 & 300 & 0 & $5.69 \%$ \\
\hline $204 ; 205 ; 206$ & $3 / 11 / 2013$ & $\# 0-24$ & 448.5 & 19.95 & 3.99 & 1.800 & 436.1 & 19.95 & 3.99 & 1.748 & 300 & 100 & $2.76 \%$ \\
\hline
\end{tabular}




\begin{tabular}{|c|c|c|c|c|c|c|c|c|c|c|c|c|c|}
\hline Experimental data number & Date of test & $\begin{array}{l}\text { Specimen } \\
\text { ID }\end{array}$ & $\begin{array}{l}\text { Weight } \\
\text { (mg) }\end{array}$ & $\begin{array}{l}\text { Before Ox } \\
\text { Average L } \\
(\mathrm{mm})\end{array}$ & $\begin{array}{l}\text { xidation } \\
\text { Average D } \\
(\mathrm{mm})\end{array}$ & $\begin{array}{l}\text { Uensıty } \\
\left(\mathrm{g} / \mathrm{cm}^{3}\right)\end{array}$ & Weight (mg) & $\begin{array}{l}\text { After Ox } \\
\text { Average L } \\
(\mathrm{mm})\end{array}$ & $\begin{array}{l}\text { idation } \\
\text { Average D } \\
(\mathrm{mm})\end{array}$ & $\begin{array}{l}\text { Uensıty } \\
\left(\mathrm{g} / \mathrm{cm}^{3}\right)\end{array}$ & $\begin{array}{l}\mathrm{P}_{\mathrm{H} 2 \mathrm{O}} \\
(\mathrm{Pa})\end{array}$ & $\begin{array}{l}\mathrm{P}_{\mathrm{H} 2} \\
(\mathrm{~Pa})\end{array}$ & $\begin{array}{l}\text { Weight } \\
\text { loss }\end{array}$ \\
\hline $207 ; 208 ; 209$ & 3/12/2013 & "\#0-25 & 4555.1 & 19.99 & 4.00 & 1.815 & 4448.5 & 19.97 & 4.00 & "1.790 & 30 & 100 & "1.45\% \\
\hline \multirow{2}{*}{$210 ; 211 ; 212$} & $3 / 14 / 2013$ & $\# 0-26$ & 454.1 & 20.00 & 3.98 & 1.824 & 449.9 & 19.99 & 3.97 & 1.819 & 300 & 100 & $0.92 \%$ \\
\hline & $3 / 18 / 2013$ & $\# 0-27$ & 447.2 & 20.01 & 3.96 & 1.811 & 384.3 & 20.00 & 3.97 & 1.549 & 300 & 0 & $14.06 \%$ significant pits \\
\hline $213 ; 214 ; 215$ & $3 / 19 / 2013$ & $\# 0-28$ & 428.0 & 20.10 & 3.91 & 1.774 & 414.4 & 20.07 & 3.90 & 1.733 & 300 & 0 & $3.17 \%$ \\
\hline $216 ; 217 ; 218 ; 219 ; 220$ & $3 / 26 / 2013$ & DB8-1 & 438.7 & 19.74 & 3.99 & 1.776 & 429.8 & 19.73 & 3.98 & 1.753 & 300 & 100 & $2.03 \%$ \\
\hline $221 ; 222 ; 223$ & $4 / 2 / 2013$ & DB8-2 & 450.5 & 20.05 & 3.98 & 1.803 & 438.5 & 20.03 & 3.98 & 1.765 & 100 & 0 & $2.66 \%$ \\
\hline $224 ; 225 ; 226 ; 227$ & $4 / 3 / 2013$ & DB8-3 & 446.0 & 20.02 & 3.98 & 1.794 & 440.5 & 20.02 & 3.97 & 1.774 & 100 & 100 & $1.24 \%$ \\
\hline \multirow[t]{3}{*}{$228 ; 229 ; 230 ; 231$} & $4 / 5 / 2013$ & DB8-4 & 446.4 & 20.01 & 3.99 & 1.785 & 434.7 & 19.93 & 3.98 & 1.751 & 100 & 50 & $2.62 \%$ \\
\hline & $4 / 16 / 2013$ & DB9-1 & 437.7 & 20.02 & 3.96 & 1.779 & 425.9 & 19.92 & 3.94 & 1.757 & 30 & 50 & $2.70 \%$ noise in the data \\
\hline & $4 / 25 / 2013$ & DB9-2 & 439.3 & 19.99 & 3.95 & 1.793 & 431.7 & 19.97 & 3.94 & 1.772 & & & $1.72 \%$ noise in the data \\
\hline \multirow[t]{3}{*}{$232 ; 233 ; 234 ; 235$} & $5 / 24 / 2013$ & DB9-3 & 440.9 & 19.99 & 3.96 & 1.792 & 430.8 & 19.96 & 3.96 & 1.751 & 100 & 50 & $2.30 \%$ \\
\hline & $5 / 28 / 2013$ & DB9-4 & 444.0 & 20.02 & 3.97 & 1.795 & 437.4 & & & & & & $1.48 \%$ test operation \\
\hline & $5 / 29 / 2013$ & DB9-5 & 437.5 & 20.02 & 3.95 & 1.786 & & & & & & & lost in the furnace \\
\hline $236 ; 237 ; 238 ; 239$ & $5 / 31 / 2013$ & DB9-6 & 438.3 & 20.01 & 3.94 & 1.801 & 433.8 & 19.96 & 3.94 & 1.783 & 30 & 50 & $1.03 \%$ lost parameters file \\
\hline $240 ; 241 ; 242 ; 243$ & $6 / 3 / 2013$ & DB10-1 & 446.9 & 20.02 & 3.98 & 1.799 & 437.9 & 19.97 & 3.97 & 1.769 & 30 & 150 & $2.02 \%$ \\
\hline $244 ; 245 ; 246 ; 247$ & $6 / 4 / 2013$ & DB10-2 & 444.9 & 20.00 & 3.98 & 1.791 & 421.5 & 19.75 & 3.98 & 1.719 & 100 & 150 & $5.25 \%$ \\
\hline $248 ; 249 ; 250 ; 251$ & $6 / 6 / 2013$ & DB10-3 & 448.5 & 20.09 & 3.98 & 1.798 & 439.6 & 20.03 & 3.97 & 1.771 & 15 & 0 & $1.99 \%$ \\
\hline $252 ; 253 ; 254 ; 255$ & $6 / 7 / 2013$ & DB10-4 & 441.0 & 20.08 & 3.95 & 1.796 & 433.8 & 20.00 & 3.95 & 1.774 & 15 & 0 & $1.63 \%$ \\
\hline $256 ; 257 ; 258 ; 259$ & $6 / 18 / 2013$ & DB10-5 & 444.9 & 20.01 & 3.97 & 1.797 & 436.1 & 19.97 & 3.97 & 1.767 & 15 & 0 & $1.97 \%$ \\
\hline $260 ; 261 ; 262 ; 263$ & $6 / 20 / 2013$ & DB10-6 & 445.8 & 20.00 & 3.98 & 1.795 & 443.1 & 19.97 & 3.98 & 1.787 & 0 & 0 & $0.61 \%$ \\
\hline $264 ; 265 ; 266 ; 267$ & $6 / 21 / 2013$ & DB10-7 & 447.3 & 20.04 & 3.98 & 1.791 & 444.8 & 20.13 & 3.98 & 1.778 & 0 & 0 & $0.56 \%$ \\
\hline $268 ; 269 ; 270$ & $7 / 15 / 2013$ & \#12--1 & 454.3 & 20.04 & 4.00 & 1.800 & 452.7 & 20.05 & 4.01 & 1.790 & 0 & 0 & $0.36 \%$ \\
\hline $271 ; 272 ; 273 ; 274 ; 275 ; 27 \epsilon$ & $7 / 25 / 2013$ & $\# 12--2$ & 448.6 & 20.00 & 4.01 & 1.778 & 444.1 & 19.99 & 4.00 & 1.769 & 15 & 0 & $1.00 \%$ \\
\hline $277 ; 278 ; 279 ; 280 ; 281 ; 282$ & $7 / 26 / 2013$ & \#12--3 & 449.2 & 20.07 & 4.00 & 1.785 & 447.5 & 20.07 & 4.00 & 1.776 & 15 & 15 & $0.39 \%$ \\
\hline $283 ; 284 ; 285 ; 286 ; 287 ; 288$ & $7 / 27 / 2013$ & $\# 12--4$ & 448.5 & 20.03 & 4.00 & 1.786 & 446.1 & 20.02 & 4.00 & 1.777 & 30 & 0 & $0.53 \%$ \\
\hline $289 ; 290 ; 291 ; 292 ; 293 ; 294$ & $7 / 29 / 2013$ & $\# 17-1$ & 453.4 & 19.97 & 4.02 & 1.794 & 447.0 & 19.97 & 4.01 & 1.770 & 30 & 30 & $1.41 \%$ \\
\hline $295 ; 296 ; 297 ; 298 ; 299 ; 30 C$ & $7 / 30 / 2013$ & $\# 17-2$ & 452.5 & 20.00 & 4.00 & 1.798 & 447.8 & 20.01 & 4.00 & 1.783 & 100 & 0 & $1.03 \%$ \\
\hline $301 ; 302 ; 303 ; 304 ; 305 ; 30 €$ & $7 / 31 / 2013$ & \#17-3 & 450.6 & 20.01 & 3.99 & 1.800 & 447.5 & 20.00 & 3.99 & 1.792 & 15 & 0 & $0.70 \%$ \\
\hline 307; 308; 309; 310; 311; 312 & $8 / 2 / 2013$ & \#17-4 & 453.8 & 19.96 & 4.01 & 1.803 & 444.2 & 19.96 & 4.01 & 1.761 & 100 & 30 & $2.13 \%$ \\
\hline $313 ; 314 ; 315 ; 316 ; 317 ; 318$ & $8 / 3 / 2013$ & \#16-1 & 452.2 & 20.01 & 4.00 & 1.796 & 434.5 & 20.01 & 4.00 & 1.727 & 150 & 0 & $3.91 \%$ \\
\hline $319 ; 320 ; 321 ; 322 ; 323 ; 324$ & $8 / 4 / 2013$ & \#16-2 & 449.4 & 20.03 & 3.99 & 1.796 & 429.8 & 20.03 & 3.99 & 1.717 & 100 & 100 & $4.35 \%$ significant pits \\
\hline $325 ; 236 ; 327 ; 328 ; 329 ; 33 \mathrm{C}$ & $8 / 5 / 2013$ & $\# 16-3$ & 447.8 & 20.03 & 3.99 & 1.793 & 441.5 & 20.02 & 3.98 & 1.771 & 100 & 150 & $1.41 \%$ \\
\hline $331 ; 332 ; 333 ; 334 ; 335 ; 336$ & $8 / 6 / 2013$ & $\# 16-4$ & 454.4 & 19.98 & 4.02 & 1.796 & 453.9 & 19.97 & 4.02 & 1.796 & 30 & 150 & $0.12 \%$ \\
\hline $337 ; 338 ; 339 ; 340 ; 341 ; 342$ & $8 / 7 / 2013$ & \#14-01 & 442.5 & 20.02 & 3.98 & 1.782 & 440.7 & 20.01 & 3.97 & 1.776 & 30 & 100 & $0.42 \%$ \\
\hline $343 ; 344 ; 345 ; 346 ; 347 ; 348$ & $8 / 8 / 2013$ & \#14-02 & 448.3 & 20.01 & 4.00 & 1.782 & 446.2 & 19.99 & 4.00 & 1.775 & 15 & 100 & $0.46 \%$ \\
\hline $349 ; 350$ & $8 / 12 / 2013$ & \#14-03 & 449.9 & 19.98 & 4.01 & 1.785 & 449.4 & 19.97 & 4.01 & 1.779 & 0 & 100 & $0.11 \%$ \\
\hline $351 ; 352 ; 353 ; 354 ; 355$ & $8 / 21 / 2013$ & \#14-04 & 451.9 & 19.97 & 4.01 & 1.794 & 435.1 & 19.97 & 4.01 & 1.730 & 100 & 100 & $3.71 \%$ \\
\hline
\end{tabular}




\section{ANNEX 6 LOG OF EXPERIMENTAL RESULTS - GRAPHITE PCEA}

\begin{tabular}{|c|c|c|c|c|c|c|c|c|c|c|c|c|c|c|c|c|}
\hline \multirow{2}{*}{$\begin{array}{l}\text { Exp data } \\
\text { number }\end{array}$} & \multirow[b]{2}{*}{ Test Date } & \multirow{2}{*}{$\begin{array}{c}\text { Specimen } \\
\text { ID }\end{array}$} & \multicolumn{2}{|c|}{$\mathrm{H} 2 \mathrm{O}$ Pressure } & \multirow{2}{*}{$\begin{array}{c}\mathrm{H} 2 \\
\text { Pressure }\end{array}$} & \multirow{2}{*}{$\begin{array}{c}\text { Temperat } \\
\text { ure }\end{array}$} & \multicolumn{2}{|c|}{ Weight } & \multicolumn{2}{|c|}{ Time in the test } & \multirow[b]{2}{*}{ Rate } & \multicolumn{2}{|c|}{ Weight loss $\%$} & \multicolumn{2}{|c|}{ Sample preparaton } & \multirow{2}{*}{$\begin{array}{l}\text { Wt loss in } \\
\text { outgassing }\end{array}$} \\
\hline & & & target & actual $^{\&}$ & & & before & after & before & after & & before & after & duration & $\overline{\text { temperature }}$ & \\
\hline & & & $\mathrm{Pa}$ & $\mathrm{Pa}$ & $\mathrm{Pa}$ & OC & $\mathrm{mg}$ & $\mathrm{mg}$ & $\mathrm{hr}$ & $\mathrm{hr}$ & $s^{-1}$ & $\%$ & $\%$ & $\mathrm{~h}$ & ${ }^{\circ} \mathrm{C}$ & $\mathrm{mg}$ \\
\hline 2 & $2 / 21 / 12$ & $\# 1-1$ & 100 & 105 & 0 & 900 & 446.79 & 446.65 & 6.97 & 9.97 & $2.86 \mathrm{E}-08$ & $0.00 \%$ & $0.03 \%$ & 4 & 1100 & 0.352 \\
\hline 3 & $2 / 21 / 12$ & $\# 1-1$ & 100 & 104 & 0 & 925 & 446.64 & 446.45 & 10.01 & 13.01 & 3.97E-08 & $0.03 \%$ & $0.08 \%$ & 4 & 1100 & 0.352 \\
\hline 4 & 2/21/12 & \#1-1 & 100 & 102 & 0 & 950 & 446.43 & 446.15 & 13.05 & 16.05 & $5.93 \mathrm{E}-08$ & $0.08 \%$ & $0.14 \%$ & 4 & 1100 & 0.352 \\
\hline 5 & $2 / 21 / 12$ & \#1-1 & 100 & 101 & 0 & 975 & 446.13 & 445.68 & 16.09 & 19.09 & $9.50 \mathrm{E}-08$ & $0.15 \%$ & $0.25 \%$ & 4 & 1100 & 0.352 \\
\hline 6 & $2 / 21 / 12$ & \#1-1 & 100 & 103 & 0 & 1000 & 445.66 & 444.91 & 19.13 & 22.13 & $1.56 \mathrm{E}-07$ & $0.25 \%$ & $0.42 \%$ & 4 & 1100 & 0.352 \\
\hline 7 & 2/22/12 & $\# 1-2$ & 50 & 69 & 0 & 900 & 444.90 & 444.79 & 6.97 & 9.97 & 2.17E-08 & $0.00 \%$ & $0.02 \%$ & 4 & 1100 & 0.242 \\
\hline 8 & $2 / 22 / 12$ & $\# 1-2$ & 50 & 68 & 0 & 925 & 444.78 & 444.65 & 10.01 & 13.01 & $2.89 \mathrm{E}-08$ & $0.03 \%$ & $0.06 \%$ & 4 & 1100 & 0.242 \\
\hline 9 & 2/22/12 & $\# 1-2$ & 50 & 65 & 0 & 950 & 444.64 & 444.44 & 13.05 & 16.05 & 4.17E-08 & $0.06 \%$ & $0.10 \%$ & 4 & 1100 & 0.242 \\
\hline 10 & $2 / 22 / 12$ & $\# 1-2$ & 50 & 66 & 0 & 975 & 444.42 & 444.11 & 16.09 & 19.09 & $6.55 \mathrm{E}-08$ & $0.11 \%$ & $0.18 \%$ & 4 & 1100 & 0.242 \\
\hline 11 & $2 / 22 / 12$ & $\# 1-2$ & 50 & 68 & 0 & 1000 & 444.09 & 443.53 & 19.13 & 22.13 & 1.19E-07 & $0.18 \%$ & $0.31 \%$ & 4 & 1100 & 0.242 \\
\hline 12 & $2 / 23 / 12$ & \#1-3 & 150 & 145 & 0 & 900 & 444.37 & 444.19 & 6.97 & 9.97 & $3.59 \mathrm{E}-08$ & $0.00 \%$ & $0.04 \%$ & 4 & 1100 & 0.726 \\
\hline 13 & 2/23/12 & \#1-3 & 150 & 140 & 0 & 925 & 444.18 & 443.97 & 10.01 & 13.01 & $4.56 \mathrm{E}-08$ & $0.04 \%$ & $0.09 \%$ & 4 & 1100 & 0.726 \\
\hline 14 & $2 / 23 / 12$ & $\# 1-3$ & 150 & 142 & 0 & 950 & 443.95 & 443.61 & 13.05 & 16.05 & 7.19E-08 & $0.09 \%$ & $0.17 \%$ & 4 & 1100 & 0.726 \\
\hline 15 & $2 / 23 / 12$ & $\# 1-3$ & 150 & 145 & 0 & 975 & 443.59 & 443.02 & 16.09 & 19.09 & $1.30 \mathrm{E}-07$ & $0.17 \%$ & $0.30 \%$ & 4 & 1100 & 0.726 \\
\hline 16 & $2 / 23 / 12$ & $\# 1-3$ & 150 & 145 & 0 & 1000 & 443.00 & 442.11 & 19.13 & 22.13 & $2.24 \mathrm{E}-07$ & $0.31 \%$ & $0.51 \%$ & 4 & 1100 & 0.726 \\
\hline 17 & $2 / 24 / 13$ & $\# 1-4$ & 250 & 255 & 0 & 900 & 445.62 & 445.41 & 6.97 & 9.97 & $2.95 \mathrm{E}-08$ & $0.00 \%$ & $0.05 \%$ & 4 & 1100 & 0.945 \\
\hline 18 & $2 / 24 / 13$ & $\# 1-4$ & 250 & 258 & 0 & 925 & 445.39 & 445.09 & 10.01 & 13.01 & 4.04E-08 & $0.05 \%$ & $0.12 \%$ & 4 & 1100 & 0.945 \\
\hline 19 & $2 / 24 / 13$ & $\# 1-4$ & 250 & 259 & 0 & 950 & 445.07 & 444.67 & 13.05 & 16.05 & $5.35 \mathrm{E}-08$ & $0.12 \%$ & $0.21 \%$ & 4 & 1100 & 0.945 \\
\hline 20 & $2 / 24 / 13$ & $\# 1-4$ & 250 & 261 & 0 & 975 & 444.65 & 444.01 & 16.09 & 19.09 & 8.57E-08 & $0.22 \%$ & $0.36 \%$ & 4 & 1100 & 0.945 \\
\hline 21 & $2 / 24 / 13$ & \#1-4 & 250 & 261 & 0 & 1000 & 443.98 & 442.77 & 19.13 & 22.13 & $1.67 \mathrm{E}-07$ & $0.37 \%$ & $0.64 \%$ & 4 & 1100 & 0.945 \\
\hline 22 & $3 / 1 / 12$ & \#2-1 & 100 & 104 & 0 & 900 & 446.25 & 446.18 & 23.47 & 26.47 & $1.48 \mathrm{E}-08$ & $0.00 \%$ & $0.02 \%$ & 20 & 1100 & 2.451 \\
\hline 23 & $3 / 1 / 12$ & \#2-1 & 100 & 99 & 0 & 925 & 446.17 & 446.07 & 26.51 & 29.51 & $2.04 \mathrm{E}-08$ & $0.02 \%$ & $0.04 \%$ & 20 & 1100 & 2.451 \\
\hline 24 & $3 / 1 / 12$ & $\# 2-1$ & 100 & 99 & 0 & 950 & 446.06 & 445.90 & 29.55 & 32.55 & 3.37E-08 & $0.04 \%$ & $0.08 \%$ & 20 & 1100 & 2.451 \\
\hline 25 & $3 / 1 / 12$ & $\# 2-1$ & 100 & 99 & 0 & 975 & 445.89 & 445.64 & 32.59 & 35.59 & 5.07E-08 & $0.08 \%$ & $0.14 \%$ & 20 & 1100 & 2.451 \\
\hline 26 & $3 / 1 / 12$ & \#2-1 & 100 & 97 & 0 & 1000 & 445.63 & 445.23 & 35.63 & 38.63 & $8.40 \mathrm{E}-08$ & $0.14 \%$ & $0.23 \%$ & 20 & 1100 & 2.451 \\
\hline 27 & $3 / 5 / 12$ & $\# 2-2$ & 70 & 65 & 0 & 900 & 445.72 & 445.44 & 6.80 & 9.80 & $5.82 \mathrm{E}-08$ & $0.00 \%$ & $0.06 \%$ & 4 & 1100 & 0.368 \\
\hline 28 & $3 / 5 / 12$ & $\# 2-2$ & 70 & 70 & 0 & 925 & 445.44 & 445.23 & 9.84 & 12.84 & 4.43E-08 & $0.06 \%$ & $0.11 \%$ & 4 & 1100 & 0.368 \\
\hline 29 & $3 / 5 / 12$ & $\# 2-2$ & 70 & 70 & 0 & 950 & 445.23 & 445.08 & 12.88 & 15.88 & $3.14 \mathrm{E}-08$ & $0.11 \%$ & $0.14 \%$ & 4 & 1100 & 0.368 \\
\hline 30 & $3 / 5 / 12$ & $\# 2-2$ & 70 & 73 & 0 & 975 & 445.09 & 444.95 & 15.93 & 18.93 & $2.79 \mathrm{E}-08$ & $0.14 \%$ & $0.17 \%$ & 4 & 1100 & 0.368 \\
\hline 31 & $3 / 5 / 12$ & $\# 2-2$ & 70 & 68 & 0 & 1000 & 444.96 & 444.87 & 18.97 & 21.97 & $1.86 \mathrm{E}-08$ & $0.17 \%$ & $0.19 \%$ & 4 & 1100 & 0.368 \\
\hline 32 & $3 / 6 / 12$ & $\# 2-3$ & 100 & 107 & 0 & 900 & 449.74 & 449.48 & 6.80 & 9.80 & 5.39E-08 & $0.00 \%$ & $0.06 \%$ & 4 & 1100 & 0.228 \\
\hline 33 & $3 / 6 / 12$ & $\# 2-3$ & 100 & 106 & 0 & 925 & 449.49 & 449.30 & 9.84 & 12.84 & $3.84 \mathrm{E}-08$ & $0.06 \%$ & $0.10 \%$ & 4 & 1100 & 0.228 \\
\hline 34 & $3 / 6 / 12$ & \#2-3 & 100 & 105 & 0 & 950 & 449.30 & 449.16 & 12.88 & 15.88 & $3.01 \mathrm{E}-08$ & $0.10 \%$ & $0.13 \%$ & 4 & 1100 & 0.228 \\
\hline 35 & $3 / 6 / 12$ & $\# 2-3$ & 100 & 104 & 0 & 975 & 449.16 & 449.04 & 15.93 & 18.93 & $2.41 \mathrm{E}-08$ & $0.13 \%$ & $0.15 \%$ & 4 & 1100 & 0.228 \\
\hline 36 & $3 / 6 / 12$ & \#2-3 & 100 & 104 & 0 & 1000 & 449.05 & 448.95 & 18.97 & 21.97 & $2.11 \mathrm{E}-08$ & $0.15 \%$ & $0.18 \%$ & 4 & 1100 & 0.228 \\
\hline
\end{tabular}




\begin{tabular}{|c|c|c|c|c|c|c|c|c|c|c|c|c|c|c|c|c|}
\hline \multirow{2}{*}{$\begin{array}{l}\text { Exp data } \\
\text { number }\end{array}$} & \multirow[b]{2}{*}{ Test Date } & \multirow{2}{*}{$\begin{array}{l}\text { Specimen } \\
\text { ID }\end{array}$} & \multicolumn{2}{|c|}{ H2O Pressure } & \multirow{2}{*}{$\begin{array}{c}\mathrm{H} 2 \\
\text { Pressure }\end{array}$} & \multirow{2}{*}{$\begin{array}{c}\text { Temperat } \\
\text { ure }\end{array}$} & \multicolumn{2}{|c|}{ Weight } & \multicolumn{2}{|c|}{ Time in the test } & \multirow[b]{2}{*}{ Rate } & \multicolumn{2}{|c|}{ Weight loss \% } & \multicolumn{2}{|c|}{ Sample preparaton } & \multirow{2}{*}{$\begin{array}{l}\text { Wt loss in } \\
\text { outgassing }\end{array}$} \\
\hline & & & target & actual $^{\&}$ & & & before & after & before & after & & before & after & duration & temperature & \\
\hline & & & $\mathrm{Pa}$ & $\mathrm{Pa}$ & $\mathrm{Pa}$ & $\mathrm{OC}$ & $\mathrm{mg}$ & $\mathrm{mg}$ & $\mathrm{hr}$ & $\mathrm{hr}$ & $s^{-1}$ & $\%$ & $\%$ & $\mathrm{~h}$ & ${ }^{\circ} \mathrm{C}$ & $\mathrm{mg}$ \\
\hline 37 & $3 / 7 / 12$ & \#2-4 & 150 & 176 & 0 & 900 & 451.08 & 450.68 & 6.80 & 9.80 & $5.37 \mathrm{E}-08$ & $0.00 \%$ & $0.09 \%$ & 4 & 1100 & 0.280 \\
\hline 38 & $3 / 7 / 12$ & $\# 2-4$ & 150 & 174 & 0 & 925 & 450.68 & 450.37 & 9.84 & 12.84 & $3.83 \mathrm{E}-08$ & $0.09 \%$ & $0.16 \%$ & 4 & 1100 & 0.280 \\
\hline 39 & $3 / 7 / 12$ & \#2-4 & 150 & 174 & 0 & 950 & 450.38 & 450.15 & 12.88 & 15.88 & $3.00 \mathrm{E}-08$ & $0.16 \%$ & $0.21 \%$ & 4 & 1100 & 0.280 \\
\hline 40 & $3 / 7 / 12$ & $\# 2-4$ & 150 & 173 & 0 & 975 & 450.15 & 449.98 & 15.93 & 18.93 & $2.40 \mathrm{E}-08$ & $0.21 \%$ & $0.24 \%$ & 4 & 1100 & 0.280 \\
\hline 41 & $3 / 7 / 12$ & \#2-4 & 150 & 174 & 0 & 1000 & 449.99 & 449.85 & 18.97 & 21.97 & $2.11 \mathrm{E}-08$ & $0.24 \%$ & $0.27 \%$ & 4 & 1100 & 0.280 \\
\hline 42 & $3 / 8 / 12$ & \#3-1 & 250 & 264 & 0 & 900 & 446.36 & 445.46 & 6.80 & 9.80 & $1.88 \mathrm{E}-07$ & $0.00 \%$ & $0.20 \%$ & 4 & 1100 & 0.263 \\
\hline 43 & $3 / 8 / 12$ & \#3-1 & 250 & 261 & 0 & 925 & 445.45 & 444.78 & 9.84 & 12.84 & $1.39 \mathrm{E}-07$ & $0.20 \%$ & $0.35 \%$ & 4 & 1100 & 0.263 \\
\hline 44 & $3 / 8 / 12$ & $\# 3-1$ & 250 & 258 & 0 & 950 & 444.78 & 444.30 & 12.88 & 15.88 & $9.94 \mathrm{E}-08$ & $0.35 \%$ & $0.46 \%$ & 4 & 1100 & 0.263 \\
\hline 45 & $3 / 8 / 12$ & \#3-1 & 250 & 247 & 0 & 975 & 444.30 & 443.99 & 15.93 & 18.93 & $6.41 E-08$ & $0.46 \%$ & $0.53 \%$ & 4 & 1100 & 0.263 \\
\hline 46 & $3 / 8 / 12$ & \#3-1 & 250 & 238 & 0 & 1000 & 444.00 & 443.83 & 18.97 & 21.97 & $3.47 \mathrm{E}-08$ & $0.53 \%$ & $0.57 \%$ & 4 & 1100 & 0.263 \\
\hline 47 & $3 / 19 / 12$ & $\# 3-2$ & 70 & 64 & 0 & 900 & 446.91 & 446.50 & 6.80 & 9.80 & $2.15 \mathrm{E}-08$ & $0.00 \%$ & $0.09 \%$ & 4 & 1100 & 0.263 \\
\hline 48 & $3 / 19 / 12$ & $\# 3-2$ & 70 & 64 & 0 & 925 & 446.50 & 446.19 & 9.84 & 12.84 & 2.87E-08 & $0.09 \%$ & $0.16 \%$ & 4 & 1100 & 0.263 \\
\hline 49 & $3 / 19 / 12$ & \#3-2 & 70 & 65 & 0 & 950 & 446.19 & 445.97 & 12.88 & 15.88 & 4.14E-08 & $0.16 \%$ & $0.21 \%$ & 4 & 1100 & 0.263 \\
\hline 50 & $3 / 19 / 12$ & $\# 3-2$ & 70 & 72 & 0 & 975 & 445.98 & 445.79 & 15.93 & 18.93 & $6.51 \mathrm{E}-08$ & $0.21 \%$ & $0.25 \%$ & 4 & 1100 & 0.263 \\
\hline 51 & $3 / 19 / 12$ & $\# 3-2$ & 70 & 72 & 0 & 1000 & 445.80 & 445.66 & 18.97 & 21.97 & $1.18 \mathrm{E}-07$ & $0.25 \%$ & $0.28 \%$ & 4 & 1100 & 0.263 \\
\hline 52 & $3 / 20 / 12$ & $\# 3-4$ & 65 & 65 & 0 & 900 & 446.91 & 446.50 & 6.80 & 9.80 & $2.16 \mathrm{E}-08$ & $0.00 \%$ & $0.09 \%$ & 4 & 1100 & 0.263 \\
\hline 53 & $3 / 20 / 12$ & $\# 3-4$ & 65 & 63 & 0 & 925 & 446.50 & 446.19 & 9.84 & 12.84 & $2.88 \mathrm{E}-08$ & $0.09 \%$ & $0.16 \%$ & 4 & 1100 & 0.263 \\
\hline 54 & $3 / 20 / 12$ & $\# 3-4$ & 65 & 65 & 0 & 950 & 446.19 & 445.97 & 12.88 & 15.88 & 4.16E-08 & $0.16 \%$ & $0.21 \%$ & 4 & 1100 & 0.263 \\
\hline 55 & $3 / 20 / 12$ & \#3-4 & 65 & 71 & 0 & 975 & 445.98 & 445.79 & 15.93 & 18.93 & $6.53 \mathrm{E}-08$ & $0.21 \%$ & $0.25 \%$ & 4 & 1100 & 0.263 \\
\hline 56 & $3 / 20 / 12$ & $\# 3-4$ & 65 & 74 & 0 & 1000 & 445.80 & 445.66 & 18.97 & 21.97 & $1.18 \mathrm{E}-07$ & $0.25 \%$ & $0.28 \%$ & 4 & 1100 & 0.263 \\
\hline 57 & $3 / 26 / 12$ & $\# 3-3$ & 150 & 148 & 0 & 900 & 444.62 & 444.53 & 6.97 & 9.97 & $1.76 \mathrm{E}-08$ & $0.00 \%$ & $0.02 \%$ & 4 & 1100 & 0.575 \\
\hline 58 & $3 / 26 / 12$ & $\# 3-3$ & 150 & 136 & 0 & 925 & 444.52 & 444.39 & 10.01 & 13.01 & $2.74 \mathrm{E}-08$ & $0.02 \%$ & $0.05 \%$ & 4 & 1100 & 0.575 \\
\hline 59 & $3 / 26 / 12$ & \#3-3 & 150 & 134 & 0 & 950 & 444.38 & 444.18 & 13.05 & 16.05 & $4.21 \mathrm{E}-08$ & $0.05 \%$ & $0.10 \%$ & 4 & 1100 & 0.575 \\
\hline 60 & $3 / 26 / 12$ & $\# 3-3$ & 150 & 133 & 0 & 975 & 444.17 & 443.87 & 16.09 & 19.09 & $6.28 \mathrm{E}-08$ & $0.10 \%$ & $0.17 \%$ & 4 & 1100 & 0.575 \\
\hline 61 & $3 / 26 / 12$ & \#3-3 & 150 & 154 & 0 & 1000 & 443.85 & 443.32 & 19.13 & 22.13 & $1.12 \mathrm{E}-07$ & $0.17 \%$ & $0.29 \%$ & 4 & 1100 & 0.575 \\
\hline 62 & 4/19/12 & DB1-1 & 250 & 247 & 0 & 900 & 444.87 & 444.75 & 6.97 & 9.97 & $2.57 \mathrm{E}-08$ & $0.00 \%$ & $0.03 \%$ & 4 & 1100 & 0.415 \\
\hline 63 & 4/19/12 & DB1-1 & 250 & 244 & 0 & 925 & 444.74 & 444.56 & 10.01 & 13.01 & $3.66 \mathrm{E}-08$ & $0.03 \%$ & $0.07 \%$ & 4 & 1100 & 0.415 \\
\hline 64 & 4/19/12 & DB1-1 & 250 & 233 & 0 & 950 & 444.55 & 444.31 & 13.05 & 16.05 & 5.17E-08 & $0.07 \%$ & $0.13 \%$ & 4 & 1100 & 0.415 \\
\hline 65 & $4 / 19 / 12$ & DB1-1 & 250 & 256 & 0 & 975 & 444.29 & 443.88 & 16.09 & 19.09 & 8.57E-08 & $0.13 \%$ & $0.22 \%$ & 4 & 1100 & 0.415 \\
\hline 66 & $4 / 19 / 12$ & DB1-1 & 250 & 260 & 0 & 1000 & 443.86 & 443.17 & 19.13 & 22.13 & 1.44E-07 & $0.23 \%$ & $0.38 \%$ & 4 & 1100 & 0.415 \\
\hline 67 & $4 / 23 / 12$ & DB1-2 & 70 & 68 & 0 & 900 & 442.62 & 442.43 & 6.97 & 9.97 & $3.71 E-08$ & $0.00 \%$ & $0.04 \%$ & 4 & 1100 & 0.743 \\
\hline 68 & 4/23/12 & DB1-2 & 70 & 63 & 0 & 925 & 442.42 & 442.23 & 10.01 & 13.01 & $3.98 \mathrm{E}-08$ & $0.04 \%$ & $0.09 \%$ & 4 & 1100 & 0.743 \\
\hline 69 & $4 / 23 / 12$ & DB1-2 & 70 & 62 & 0 & 950 & 442.22 & 441.99 & 13.05 & 16.05 & $4.82 \mathrm{E}-08$ & $0.09 \%$ & $0.14 \%$ & 4 & 1100 & 0.743 \\
\hline 70 & $4 / 23 / 12$ & DB1-2 & 70 & 66 & 0 & 975 & 441.97 & 441.68 & 16.09 & 19.09 & $6.24 \mathrm{E}-08$ & $0.15 \%$ & $0.21 \%$ & 4 & 1100 & 0.743 \\
\hline 71 & $4 / 23 / 12$ & DB1-2 & 70 & 71 & 0 & 1000 & 441.66 & 441.22 & 19.13 & 22.13 & $9.22 \mathrm{E}-08$ & $0.22 \%$ & $0.32 \%$ & 4 & 1100 & 0.743 \\
\hline 72 & $4 / 24 / 12$ & DB1-3 & 70 & 62 & 0 & 900 & 445.21 & 445.07 & 6.97 & 9.97 & $3.02 \mathrm{E}-08$ & $0.00 \%$ & $0.03 \%$ & 4 & 1100 & 0.357 \\
\hline 73 & $4 / 24 / 12$ & DB1-3 & 70 & 64 & 0 & 925 & 445.06 & 444.89 & 10.01 & 13.01 & 3.54E-08 & $0.03 \%$ & $0.07 \%$ & 4 & 1100 & 0.357 \\
\hline 74 & $4 / 24 / 12$ & DB1-3 & 70 & 63 & 0 & 950 & 444.88 & 444.67 & 13.05 & 16.05 & $4.38 \mathrm{E}-08$ & $0.07 \%$ & $0.12 \%$ & 4 & 1100 & 0.357 \\
\hline 75 & $4 / 24 / 12$ & DB1-3 & 70 & 67 & 0 & 975 & 444.65 & 444.38 & 16.09 & 19.09 & $5.76 \mathrm{E}-08$ & $0.12 \%$ & $0.19 \%$ & 4 & 1100 & 0.357 \\
\hline 76 & $4 / 24 / 12$ & DB1-3 & 70 & 70 & 0 & 1000 & 444.36 & 444.02 & 19.13 & 22.13 & $7.20 \mathrm{E}-08$ & $0.19 \%$ & $0.27 \%$ & 4 & 1100 & 0.357 \\
\hline
\end{tabular}




\begin{tabular}{|c|c|c|c|c|c|c|c|c|c|c|c|c|c|c|c|c|}
\hline \multirow{2}{*}{$\begin{array}{l}\text { Exp data } \\
\text { number }\end{array}$} & \multirow[b]{2}{*}{ Test Date } & \multirow{2}{*}{$\begin{array}{c}\text { Specimen } \\
\text { ID }\end{array}$} & \multicolumn{2}{|c|}{$\mathrm{H} 2 \mathrm{O}$ Pressure } & \multirow{2}{*}{$\begin{array}{c}\mathrm{H} 2 \\
\text { Pressure }\end{array}$} & \multirow{2}{*}{$\begin{array}{c}\text { Temperat } \\
\text { ure }\end{array}$} & \multicolumn{2}{|c|}{ Weight } & \multicolumn{2}{|c|}{ Time in the test } & \multirow[b]{2}{*}{ Rate } & \multicolumn{2}{|c|}{ Weight loss \% } & \multicolumn{2}{|c|}{ Sample preparaton } & \multirow{2}{*}{$\begin{array}{l}\text { Wt loss in } \\
\text { outgassing }\end{array}$} \\
\hline & & & target & actual $^{\&}$ & & & before & after & before & after & & before & after & duration & temperature & \\
\hline & & & $\mathrm{Pa}$ & $\mathrm{Pa}$ & $\mathrm{Pa}$ & $\mathrm{OC}$ & $\mathrm{mg}$ & $\mathrm{mg}$ & $\mathrm{hr}$ & $\mathrm{hr}$ & $\mathrm{s}^{-1}$ & $\%$ & $\%$ & $\mathrm{~h}$ & ${ }^{\circ} \mathrm{C}$ & $\mathrm{mg}$ \\
\hline 77 & $4 / 26 / 12$ & DB1-4 & 50 & 49 & 0 & 900 & 445.89 & 445.71 & 6.97 & 9.97 & $3.83 \mathrm{E}-08$ & $0.00 \%$ & $0.04 \%$ & 4 & 1100 & 0.455 \\
\hline 78 & $4 / 26 / 12$ & DB1-4 & 50 & 47 & 0 & 925 & 445.69 & 445.47 & 10.01 & 13.01 & 4.59E-08 & $0.04 \%$ & $0.09 \%$ & 4 & 1100 & 0.455 \\
\hline 79 & $4 / 26 / 12$ & DB1-4 & 50 & 47 & 0 & 950 & 445.46 & 445.23 & 13.05 & 16.05 & $4.91 \mathrm{E}-08$ & $0.10 \%$ & $0.15 \%$ & 4 & 1100 & 0.455 \\
\hline 80 & $4 / 26 / 12$ & DB1-4 & 50 & 48 & 0 & 975 & 445.21 & 444.92 & 16.09 & 19.09 & $6.06 \mathrm{E}-08$ & $0.15 \%$ & $0.22 \%$ & 4 & 1100 & 0.455 \\
\hline 81 & $4 / 26 / 12$ & DB1-4 & 50 & 56 & 0 & 1000 & 444.90 & 444.50 & 19.13 & 22.13 & $8.45 \mathrm{E}-08$ & $0.22 \%$ & $0.31 \%$ & 4 & 1100 & 0.455 \\
\hline 82 & $5 / 1 / 12$ & DB1-5 & 30 & 31 & 0 & 900 & 447.44 & 447.21 & 6.97 & 9.97 & $3.85 \mathrm{E}-08$ & $0.00 \%$ & $0.05 \%$ & 4 & 1100 & 0.648 \\
\hline 83 & $5 / 1 / 12$ & DB1-5 & 30 & 31 & 0 & 925 & 447.20 & 447.01 & 10.01 & 13.01 & $3.88 \mathrm{E}-08$ & $0.05 \%$ & $0.09 \%$ & 4 & 1100 & 0.648 \\
\hline 84 & $5 / 1 / 12$ & DB1-5 & 30 & 30 & 0 & 950 & 447.00 & 446.79 & 13.05 & 16.05 & 4.38E-08 & $0.10 \%$ & $0.15 \%$ & 4 & 1100 & 0.648 \\
\hline 85 & $5 / 1 / 12$ & DB1-5 & 30 & 31 & 0 & 975 & 446.78 & 446.51 & 16.09 & 19.09 & $5.51 \mathrm{E}-08$ & $0.15 \%$ & $0.21 \%$ & 4 & 1100 & 0.648 \\
\hline 86 & $5 / 1 / 12$ & DB1-5 & 30 & 35 & 0 & 1000 & 446.49 & 446.13 & 19.13 & 22.13 & 7.73E-08 & $0.21 \%$ & $0.29 \%$ & 4 & 1100 & 0.648 \\
\hline 87 & $5 / 2 / 12$ & DB2-1 & 200 & 216 & 0 & 900 & 450.49 & 450.30 & 6.97 & 9.97 & 4.10E-08 & $0.00 \%$ & $0.04 \%$ & 4 & 1100 & 0.436 \\
\hline 88 & $5 / 2 / 12$ & DB2-1 & 200 & 207 & 0 & 925 & 450.28 & 450.03 & 10.01 & 13.01 & $5.34 \mathrm{E}-08$ & $0.05 \%$ & $0.10 \%$ & 4 & 1100 & 0.436 \\
\hline 89 & $5 / 2 / 12$ & DB2-1 & 200 & 204 & 0 & 950 & 450.01 & 449.66 & 13.05 & 16.05 & 7.31E-08 & $0.11 \%$ & $0.18 \%$ & 4 & 1100 & 0.436 \\
\hline 90 & $5 / 2 / 12$ & DB2-1 & 200 & 207 & 0 & 975 & 449.64 & 449.10 & 16.09 & 19.09 & $1.12 \mathrm{E}-07$ & $0.19 \%$ & $0.31 \%$ & 4 & 1100 & 0.436 \\
\hline 91 & $5 / 2 / 12$ & DB2-1 & 200 & 236 & 0 & 1000 & 449.08 & 448.11 & 19.13 & 22.13 & $2.02 \mathrm{E}-07$ & $0.31 \%$ & $0.53 \%$ & 4 & 1100 & 0.436 \\
\hline 92 & $5 / 11 / 12$ & DB2-2 & 100 & 96 & 0 & 900 & 443.97 & 443.80 & 6.97 & 9.97 & $3.46 \mathrm{E}-08$ & $0.00 \%$ & $0.04 \%$ & 4 & 1100 & 0.403 \\
\hline 93 & $5 / 11 / 12$ & DB2-2 & 100 & 95 & 0 & 925 & 443.79 & 443.58 & 10.01 & 13.01 & 4.46E-08 & $0.04 \%$ & $0.09 \%$ & 4 & 1100 & 0.403 \\
\hline 94 & $5 / 11 / 12$ & DB2-2 & 100 & 98 & 0 & 950 & 443.57 & 443.32 & 13.05 & 16.05 & 5.31E-08 & $0.09 \%$ & $0.15 \%$ & 4 & 1100 & 0.403 \\
\hline 95 & $5 / 11 / 12$ & DB2-2 & 100 & 99 & 0 & 975 & 443.30 & 442.96 & 16.09 & 19.09 & $7.24 \mathrm{E}-08$ & $0.15 \%$ & $0.23 \%$ & 4 & 1100 & 0.403 \\
\hline 96 & $5 / 11 / 12$ & DB2-2 & 100 & 98 & 0 & 1000 & 442.94 & 442.46 & 19.13 & 22.13 & $1.13 \mathrm{E}-07$ & $0.23 \%$ & $0.34 \%$ & 4 & 1100 & 0.403 \\
\hline 97 & $5 / 14 / 12$ & DB2-3 & 150 & 140 & 0 & 900 & 443.70 & 443.52 & 6.97 & 9.97 & 3.77E-08 & $0.00 \%$ & $0.04 \%$ & 4 & 1100 & 0.464 \\
\hline 98 & $5 / 14 / 12$ & DB2-3 & 150 & 157 & 0 & 925 & 443.50 & 443.26 & 10.01 & 13.01 & 5.06E-08 & $0.04 \%$ & $0.10 \%$ & 4 & 1100 & 0.464 \\
\hline 99 & $5 / 14 / 12$ & DB2-3 & 150 & 153 & 0 & 950 & 443.25 & 442.94 & 13.05 & 16.05 & 6.59E-08 & $0.10 \%$ & $0.17 \%$ & 4 & 1100 & 0.464 \\
\hline 100 & $5 / 14 / 12$ & DB2-3 & 150 & 153 & 0 & 975 & 442.92 & 442.47 & 16.09 & 19.09 & $9.49 \mathrm{E}-08$ & $0.18 \%$ & $0.28 \%$ & 4 & 1100 & 0.464 \\
\hline 101 & $5 / 14 / 12$ & DB2-3 & 150 & 159 & 0 & 1000 & 442.45 & 441.71 & 19.13 & 22.13 & $1.56 \mathrm{E}-07$ & $0.28 \%$ & $0.45 \%$ & 4 & 1100 & 0.464 \\
\hline 102 & $5 / 16 / 12$ & DB2-5 & 100 & 103 & 0 & 900 & 448.47 & 448.20 & 6.97 & 9.97 & 5.57E-08 & $0.00 \%$ & $0.06 \%$ & 4 & 1100 & 0.399 \\
\hline 103 & $5 / 16 / 12$ & DB2-5 & 100 & 96 & 0 & 925 & 448.18 & 447.80 & 10.01 & 13.01 & 7.91E-08 & $0.06 \%$ & $0.15 \%$ & 4 & 1100 & 0.399 \\
\hline 104 & $5 / 16 / 12$ & DB2-5 & 100 & 97 & 0 & 950 & 447.78 & 447.28 & 13.05 & 16.05 & $1.05 \mathrm{E}-07$ & $0.15 \%$ & $0.27 \%$ & 4 & 1100 & 0.399 \\
\hline 105 & $5 / 16 / 12$ & DB2-5 & 100 & 97 & 0 & 975 & 447.26 & 446.63 & 16.09 & 19.09 & $1.31 \mathrm{E}-07$ & $0.27 \%$ & $0.41 \%$ & 4 & 1100 & 0.399 \\
\hline 106 & $5 / 16 / 12$ & DB2-5 & 100 & 110 & 0 & 1000 & 446.61 & 445.73 & 19.13 & 22.13 & $1.84 \mathrm{E}-07$ & $0.41 \%$ & $0.61 \%$ & 4 & 1100 & 0.399 \\
\hline 107 & $5 / 17 / 12$ & DB2-6 & 150 & 156 & 0 & 900 & 444.23 & 444.03 & 6.97 & 9.97 & $4.11 \mathrm{E}-08$ & $0.00 \%$ & $0.04 \%$ & 4 & 1100 & 0.442 \\
\hline 108 & $5 / 17 / 12$ & DB2-6 & 150 & 156 & 0 & 925 & 444.02 & 443.73 & 10.01 & 13.01 & $6.10 \mathrm{E}-08$ & $0.05 \%$ & $0.11 \%$ & 4 & 1100 & 0.442 \\
\hline 109 & $5 / 17 / 12$ & DB2-6 & 150 & 157 & 0 & 950 & 443.71 & 443.30 & 13.05 & 16.05 & $8.54 \mathrm{E}-08$ & $0.12 \%$ & $0.21 \%$ & 4 & 1100 & 0.442 \\
\hline 110 & $5 / 17 / 12$ & DB2-6 & 150 & 161 & 0 & 975 & 443.29 & 442.72 & 16.09 & 19.09 & 1.19E-07 & $0.21 \%$ & $0.34 \%$ & 4 & 1100 & 0.442 \\
\hline 111 & $5 / 17 / 12$ & DB2-6 & 150 & 159 & 0 & 1000 & 442.70 & 441.91 & 19.13 & 22.13 & $1.66 \mathrm{E}-07$ & $0.34 \%$ & $0.52 \%$ & 4 & 1100 & 0.442 \\
\hline 112 & $5 / 21 / 12$ & DB2-7 & 500 & 514 & 0 & 900 & 445.30 & 445.07 & 6.97 & 9.97 & $3.84 \mathrm{E}-08$ & $0.00 \%$ & $0.05 \%$ & 4 & 1100 & 0.547 \\
\hline 113 & $5 / 21 / 12$ & DB2-7 & 500 & 493 & 0 & 925 & 445.06 & 444.60 & 10.01 & 13.01 & $4.60 \mathrm{E}-08$ & $0.06 \%$ & $0.16 \%$ & 4 & 1100 & 0.547 \\
\hline 114 & $5 / 21 / 12$ & DB2-7 & 500 & 498 & 0 & 950 & 444.58 & 443.89 & 13.05 & 16.05 & $4.92 \mathrm{E}-08$ & $0.16 \%$ & $0.32 \%$ & 4 & 1100 & 0.547 \\
\hline 115 & $5 / 21 / 12$ & DB2-7 & 500 & 494 & 0 & 975 & 443.87 & 442.80 & 16.09 & 19.09 & 6.07E-08 & $0.32 \%$ & $0.56 \%$ & 4 & 1100 & 0.547 \\
\hline 116 & $5 / 21 / 12$ & DB2-7 & 500 & 577 & 0 & 1000 & 442.77 & 440.75 & 19.13 & 22.13 & $8.47 \mathrm{E}-08$ & $0.57 \%$ & $1.02 \%$ & 4 & 1100 & 0.547 \\
\hline
\end{tabular}




\begin{tabular}{|c|c|c|c|c|c|c|c|c|c|c|c|c|c|c|c|c|}
\hline \multirow{2}{*}{$\begin{array}{l}\text { Exp data } \\
\text { number }\end{array}$} & \multirow[b]{2}{*}{ Test Date } & \multirow{2}{*}{$\begin{array}{c}\text { Specimen } \\
\text { ID }\end{array}$} & \multicolumn{2}{|c|}{$\mathrm{H} 2 \mathrm{O}$ Pressure } & \multirow{2}{*}{$\begin{array}{c}\mathrm{H} 2 \\
\text { Pressure }\end{array}$} & \multirow{2}{*}{$\begin{array}{c}\text { Temperat } \\
\text { ure }\end{array}$} & \multicolumn{2}{|c|}{ Weight } & \multicolumn{2}{|c|}{ Time in the test } & \multirow[b]{2}{*}{ Rate } & \multicolumn{2}{|c|}{ Weight loss \% } & \multicolumn{2}{|c|}{ Sample preparaton } & \multirow{2}{*}{$\begin{array}{l}\text { Wt loss in } \\
\text { outgassing }\end{array}$} \\
\hline & & & target & actual $^{\&}$ & & & before & after & before & after & & before & after & duration & temperature & \\
\hline & & & $\mathrm{Pa}$ & $\mathrm{Pa}$ & $\mathrm{Pa}$ & $\mathrm{OC}$ & $\mathrm{mg}$ & $\mathrm{mg}$ & $\mathrm{hr}$ & $\mathrm{hr}$ & $\mathrm{s}^{-1}$ & $\%$ & $\%$ & $\mathrm{~h}$ & ${ }^{\circ} \mathrm{C}$ & $\mathrm{mg}$ \\
\hline 117 & $5 / 22 / 12$ & DB2-8 & 750 & 801 & 0 & 900 & 447.67 & 447.39 & 6.97 & 9.97 & $5.75 \mathrm{E}-08$ & $0.00 \%$ & $0.06 \%$ & 4 & 1100 & 0.781 \\
\hline 118 & $5 / 22 / 12$ & DB2-8 & 750 & 778 & 0 & 925 & 447.38 & 447.00 & 10.01 & 13.01 & $7.89 \mathrm{E}-08$ & $0.07 \%$ & $0.15 \%$ & 4 & 1100 & 0.781 \\
\hline 119 & $5 / 22 / 12$ & DB2-8 & 750 & 774 & 0 & 950 & 446.98 & 446.31 & 13.05 & 16.05 & $1.38 \mathrm{E}-07$ & $0.15 \%$ & $0.30 \%$ & 4 & 1100 & 0.781 \\
\hline 120 & $5 / 22 / 12$ & DB2-8 & 750 & 777 & 0 & 975 & 446.29 & 444.97 & 16.09 & 19.09 & $2.73 E-07$ & $0.31 \%$ & $0.60 \%$ & 4 & 1100 & 0.781 \\
\hline 121 & $5 / 22 / 12$ & DB2-8 & 750 & 846 & 0 & 1000 & 444.93 & 442.08 & 19.13 & 22.13 & $5.94 \mathrm{E}-07$ & $0.61 \%$ & $1.25 \%$ & 4 & 1100 & 0.781 \\
\hline 122 & $5 / 23 / 12$ & DB3-1 & 3 & 3 & 0 & 900 & 444.87 & 444.74 & 6.97 & 9.97 & $2.66 \mathrm{E}-08$ & $0.00 \%$ & $0.03 \%$ & 4 & 1100 & 0.423 \\
\hline 123 & $5 / 23 / 12$ & DB3-1 & 3 & 3 & 0 & 925 & 444.73 & 444.56 & 10.01 & 13.01 & 3.57E-08 & $0.03 \%$ & $0.07 \%$ & 4 & 1100 & 0.423 \\
\hline 124 & $5 / 23 / 12$ & DB3-1 & 3 & 3 & 0 & 950 & 444.55 & 444.37 & 13.05 & 16.05 & 3.83E-08 & $0.07 \%$ & $0.11 \%$ & 4 & 1100 & 0.423 \\
\hline 125 & $5 / 23 / 12$ & DB3-1 & 3 & 3 & 0 & 975 & 444.36 & 444.15 & 16.09 & 19.09 & 4.37E-08 & $0.12 \%$ & $0.16 \%$ & 4 & 1100 & 0.423 \\
\hline 126 & $5 / 23 / 12$ & DB3-1 & 3 & 3 & 0 & 1000 & 444.14 & 443.90 & 19.13 & 22.13 & 4.99E-08 & $0.17 \%$ & $0.22 \%$ & 4 & 1100 & 0.423 \\
\hline 127 & $6 / 1 / 12$ & DB3-3 & 150 & 150 & 0 & 1200 & 443.07 & 420.32 & 2.50 & 6.70 & $4.81 \mathrm{E}-06$ & $0.00 \%$ & $0.02 \%$ & 4 & 1100 & 0.453 \\
\hline 128 & $5 / 31 / 12$ & DB3-3 & 150 & 132 & 0 & 750 & 444.23 & 444.13 & 7.40 & 17.40 & $3.85 \mathrm{E}-08$ & $0.03 \%$ & $0.08 \%$ & 4 & 1100 & 0.453 \\
\hline 129 & $5 / 31 / 12$ & DB3-3 & 150 & 154 & 0 & 850 & 444.11 & 443.89 & 17.48 & 24.48 & 4.61E-08 & $0.26 \%$ & $5.38 \%$ & 4 & 1100 & 0.453 \\
\hline 130 & $6 / 27 / 12$ & DB3-4 & 75 & 66 & 0 & 900 & 410.97 & 410.62 & 4.36 & 8.13 & $6.13 \mathrm{E}-08$ & $8.38 \%$ & $8.45 \%$ & 2 & 1000 & 0.148 \\
\hline 132 & $6 / 28 / 12$ & DB3-5 & 75 & 62 & 0 & 900 & 444.24 & 443.96 & 4.97 & 10.97 & $4.15 \mathrm{E}-08$ & $0.00 \%$ & $0.07 \%$ & 2 & 1000 & 0.144 \\
\hline 134 & $7 / 3 / 12$ & DB3-6 & 75 & 68 & 0 & 900 & 445.85 & 445.31 & 4.97 & 10.97 & $9.00 \mathrm{E}-08$ & $0.40 \%$ & $0.52 \%$ & 2 & 1000 & 0.342 \\
\hline 131 & $6 / 27 / 12$ & DB3-4 & 75 & 65 & 100 & 900 & 372.68 & 372.34 & 8.49 & 23.21 & $1.70 \mathrm{E}-08$ & $9.24 \%$ & $9.32 \%$ & 2 & 1000 & 0.148 \\
\hline 133 & $6 / 28 / 12$ & DB3-5 & 75 & 66 & 100 & 900 & 443.66 & 443.52 & 10.31 & 24.29 & 5.60E-09 & $0.07 \%$ & $0.10 \%$ & 2 & 1000 & 0.144 \\
\hline 135 & $7 / 3 / 12$ & DB3-6 & 75 & 68 & 100 & 900 & 442.86 & 440.82 & 10.31 & 24.29 & $3.72 \mathrm{E}-08$ & $0.55 \%$ & $1.01 \%$ & 2 & 1000 & 0.342 \\
\hline 136 & $7 / 5 / 12$ & DB3-7 & 30 & 27 & 0 & 900 & 442.15 & 441.81 & 4.97 & 10.97 & 3.67E-08 & $0.01 \%$ & $0.08 \%$ & 2 & 1200 & 0.326 \\
\hline 137 & $7 / 5 / 12$ & DB3-7 & 30 & 28 & 0 & 1100 & 441.64 & 437.85 & 11.30 & 17.30 & 4.11E-07 & $0.12 \%$ & $0.98 \%$ & 2 & 1200 & 0.326 \\
\hline 138 & $7 / 9 / 12$ & DB3-8 & 300 & 252 & 0 & 900 & 442.10 & 441.46 & 4.97 & 10.97 & $6.94 \mathrm{E}-08$ & $0.15 \%$ & $0.30 \%$ & 2 & 1200 & 0.516 \\
\hline 139 & $7 / 9 / 12$ & DB3-8 & 300 & 242 & 0 & 1100 & 441.10 & 425.95 & 11.30 & 17.30 & $1.64 \mathrm{E}-06$ & $0.38 \%$ & $3.80 \%$ & 2 & 1200 & 0.516 \\
\hline 140 & $7 / 10 / 12$ & DB4-1 & 300 & 260 & 100 & 900 & 439.88 & 439.79 & 4.97 & 10.97 & $1.02 \mathrm{E}-08$ & $0.01 \%$ & $0.03 \%$ & 2 & 1200 & 0.293 \\
\hline 141 & $7 / 10 / 12$ & DB4-1 & 300 & 260 & 100 & 1100 & 439.63 & 434.19 & 11.30 & 17.30 & 5.89E-07 & $0.06 \%$ & $1.30 \%$ & 2 & 1200 & 0.293 \\
\hline 142 & $7 / 11 / 12$ & DB4-2 & 300 & 245 & 0 & 900 & 438.18 & 437.84 & 4.97 & 10.97 & $3.78 \mathrm{E}-08$ & $0.01 \%$ & $0.09 \%$ & 2 & 1200 & 0.286 \\
\hline 143 & $7 / 11 / 12$ & DB4-2 & 300 & 247 & 0 & 1100 & 437.60 & 424.88 & 11.30 & 17.30 & 1.39E-06 & $0.14 \%$ & $3.04 \%$ & 2 & 1200 & 0.286 \\
\hline 144 & $7 / 12 / 12$ & DB4-3 & 30 & 28 & 0 & 900 & 443.09 & 442.79 & 4.97 & 10.97 & 3.33E-08 & $0.00 \%$ & $0.07 \%$ & 2 & 1200 & 0.287 \\
\hline 145 & $7 / 12 / 12$ & DB4-3 & 30 & 29 & 0 & 1100 & 442.63 & 439.29 & 11.30 & 17.30 & $3.60 \mathrm{E}-07$ & $0.11 \%$ & $0.86 \%$ & 2 & 1200 & 0.287 \\
\hline 146 & $7 / 16 / 12$ & DB4-4 & 30 & 30 & 100 & 900 & 443.34 & 443.18 & 4.97 & 10.97 & $1.70 \mathrm{E}-08$ & $0.10 \%$ & $0.13 \%$ & 2 & 1200 & 0.638 \\
\hline 147 & $7 / 16 / 12$ & DB4-4 & 30 & 30 & 100 & 1100 & 443.06 & 441.63 & 11.30 & 17.30 & $1.56 \mathrm{E}-07$ & $0.16 \%$ & $0.48 \%$ & 2 & 1200 & 0.638 \\
\hline 148 & $7 / 17 / 12$ & DB4-5 & 300 & 241 & 0 & 900 & 440.93 & 440.51 & 4.97 & 10.97 & 4.99E-08 & $0.21 \%$ & $0.30 \%$ & 2 & 1200 & 0.553 \\
\hline 149 & $7 / 17 / 12$ & DB4-5 & 300 & 244 & 0 & 1100 & 439.92 & 419.12 & 11.30 & 17.30 & $2.27 \mathrm{E}-06$ & $0.44 \%$ & $5.14 \%$ & 2 & 1200 & 0.553 \\
\hline 150 & $7 / 18 / 12$ & DB4-6 & 30 & 35 & 0 & 900 & 446.42 & 446.08 & 4.97 & 10.97 & 3.64E-08 & $0.01 \%$ & $0.08 \%$ & 2 & 1200 & 0.553 \\
\hline 151 & $7 / 18 / 12$ & DB4-6 & 30 & 38 & 0 & 1100 & 445.91 & 442.11 & 11.30 & 17.30 & 4.07E-07 & $0.12 \%$ & $0.97 \%$ & 2 & 1200 & 0.553 \\
\hline 152 & $7 / 19 / 12$ & DB4-7 & 300 & 264 & 100 & 900 & 442.05 & 441.46 & 4.97 & 10.97 & $6.38 \mathrm{E}-08$ & $0.02 \%$ & $0.15 \%$ & 2 & 1200 & 1.566 \\
\hline 153 & $7 / 19 / 12$ & DB4-7 & 300 & 244 & 100 & 1100 & 441.23 & 433.90 & 11.30 & 17.30 & 7.91E-07 & $0.20 \%$ & $1.86 \%$ & 2 & 1200 & 1.566 \\
\hline 154 & $7 / 20 / 12$ & DB4-8 & 300 & 241 & 0 & 900 & 439.51 & 438.61 & 4.97 & 10.97 & $9.83 \mathrm{E}-08$ & $0.01 \%$ & $0.22 \%$ & 2 & 1200 & 0.325 \\
\hline 155 & $7 / 20 / 12$ & DB4-8 & 300 & 239 & 0 & 1100 & 438.26 & 423.76 & 11.30 & 17.30 & $1.60 \mathrm{E}-06$ & $0.30 \%$ & $3.60 \%$ & 2 & 1200 & 0.325 \\
\hline 156 & $7 / 23 / 12$ & $\# 10-1$ & 30 & 41 & 0 & 900 & 430.35 & 429.71 & 4.97 & 10.97 & $7.32 \mathrm{E}-08$ & $2.66 \%$ & $2.80 \%$ & 2 & 1200 & 11.618 \\
\hline
\end{tabular}




\begin{tabular}{|c|c|c|c|c|c|c|c|c|c|c|c|c|c|c|c|c|}
\hline \multirow{2}{*}{$\begin{array}{l}\text { Exp data } \\
\text { number }\end{array}$} & \multirow[b]{2}{*}{ Test Date } & \multirow{2}{*}{$\begin{array}{c}\text { Specimen } \\
\text { ID }\end{array}$} & \multicolumn{2}{|c|}{$\mathrm{H} 2 \mathrm{O}$ Pressure } & \multirow{2}{*}{$\begin{array}{c}\mathrm{H} 2 \\
\text { Pressure }\end{array}$} & \multirow{2}{*}{$\begin{array}{c}\text { Temperat } \\
\text { ure }\end{array}$} & \multicolumn{2}{|c|}{ Weight } & \multicolumn{2}{|c|}{ Time in the test } & \multirow[b]{2}{*}{ Rate } & \multicolumn{2}{|c|}{ Weight loss \% } & \multicolumn{2}{|c|}{ Sample preparaton } & \multirow{2}{*}{$\begin{array}{l}\text { Wt loss in } \\
\text { outgassing }\end{array}$} \\
\hline & & & target & actual $^{\&}$ & & & before & after & before & after & & before & after & duration & temperature & \\
\hline & & & $\mathrm{Pa}$ & $\mathrm{Pa}$ & $\mathrm{Pa}$ & $\mathrm{OC}$ & $\mathrm{mg}$ & $\mathrm{mg}$ & $\mathrm{hr}$ & $\mathrm{hr}$ & $\mathrm{s}^{-1}$ & $\%$ & $\%$ & $\mathrm{~h}$ & ${ }^{\circ} \mathrm{C}$ & $\mathrm{mg}$ \\
\hline 157 & $7 / 23 / 12$ & \#10-1 & 30 & 36 & 0 & 1100 & 429.39 & 422.36 & 11.30 & 17.30 & $7.91 \mathrm{E}-07$ & $2.87 \%$ & $4.46 \%$ & 2 & 1200 & 11.618 \\
\hline 158 & $7 / 24 / 12$ & $\# 10-2$ & 30 & 30 & 100 & 900 & 440.35 & 439.90 & 4.97 & 10.97 & $4.88 \mathrm{E}-08$ & $0.01 \%$ & $0.11 \%$ & 2 & 1200 & 0.327 \\
\hline 159 & $7 / 24 / 12$ & $\# 10-2$ & 30 & 31 & 100 & 1100 & 439.74 & 436.65 & 11.30 & 17.30 & 3.37E-07 & $0.14 \%$ & $0.85 \%$ & 2 & 1200 & 0.327 \\
\hline 160 & $7 / 26 / 12$ & $\# 11-1$ & 300 & 258 & 0 & 900 & 451.98 & 451.60 & 4.97 & 10.97 & 4.00E-08 & $0.01 \%$ & $0.09 \%$ & 2 & 1200 & 0.389 \\
\hline 161 & $7 / 26 / 12$ & \#11-1 & 300 & 255 & 0 & 1100 & 451.30 & 440.01 & 11.30 & 17.30 & $1.20 \mathrm{E}-06$ & $0.16 \%$ & $2.65 \%$ & 2 & 1200 & 0.389 \\
\hline 162 & $7 / 31 / 12$ & $\# 11-2$ & 30 & 31 & 0 & 900 & 442.12 & 441.62 & 4.97 & 10.97 & $5.44 \mathrm{E}-08$ & $0.10 \%$ & $0.22 \%$ & 2 & 1200 & 0.514 \\
\hline 163 & $7 / 31 / 12$ & $\# 11-2$ & 30 & 28 & 0 & 1100 & 441.46 & 438.10 & 11.30 & 17.30 & 3.63E-07 & $0.25 \%$ & $1.01 \%$ & 2 & 1200 & 0.514 \\
\hline 164 & $8 / 1 / 12$ & $\# 0-2$ & 300 & 246 & 100 & 900 & 445.43 & 445.09 & 4.97 & 10.97 & $3.57 \mathrm{E}-08$ & $0.00 \%$ & $0.08 \%$ & 2 & 1200 & 0.263 \\
\hline 165 & $8 / 1 / 12$ & $\# 0-2$ & 300 & 241 & 100 & 1100 & 444.92 & 440.22 & 11.30 & 17.30 & 5.03E-07 & $0.12 \%$ & $1.17 \%$ & 2 & 1200 & 0.263 \\
\hline 166 & $8 / 6 / 12$ & $\# 0-4$ & 300 & 245 & 0 & 900 & 442.27 & 442.00 & 4.97 & 10.97 & $2.88 \mathrm{E}-08$ & $0.08 \%$ & $0.14 \%$ & 2 & 1200 & 0.556 \\
\hline 167 & $8 / 6 / 12$ & $\# 0-4$ & 300 & 245 & 0 & 1100 & 441.75 & 432.24 & 11.30 & 17.30 & $1.04 \mathrm{E}-06$ & $0.20 \%$ & $2.35 \%$ & 2 & 1200 & 0.556 \\
\hline 168 & $8 / 7 / 12$ & $\# 0-5$ & 30 & 29 & 0 & 900 & 443.94 & 443.39 & 4.97 & 10.97 & $5.92 \mathrm{E}-08$ & $0.01 \%$ & $0.13 \%$ & 2 & 1200 & 0.428 \\
\hline 169 & $8 / 7 / 12$ & $\# 0-5$ & 30 & 28 & 0 & 1100 & 443.21 & 439.65 & 11.30 & 17.30 & $3.82 \mathrm{E}-07$ & $0.17 \%$ & $0.97 \%$ & 2 & 1200 & 0.428 \\
\hline 170 & $8 / 8 / 12$ & $\# 0-6$ & 30 & 29 & 100 & 900 & 454.04 & 453.89 & 4.97 & 10.97 & $1.63 \mathrm{E}-08$ & $0.00 \%$ & $0.04 \%$ & 2 & 1200 & 0.339 \\
\hline 171 & $8 / 8 / 12$ & $\# 0-6$ & 30 & 28 & 100 & 1100 & 453.80 & 453.00 & 11.30 & 17.30 & $8.45 \mathrm{E}-08$ & $0.06 \%$ & $0.23 \%$ & 2 & 1200 & 0.339 \\
\hline 172 & $8 / 9 / 12$ & $\# 0-7$ & 300 & 236 & 0 & 900 & 447.28 & 446.36 & 4.97 & 10.97 & $9.85 \mathrm{E}-08$ & $0.01 \%$ & $0.21 \%$ & 2 & 1200 & 0.382 \\
\hline 173 & $8 / 9 / 12$ & $\# 0-7$ & 300 & 245 & 0 & 1100 & 445.81 & 417.73 & 11.30 & 17.30 & $3.01 \mathrm{E}-06$ & $0.34 \%$ & $6.61 \%$ & 2 & 1200 & 0.382 \\
\hline 174 & $8 / 13 / 12$ & $\# 0-8$ & 30 & 25 & 0 & 900 & 442.12 & 441.32 & 4.97 & 10.97 & $8.70 \mathrm{E}-08$ & $0.01 \%$ & $0.19 \%$ & 2 & 1200 & 0.531 \\
\hline 175 & $8 / 13 / 12$ & $\# 0-8$ & 30 & 27 & 0 & 1100 & 441.10 & 435.42 & 11.30 & 17.30 & $6.15 \mathrm{E}-07$ & $0.24 \%$ & $1.53 \%$ & 2 & 1200 & 0.531 \\
\hline 176 & $8 / 15 / 12$ & $\# 0-10$ & 300 & 234 & 100 & 900 & 454.52 & 454.16 & 4.97 & 10.97 & $3.81 \mathrm{E}-08$ & $0.04 \%$ & $0.11 \%$ & 2 & 1200 & 0.320 \\
\hline 177 & $8 / 15 / 12$ & $\# 0-10$ & 300 & 242 & 100 & 1100 & 453.93 & 446.57 & 11.30 & 17.30 & 7.79E-07 & $0.17 \%$ & $1.78 \%$ & 2 & 1200 & 0.320 \\
\hline 181 & $8 / 16 / 12$ & \#0-11 & 30 & 29 & 0 & 900 & 441.63 & 441.45 & 4.97 & 10.97 & $1.98 \mathrm{E}-08$ & $0.00 \%$ & $0.04 \%$ & 2 & 1200 & 0.353 \\
\hline 182 & $8 / 16 / 12$ & $\# 0-11$ & 30 & 29 & 0 & 1100 & 441.33 & 438.70 & 11.30 & 17.30 & $2.83 \mathrm{E}-07$ & $0.07 \%$ & $0.67 \%$ & 2 & 1200 & 0.353 \\
\hline 183 & $10 / 18 / 12$ & $\# 0-12$ & 300 & 242 & 0 & 900 & 441.30 & 439.61 & 5.05 & 11.05 & $1.79 \mathrm{E}-07$ & $0.26 \%$ & $0.64 \%$ & 2 & 1200 & 0.956 \\
\hline 184 & $10 / 18 / 12$ & $\# 0-12$ & 300 & 228 & 0 & 1100 & 422.84 & 303.58 & 11.38 & 17.38 & $1.38 \mathrm{E}-05$ & $4.43 \%$ & $31.38 \%$ & 2 & 1200 & 0.956 \\
\hline 185 & $10 / 18 / 12$ & $\# 0-12$ & 300 & 271 & 0 & 900 & 415.90 & 414.37 & 17.72 & 23.72 & $1.73 \mathrm{E}-07$ & $6.00 \%$ & $6.34 \%$ & 2 & 1200 & 0.956 \\
\hline 186 & $10 / 23 / 12$ & $\# 0-13$ & 30 & 30 & 100 & 900 & 445.12 & 444.82 & 0.30 & 5.96 & $3.25 \mathrm{E}-08$ & $0.17 \%$ & $0.23 \%$ & 2 & 1200 & 0.778 \\
\hline 188 & $10 / 23 / 12$ & $\# 0-13$ & 30 & 31 & 100 & 900 & 443.25 & 442.97 & 12.79 & 18.14 & $3.23 \mathrm{E}-08$ & $0.59 \%$ & $0.65 \%$ & 2 & 1200 & 0.778 \\
\hline 187 & $10 / 23 / 12$ & $\# 0-13$ & 30 & 28 & 100 & 1100 & 444.63 & 443.19 & 6.36 & 12.24 & $1.53 \mathrm{E}-07$ & $0.28 \%$ & $0.60 \%$ & 2 & 1200 & 0.778 \\
\hline 189 & $10 / 25 / 12$ & $\# 0-14$ & 30 & 30 & 100 & 900 & 449.71 & 449.08 & 4.97 & 10.97 & $6.64 \mathrm{E}-08$ & $0.02 \%$ & $0.16 \%$ & 2 & 1200 & 0.125 \\
\hline 191 & $10 / 25 / 12$ & $\# 0-14$ & 30 & 31 & 100 & 900 & 445.88 & 445.27 & 17.63 & 23.63 & $7.06 \mathrm{E}-08$ & $0.87 \%$ & $1.01 \%$ & 2 & 1200 & 0.125 \\
\hline 190 & $10 / 25 / 12$ & $\# 0-14$ & 30 & 28 & 100 & 1100 & 448.83 & 445.91 & 11.30 & 17.30 & $3.10 \mathrm{E}-07$ & $0.22 \%$ & $0.87 \%$ & 2 & 1200 & 0.125 \\
\hline 192 & $10 / 30 / 12$ & DB-26 & 300 & 270 & 100 & 900 & 441.36 & 441.12 & 4.97 & 10.97 & $2.54 \mathrm{E}-08$ & $0.00 \%$ & $0.05 \%$ & 2 & 1200 & 0.201 \\
\hline 194 & $10 / 30 / 12$ & DB-26 & 300 & 261 & 100 & 900 & 437.10 & 436.81 & 17.63 & 23.63 & $3.33 \mathrm{E}-08$ & $0.96 \%$ & $1.03 \%$ & 2 & 1200 & 0.201 \\
\hline 193 & $10 / 30 / 12$ & DB-26 & 300 & 219 & 100 & 1100 & 441.07 & 437.15 & 11.30 & 17.30 & $4.01 \mathrm{E}-07$ & $0.06 \%$ & $0.95 \%$ & 2 & 1200 & 0.201 \\
\hline 195 & $11 / 5 / 12$ & $\# 0-16$ & 30 & 26 & 100 & 900 & 442.00 & 441.47 & 4.97 & 10.97 & $5.84 \mathrm{E}-08$ & $-0.07 \%$ & $0.05 \%$ & 2 & 1200 & 0.209 \\
\hline 197 & $11 / 5 / 12$ & $\# 0-16$ & 30 & 30 & 100 & 900 & 440.40 & 440.09 & 17.63 & 23.63 & $3.55 \mathrm{E}-08$ & $0.30 \%$ & $0.37 \%$ & 2 & 1200 & 0.209 \\
\hline 196 & $11 / 5 / 12$ & \#0-16 & 30 & 25 & 100 & 1100 & 441.29 & 440.35 & 11.30 & 17.30 & $1.01 \mathrm{E}-07$ & $0.10 \%$ & $0.31 \%$ & 2 & 1200 & 0.209 \\
\hline 198 & $2 / 21 / 13$ & $\# 0-19$ & 300 & 298 & 0 & 900 & 449.92 & 449.16 & 5.16 & 11.06 & 5.95E-08 & $0.01 \%$ & $0.18 \%$ & 2 & 1200 & 0.141 \\
\hline 199 & $2 / 21 / 13$ & \#0-19 & 300 & 308 & 0 & 1100 & 448.79 & 420.35 & 11.38 & 17.38 & $2.09 \mathrm{E}-06$ & $0.26 \%$ & $6.58 \%$ & 2 & 1200 & 0.141 \\
\hline
\end{tabular}




\begin{tabular}{|c|c|c|c|c|c|c|c|c|c|c|c|c|c|c|c|c|}
\hline \multirow{2}{*}{$\begin{array}{l}\text { Exp data } \\
\text { number }\end{array}$} & \multirow[b]{2}{*}{ Test Date } & \multirow{2}{*}{$\begin{array}{c}\text { Specimen } \\
\text { ID }\end{array}$} & \multicolumn{2}{|c|}{$\mathrm{H} 2 \mathrm{O}$ Pressure } & \multirow{2}{*}{$\begin{array}{c}\mathrm{H} 2 \\
\text { Pressure }\end{array}$} & \multirow{2}{*}{$\begin{array}{c}\text { Temperat } \\
\text { ure }\end{array}$} & \multicolumn{2}{|c|}{ Weight } & \multicolumn{2}{|c|}{ Time in the test } & \multirow[b]{2}{*}{ Rate } & \multicolumn{2}{|c|}{ Weight loss \% } & \multicolumn{2}{|c|}{ Sample preparaton } & \multirow{2}{*}{$\begin{array}{l}\text { Wt loss in } \\
\text { outgassing }\end{array}$} \\
\hline & & & target & actual $^{\&}$ & & & before & after & before & after & & before & after & duration & temperature & \\
\hline & & & $\mathrm{Pa}$ & $\mathrm{Pa}$ & $\mathrm{Pa}$ & $\mathrm{OC}$ & $\mathrm{mg}$ & $\mathrm{mg}$ & $\mathrm{hr}$ & $\mathrm{hr}$ & $\mathrm{s}^{-1}$ & $\%$ & $\%$ & $\mathrm{~h}$ & ${ }^{\circ} \mathrm{C}$ & $\mathrm{mg}$ \\
\hline 200 & $2 / 21 / 13$ & \#0-19 & 300 & 313 & 0 & 900 & 420.35 & 419.70 & 19.18 & 19.38 & $5.52 \mathrm{E}-08$ & $6.58 \%$ & $6.73 \%$ & 2 & 1200 & 0.141 \\
\hline 201 & $3 / 5 / 13$ & $\# 0-22$ & 30 & 30 & 100 & 900 & 445.95 & 445.75 & 5.05 & 11.05 & $2.08 \mathrm{E}-08$ & $0.06 \%$ & $0.10 \%$ & 2 & 1200 & 0.219 \\
\hline 203 & $3 / 5 / 13$ & $\# 0-22$ & 30 & 28 & 100 & 900 & 445.05 & 444.93 & 17.72 & 23.72 & $1.24 \mathrm{E}-08$ & $0.26 \%$ & $0.29 \%$ & 2 & 1200 & 0.219 \\
\hline 202 & $3 / 5 / 13$ & $\# 0-22$ & 30 & 28 & 100 & 1100 & 445.63 & 444.98 & 11.38 & 17.38 & $6.79 \mathrm{E}-08$ & $0.13 \%$ & $0.28 \%$ & 2 & 1200 & 0.219 \\
\hline 178 & $3 / 7 / 13$ & \#0-23 & 300 & 306 & 0 & 900 & 446.44 & 445.75 & 4.97 & 11.30 & 7.18E-08 & $0.01 \%$ & $0.17 \%$ & 2 & 1200 & 0.125 \\
\hline 179 & $3 / 7 / 13$ & $\# 0-23$ & 300 & 304 & 0 & 1100 & 445.40 & 423.14 & 11.51 & 17.38 & 2.31E-06 & $0.25 \%$ & $5.23 \%$ & 2 & 1200 & 0.125 \\
\hline 180 & $3 / 7 / 13$ & $\# 0-23$ & 300 & 307 & 0 & 900 & 422.41 & 421.58 & 17.71 & 23.71 & $9.14 \mathrm{E}-08$ & $5.40 \%$ & $5.58 \%$ & 2 & 1200 & 0.125 \\
\hline 204 & $3 / 11 / 13$ & $\# 0-24$ & 300 & 299 & 100 & 900 & 448.28 & 447.94 & 5.20 & 11.05 & $3.43 \mathrm{E}-08$ & $0.01 \%$ & $0.09 \%$ & 2 & 1200 & 0.165 \\
\hline 206 & $3 / 11 / 13$ & $\# 0-24$ & 300 & 304 & 100 & 900 & 436.77 & 436.28 & 17.72 & 23.72 & $5.28 \mathrm{E}-08$ & $2.58 \%$ & $2.69 \%$ & 2 & 1200 & 0.165 \\
\hline 205 & $3 / 11 / 13$ & $\# 0-24$ & 300 & 289 & 100 & 1100 & 447.67 & 437.27 & 11.38 & 17.38 & 1.09E-06 & $0.15 \%$ & $2.47 \%$ & 2 & 1200 & 0.165 \\
\hline 207 & $3 / 12 / 13$ & $\# 0-25$ & 30 & 33 & 100 & 900 & 454.48 & 454.06 & 7.14 & 11.05 & $6.95 \mathrm{E}-08$ & $0.08 \%$ & $0.17 \%$ & 2 & 1200 & 0.227 \\
\hline 209 & $3 / 12 / 13$ & $\# 0-25$ & 30 & 30 & 100 & 900 & 450.43 & 448.89 & 17.63 & 23.63 & $1.60 \mathrm{E}-07$ & $0.97 \%$ & $1.31 \%$ & 2 & 1200 & 0.227 \\
\hline 208 & $3 / 12 / 13$ & $\# 0-25$ & 30 & 29 & 100 & 1100 & 453.91 & 450.49 & 11.30 & 17.30 & $3.41 \mathrm{E}-07$ & $0.21 \%$ & $0.96 \%$ & 2 & 1200 & 0.227 \\
\hline 210 & $3 / 14 / 13$ & $\# 0-26$ & 300 & 301 & 100 & 900 & 453.93 & 453.72 & 4.97 & 10.97 & 2.11E-08 & $0.00 \%$ & $0.05 \%$ & 2 & 1200 & 0.145 \\
\hline 212 & $3 / 14 / 13$ & $\# 0-26$ & 300 & 307 & 100 & 900 & 445.73 & 445.28 & 17.63 & 23.63 & 4.80E-08 & $1.81 \%$ & $1.91 \%$ & 2 & 1200 & 0.145 \\
\hline 211 & $3 / 14 / 13$ & $\# 0-26$ & 300 & 309 & 100 & 1100 & 453.48 & 446.15 & 11.30 & 17.30 & 7.73E-07 & $0.10 \%$ & $1.72 \%$ & 2 & 1200 & 0.145 \\
\hline 213 & $3 / 20 / 13$ & $\# 0-28$ & 300 & 311 & 0 & 900 & 427.49 & 427.25 & 7.35 & 10.97 & $4.35 \mathrm{E}-08$ & $0.04 \%$ & $0.10 \%$ & 2 & 1200 & 0.331 \\
\hline 214 & $3 / 20 / 13$ & $\# 0-28$ & 300 & 331 & 0 & 1100 & 427.08 & 415.75 & 11.30 & 17.30 & $1.25 \mathrm{E}-06$ & $0.14 \%$ & $2.79 \%$ & 2 & 1200 & 0.331 \\
\hline 215 & $3 / 20 / 13$ & $\# 0-28$ & 300 & 346 & 0 & 900 & 415.68 & 415.25 & 17.63 & 23.63 & $5.32 \mathrm{E}-08$ & $2.80 \%$ & $2.90 \%$ & 2 & 1200 & 0.331 \\
\hline 220 & $3 / 26 / 13$ & DB8-1 & 300 & 307 & 30 & 900 & 430.15 & 430.12 & 21.63 & 23.63 & 7.69E-09 & $1.91 \%$ & $1.92 \%$ & 2 & 1200 & 0.217 \\
\hline 219 & $3 / 26 / 13$ & DB8-1 & 300 & 305 & 50 & 900 & 430.17 & 430.15 & 19.63 & 21.63 & 8.01E-09 & $1.91 \%$ & $1.91 \%$ & 2 & 1200 & 0.217 \\
\hline 216 & $3 / 26 / 13$ & DB8-1 & 300 & 312 & 100 & 900 & 438.37 & 438.10 & 5.20 & 10.86 & 3.10E-08 & $0.03 \%$ & $0.10 \%$ & 2 & 1200 & 0.217 \\
\hline 218 & $3 / 26 / 13$ & DB8-1 & 300 & 304 & 100 & 900 & 430.18 & 430.17 & 17.63 & 19.63 & 4.85E-09 & $1.90 \%$ & $1.91 \%$ & 2 & 1200 & 0.217 \\
\hline 217 & $3 / 26 / 13$ & DB8-1 & 300 & 328 & 100 & 1100 & 437.59 & 430.32 & 11.30 & 17.30 & $7.95 \mathrm{E}-07$ & $0.21 \%$ & $1.87 \%$ & 2 & 1200 & 0.217 \\
\hline 221 & $4 / 2 / 13$ & DB8-2 & 100 & 101 & 0 & 900 & 450.27 & 449.88 & 2.01 & 7.85 & 4.11E-08 & $0.01 \%$ & $0.09 \%$ & 2 & 1200 & 0.217 \\
\hline 222 & $4 / 2 / 13$ & DB8-2 & 100 & 101 & 0 & 1000 & 449.76 & 448.04 & 8.35 & 13.96 & 1.90E-07 & $0.12 \%$ & $0.50 \%$ & 2 & 1200 & 0.217 \\
\hline 223 & $4 / 2 / 13$ & DB8-2 & 100 & 106 & 0 & 1100 & 447.69 & 439.64 & 14.49 & 20.37 & $8.50 \mathrm{E}-07$ & $0.58 \%$ & $2.37 \%$ & 2 & 1200 & 0.217 \\
\hline 224 & $4 / 3 / 13$ & DB8-3 & 100 & 108 & 100 & 900 & 445.87 & 445.65 & 5.03 & 10.81 & $2.37 \mathrm{E}-08$ & $-0.01 \%$ & $0.04 \%$ & 2 & 1200 & 0.202 \\
\hline 225 & $4 / 3 / 13$ & DB8-3 & 100 & 101 & 100 & 1000 & 445.55 & 444.17 & 11.18 & 16.79 & $1.54 \mathrm{E}-07$ & $0.06 \%$ & $0.37 \%$ & 2 & 1200 & 0.202 \\
\hline 226 & $4 / 3 / 13$ & DB8-3 & 100 & 107 & 100 & 1100 & 443.98 & 442.33 & 17.19 & 19.81 & $3.94 \mathrm{E}-07$ & $0.42 \%$ & $0.79 \%$ & 2 & 1200 & 0.202 \\
\hline 227 & $4 / 3 / 13$ & DB8-3 & 100 & 97 & 100 & 1100 & 442.33 & 440.86 & 19.81 & 23.02 & $2.86 \mathrm{E}-07$ & $0.79 \%$ & $1.11 \%$ & 2 & 1200 & 0.202 \\
\hline 228 & $4 / 15 / 13$ & DB8-4 & 100 & 95 & 50 & 900 & 445.30 & 444.61 & 4.74 & 10.58 & 7.30E-08 & $0.18 \%$ & $0.34 \%$ & 2 & 1200 & 0.283 \\
\hline 229 & $4 / 15 / 13$ & DB8-4 & 100 & 94 & 50 & 1000 & 444.47 & 443.12 & 11.18 & 14.50 & $2.42 \mathrm{E}-07$ & $0.37 \%$ & $0.67 \%$ & 2 & 1200 & 0.283 \\
\hline 230 & $4 / 15 / 13$ & DB8-4 & 100 & 115 & 50 & 1000 & 443.12 & 441.84 & 14.50 & 16.71 & $3.62 \mathrm{E}-07$ & $0.67 \%$ & $0.96 \%$ & 2 & 1200 & 0.283 \\
\hline 231 & $4 / 15 / 13$ & DB8-4 & 100 & 123 & 50 & 1100 & 441.42 & 435.28 & 17.25 & 23.09 & $6.61 \mathrm{E}-07$ & $1.05 \%$ & $2.43 \%$ & 2 & 1200 & 0.283 \\
\hline 232 & $5 / 24 / 13$ & DB9-3 & 100 & 102 & 50 & 900 & 439.93 & 439.21 & 4.94 & 10.82 & 7.77E-08 & $0.12 \%$ & $0.28 \%$ & 2 & 1200 & 0.467 \\
\hline 233 & $5 / 24 / 13$ & DB9-3 & 100 & 83 & 50 & 1000 & 439.11 & 437.04 & 11.05 & 16.93 & $2.22 \mathrm{E}-07$ & $0.30 \%$ & $0.77 \%$ & 2 & 1200 & 0.467 \\
\hline 234 & $5 / 24 / 13$ & DB9-3 & 100 & 78 & 50 & 1100 & 436.85 & 434.32 & 17.21 & 19.48 & 7.11E-07 & $0.82 \%$ & $1.39 \%$ & 2 & 1200 & 0.467 \\
\hline 235 & $5 / 24 / 13$ & DB9-3 & 100 & 80 & 50 & 1100 & 433.55 & 431.14 & 20.25 & 23.08 & $5.44 \mathrm{E}-07$ & $1.57 \%$ & $2.11 \%$ & 2 & 1200 & 0.467 \\
\hline 236 & $5 / 31 / 13$ & DB9-6 & 30 & 32 & 50 & 900 & 437.96 & 437.63 & 5.46 & 10.72 & $3.98 \mathrm{E}-08$ & $0.00 \%$ & $0.07 \%$ & 2 & 1200 & 0.312 \\
\hline
\end{tabular}




\begin{tabular}{|c|c|c|c|c|c|c|c|c|c|c|c|c|c|c|c|c|}
\hline \multirow{3}{*}{$\begin{array}{l}\text { Exp data } \\
\text { number }\end{array}$} & \multirow[b]{3}{*}{ Test Date } & \multirow{3}{*}{$\begin{array}{c}\text { Specimen } \\
\text { ID }\end{array}$} & \multirow{2}{*}{\multicolumn{2}{|c|}{$\mathrm{H} 2 \mathrm{O}$ Pressure }} & \multirow{3}{*}{$\begin{array}{c}\mathrm{H} 2 \\
\text { Pressure }\end{array}$} & \multirow{3}{*}{$\begin{array}{c}\text { Temperat } \\
\text { ure }\end{array}$} & \multirow{2}{*}{\multicolumn{2}{|c|}{ Weight }} & \multirow{2}{*}{\multicolumn{2}{|c|}{ Time in the test }} & \multirow[b]{3}{*}{ Rate } & \multirow{2}{*}{\multicolumn{2}{|c|}{ Weight loss \% }} & \multirow{2}{*}{\multicolumn{2}{|c|}{ Sample preparaton }} & \multirow{3}{*}{$\begin{array}{l}\text { Wt loss in } \\
\text { outgassing }\end{array}$} \\
\hline & & & & & & & & & & & & & & & & \\
\hline & & & target & actual $^{\&}$ & & & before & after & before & after & & before & after & duration & temperature & \\
\hline & & & $\mathrm{Pa}$ & $\mathrm{Pa}$ & $\mathrm{Pa}$ & $O C$ & $\mathrm{mg}$ & $\mathrm{mg}$ & $\mathrm{hr}$ & $\mathrm{hr}$ & $s^{-1}$ & $\%$ & $\%$ & $\mathrm{~h}$ & ${ }^{\circ} \mathrm{C}$ & $\mathrm{mg}$ \\
\hline 237 & $5 / 31 / 13$ & DB9-6 & 30 & 28 & 50 & 1000 & 437.50 & 436.69 & 11.35 & 16.70 & $9.67 \mathrm{E}-08$ & $0.10 \%$ & $0.29 \%$ & 2 & 1200 & 0.312 \\
\hline 238 & $5 / 31 / 13$ & DB9-6 & 30 & 27 & 50 & 1100 & 436.27 & 435.56 & 18.02 & 19.81 & $2.53 \mathrm{E}-07$ & $0.38 \%$ & $0.54 \%$ & 2 & 1200 & 0.312 \\
\hline 239 & $5 / 31 / 13$ & DB9-6 & 30 & 23 & 50 & 1100 & 435.55 & 434.14 & 19.81 & 23.11 & $2.73 \mathrm{E}-07$ & $0.55 \%$ & $0.87 \%$ & 2 & 1200 & 0.312 \\
\hline 240 & $6 / 3 / 13$ & DB10-1 & 30 & 33 & 150 & 900 & 445.76 & 445.38 & 5.49 & 10.65 & 4.57E-08 & $-0.05 \%$ & $0.03 \%$ & 2 & 1200 & 1.329 \\
\hline 241 & $6 / 3 / 13$ & DB10-1 & 30 & 32 & 150 & 1000 & 445.19 & 443.56 & 11.13 & 16.81 & 1.79E-07 & $0.08 \%$ & $0.44 \%$ & 2 & 1200 & 1.329 \\
\hline 242 & $6 / 3 / 13$ & DB10-1 & 30 & 33 & 150 & 1100 & 443.29 & 441.45 & 17.21 & 19.45 & $5.12 \mathrm{E}-07$ & $0.50 \%$ & $0.92 \%$ & 2 & 1200 & 1.329 \\
\hline 243 & $6 / 3 / 13$ & DB10-1 & 30 & 34 & 150 & 1100 & 441.45 & 437.70 & 19.45 & 23.06 & $6.54 \mathrm{E}-07$ & $0.92 \%$ & $1.76 \%$ & 2 & 1200 & 1.329 \\
\hline 244 & $6 / 4 / 13$ & DB10-2 & 100 & 99 & 150 & 900 & 444.77 & 443.83 & 5.46 & 10.64 & $1.13 \mathrm{E}-07$ & $-0.04 \%$ & $0.17 \%$ & 2 & 1200 & 0.255 \\
\hline 245 & $6 / 4 / 13$ & DB10-2 & 100 & 100 & 150 & 1000 & 441.97 & 437.97 & 12.96 & 16.77 & $6.59 \mathrm{E}-07$ & $0.59 \%$ & $1.49 \%$ & 2 & 1200 & 0.255 \\
\hline 246 & $6 / 4 / 13$ & DB10-2 & 100 & 100 & 150 & 1100 & 437.20 & 433.75 & 17.28 & 18.97 & 1.30E-06 & $1.67 \%$ & $2.44 \%$ & 2 & 1200 & 0.255 \\
\hline 247 & $6 / 4 / 13$ & DB10-2 & 100 & 99 & 150 & 1100 & 433.75 & 422.42 & 18.97 & 21.14 & $1.75 \mathrm{E}-06$ & $2.44 \%$ & $4.99 \%$ & 2 & 1200 & 0.255 \\
\hline 248 & $6 / 6 / 13$ & DB10-3 & 15 & 16 & 0 & 900 & 448.25 & 447.70 & 5.97 & 10.79 & 7.10E-08 & $-0.01 \%$ & $0.11 \%$ & 2 & 1200 & 0.307 \\
\hline 249 & $6 / 6 / 13$ & DB10-3 & 15 & 16 & 0 & 1000 & 446.98 & 445.71 & 12.89 & 16.56 & $2.16 \mathrm{E}-07$ & $0.27 \%$ & $0.56 \%$ & 2 & 1200 & 0.307 \\
\hline 250 & $6 / 6 / 13$ & DB10-3 & 15 & 16 & 0 & 1100 & 445.29 & 443.78 & 17.27 & 19.28 & 4.71E-07 & $0.65 \%$ & $0.99 \%$ & 2 & 1200 & 0.307 \\
\hline 251 & $6 / 6 / 13$ & DB10-3 & 15 & 16 & 0 & 1100 & 443.78 & 440.32 & 19.28 & 23.08 & $5.70 \mathrm{E}-07$ & $0.99 \%$ & $1.76 \%$ & 2 & 1200 & 0.307 \\
\hline 252 & $6 / 7 / 13$ & DB10-4 & 15 & 15 & 0 & 900 & 440.88 & 440.37 & 6.09 & 10.83 & $6.85 \mathrm{E}-08$ & $-0.03 \%$ & $0.09 \%$ & 2 & 1200 & 0.220 \\
\hline 253 & $6 / 7 / 13$ & DB10-4 & 15 & 15 & 0 & 1000 & 439.86 & 438.79 & 12.70 & 16.81 & $1.64 \mathrm{E}-07$ & $0.21 \%$ & $0.45 \%$ & 2 & 1200 & 0.220 \\
\hline 254 & $6 / 7 / 13$ & DB10-4 & 15 & 15 & 0 & 1100 & 438.38 & 437.08 & 17.53 & 19.60 & 3.96E-07 & $0.54 \%$ & $0.83 \%$ & 2 & 1200 & 0.220 \\
\hline 255 & $6 / 7 / 13$ & DB10-4 & 15 & 15 & 0 & 1100 & 437.08 & 434.45 & 19.60 & 23.14 & $4.72 \mathrm{E}-07$ & $0.83 \%$ & $1.43 \%$ & 2 & 1200 & 0.220 \\
\hline 256 & $6 / 18 / 13$ & DB10-5 & 15 & 15 & 0 & 900 & 444.29 & 443.58 & 6.03 & 10.81 & $9.34 \mathrm{E}-08$ & $0.03 \%$ & $0.19 \%$ & 2 & 1200 & 0.449 \\
\hline 257 & $6 / 18 / 13$ & DB10-5 & 15 & 15 & 0 & 1000 & 443.39 & 441.50 & 11.15 & 16.79 & 2.10E-07 & $0.23 \%$ & $0.65 \%$ & 2 & 1200 & 0.449 \\
\hline 258 & $6 / 18 / 13$ & DB10-5 & 15 & 15 & 0 & 1100 & 441.11 & 440.14 & 17.36 & 18.74 & $4.42 \mathrm{E}-07$ & $0.74 \%$ & $0.96 \%$ & 2 & 1200 & 0.449 \\
\hline 259 & $6 / 18 / 13$ & DB10-5 & 15 & 16 & 0 & 1100 & 440.14 & 436.81 & 18.74 & 23.02 & 4.91E-07 & $0.96 \%$ & $1.71 \%$ & 2 & 1200 & 0.449 \\
\hline 260 & $6 / 20 / 13$ & DB10-6 & 0 & 3 & 0 & 900 & 445.71 & 445.37 & 4.88 & 10.81 & 3.67E-08 & $-0.06 \%$ & $0.01 \%$ & 2 & 1200 & 0.400 \\
\hline 261 & $6 / 20 / 13$ & DB10-6 & 0 & 3 & 0 & 1000 & 445.23 & 444.73 & 11.12 & 16.81 & $5.50 \mathrm{E}-08$ & $0.05 \%$ & $0.16 \%$ & 2 & 1200 & 0.400 \\
\hline 262 & $6 / 20 / 13$ & DB10-6 & 0 & 3 & 0 & 1100 & 444.55 & 443.70 & 17.30 & 23.05 & 9.17E-08 & $0.20 \%$ & $0.39 \%$ & 2 & 1200 & 0.400 \\
\hline 264 & $6 / 21 / 13$ & DB10-7 & 0 & 3 & 0 & 900 & 447.26 & 446.96 & 5.11 & 10.66 & $3.31 \mathrm{E}-08$ & $-0.07 \%$ & $0.00 \%$ & 2 & 1200 & 0.335 \\
\hline 265 & $6 / 21 / 13$ & DB10-7 & 0 & 3 & 0 & 1000 & 446.82 & 446.30 & 11.09 & 16.81 & 5.61E-08 & $0.03 \%$ & $0.15 \%$ & 2 & 1200 & 0.335 \\
\hline 266 & $6 / 21 / 13$ & DB10-7 & 0 & 3 & 0 & 1100 & 446.11 & 445.34 & 17.36 & 23.00 & $8.46 \mathrm{E}-08$ & $0.19 \%$ & $0.36 \%$ & 2 & 1200 & 0.335 \\
\hline 268 & $7 / 15 / 13$ & \#12--1 & 0 & 3 & 0 & 900 & 454.27 & 454.12 & 4.93 & 10.81 & $1.50 \mathrm{E}-08$ & $-0.07 \%$ & $-0.04 \%$ & 2 & 1200 & 0.378 \\
\hline 269 & $7 / 15 / 13$ & $\# 12--1$ & 0 & 3 & 0 & 1000 & 454.00 & 452.74 & 11.07 & 16.98 & $1.30 \mathrm{E}-07$ & $-0.02 \%$ & $0.26 \%$ & 2 & 1200 & 0.378 \\
\hline 270 & $7 / 15 / 13$ & \#12--1 & 0 & 3 & 0 & 1100 & 453.60 & 453.10 & 17.20 & 23.03 & $5.27 \mathrm{E}-08$ & $0.07 \%$ & $0.18 \%$ & 2 & 1200 & 0.378 \\
\hline 271 & $7 / 25 / 13$ & \#12--2 & 15 & 15 & 0 & 800 & 448.61 & 448.47 & 4.32 & 7.39 & $2.72 \mathrm{E}-08$ & $-0.04 \%$ & $-0.01 \%$ & 1 & 1200 & 0.210 \\
\hline 272 & $7 / 25 / 13$ & \#12--2 & 15 & 15 & 0 & 850 & 448.39 & 448.08 & 7.70 & 10.49 & $6.93 \mathrm{E}-08$ & $0.01 \%$ & $0.08 \%$ & 1 & 1200 & 0.210 \\
\hline 273 & $7 / 25 / 13$ & $\# 12--2$ & 15 & 14 & 0 & 900 & 447.96 & 447.51 & 10.90 & 13.53 & $1.08 \mathrm{E}-07$ & $0.10 \%$ & $0.20 \%$ & 1 & 1200 & 0.210 \\
\hline 274 & $7 / 25 / 13$ & $\# 12--2$ & 15 & 14 & 0 & 950 & 447.38 & 446.66 & 13.84 & 16.66 & $1.58 \mathrm{E}-07$ & $0.23 \%$ & $0.39 \%$ & 1 & 1200 & 0.210 \\
\hline 275 & $7 / 25 / 13$ & \#12--2 & 15 & 14 & 0 & 1000 & 446.54 & 445.62 & 16.68 & 19.75 & $1.88 \mathrm{E}-07$ & $0.42 \%$ & $0.63 \%$ & 1 & 1200 & 0.210 \\
\hline 276 & $7 / 25 / 13$ & \#12--2 & 15 & 15 & 0 & 1100 & 445.37 & 444.57 & 20.03 & 21.57 & $3.22 \mathrm{E}-07$ & $0.68 \%$ & $0.86 \%$ & 1 & 1200 & 0.210 \\
\hline
\end{tabular}




\begin{tabular}{|c|c|c|c|c|c|c|c|c|c|c|c|c|c|c|c|c|}
\hline \multirow{2}{*}{$\begin{array}{l}\text { Exp data } \\
\text { number }\end{array}$} & \multirow[b]{2}{*}{ Test Date } & \multirow{2}{*}{$\begin{array}{c}\text { Specimen } \\
\text { ID }\end{array}$} & \multicolumn{2}{|c|}{$\mathrm{H} 2 \mathrm{O}$ Pressure } & \multirow{2}{*}{$\begin{array}{c}\mathrm{H} 2 \\
\text { Pressure }\end{array}$} & \multirow{2}{*}{$\begin{array}{c}\text { Temperat } \\
\text { ure }\end{array}$} & \multicolumn{2}{|c|}{ Weight } & \multicolumn{2}{|c|}{ Time in the test } & \multirow[b]{2}{*}{ Rate } & \multicolumn{2}{|c|}{ Weight loss \% } & \multicolumn{2}{|c|}{ Sample preparaton } & \multirow{2}{*}{$\begin{array}{l}\text { Wt loss in } \\
\text { outgassing }\end{array}$} \\
\hline & & & target & actual $^{\&}$ & & & before & after & before & after & & before & after & duration & temperature & \\
\hline & & & $\mathrm{Pa}$ & $\mathrm{Pa}$ & $\mathrm{Pa}$ & $\mathrm{OC}$ & $\mathrm{mg}$ & $\mathrm{mg}$ & $\mathrm{hr}$ & $\mathrm{hr}$ & $\mathrm{s}^{-1}$ & $\%$ & $\%$ & $\mathrm{~h}$ & ${ }^{\circ} \mathrm{C}$ & $\mathrm{mg}$ \\
\hline 277 & $7 / 26 / 13$ & \#12--3 & 15 & 14 & 30 & 800 & 448.82 & 448.82 & 4.41 & 7.45 & $8.14 \mathrm{E}-10$ & $-0.07 \%$ & $-0.07 \%$ & 1 & 1200 & 0.132 \\
\hline 278 & $7 / 26 / 13$ & $\# 12--3$ & 15 & 15 & 30 & 850 & 448.76 & 448.73 & 7.59 & 10.52 & 5.49E-09 & $-0.06 \%$ & $-0.05 \%$ & 1 & 1200 & 0.132 \\
\hline 279 & $7 / 26 / 13$ & $\# 12--3$ & 15 & 14 & 30 & 900 & 448.67 & 448.59 & 10.74 & 13.62 & $1.83 \mathrm{E}-08$ & $-0.04 \%$ & $-0.02 \%$ & 1 & 1200 & 0.132 \\
\hline 280 & $7 / 26 / 13$ & \#12--3 & 15 & 14 & 30 & 950 & 448.52 & 448.37 & 13.76 & 16.57 & $3.26 \mathrm{E}-08$ & $-0.01 \%$ & $0.03 \%$ & 1 & 1200 & 0.132 \\
\hline 281 & $7 / 26 / 13$ & $\# 12--3$ & 15 & 14 & 30 & 1000 & 448.29 & 448.04 & 16.97 & 19.70 & $5.61 \mathrm{E}-08$ & $0.05 \%$ & $0.10 \%$ & 1 & 1200 & 0.132 \\
\hline 282 & $7 / 26 / 13$ & $\# 12--3$ & 15 & 14 & 30 & 1100 & 447.82 & 447.28 & 20.26 & 22.83 & $1.31 \mathrm{E}-07$ & $0.15 \%$ & $0.27 \%$ & 1 & 1200 & 0.132 \\
\hline 283 & $7 / 27 / 13$ & $\# 12-04$ & 30 & 31 & 0 & 800 & 448.82 & 448.81 & 4.46 & 7.42 & $2.30 \mathrm{E}-09$ & $-0.10 \%$ & $-0.10 \%$ & 1 & 1200 & 0.117 \\
\hline 284 & $7 / 27 / 13$ & $\# 12-04$ & 30 & 31 & 0 & 850 & 448.75 & 448.71 & 7.73 & 10.43 & $9.63 \mathrm{E}-09$ & $-0.09 \%$ & $-0.08 \%$ & 1 & 1200 & 0.117 \\
\hline 285 & $7 / 27 / 13$ & $\# 12-04$ & 30 & 31 & 0 & 900 & 448.64 & 448.53 & 10.77 & 13.56 & $2.53 \mathrm{E}-08$ & $-0.06 \%$ & $-0.04 \%$ & 1 & 1200 & 0.117 \\
\hline 286 & $7 / 27 / 13$ & $\# 12-04$ & 30 & 31 & 0 & 950 & 448.45 & 448.27 & 13.87 & 16.60 & 4.06E-08 & $-0.02 \%$ & $0.02 \%$ & 1 & 1200 & 0.117 \\
\hline 287 & $7 / 27 / 13$ & $\# 12-04$ & 30 & 31 & 0 & 1000 & 448.19 & 447.90 & 16.88 & 19.70 & 6.37E-08 & $0.04 \%$ & $0.10 \%$ & 1 & 1200 & 0.117 \\
\hline 288 & $7 / 27 / 13$ & $\# 12-04$ & 30 & 31 & 0 & 1100 & 447.69 & 446.57 & 20.07 & 22.77 & $2.58 \mathrm{E}-07$ & $0.15 \%$ & $0.40 \%$ & 1 & 1200 & 0.117 \\
\hline 289 & $7 / 29 / 13$ & \#17-01 & 30 & 31 & 30 & 800 & 453.60 & 453.59 & 4.10 & 7.39 & 3.16E-09 & $-0.08 \%$ & $-0.07 \%$ & 1 & 1200 & 0.108 \\
\hline 290 & $7 / 29 / 13$ & \#17-01 & 30 & 32 & 30 & 850 & 453.52 & 453.29 & 7.67 & 10.49 & 4.97E-08 & $-0.06 \%$ & $-0.01 \%$ & 1 & 1200 & 0.108 \\
\hline 291 & $7 / 29 / 13$ & \#17-01 & 30 & 32 & 30 & 900 & 453.21 & 452.70 & 10.74 & 13.62 & 1.07E-07 & $0.01 \%$ & $0.12 \%$ & 1 & 1200 & 0.108 \\
\hline 292 & $7 / 29 / 13$ & \#17-01 & 30 & 32 & 30 & 950 & 452.61 & 451.76 & 13.81 & 16.66 & $1.82 \mathrm{E}-07$ & $0.14 \%$ & $0.33 \%$ & 1 & 1200 & 0.108 \\
\hline 293 & $7 / 29 / 13$ & $\# 17-01$ & 30 & 32 & 30 & 1000 & 451.61 & 450.30 & 16.91 & 19.76 & 2.83E-07 & $0.36 \%$ & $0.65 \%$ & 1 & 1200 & 0.108 \\
\hline 294 & $7 / 29 / 13$ & $\# 17-01$ & 30 & 33 & 30 & 1100 & 449.98 & 447.38 & 20.09 & 22.94 & $5.62 \mathrm{E}-07$ & $0.72 \%$ & $1.30 \%$ & 1 & 1200 & 0.108 \\
\hline 295 & $7 / 30 / 13$ & \#17-02 & 100 & 104 & 0 & 800 & 452.73 & 452.72 & 4.10 & 7.42 & $1.85 \mathrm{E}-09$ & $-0.10 \%$ & $-0.10 \%$ & 1 & 1200 & 0.212 \\
\hline 296 & $7 / 30 / 13$ & \#17-02 & 100 & 100 & 0 & 850 & 452.65 & 452.63 & 7.70 & 10.49 & 6.38E-09 & $-0.09 \%$ & $-0.08 \%$ & 1 & 1200 & 0.212 \\
\hline 297 & $7 / 30 / 13$ & $\# 17-02$ & 100 & 101 & 0 & 900 & 452.56 & 452.42 & 10.74 & 13.62 & $2.90 \mathrm{E}-08$ & $-0.07 \%$ & $-0.04 \%$ & 1 & 1200 & 0.212 \\
\hline 298 & $7 / 30 / 13$ & $\# 17-02$ & 100 & 103 & 0 & 950 & 452.34 & 452.05 & 13.81 & 16.66 & $6.33 \mathrm{E}-08$ & $-0.02 \%$ & $0.05 \%$ & 1 & 1200 & 0.212 \\
\hline 299 & $7 / 30 / 13$ & \#17-02 & 100 & 102 & 0 & 1000 & 451.92 & 451.36 & 17.08 & 19.76 & $1.27 \mathrm{E}-07$ & $0.08 \%$ & $0.20 \%$ & 1 & 1200 & 0.212 \\
\hline 300 & $7 / 30 / 13$ & \#17-02 & 100 & 103 & 0 & 1100 & 450.90 & 448.34 & 20.29 & 22.80 & $6.27 \mathrm{E}-07$ & $0.30 \%$ & $0.87 \%$ & 1 & 1200 & 0.212 \\
\hline 301 & $7 / 31 / 13$ & \#17-03 & 15 & 17 & 0 & 800 & 450.62 & 450.61 & 5.52 & 7.39 & 3.63E-09 & $-0.07 \%$ & $-0.07 \%$ & 1 & 1200 & 0.333 \\
\hline 302 & $7 / 31 / 13$ & \#17-03 & 15 & 14 & 0 & 850 & 450.54 & 450.43 & 7.73 & 10.43 & $2.56 \mathrm{E}-08$ & $-0.06 \%$ & $-0.03 \%$ & 1 & 1200 & 0.333 \\
\hline 303 & $7 / 31 / 13$ & \#17-03 & 15 & 13 & 0 & 900 & 450.35 & 450.17 & 10.80 & 13.53 & 4.04E-08 & $-0.01 \%$ & $0.03 \%$ & 1 & 1200 & 0.333 \\
\hline 304 & $7 / 31 / 13$ & \#17-03 & 15 & 13 & 0 & 950 & 450.09 & 449.81 & 13.84 & 16.69 & $6.00 \mathrm{E}-08$ & $0.04 \%$ & $0.11 \%$ & 1 & 1200 & 0.333 \\
\hline 305 & $7 / 31 / 13$ & \#17-03 & 15 & 14 & 0 & 1000 & 449.74 & 449.27 & 16.91 & 19.81 & $9.95 \mathrm{E}-08$ & $0.12 \%$ & $0.23 \%$ & 1 & 1200 & 0.333 \\
\hline 306 & $7 / 31 / 13$ & \#17-03 & 15 & 14 & 0 & 1100 & 449.07 & 448.12 & 20.07 & 22.89 & $2.08 \mathrm{E}-07$ & $0.27 \%$ & $0.48 \%$ & 1 & 1200 & 0.333 \\
\hline 307 & $8 / 2 / 13$ & \#17-04 & 100 & 104 & 30 & 800 & 454.13 & 454.13 & 6.14 & 7.11 & $-8.83 \mathrm{E}-11$ & $-0.10 \%$ & $-0.10 \%$ & 1 & 1200 & 0.152 \\
\hline 308 & $8 / 2 / 13$ & \#17-04 & 100 & 101 & 30 & 850 & 454.07 & 454.07 & 7.78 & 10.43 & $1.41 \mathrm{E}-10$ & $-0.08 \%$ & $-0.08 \%$ & 1 & 1200 & 0.152 \\
\hline 309 & $8 / 2 / 13$ & \#17-04 & 100 & 100 & 30 & 900 & 454.00 & 453.70 & 10.95 & 13.48 & $7.18 \mathrm{E}-08$ & $-0.07 \%$ & $0.00 \%$ & 1 & 1200 & 0.152 \\
\hline 310 & $8 / 2 / 13$ & $\# 17-04$ & 100 & 100 & 30 & 950 & 453.54 & 452.73 & 13.95 & 16.60 & $1.87 \mathrm{E}-07$ & $0.03 \%$ & $0.21 \%$ & 1 & 1200 & 0.152 \\
\hline 311 & $8 / 2 / 13$ & $\# 17-04$ & 100 & 122 & 30 & 1000 & 452.08 & 450.75 & 17.73 & 19.66 & $4.24 \mathrm{E}-07$ & $0.35 \%$ & $0.65 \%$ & 1 & 1200 & 0.152 \\
\hline 312 & $8 / 2 / 13$ & \#17-04 & 100 & 102 & 30 & 1100 & 449.19 & 444.96 & 20.76 & 22.86 & $1.25 \mathrm{E}-06$ & $0.99 \%$ & $1.92 \%$ & 1 & 1200 & 0.152 \\
\hline 313 & $8 / 3 / 13$ & \#16-01 & 150 & 153 & 0 & 800 & 452.46 & 452.44 & 4.66 & 7.36 & $3.18 \mathrm{E}-09$ & $-0.09 \%$ & $-0.09 \%$ & 1 & 1200 & 0.095 \\
\hline 314 & $8 / 3 / 13$ & \#16-01 & 150 & 155 & 0 & 850 & 452.38 & 452.36 & 7.76 & 10.49 & 5.85E-09 & $-0.07 \%$ & $-0.07 \%$ & 1 & 1200 & 0.095 \\
\hline 315 & $8 / 3 / 13$ & \#16-01 & 150 & 158 & 0 & 900 & 452.22 & 451.91 & 11.38 & 13.56 & 8.71E-08 & $-0.04 \%$ & $0.03 \%$ & 1 & 1200 & 0.095 \\
\hline 316 & $8 / 3 / 13$ & \#16-01 & 150 & 162 & 0 & 950 & 451.46 & 450.53 & 14.68 & 16.52 & $3.11 \mathrm{E}-07$ & $0.13 \%$ & $0.34 \%$ & 1 & 1200 & 0.095 \\
\hline
\end{tabular}




\begin{tabular}{|c|c|c|c|c|c|c|c|c|c|c|c|c|c|c|c|c|}
\hline \multirow{2}{*}{$\begin{array}{l}\text { Exp data } \\
\text { number }\end{array}$} & \multirow[b]{2}{*}{ Test Date } & \multirow{2}{*}{$\begin{array}{c}\text { Specimen } \\
\text { ID }\end{array}$} & \multicolumn{2}{|c|}{ H2O Pressure } & \multirow{2}{*}{$\begin{array}{c}\mathrm{H} 2 \\
\text { Pressure }\end{array}$} & \multirow{2}{*}{$\begin{array}{c}\text { Temperat } \\
\text { ure }\end{array}$} & \multicolumn{2}{|c|}{ Weight } & \multicolumn{2}{|c|}{ Time in the test } & \multirow[b]{2}{*}{ Rate } & \multicolumn{2}{|c|}{ Weight loss \% } & \multicolumn{2}{|c|}{ Sample preparaton } & \multirow{2}{*}{$\begin{array}{l}\text { Wt loss in } \\
\text { outgassing }\end{array}$} \\
\hline & & & target & actual $^{\&}$ & & & before & after & before & after & & before & after & duration & temperature & \\
\hline & & & $\mathrm{Pa}$ & $\mathrm{Pa}$ & $\mathrm{Pa}$ & $\mathrm{OC}$ & $\mathrm{mg}$ & $\mathrm{mg}$ & $\mathrm{hr}$ & $\mathrm{hr}$ & $s^{-1}$ & $\%$ & $\%$ & $\mathrm{~h}$ & ${ }^{\circ} \mathrm{C}$ & $\mathrm{mg}$ \\
\hline 317 & $8 / 3 / 13$ & \#16-01 & 150 & 165 & 0 & 1000 & 449.72 & 446.51 & 17.33 & 19.70 & $8.38 \mathrm{E}-07$ & $0.52 \%$ & $1.23 \%$ & 1 & 1200 & 0.095 \\
\hline 318 & $8 / 3 / 13$ & $\# 16-01$ & 150 & 165 & 0 & 1100 & 443.52 & 435.22 & 20.75 & 22.89 & $2.43 \mathrm{E}-06$ & $1.89 \%$ & $3.72 \%$ & 1 & 1200 & 0.095 \\
\hline 319 & $8 / 4 / 13$ & $\# 16-02$ & 100 & 110 & 100 & 800 & 449.81 & 449.80 & 4.66 & 7.22 & 1.69E-09 & $-0.11 \%$ & $-0.11 \%$ & 1 & 1200 & 0.092 \\
\hline 320 & $8 / 4 / 13$ & $\# 16-02$ & 100 & 106 & 100 & 850 & 449.73 & 449.68 & 7.87 & 10.38 & $1.28 \mathrm{E}-08$ & $-0.09 \%$ & $-0.08 \%$ & 1 & 1200 & 0.092 \\
\hline 321 & $8 / 4 / 13$ & $\# 16-02$ & 100 & 108 & 100 & 900 & 449.47 & 448.81 & 11.38 & 13.51 & $1.94 \mathrm{E}-07$ & $-0.04 \%$ & $0.11 \%$ & 1 & 1200 & 0.092 \\
\hline 322 & $8 / 4 / 13$ & $\# 16-02$ & 100 & 117 & 100 & 950 & 448.00 & 446.12 & 14.53 & 16.39 & $6.26 \mathrm{E}-07$ & $0.29 \%$ & $0.71 \%$ & 1 & 1200 & 0.092 \\
\hline 323 & $8 / 4 / 13$ & $\# 16-02$ & 100 & 107 & 100 & 1000 & 445.46 & 441.15 & 16.92 & 19.59 & 1.00E-06 & $0.86 \%$ & $1.82 \%$ & 1 & 1200 & 0.092 \\
\hline 324 & $8 / 4 / 13$ & $\# 16-02$ & 100 & 112 & 100 & 1100 & 438.33 & 432.62 & 20.70 & 22.92 & 1.63E-06 & $2.44 \%$ & $3.71 \%$ & 1 & 1200 & 0.092 \\
\hline 325 & $8 / 5 / 13$ & \#16-03 & 100 & 105 & 150 & 800 & 0.44 & 0.44 & 4.77 & 7.45 & $-1.16 \mathrm{E}-09$ & $-0.10 \%$ & $-0.10 \%$ & 1 & 1200 & 0.097 \\
\hline 326 & $8 / 5 / 13$ & $\# 16-03$ & 100 & 108 & 150 & 850 & 0.38 & 0.38 & 7.76 & 10.43 & 1.16E-09 & $-0.09 \%$ & $-0.08 \%$ & 1 & 1200 & 0.097 \\
\hline 327 & $8 / 5 / 13$ & $\# 16-03$ & 100 & 111 & 150 & 900 & 0.26 & 0.03 & 11.36 & 13.48 & $6.67 \mathrm{E}-08$ & $-0.06 \%$ & $-0.01 \%$ & 1 & 1200 & 0.097 \\
\hline 328 & $8 / 5 / 13$ & $\# 16-03$ & 100 & 115 & 150 & 950 & -0.15 & -0.80 & 14.09 & 16.41 & $1.72 \mathrm{E}-07$ & $0.03 \%$ & $0.18 \%$ & 1 & 1200 & 0.097 \\
\hline 329 & $8 / 5 / 13$ & \#16-03 & 100 & 122 & 150 & 1000 & -1.30 & -2.36 & 17.50 & 19.56 & $3.21 \mathrm{E}-07$ & $0.29 \%$ & $0.53 \%$ & 1 & 1200 & 0.097 \\
\hline 330 & $8 / 5 / 13$ & $\# 16-03$ & 100 & 110 & 150 & 1100 & -3.45 & -5.61 & 20.85 & 22.86 & $6.71 \mathrm{E}-07$ & $0.77 \%$ & $1.25 \%$ & 1 & 1200 & 0.097 \\
\hline 331 & $8 / 6 / 13$ & $\# 16-04$ & 30 & 31 & 150 & 800 & 454.72 & 454.72 & 4.91 & 7.42 & $-7.30 \mathrm{E}-10$ & $-0.09 \%$ & $-0.09 \%$ & 1 & 1200 & 0.096 \\
\hline 332 & $8 / 6 / 13$ & $\# 16-04$ & 30 & 32 & 150 & 850 & 454.67 & 454.67 & 7.67 & 10.49 & $0.00 \mathrm{E}+00$ & $-0.08 \%$ & $-0.08 \%$ & 1 & 1200 & 0.096 \\
\hline 333 & $8 / 6 / 13$ & $\# 16-04$ & 30 & 34 & 150 & 900 & 454.61 & 454.59 & 10.88 & 13.51 & 4.41E-09 & $-0.07 \%$ & $-0.07 \%$ & 1 & 1200 & 0.096 \\
\hline 334 & $8 / 6 / 13$ & $\# 16-04$ & 30 & 36 & 150 & 950 & 454.53 & 454.48 & 13.93 & 16.57 & 1.13E-08 & $-0.05 \%$ & $-0.04 \%$ & 1 & 1200 & 0.096 \\
\hline 335 & $8 / 6 / 13$ & $\# 16-04$ & 30 & 40 & 150 & 1000 & 454.41 & 454.32 & 16.97 & 19.79 & $1.91 \mathrm{E}-08$ & $-0.03 \%$ & $-0.01 \%$ & 1 & 1200 & 0.096 \\
\hline 336 & $8 / 6 / 13$ & $\# 16-04$ & 30 & 33 & 150 & 1100 & 454.19 & 454.04 & 20.09 & 22.83 & 3.19E-08 & $0.02 \%$ & $0.06 \%$ & 1 & 1200 & 0.096 \\
\hline 337 & 8/7/13 & $\# 14-01$ & 30 & 31 & 100 & 800 & 442.91 & 442.91 & 4.74 & 7.34 & $-1.45 \mathrm{E}-09$ & $-0.10 \%$ & $-0.10 \%$ & 1 & 1200 & 0.081 \\
\hline 338 & $8 / 7 / 13$ & $\# 14-01$ & 30 & 31 & 100 & 850 & 442.86 & 442.83 & 7.70 & 10.46 & 5.91E-09 & $-0.09 \%$ & $-0.08 \%$ & 1 & 1200 & 0.081 \\
\hline 339 & $8 / 7 / 13$ & $\# 14-01$ & 30 & 32 & 100 & 900 & 442.77 & 442.65 & 10.80 & 13.59 & $2.74 \mathrm{E}-08$ & $-0.07 \%$ & $-0.04 \%$ & 1 & 1200 & 0.081 \\
\hline 340 & $8 / 7 / 13$ & $\# 14-01$ & 30 & 33 & 100 & 950 & 442.57 & 442.31 & 13.64 & 16.69 & 5.35E-08 & $-0.03 \%$ & $0.03 \%$ & 1 & 1200 & 0.081 \\
\hline 341 & $8 / 7 / 13$ & \#14-01 & 30 & 34 & 100 & 1000 & 442.23 & 441.87 & 16.91 & 19.76 & 8.00E-08 & $0.05 \%$ & $0.13 \%$ & 1 & 1200 & 0.081 \\
\hline 342 & $8 / 7 / 13$ & \#14-01 & 30 & 34 & 100 & 1100 & 441.70 & 441.10 & 20.81 & 22.89 & $1.83 \mathrm{E}-07$ & $0.17 \%$ & $0.31 \%$ & 1 & 1200 & 0.081 \\
\hline 343 & $8 / 8 / 13$ & $\# 14-02$ & 15 & 15 & 100 & 800 & 442.87 & 442.86 & 4.59 & 7.34 & $9.12 \mathrm{E}-10$ & $-0.09 \%$ & $-0.09 \%$ & 1 & 1200 & 0.092 \\
\hline 344 & $8 / 8 / 13$ & $\# 14-02$ & 15 & 16 & 100 & 850 & 442.81 & 442.74 & 7.86 & 10.37 & 1.67E-08 & $-0.08 \%$ & $-0.07 \%$ & 1 & 1200 & 0.092 \\
\hline 345 & $8 / 8 / 13$ & $\# 14-02$ & 15 & 17 & 100 & 900 & 442.66 & 442.51 & 10.94 & 13.51 & 3.66E-08 & $-0.05 \%$ & $-0.01 \%$ & 1 & 1200 & 0.092 \\
\hline 346 & $8 / 8 / 13$ & $\# 14-02$ & 15 & 14 & 100 & 950 & 442.42 & 442.13 & 13.97 & 16.56 & 7.13E-08 & $0.01 \%$ & $0.07 \%$ & 1 & 1200 & 0.092 \\
\hline 347 & $8 / 8 / 13$ & $\# 14-02$ & 15 & 22 & 100 & 1000 & 442.02 & 441.62 & 16.94 & 19.64 & $9.31 \mathrm{E}-08$ & $0.10 \%$ & $0.19 \%$ & 1 & 1200 & 0.092 \\
\hline 348 & $8 / 8 / 13$ & $\# 14-02$ & 15 & 22 & 100 & 1100 & 441.43 & 440.85 & 20.08 & 22.94 & $1.28 \mathrm{E}-07$ & $0.23 \%$ & $0.36 \%$ & 1 & 1200 & 0.092 \\
\hline 349 & $8 / 12 / 13$ & $\# 14-03$ & 0 & 4 & 0 & 950 & 453.54 & 453.44 & 3.84 & 8.36 & $1.44 \mathrm{E}-08$ & $-0.06 \%$ & $-0.04 \%$ & 1 & 1200 & 0.108 \\
\hline 350 & $8 / 12 / 13$ & $\# 14-03$ & 0 & 4 & 0 & 950 & 453.42 & 453.36 & 8.86 & 18.54 & 3.86E-09 & $-0.04 \%$ & $-0.02 \%$ & 1 & 1200 & 0.108 \\
\hline 351 & $8 / 21 / 13$ & $\# 14-04$ & 3 & 3 & 0 & 950 & 451.96 & 451.86 & 2.79 & 5.13 & $2.60 \mathrm{E}-08$ & $-0.06 \%$ & $-0.03 \%$ & 1 & 1200 & 0.190 \\
\hline 352 & $8 / 21 / 13$ & $\# 14-04$ & 100 & 106 & 0 & 950 & 450.95 & 448.69 & 5.37 & 7.98 & 5.33E-07 & $0.17 \%$ & $0.67 \%$ & 1 & 1200 & 0.190 \\
\hline 353 & $8 / 21 / 13$ & $\# 14-04$ & 100 & 101 & 100 & 950 & 448.18 & 445.56 & 8.64 & 12.07 & 4.73E-07 & $0.78 \%$ & $1.36 \%$ & 1 & 1200 & 0.190 \\
\hline 354 & $8 / 21 / 13$ & $\# 14-04$ & 100 & 103 & 100 & 950 & 445.56 & 441.13 & 12.07 & 16.93 & $5.68 \mathrm{E}-07$ & $1.36 \%$ & $2.34 \%$ & 1 & 1200 & 0.190 \\
\hline 355 & $8 / 21 / 13$ & $\# 14-04$ & 100 & 108 & 100 & 950 & 441.13 & 435.57 & 16.93 & 22.59 & 6.19E-07 & $2.34 \%$ & $3.57 \%$ & 1 & 1200 & 0.190 \\
\hline
\end{tabular}




\section{DISTRIBUTION LIST}

\section{Oak Ridge National Laboratory}

Cristian Contescu

Timothy Burchell

Anne Campbell

Yutai Katoh

Nidia Gallego

John Hunn

Weiju Ren

Mark Vance

\section{University of Tennessee}

Robert Mee

\section{Idaho National Laboratory \\ Mark Caroll \\ Diane Crosson \\ Michael Davenport \\ Hans Gougar \\ Laurence Hull \\ David Jensen \\ Joshua Kane \\ Travis Mitchell \\ David Petti \\ Rebecca Smith \\ David Swank \\ William Windes}

\section{Argonne National Laboratory}

Sam Shan

\section{Department of Energy}

William Corwin

Thomas O’Connor

Carl Sink contescuci@ornl.gov

burchelltd@ornl.gov

campbellaa@ornl.gov

katohy@ornl.gov

gallegonc@ornl.gov

hunnjd@ornl.gov

renw@ornl.gov

vancemc@ornl.gov

rmee@utk.edu

Mark.Caroll@inl.gov

Diane.Crosson@inl.gov

Michael.Davenport@inl.gov

Hans.Gougar@inl.gov

Laurence.Hull@inl.gov

David.Jensen@inl.gov

Joshua.Kane@inl.gov

Travis.Mitchell@inl.gov

David.Petti@inl.gov

Rebecca.Smith@inl.gov

w.swank@inl.gov

William.Windes@inl.gov

ssham@anl.gov

William.Corwin@Nuclear.Energy.gov

Tom.OConnor@Nuclear.Energy.gov

Carl.Sink@Nuclear.Energy.gov 